\title{
International Workshop on Characterization and PIE Needs for Fundamental Understanding of Fuels Performance and Safety
}

June 16-17, 2011

Paris, France

December 2011

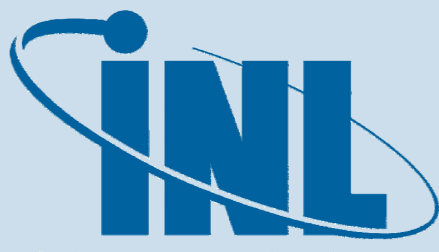

Idaho National Laboratory
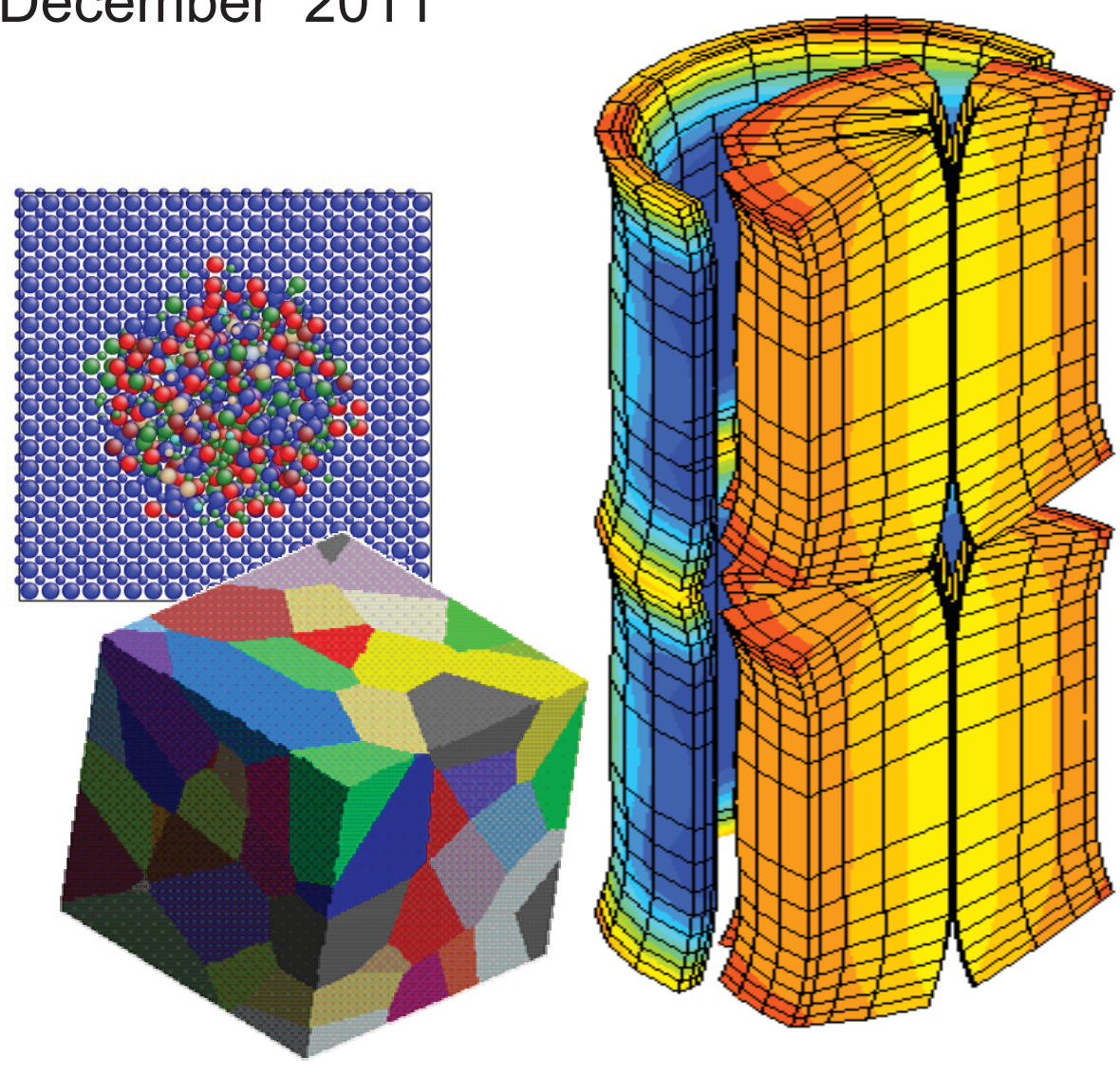


\section{DISCLAIMER}

This information was prepared as an account of work sponsored by an agency of the U.S. Government. Neither the U.S. Government nor any agency thereof, nor any of their employees, makes any warranty, expressed or implied, or assumes any legal liability or responsibility for the accuracy, completeness, or usefulness, of any information, apparatus, product, or process disclosed, or represents that its use would not infringe privately owned rights. References herein to any specific commercial product, process, or service by trade name, trade mark, manufacturer, or otherwise, does not necessarily constitute or imply its endorsement, recommendation, or favoring by the U.S. Government or any agency thereof. The views and opinions of authors expressed herein do not necessarily state or reflect those of the U.S. Government or any agency thereof. 
INL/EXT-11-23544

\section{International Workshop on Characterization and PIE Needs for Fundamental Understanding of Fuels Performance and Safety}

June 16-17, 2011

Paris, France

December 2011

Idaho National Laboratory

Idaho Falls, Idaho 83415

http://www.inl.gov

Prepared for the

U.S. Department of Energy

Office of Nuclear Energy

Under DOE Idaho Operations Office

Contract DE-AC07-05ID14517 
This page intentionally left blank. 


\section{EXECUTIVE SUMMARY}

Global energy consumption is expected to increase dramatically in the next decades, driven by rising standards of living and growing population worldwide. The increased need for more energy will require enormous growth in energy generation capacity, more secure and diversified energy sources, and a successful strategy to tame greenhouse gas emissions. Among the various alternative energy strategies, building an energy infrastructure that capitalizes on nuclear energy may enable a secure and clean energy future worldwide.

Developing advanced nuclear fuel for light water reactors (LWRs) and new innovative fuels for future reactor designs will require an International collaborative effort. Characterization and postirradiation examination (PIE) capability is very important to advance nuclear energy as an option to meet global energy goals. Understanding the behavior of fuels and materials in a nuclear reactor environment is the limiting factor in nuclear plant safety, longevity, efficiency, and economics. State-of-the art characterization and PIE capabilities are required to transition into a "science-based" approach in the development of advanced fuels and materials, enabling a fundamental understanding of the behavior under irradiation.

The International Workshop on Characterization and PIE Needs for Fundamental Understanding of Fuels Performance and Safety was held June 16-17, 2011, in Paris, France. The Organization for Economic Co-operation and Development (OECD), Nuclear Energy Agency (NEA) Working Party on the Fuel Cycle (WPFC) sponsored the workshop to identify gaps in global capabilities that need to be filled to meet projected needs in the 21 st century.

First and foremost, the workshop brought nine countries and associated international organizations, together in support of common needs for nuclear fuels and materials testing, characterization, PIE, and modeling capabilities. Finland, France, Germany, Republic of Korea, Russian Federation, Sweden, Switzerland, United Kingdom, United States of America, IAEA, and ITU (on behalf of European Union Joint Research Centers) discussed issues and opportunities for future technical advancements and collaborations.

Second, the presentations provided a base level of understanding of current international capabilities. Three main categories were covered: (1) status of facilities and near term plans, (2) PIE needs from fuels engineering and material science perspectives, and (3) novel PIE techniques being developed to meet the needs. The International presentations provided valuable data consistent with the outcome of the National Workshop held in March 2011.

Finally, the panel discussion on 21st century PIE capabilities, created a unified approach for future collaborations. In conclusion, (1) existing capabilities are not sufficient to meet the needs of a sciencebased approach, (2) safety issues and fuels behavior during abnormal conditions will receive more focus post-Fukushima; therefore we need to adopt our techniques to those issues, and (3) International collaboration is needed in the areas of codes and standards development for the new techniques.

The problems and needs discussed in the workshop are too big for any single country or institution to overcome. An International characterization and PIE capability development project is an ideal solution but that requires dealing with a number of obstacles in terms of international transport of radioactive materials, codes and standards, and regulatory requirements. However, if these obstacles can be overcome, the benefits would be tremendous in terms of advancing the performance and safety of nuclear energy worldwide. Please contact Lori Braase, lori.braase@inl.gov, or Kemal Pasamehmetoglu, kemal.pasamehmetoglu@inl.gov, for information regarding the workshop or this report. 
This page intentionally left blank. 


\section{CONTENTS}

FIGURES vi

TABLES vi

ACRONYMS vii

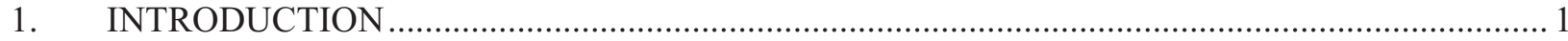

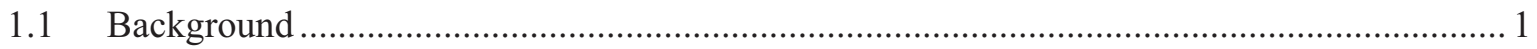

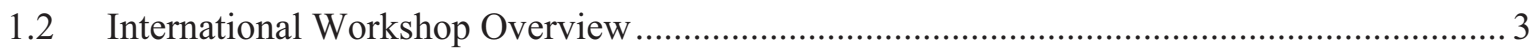

2. REVIEW OF INTERNATIONAL PIE CAPABILITIES AND PLANS …................................... 4

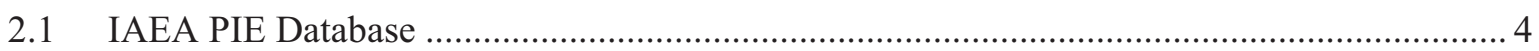

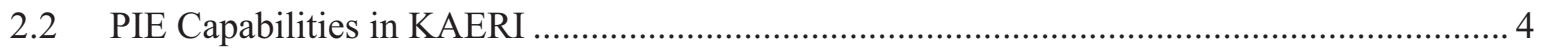

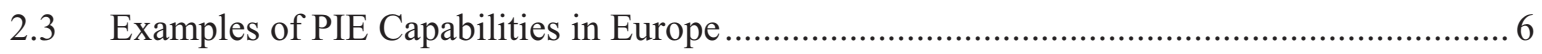

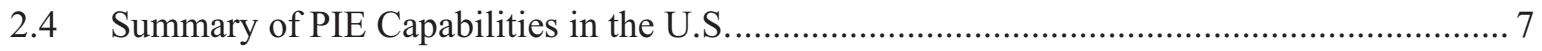

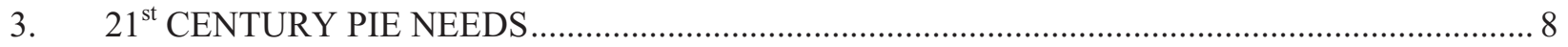

3.1 Fuel Performance Codes: Characterization and PIE needs ............................................... 8

3.2 Atomistic Modeling: Characterization and PIE needs ...................................................... 9

3.3 Fuel Design and Safety Testing: PIE Needs ............................................................... 9

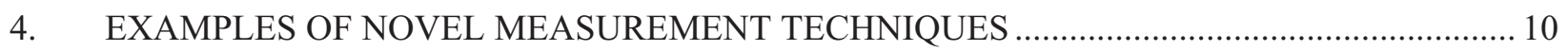

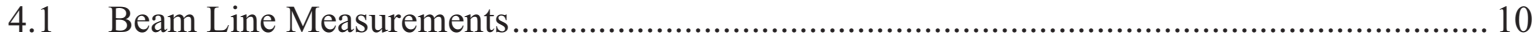

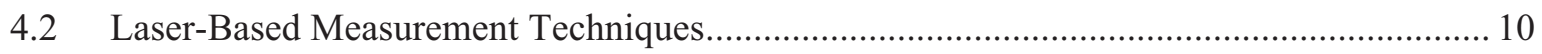

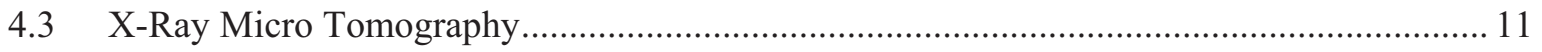

4.4 Density Measurements with X-Ray Absorption …........................................................ 12

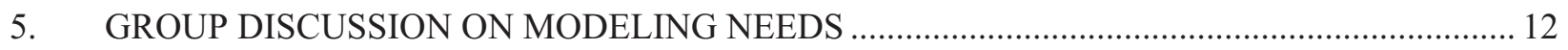

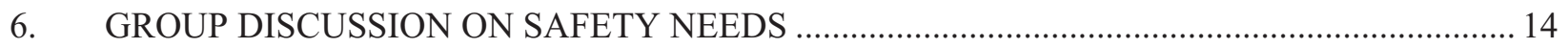

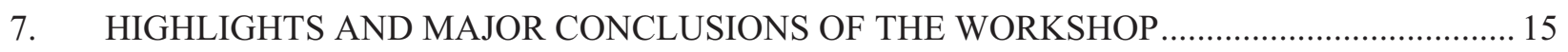

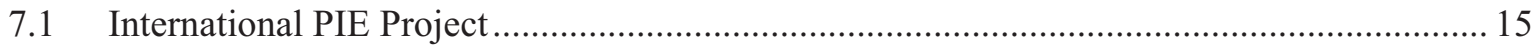

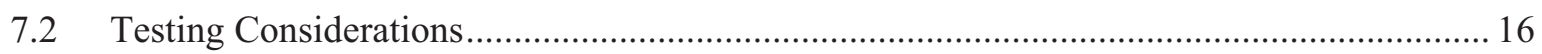

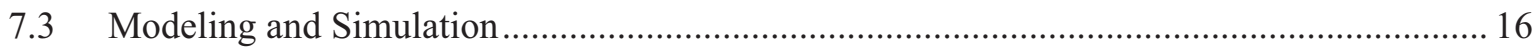

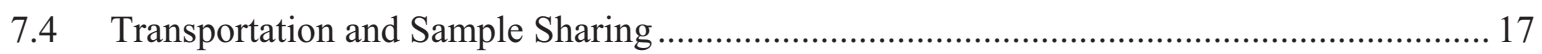

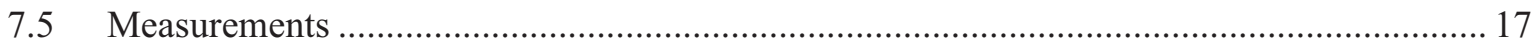

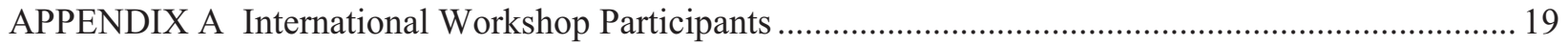

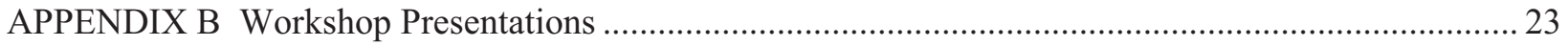




\section{FIGURES}

Figure 1. Major Elements of a Goal Oriented Science-Based Approach...................................................2

Figure 2. The length and time scales relevant to understanding fuels and materials under

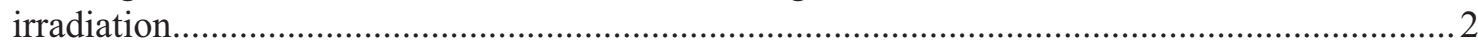

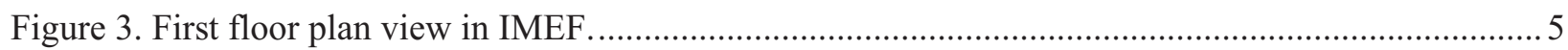

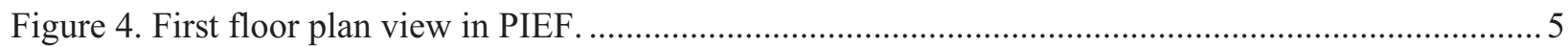

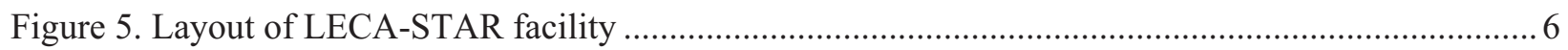

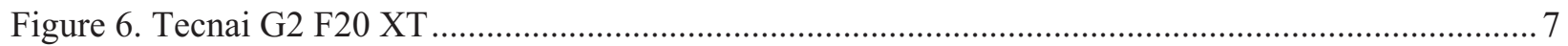

Figure 7. Irradiated Materials Characterization Laboratory (IMCL) ..................................................... 7

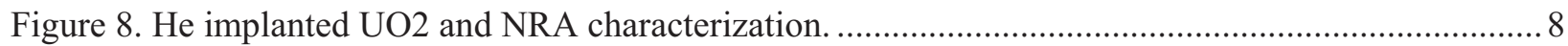

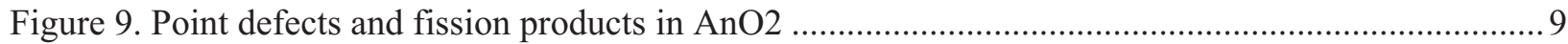

Figure 10. Scanning Thermal Diffusivity Measurement (STDM) technique ........................................ 10

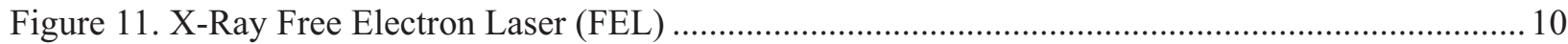

Figure 12. Combining Laser Ultrasonics and Resonance Ultrasound Spectroscopy ............................... 11

Figure 13. Actual imaging resolution of current system surrogate TRISO particle at $1.4 \mu \mathrm{m}$

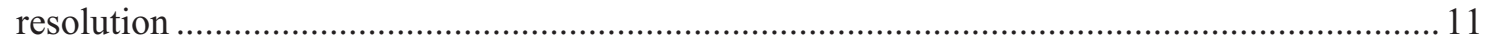

Figure 14. X-Ray Powder Diffractometer (Seifert XRD 3000 PTS) ................................................... 12

\section{TABLES}

Table 1. Needs for Performance Codes 13

Table 2. Needs for Atomistic Codes 


\section{ACRONYMS}

$\mu \quad$ micro

AES Auger Electron Spectroscopy

AFM Atomic Force Microscopy

AGR Advanced Gas Reactor

AHTR Advanced High Temperature Reactor

ANL Argonne National Laboratory

ATR-NSUF Advanced Test Reactor-National Scientific User Facility

BESAC Basic Energy Sciences Advisory Committee

CEA Commissariat à l'Energie Atomique

CO Carbon Monoxide

DBTT Ductile-Brittle Transition Temperature

DOE U.S. Department of Energy

DPA Displacements per atom

EDM Electrical Discharge Machining

EDS Energy Dispersive Spectroscopy

EELS Electron Energy Loss Spectroscopy

EMI electromagnetic interference

EPMA Electron Probe Micro Analyzer

EPRI Electric Power Research Institute

FCRD Fuel Cycle Research and Development

FG fission gases

FHR Fluoride Salt-cooled High Temperature Reactor

FIB Focused Ion Beam

FP fission products

GCR Gas Cooled Reactor

GNF Global Nuclear Fuel

HR-TEM High Resolution Transmission Electron Microscope

HTGR High Temperature Gas Cooled Reactor

HTR High Temperature Reactor

HTTR High Temperature Test Reactor

IASCC Irradiation Assisted Stress Corrosion Cracking

ICP-MS Inductively Coupled Plasma Mass Spectrometry

IMCL Irradiated Materials Characterization Laboratory

INL Idaho National Laboratory

IVEM Intermediate Voltage Electron Microscope 
LANL Los Alamos National Laboratory

LECA-STAR Postirradiation Examinations Laboratory at CEA-Cadarache

LLNL Lawrence Livermore National Laboratory

LOCA Loss-of-Coolant Accident

LWR Light Water Reactor

M\&S Modeling and Simulation

MaRIE Matter-Radiation Interactions in Extremes (LANL)

NDE Non-destructive Examination

$\mathrm{NE}$

Department of Energy Office of Nuclear Energy

NEA Nuclear Energy Agency

NGNP Next Generation Nuclear Plant

NMR Nuclear Magnetic Resonance

NRA Nuclear Reaction Analysis

NRC Nuclear Regulatory Commission

NRF Nuclear Resonance Fluorescence

OECD Organization for Economic Co-operation and Development

OIM Orientation Imaging Microscopy

ORNL Oak Ridge National Laboratory

PBR Pebble Bed Reactor

PDF atomic pair distribution function

PIE Postirradiation Examination

PMR Prismatic Modular Reactor

PNNL Pacific Northwest National Laboratory

R\&D Research and Development

SANS Single Angle Neutron Scattering

SAXS Single Angle X-ray Scattering

SCC Stress Corrosion Cracking

SEM Scanning Electron Microscope

$\mathrm{SiC} \quad$ Silicon Carbide

SIMS Secondary Ion Mass Spectrometry

SNL Sandia National Laboratory

STDM Statistical Time Division Multiplexing

STEM Scanning Transmission Electron Microscope

TAMU Texas A\&M University

TEM Transmission Electron Microscope

TRISO Tristructural-Isotopic Fuel 
XAS X-ray Absorption Spectroscopy

XPS X-ray Photoelectron Spectroscopy

XRD X-ray Diffraction 
This page intentionally left blank. 


\section{International Workshop on Characterization and PIE Needs to Support Science-Based Development of Innovative Fuels}

\section{INTRODUCTION}

The coupled challenges of a doubling of the world's energy needs by the year 2050 and increasing demands for "clean" energy sources that do not add more carbon dioxide and pollutants to the environment have resulted in increased worldwide attention to the possibilities of advanced nuclear energy as a long-term solution for a secure energy future. Increased interest in nuclear energy also triggered the search for next generation of nuclear fuel with enhanced performance and safety, and with reduced waste generation for the light water reactors that are currently used worldwide and that will continue to remain the preferred nuclear power technology for decades to come.

At the same time, other reactor technologies are also being developed to increase the use of nuclear energy beyond just electricity production (process heat applications). Small modular reactors are being considered because of their lower capital cost and their potential deployment to meet local energy demands. To enhance the utilization of natural resources and to minimize the amount of transuranic waste, fast reactors are likely to be the technology choice for the future. Many different innovative fuel types are being considered for these reactors and considerable fuels research is being conducted in various countries that are currently using nuclear energy or that are considering nuclear energy as part of their energy portfolio in the near future. Furthermore, after the events in the Fukushima plants in Japan, there is a renewed emphasis on understanding the fuel behavior during beyond-design basis events.

Fuel development (including the cladding) relies heavily on understanding the fuel performance under neutron irradiation. The major part of the research is devoted to irradiating samples of candidate fuel and cladding types in reactors. Developing an advanced characterization and postirradiation examination (PIE) capability is critical the fuels and materials research programs across the globe. Understanding the behavior of fuels and materials in a nuclear reactor environment is a limiting factor in nuclear plant safety, longevity, efficiency, and economics. State-of-the art characterization and PIE capabilities are required to transition into a "science-based" approach in the development of advanced fuels and materials, enabling a fundamental understanding of fuels and materials behavior under irradiation. In recent decades, considerable advances are

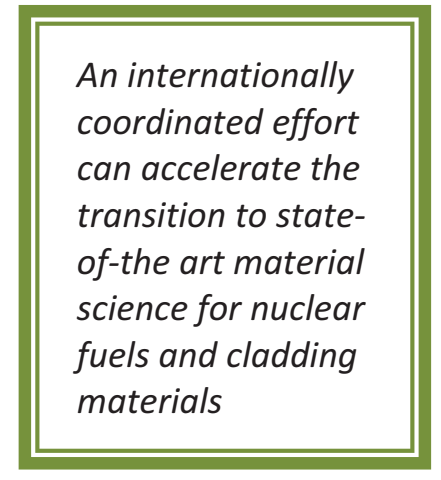
made in instrumentation technologies as applied to material science. However, most of those advances are not translated into the nuclear energy field. Application of such technologies and methods to highly irradiated materials will provide considerable advances compared to today's PIE capabilities. Many countries are increasing their PIE capabilities and with an internationally coordinated effort, the transition to state-of-the art material science for nuclear fuels and cladding materials, can be accelerated to benefit everyone.

\subsection{Background}

The traditional approach to fuel development is generally empirical and relies mainly on measurements of engineering scale performance parameters before and after irradiation testing. This empirical approach is time consuming and expensive. Furthermore, the engineering-scale parameters that are measured provide an integral view of multiple, strongly interactive phenomena that occur at lower-length and time scales. 
Phenomenological understanding of irradiation behavior is not directly possible through traditional PIE efforts because fuel development requires multiple iterations and does not readily enable the scientists and engineers to design fuels and materials for the desired performance. A science-based fuel development approach aimed at a fundamental understanding of fuel and cladding behavior under irradiation requires measurements and understanding at the lower-length and time scales. Such measurement capabilities for high-dose materials and irradiated fuels are being developed internationally in multiple locations.

The "Goal Oriented Science-Based" approach, depicted in Figure 1, combines theory, experimentation, and highperformance modeling and simulation to develop the fundamental understanding that will lead to new technologies. Advanced modeling and simulation tools will be used in conjunction with smaller-scale, phenomenon-specific experiments informed by theory to reduce the need for large, expensive integrated experiments. Insights gained by advanced modeling and

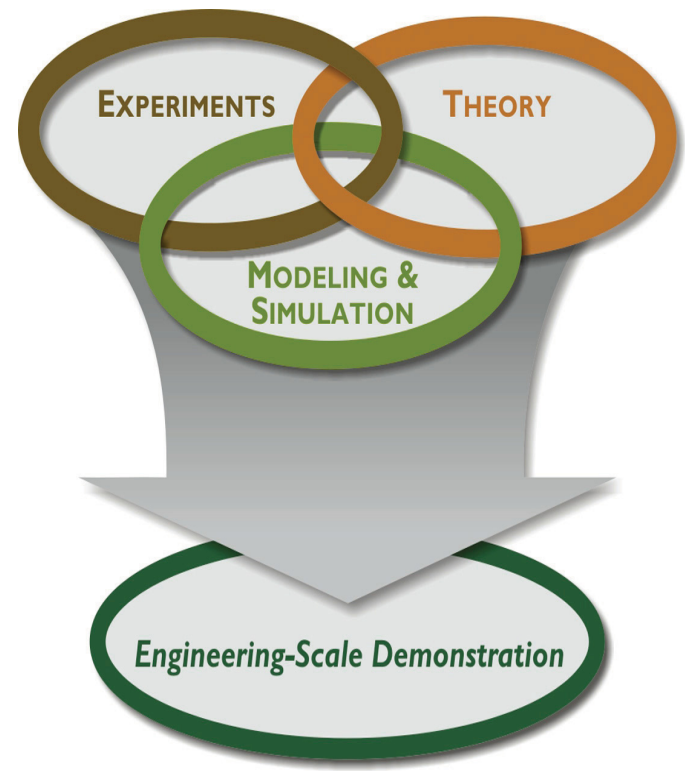

Figure 1. Major Elements of a Goal Oriented Science-Based Approach (Presentation 8). simulation can lead to new theoretical understanding and, in turn, can improve models and experimental design. The different length and time scales relevant to fuels and materials behavior under irradiation is depicted in Figure 2. The ellipse with yellow shade indicates that the traditional PIE domain at the engineering-scale is presently being extended into the mesoscale region with measurements at the microstructural level becoming more and more routine.

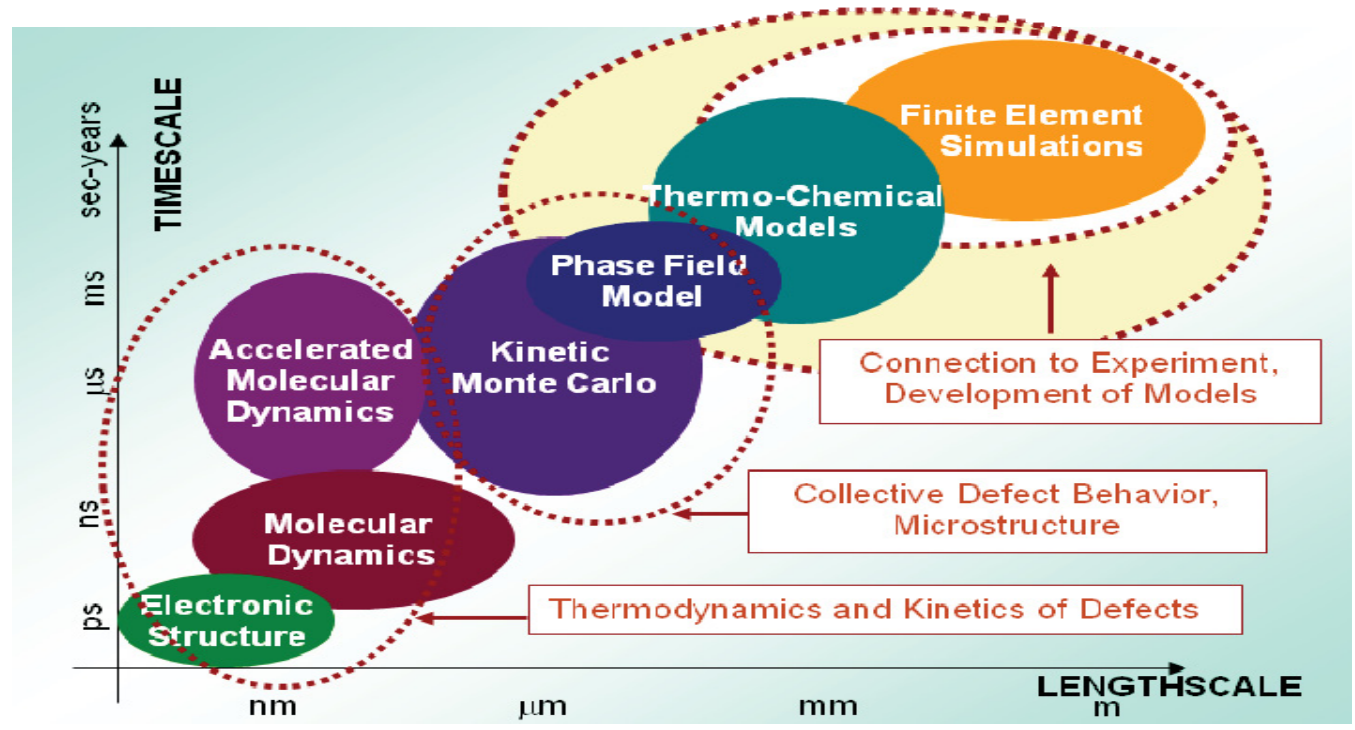

Figure 2. The length and time scales relevant to understanding fuels and materials under irradiation (Presentation \#1).

The first step to achieve a state-of-the art characterization and PIE infrastructure is to adapt currently available instruments and scientific techniques for use with highly radioactive fuels and material samples. 
The objective is to start characterizing radioactive samples at the nano-tomicro scale resolutions. Some of these instruments, when applied to radioactive materials characterization, require special facilities with very strict environmental control.

The second step is to design and develop instruments that currently do not exist but are required to measure properties at various length and time scales in order to support a complete fundamental understanding of radioactive materials behavior. These instruments would be valuable in understanding separate effect phenomenology and supporting the multi-physics, multi-scale, predictive fuel performance modeling efforts. These sophisticated

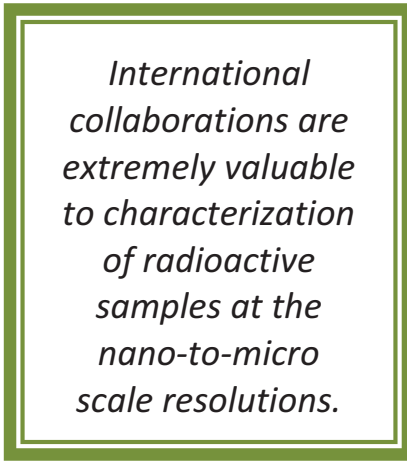
capabilities will require new facilities with specialized environmental control and integration among multiple techniques.

International collaborations in terms of sharing experiences, technique development, samples, and benchmark results will be extremely valuable in achieving the objective. This was the primary motivation of this workshop.

\subsection{International Workshop Overview}

The International Workshop on Characterization and PIE Needs for Fundamental Understanding of Fuels Performance and Safety was held at OECD-NEA on June 16, 2011, in Paris, France.

The objectives of the workshop were

- To review the existing characterization and PIE capabilities and the novel techniques that are being developed at the international facilities

- To identify the gaps to meet the needs of 21 st century characterization and PIE capabilities.

The scope of the workshop included a series of presentations by experts from various organizations on the status of existing facilities, capabilities and near-term plans. The presentations covered related activities in IAEA, Europe, South Korea and the U.S. It was not possible to cover all the existing and planning capabilities world-wide, but a considerable cross-section was represented in the workshop.

The second topic of discussion was the characterization and PIE needs for 21 st century fuel development efforts. The topics were addressed through invited presentations by international experts, covering modeling, fuel design, and safety perspectives.

A third topic covered during the workshop was focused on new techniques that are being developed at various institutions, such as those being used in the French LECA-STAR facility, as well as beam-lines, $\mathrm{X}$-Ray absorption, X-ray microtomography, and laser-based acoustic techniques.

Finally, a panel discussion was organized to discuss the integration of testing, characterization, and PIE with modeling and simulation. Safety was one of the topics relative to the Fukushima Daiichi accident in Japan earlier this year. One of the issues is whether we currently have the right PIE equipment to determine fuel behavior when cladding fails or how steams reacts with the cladding and the failed fuel. Other topics covered by the panel discussion include thermodynamics, thermal conductivity, irradiation conditions, microstructure, geometry, and properties.

The workshop was attended by representatives from nine countries (Finland, France, Germany, Republic of Korea, Russian Federation, Sweden, Switzerland, United Kingdom and United States of America), and two International Organizations (International Atomic Energy Agency and Institute for Transuranium Elements). The workshop participants are listed in Appendix A. 
Unfortunately, the experts from Japan were not able to join the workshop because of the disastrous earthquake and tsunami in Japan, followed by the unfortunate events in the Fukushima power plants. Their expertise and contributions to the discussions were surely missed.

\section{REVIEW OF INTERNATIONAL PIE CAPABILITIES AND PLANS}

A summary of the presentations related to PIE capabilities and future plans is provided in this section. The relevant presentations are included in Appendix B.

\subsection{IAEA PIE Database}

Dr. Uddharan Basak (IAEA) reviewed the agency's activities related to the PIE database (HOTLAB PIE Database). The database was created in 1990 and published in 1996. It was converted to an electronic database in 2003 and modifications and updates were last added in 2010. It covers 42 facilities in 22 countries and information for 19 casks. The database contains general information and cell characteristics, acceptance criteria for irradiated components, available PIE technology, refabrication and instrumentation capabilities, storage and conditioning capabilities, and technical and licensing data for casks. The database appears to be a very valuable source for the hot-cell based PIE capabilities. However, PIE capabilities that may not require standard hot-cells (shielded boxes, small-cells with removable walls, etc.) that may be more appropriate with the modern instruments and that require analyses of very small samples are not included in the database. Additional information can be accessed at http://wwwnfcis.iaea.org/PIE/PIEMain.asp

\subsection{PIE Capabilities in KAERI}

Dr. ByoungOon Lee (KAERI) provided an overview of metallic fuel development activities in Republic of Korea with emphasis on PIE capabilities. The presentation included the overview of the IMEF (Figure 3) where the PIE capabilities reside. PIEF (Figure 4) also is used for testing and evaluating the performance and integrity of fuel discharged from the reactor. IMEF includes the necessary nondestructive and destructive examination capabilities with state-of-the art equipment. At present, the emphasis of this facility is on meeting the needs of traditional PIE, but certainly offers opportunities for implementing new capabilities as well. 


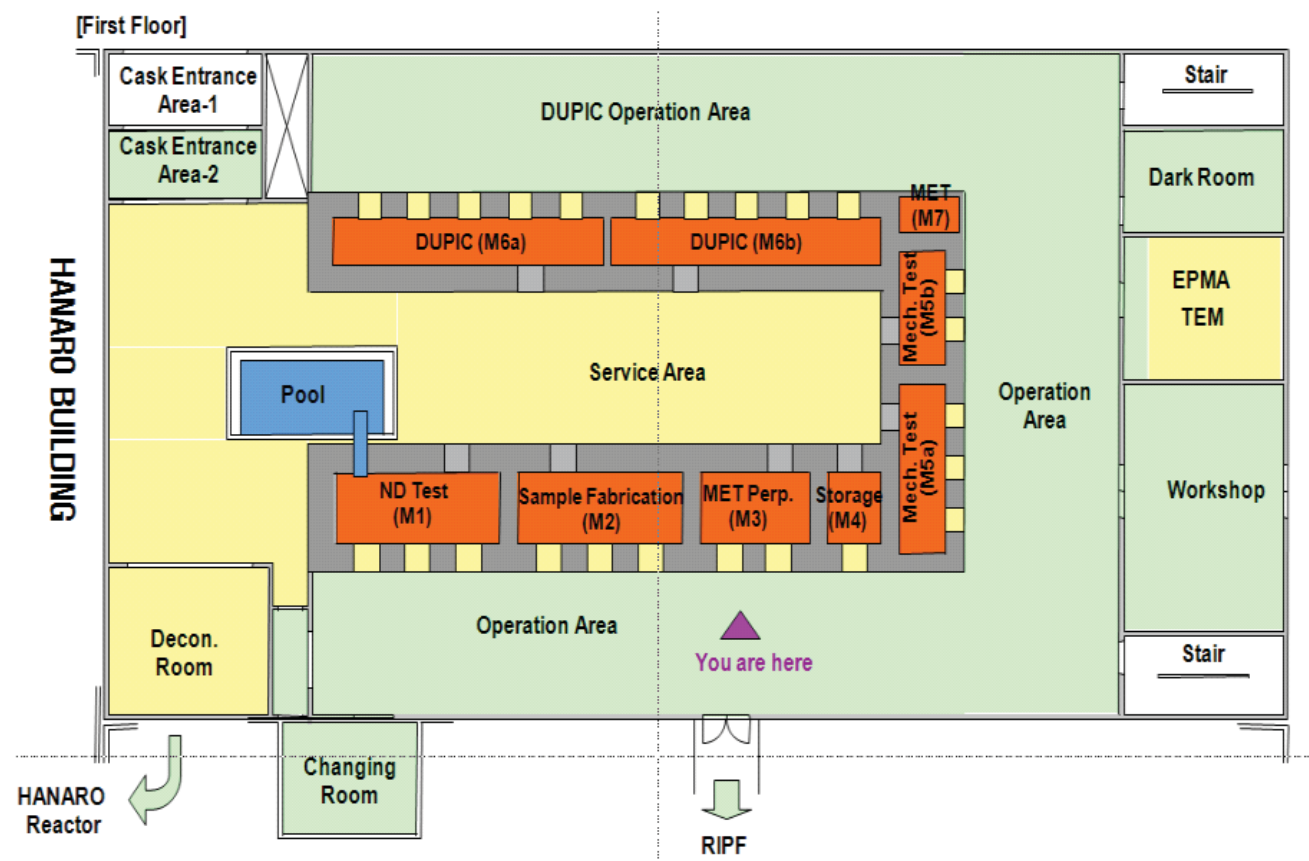

Figure 3. First floor plan view in IMEF (Presentation \#4).

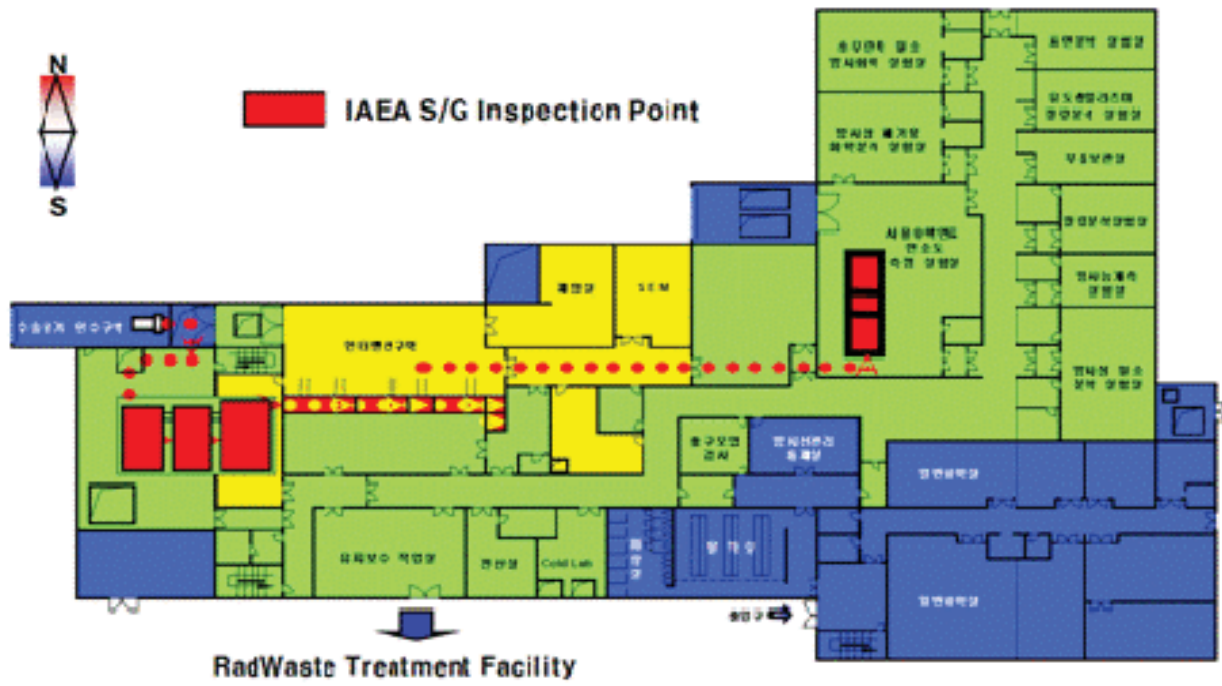

Figure 4. First floor plan view in PIEF (Presentation \#4). 


\subsection{Examples of PIE Capabilities in Europe}

A general overview of the CEA LECA-STAR (Figure 5) facility in France was provided by Dr. Jerome Lamontagne and Dr. Francois Sudreau. Dr. Lamontagne provided an overview of equipment and capability, such as:

- SEM - morphological analyses

- EPMA - quantitative method of non-destructive elemental analysis

- $\quad$ SIMS - isotopic and gas analysis

- $\mathrm{XRD}$ - crystalline analyses

- SEM-FIB - 3D imaging of microstructure and preparation of thin samples

- EBSD - interaction between a crystal and the primary electrons

- TEM - microstructure analysis at a nanometric scale

- MARS - multipurpose beamline.

Dr. Sudreau's presentation (see Appendix B) included a specific example of in cell testing and state-ofthe art measurement techniques for fission gas release behavior in irradiated fuels.

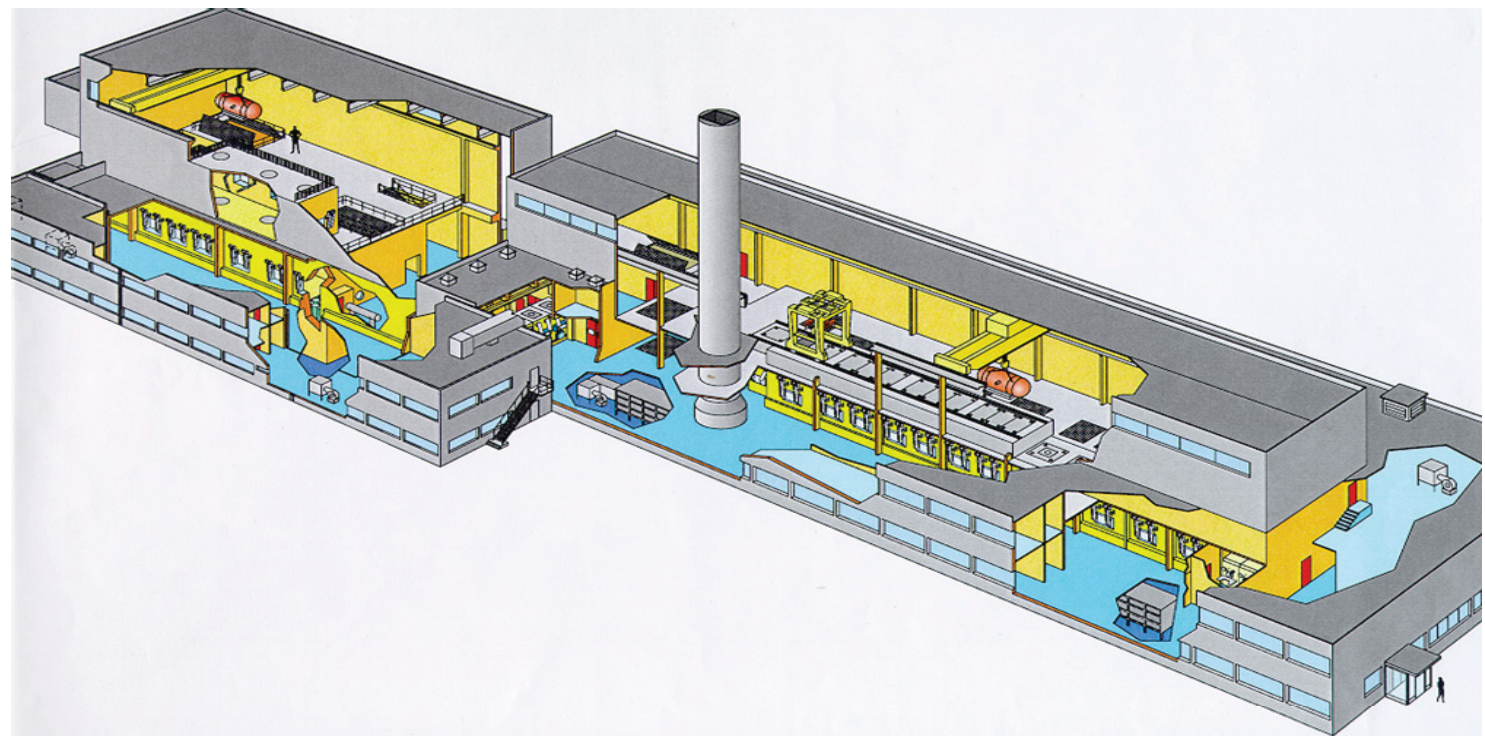

Figure 5. Layout of LECA-STAR facility (Presentation \#13).

Dr. Joe Summers (ITU) presented the TEM Facility development, which is a new addition to their capabilities. The presentation also summarized the activities associated with the refurbishment and replacement of aging equipment in European facilities (CEA, JRC-ITU, SCK-CEN, and NRG) including the new TEM capabilities. Figure 6 is a picture of the Tecnai $\mathrm{G}^{2}$ F20 XT, which is remote controlled and adapted for nuclear materials. 


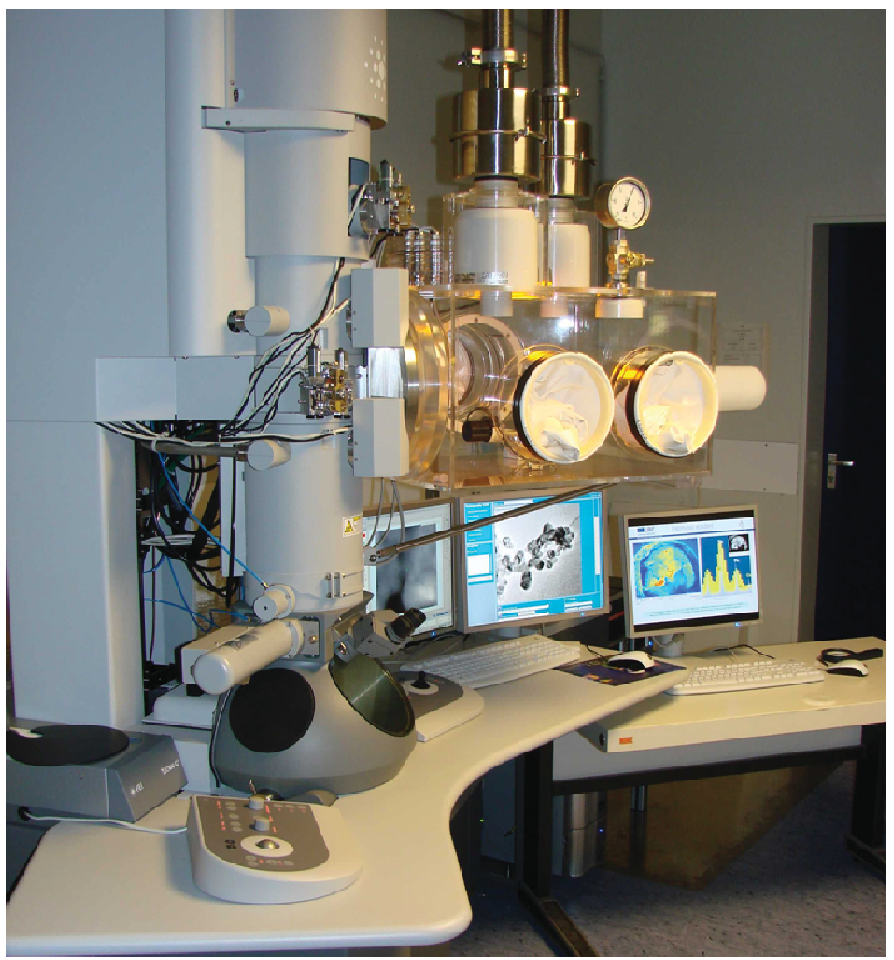

Figure 6. Tecnai ${ }^{\mathrm{TM}} \mathrm{G}^{2}$ F20 XT (Presentation \#3).

\subsection{Summary of PIE Capabilities in the U.S.}

The U.S. presentation was provided by Dr. Dennis Miotla (U.S. DOE). The presentation provided a short summary of existing capabilities and future facilities with state-of-the art equipment. Dr Miotla emphasized DOE's plan to invest in facilities and capabilities that are adaptable to changing technologies, sustainable, and most importantly, accessible to researchers worldwide. Figure 7 show a drawing of the Irradiated Materials Characterization Laboratory (IMCL) at the Idaho National Laboratory (INL). This facility is currently under construction and should be complete by the end of 2012. It will house PIE equipment in shielded cells designed to examine radioactive fuel and materials samples.

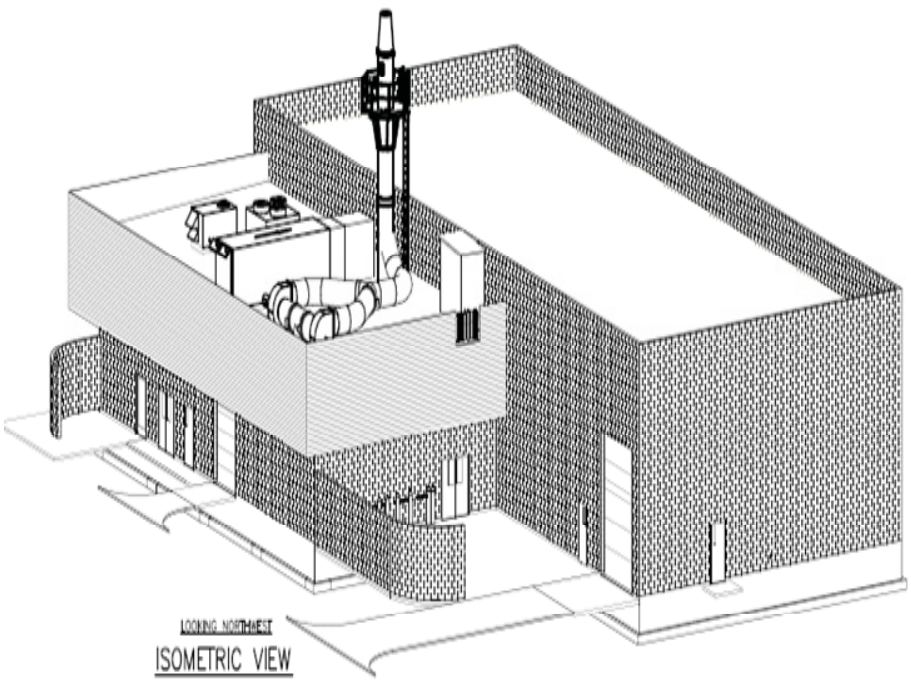

Figure 7. Irradiated Materials Characterization Laboratory (IMCL) (Presentation \#5) 


\section{3. $21^{\text {st }}$ CENTURY PIE NEEDS}

In this session, three presentations were provided to outline the PIE needs from a modeling and simulation, fuel design, and nuclear engineering perspectives. All the related presentations are included in Appendix B.

\subsection{Fuel Performance Codes: Characterization and PIE needs}

Dr. Vincent Bouineau (CEA) presented performance code PIE needs for physical properties and behavior laws for code improvement and validation. Additional points of emphasis include:

- Analytical experiments on simulated fuels to understand basic physio-chemicals behavior (see Figure 8 for helium implanted $\mathrm{UO}_{2}$ and NRA characterization)

- Analytical irradiation; some characteristics are fixed or adjusted during the irradiation and must be known also as function of radial (and axial) position.

- Integral or semi-integral irradiation

- Characteristics needed as function of radial and axial position.

- In the worse case after the fabrication and during PIE and in the best case all along the irradiation.

When modeling fuel with minor actinides, improvements MUST BE COMPLETED with

- More accuracy on fabrication data and irradiation conditions

- Analytical experiments

- More instrumentation in core, especially in MTR (also in prototype?)

- More characterizations in hot cell
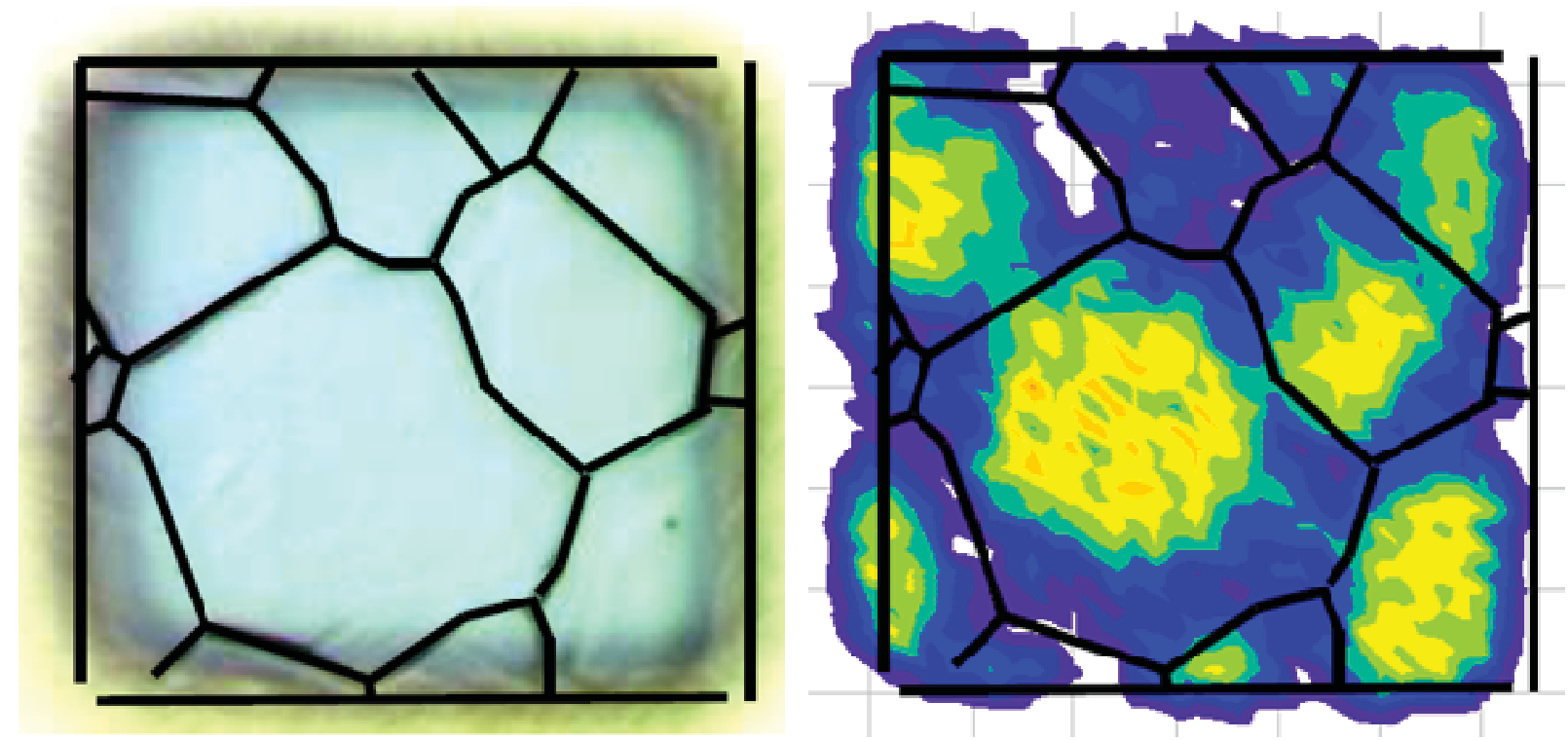

Figure 8. He implanted $\mathrm{UO}_{2}$ and NRA characterization (Presentation \#6). G. Martin, P. Garcia, C. Sabathier, G. Carlot, T. Sauvage, P. Desgardin, C. Raepsaet, H. Khodja, Nuclear Instruments and Methods in Physics Research Section B 268, 2133 (2010) 


\subsection{Atomistic Modeling: Characterization and PIE needs}

Dr. Michel Freyss (CEA) presented atomistic modeling techniques (first-principles calculations, molecular dynamics with empirical potentials, cluster dynamics) and the corresponding characterization and PIE needs. He emphasized that most of the material data to validate the atomistic scale models, especially for innovative fuels such as mixed oxides and carbides, do not exist and are difficult to obtain. TEM, XAS, diffusion experiments, etc., are relevant techniques (see Table 2). The needs include material data (local crystal structure, electronic structure, chemical order, elastic constants, etc.), activation energies for atom diffusion, self-diffusion, and fission product diffusion coefficients, radiation damage, etc. Figure 9 is a representation of point defects and fission products in $\mathrm{UO}_{2}$ as modeled using firstprinciples calculations.

\section{$2 \times 2 \times 2$ cubic supercells}
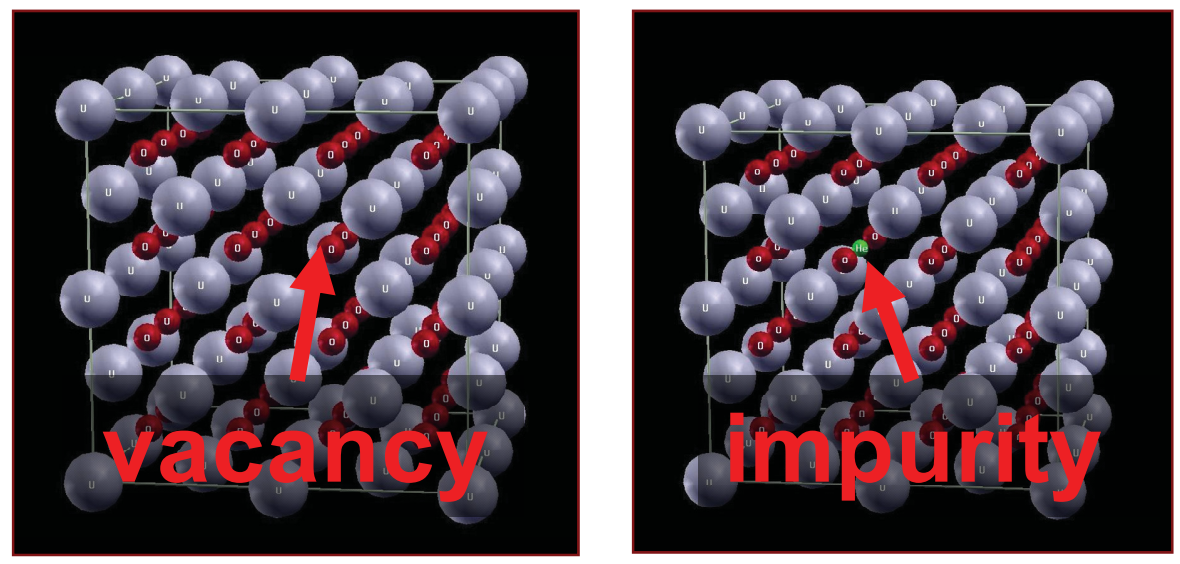

Figure 9. Point defects and fission products in $\mathrm{UO}_{2}$ (Presentation \#7).

\subsection{Fuel Design and Safety Testing: PIE Needs}

Dr. Steve Hayes (INL) presented the characterization needs from the fuel design and safety perspective. Standard PIE measurements are essential when using equipment with higher accuracy. However, those need to be supplemented by micro- to nano-scale characterization techniques to reach a fundamental understanding. This is primarily driven by the length and cost of licensing a new fuel. The limited access to certain facilities (e.g. fast test reactors) also requires a better understanding of the fuel behavior because only a few prototypic tests can be conducted during the development phase. Figure 10 is a picture of the in-cell Scanning Thermal Diffusivity Measurement (STDM) equipment at the INL. 


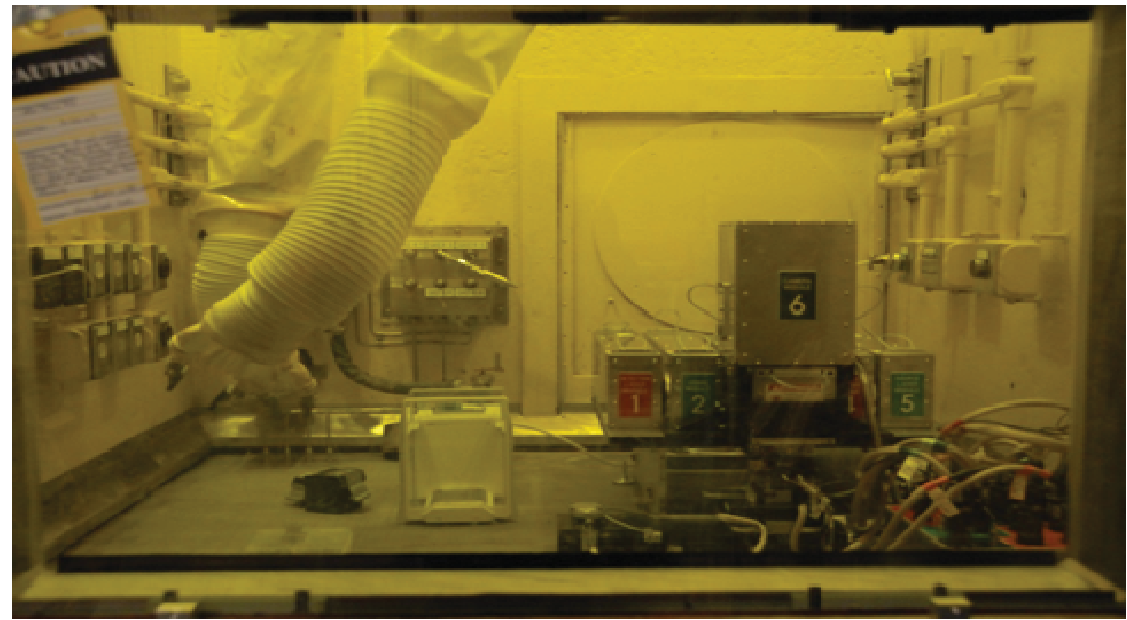

Figure 10. Scanning Thermal Diffusivity Measurement (STDM) technique (Presentation \#8).

\section{EXAMPLES OF NOVEL MEASUREMENT TECHNIQUES}

A few examples of new techniques are discussed in this session. All the associated presentations are included in Appendix B.

\subsection{Beam Line Measurements}

Dr. Manuel Pouchon (PSI) presented an overview of the beam line facilities available for materials research. These include X-ray beam lines with synchrotron light sources and free electron lasers (FEL) as shown in Figure 11. Particle beams (neutrons and ion beams) were also discussed. The techniques provide valuable data at lower length and time scales and are particularly beneficial for data in support of atomistic models. However, access to the beam lines is limited and requires a long planning time. Furthermore, the use of irradiated fuel samples is currently not possible in most available beam lines.

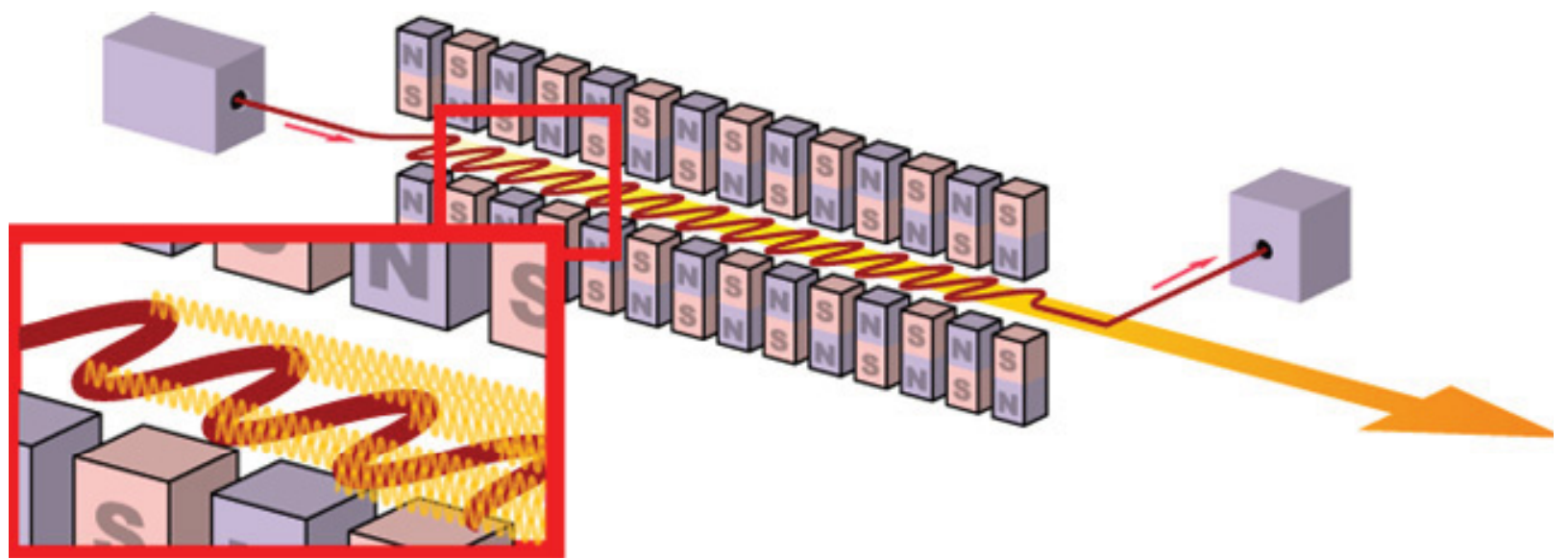

Figure 11. X-Ray Free Electron Laser (FEL) (Presentation \#9).

\subsection{Laser-Based Measurement Techniques}

Dr Rory Kennedy (INL) presented the development of the laser-based measurement techniques. The development includes measurements (at micron-scale) for thermal diffusivity and thermal conductivity, 
average elastic constants, ultrasonic attenuation and microstructure, and dispersion relations. Because it can be remotely operated, this technique is amenable for in-pile, real time applications. Dr. Kennedy provided some examples of data being collected and also the development path for future applications. Figure 12shows the schematic for the Combined Laser Ultrasonics and Resonance Ultrasound Spectroscopy.

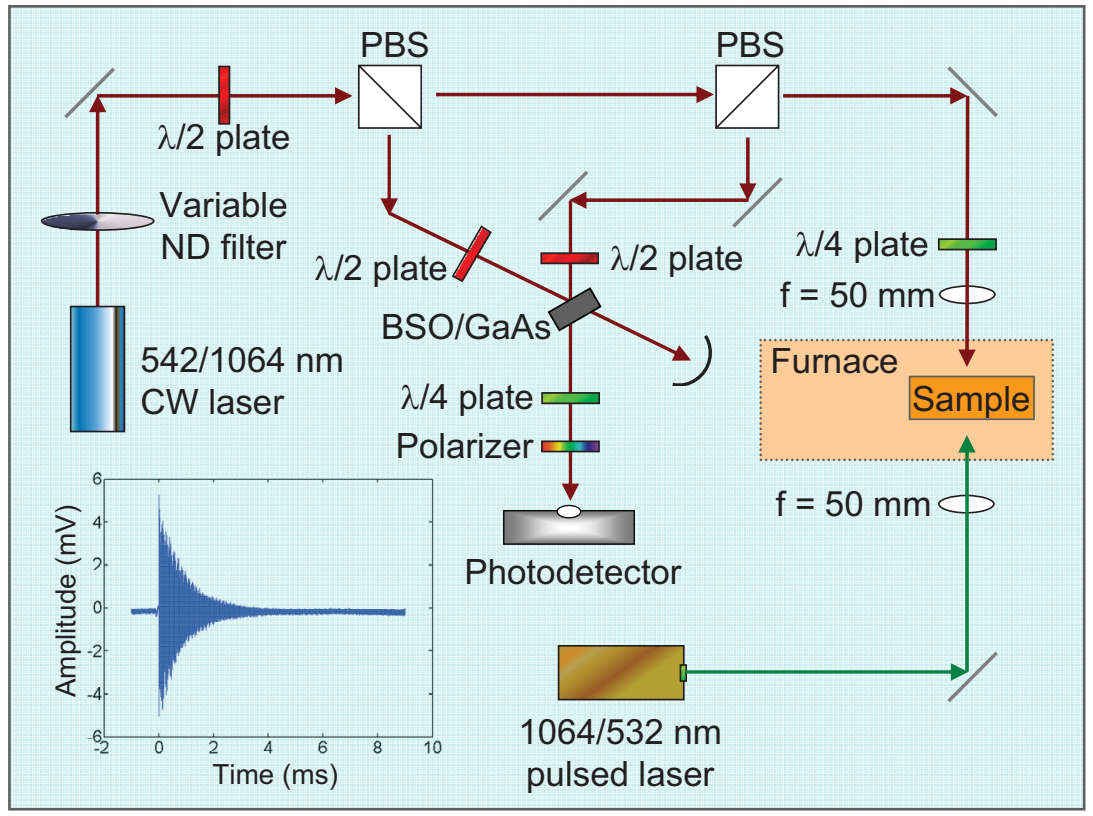

Figure 12. Combining Laser Ultrasonics and Resonance Ultrasound Spectroscopy (Presentation \#10).

\subsection{X-Ray Micro Tomography}

Dr. Lance Snead (ORNL) presented the application of X-Ray microtomography technique to TRISO fuel development and graphite studies. Currently, the resolution is $1.4 \mu \mathrm{m}$ (see Figure 13) but improvements are underway to obtain sub-micron resolution with a potential for $70 \mathrm{~nm}$ resolution. Also, the development at ORNL continues to apply this technique to samples with higher radiation dose.

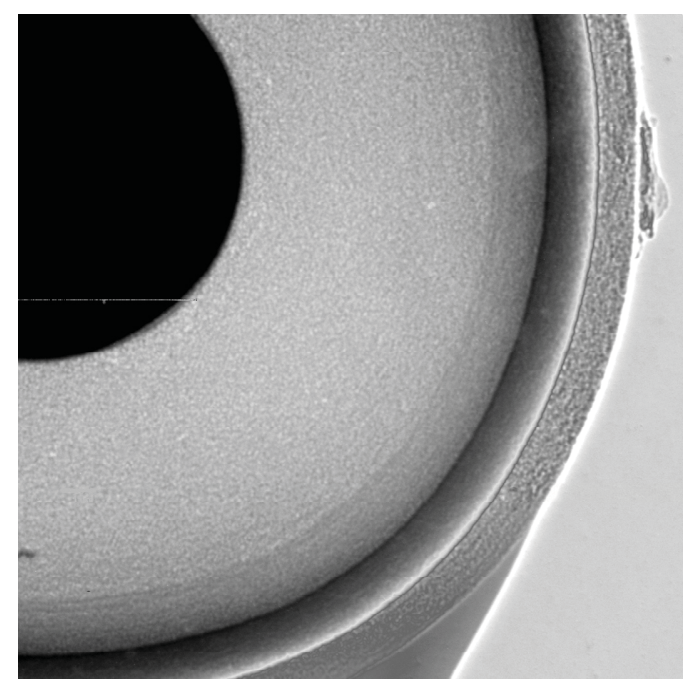

Figure 13. Actual imaging resolution of current system surrogate TRISO particle at $1.4 \mu \mathrm{m}$ resolution (Presentation \#11). 


\subsection{Density Measurements with X-Ray Absorption}

Dr. Somers (ITU) presented the X-ray absorption technique for local density measurements on nuclear materials. Figure 14 shows the X-Ray Powder Diffractometer schematic. The advantages of using X-Ray absorption as a complementary alternative to immersion techniques are listed below.

- Non destructive method, a fuel disk with parallel sides is required

- Not affected by temperature and pressure fluctuations in the hot cell

- Radial total porosity/density profiles on fuel pellets can be measured

- Easily repeatable and fast measurements

However, the technique has some disadvantages, such as:

- Fuel cracks must be avoided (similar to diffusivity measurements with laser flash)

- Difficult calibration (solid fission products cannot be considered, only empirical corrections)

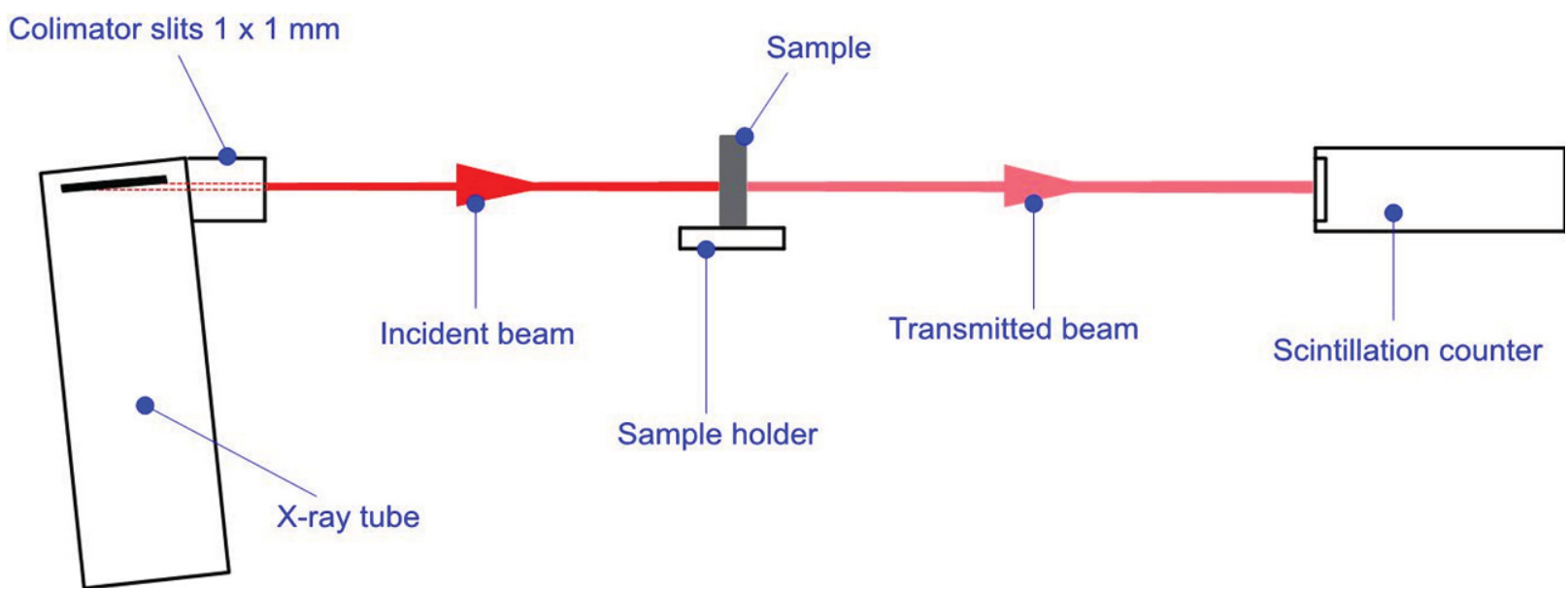

Figure 14. X-Ray Powder Diffractometer (Seifert XRD 3000 PTS) (Presentation \#14).

\section{GROUP DISCUSSION ON MODELING NEEDS}

Due to the strong international support for modeling, the PIE and characterization needs were grouped to support fuel performance modeling and simulations. It was recommended that the modeling needs be prioritized by the areas that give us the biggest advantage (bang for the buck). An integrated approach should be used to close down on modeling needs quickly. Table 1 and Table 2 summarize the results of the discussion. Table 1 includes both the currently available techniques and the future possibilities to close the data gaps. For future capabilities, instruments and techniques are listed but those are not necessarily available inside a suitable facility at present. 
Table 1. Needs for Performance Codes

\begin{tabular}{|c|c|}
\hline Parameter & Device For Measurement on Irradiated Fuel \\
\hline \multicolumn{2}{|l|}{ Composition } \\
\hline $\begin{array}{l}\text { Fuel composition: } \\
\text { - U, Pu, MA } \\
\text { - Isotopic composition } \\
\text { - Fission products, impurities }\end{array}$ & $\begin{array}{l}\text { - EPMA } \\
\text { - EPMA+ SIMS + isotopic dissolution + mass spectroscopy } \\
\text { - ICPMS } \\
\text { - PIXE on active samples } \\
\text { - X-ray fluorescence and absorption spectroscopy }\end{array}$ \\
\hline Gases (helium and fission gases) & $\begin{array}{l}\text { - EPMA + SIMS } \\
\text { - TEM } \\
\text { - EBSD } \\
\text { - NRA } \\
\text { - Laser ablation } \\
\text { - X-ray fluorescence and absorption spectroscopy }\end{array}$ \\
\hline Stoichiometry $(\mathrm{O} / \mathrm{M})$ & $\begin{array}{l}\text { - EPMA } \\
\text { - SIMS } \\
\text { - Electrochemical Cell } \\
\end{array}$ \\
\hline $\begin{array}{l}\text { Chemical form of each component inside the } \\
\text { fuel (single or multiple phases) }\end{array}$ & $\begin{array}{l}\text { - XRD and micro focus XRD } \\
\text { - TEM } \\
\text { - EXAFS } \\
\text { - SIMS + EPMA }\end{array}$ \\
\hline $\begin{array}{l}\text { Interaction with other components } \\
\text { (especially cladding) }\end{array}$ & $\begin{array}{l}\text { - EPMA, SEM, TEM } \\
\text { - SIMS } \\
\text { - Beam line (some beam lines allow samples with MAs but } \\
\text { irradiated fuel samples are not easily permissible ) }\end{array}$ \\
\hline \multicolumn{2}{|l|}{ Clad wastage } \\
\hline Gas composition and pressure in the gap & - Puncturing + spectrometry analysis \\
\hline \multicolumn{2}{|l|}{ Microstructure } \\
\hline Density & $\begin{array}{l}\text { - Tomography } \\
\text { - Tomography 3D } \\
\text { - Immersion }\end{array}$ \\
\hline Porosity (open, closed, shape of porosity) & $\begin{array}{l}\text { - SEM-FIB } \\
\text { - Micro beam XR tomography may be a possibility }\end{array}$ \\
\hline Grain size, cracks & $\begin{array}{l}\text { - SEM-FIB } \\
\text { - EBSD } \\
\text { - Nano-indentation for cracks is a question }\end{array}$ \\
\hline Columnar grain diameter & -Metallography \\
\hline Bubbles interconnection & -SEM-FIB \\
\hline \multicolumn{2}{|l|}{ Geometry } \\
\hline Fissile column length, & - Gamma spectrometry et X-Ray \\
\hline Gap closure and pellet/clad contact & $\begin{array}{l}\text { - Diametral Metrology } \\
\text { - Neutron Radiography with high resolution }\end{array}$ \\
\hline Pellet diameter & -Metallography \\
\hline Inner/outer clad diameter & $\begin{array}{l}\text { - Diametral metrology, Eddy Current, US methods to be } \\
\text { developed }\end{array}$ \\
\hline Fuel central hole & - X-Ray, gamma spectrometry, metallography \\
\hline
\end{tabular}




\begin{tabular}{|l|l|}
\hline \multicolumn{1}{|c|}{ Parameter } & \multicolumn{1}{c|}{ Device For Measurement on Irradiated Fuel } \\
\hline Properties & \\
\hline Thermal diffusivity & - Laser flash \\
\hline Thermal diffusivity & - Calorimeter \\
\hline Thermal expansion & \\
\hline Melting point & \\
\hline Eutectics & \\
\hline Young modulus & - Nano indentation \\
\hline Creep & - Indentation \\
\hline
\end{tabular}

Table 2. Needs for Atomistic Codes

\begin{tabular}{|l|l|}
\hline \multicolumn{1}{|c|}{ Modelling Type Parameter } & \multicolumn{1}{c|}{ Device For Measurement on Irradiated Fuel } \\
\hline Ab initio & \\
\hline $\begin{array}{l}\text { Material properties: composition, crystal } \\
\text { structure, chemical order, elastic constants, } \\
\text { phonon spectra, electronic structure, } \\
\text { thermodynamic data, etc. }\end{array}$ & - XRD, XAS, NMR, Raman, PES (XPS and UPS) \\
\hline $\begin{array}{l}\text { Activation energies of diffusion (self- } \\
\text { diffusion and gas diffusion) }\end{array}$ & - PAS, TEM \\
\hline Empirical potentials & Same as ab initio \\
\hline Material properties & Same as fuel performance code and ab initio \\
\hline Material thermo-mechanical properties & - SEM-FIB, TEM, PAS, EBSD \\
\hline Radiation damage, microstructure evolution & - SAX, TEM, NRA \\
\hline Fission gas and helium bubbles & \\
\hline Cluster dynamics & - TDS, SIMS \\
\hline Atomic diffusion coefficients & - SAX, TEM \\
\hline $\begin{array}{l}\text { Size and density of fission gas and helium } \\
\text { bubbles }\end{array}$ & \\
\hline
\end{tabular}

\section{GROUP DISCUSSION ON SAFETY NEEDS}

The PIE workshop took place shortly after the Fukushima nuclear plant accidents in Japan. Therefore it was decided to include safety needs as part of the workshop discussions. The following are the important conclusions and highlights that resulted from that discussion.

The current infrastructure is not sufficient to answer all the questions we face in case of considerable fuel and cladding damage. The primary questions are

- How does the cladding fail (rupture, melting, etc.)?

- What happens to fuel when cladding fails?

- How does steam react with cladding and fuel?

In conclusion, the current testing, characterization and PIE capabilities are not sufficient to fully answer the questions.

During the accidents, the phenomena were very complex and with thermodynamic non-equilibrium phases. The ability to collect and analyze the data during testing is important because it is hard to 
deconvolute the data after the testing to understand what is happening. Instrumented in-pile transient testing is very valuable up to and beyond failure, but the information that can be gathered is limited and such test reactors are not readily available for destructive testing. The discussion resulted in a number of strong recommendations.

1. Hot-cell furnace tests combined with characterization and PIE to understand the detailed behavior under accident conditions.

2. Standard characterization and PIE equipment are not totally adequate for severe accident testing (temperature limitations, etc.). New measurement techniques should be explored, especially to measure chemical forms of the products.

3. Small size clad-fuel in pile experiments would be useful to gain fundamental understanding of local phenomena.

4. Additional properties data on irradiated fuel samples (emphasis on accident conditions)

Since this type of testing is expensive, a strong international collaborative effort is essential to fully understand the fuel behavior under severe accident conditions. Some capabilities exist (e.g. Studvik, VERDON in STAR hot cells at CEA), some capabilities are being developed (e.g. STAR hot cells at CEA), some capabilities for continuous interrogation and characterizations are being considered (MaRIE at LANL) but much more is needed, along with some fundamental thermo-chemistry data relevant to accident conditions. This is a high-temperature thermodynamics problem with coupled fuel and cladding behavior.

The OECD/NEA Expert Group should consider adding severe accident testing to their charter as a means of starting the international collaborative effort. The first step would be a review of existing capabilities.

As a follow on step, the design of a test facility could be another international collaboration effort. The design would include the size and scope of testing, data needs, data collection methods, design of new instruments and techniques for data collection, data storage and analyses, etc. The involvement of safety authorities (e.g. NRC) would also be very valuable.

In conclusion, there is opportunity to look into a test facility design as an integral international capability to do testing and characterization simultaneously, in one place to understand the data.

\section{HIGHLIGHTS AND MAJOR CONCLUSIONS OF THE WORKSHOP}

The workshop confirmed that there is considerable infrastructure in place and new capabilities are being developed around the world. However, to fully-support the science-based development of fuels and cladding, and to understand their behavior under accident conditions, all the needed capabilities do not exist. It is not likely or desirable to have all of these capabilities in one location. An international collaboration where a set of capabilities is fully connected providing a collective characterization and PIE laboratory spread across the globe is a very strong possibility. Also, running new, large-scale experiments are difficult and expensive due to facility limitations (e.g. limited number of fast test reactors). Therefore, the information gained from a given experiment must be maximized using collective resources. The following are the major elements of such an international collaboration.

\subsection{International PIE Project}

- An international working group or an expert group can be formed to create and coordinate an International characterization and PIE project. The Innovative Fuels Expert Group can function 
during the early planning phases but a larger and more formal group will likely be needed for implementation.

- The group must provide a joint definition of the data requirements to lead towards a pure sciencebased predictive modeling approach, which in turn will define the types of characterization tests required and the necessary measurement techniques. This will also define the measurement technology shortfalls and the need for additional technique and equipment development work.

- The characterization and PIE needs may be different for the different phases of the fuel development process. It would be beneficial to define the needs as a function of technology readiness level and decision points during the development process, all the way up to licensing. Statistical issues become important as we approach the licensing phase.

- The licensing approach can be adapted to the new paradigm of science-based approach. However, this requires collaborations among the licensing authorities, scientists, and engineers in the early stages.

- Codes and standards vary between countries. Efforts to synchronize the codes and standards would be very beneficial.

- Funding limitations and expertise prevent doing all the work in one location. Resource sharing, especially for expertise and field experience, is important to success.

- Special sub-projects and teams can be established to address high priority needs (e.g. helium measurements in used fuel, full length tomography, etc.)

\subsection{Testing Considerations}

- Maximizing the information gained from a given irradiation testing is important by sharing samples and utilizing the collective resources.

- Transient testing capability, experiments, and data from such tests are limited. Strong collaborations on transient testing of fresh and irradiated fuels are needed.

- Combined testing and characterization facilities that can provide fundamental thermodynamic data to examine fuels and cladding under severe accident conditions do not exist.

\subsection{Modeling and Simulation}

- Advanced modeling and simulation is a powerful tool for fuel development. However, all the necessary data for model development and validation do not exist, especially at lower length and time scales. The ongoing strong international collaboration on modeling and simulation can be a driver for similar collaboration on data collection.

- Benchmarks among codes and models are important even when we compare them to data, because we do not measure everything in experiments. Code-to-code and model-to-model benchmarks allow for comparison of many more parameters. Favorable comparisons increase confidence in predictions.

- Standard benchmarks for codes developed in multiple institutions would be very beneficial. 


\subsection{Transportation and Sample Sharing}

- Global transportation of irradiated fuels and materials is an obstacle. There are few remaining test reactors. In addition, fabrication, irradiation testing, and characterization are all done in different countries. A universally licensed cask to transport samples between test and PIE facilities would be very beneficial.

- To enable the collaboration among international facilities, international regulations must be evaluated and updated to facilitate international collaborative testing. It should not be a special effort to transport every sample.

\subsection{Measurements}

- Sample preparation is important to advanced examination capability; therefore, standards must be developed for sample preparation.

- International standards for TRU materials (e.g. plutonium) must be developed to be able to compare data.

- Some measurements techniques are useful for multiple parameters and the main PIE hotcells should include such standard techniques (a specialists' team can identify such a standard basic capability matrix (e.g. TEM, EPMA, SIMS).

- For some of the novel measurement techniques, no standards exist. The development of an international standard would be needed if data will be shared among the collaborators.

- Periodic round-robin testing on samples among the collaborators will enhance the confidence on the data.

- The ability to perform characterization and PIE for fuel under severe accident conditions (beyond failure) is a new challenge. The capabilities are quite limited in this area.

- There is a certain volume of work that needs to be done to complete the spectrum for thermodynamic specific data, including fresh fuel. A free access international validated thermodynamic database would be beneficial.

- Trace element detection is very limited (SIMS measurements) and we are not ready to generate validated compositions for spent fuels, etc. 
This page intentionally left blank. 


\section{APPENDIX A}

\section{International Workshop Participants}




\section{Appendix A International Workshop Participants}

FINLAND

HÄKINEN, Silja

VTT

PO Box 1000

FI-02044 VTT silja.holopainen@vtt.fi

+358207226710

\section{FRANCE}

BOUINEAU, Vincent

CEA-Cadarache DEN/DEC/SESC/LSC, Bat 151, 13108 St. Paul-lez-Durance Cedex

CHAUVIN, Nathalie

CEA-Cadarache DEN/DEC/SESC Bat 151 13108 St. Paul-lez-Durance Cedex

FREYSS, Michel

CEA-Cadarache DEN/DEC/SESC/LLCC, Bat. 352 13108 St. Paul-lez-Durance Cedex

LAMONTAGNE, Jerome

SUDREAU, Francois

CEA-Cadarache DEN/DEC/SA3C/L2EC, Bat 316, 13108 St. Paul-lez-Durance Cedex

CEA-Cadarache DEN/DEC/SA3C, Bat 315 13108 St. Paul-lez-Durance Cedex

vincent bouineau@cea.fr +33442252965

nathalie.chauvin@cea.fr +33442254810

michel.freyss@cea.fr +33442256509

jerome.lamontagne@cea.fr +33442253363

francois.sudreau@cea.fr +33442254529

\section{GERMANY}

GABRIELLI, Fabrizio

Karlsruhe Institute of Technology

Hermann-von-Helholtplatz, 1

fabrizio.gabrielli@kit.edu

D-76344 Eggenstein-Leopoldshafen

\section{KOREA (REPUBLIC OF)}

LEE, Byoung-Oon
Fuel section, HYPER Project

KAERI

P.O. Box Yusong

Daejon 305-600 bolee@kaeri.re.kr

+82428682645

\section{RUSSIAN FEDERATION}

IAKOVLEV, Valeriy

SSC RIAR JSC

adm@niiar.ru

Ulyanovsk region, Russia 


\section{SWEDEN}

CORLEONI, Francesco

Market \& Development Materials Technology

Studsvik Nuclear AB

SE-611 82 Nyk?ing francesco.corleoni@studsvik.se $+46155221106$

\section{SWITZERLAND}

POUCHON, Manuel Alexandre

Nuclear Energy and Safety / High Temperature Materials

Paul Scherrer Institut

5232 Villigen PSI Aargau manuel.pouchon@psi.ch +41563102245

\section{UNITED KINGDOM}

IVISON, Philip

WILLIAMSON, Robert

Technical Manager, PIE

National Nuclear Laboratory

phil.ivison@nnl.co.uk

Sellafield

Seascale, Cumbria

Head of Operational Planning

NNL Facilities

+441946781490

Sellafield

Seascale, Cumbria

CA20 1PG

\section{UNITED STATES OF AMERICA}

BRAASE, Lori

FINCK, Phillip J

GRIFFITH, Andrew

HAYES, Steven

KENNEDY, J. Rory

MIOTLA, Dennis
Idaho National Lab

Systems Engineering

P.O. Box 1625

Idaho Falls, Idaho 83415-3634

Idaho National Lab

Associate Lab. Director, NS\&T

P.O. Box 1625 ,

Idaho Falls, Idaho 83415-3860

Office of Nuclear Energy

Department of Energy

Idaho National Lab

Irradiation Testing \& Mod/Sim

P.O. Box 1625,

Idaho Falls, Idaho 83415

Idaho National Lab

Metallic Fuels

P.O. Box 1625 ,

Idaho Falls, Idaho 83415-6188

Office of Nuclear Energy

Department of Energy lori.braase@inl.gov

+12085267763

robert.williamson@nnl.co.uk +44 (0)1946 781420 phillip.finck@inl.gov

+12085269447

andrew.griffith@nuclear.energy

+13019037120

steven.hayes@inl.gov +1 208-526-7255

rory.kennedy@inl.gov

+12085337795

dennis.miotla@hq.doe.gov

+13019035427 
PASAMEHMETOGLU, Kemal

SALEH, Tarik

SNEAD, Lance
Idaho National Lab

Division Director, NF\&M

P.O. Box 1625 ,

Idaho Falls, Idaho 83415

Los Alamos National Lab

Nuclear Materials

Oak Ridge National Lab

1 Bethel Valley Road

Oak Ridge, TN

MS 6140 kemal.pasamehmetoglu@inl.gov

+12085265305

tsaleh@lanl.gov

+15056651670

sneadll@ornl.gov

INTERNATIONAL ORGANISATIONS

BASAK, Uddharan

SOMERS, Joseph

CHOI, Yong-Joon
International Atomic Energy Agency

Vienna International Centre

PO Box 100

1400 Vienna, Austria

Institute for Transuranium Elements

Postfach 2340

D-76125 Karlsruhe

OECD Nuclear Energy Agency

12 boul. des Iles

92130 Issy-les-Moulineaux
U.Basak@iaea.org +43 (1) 260022771

+497247951359

yongjoon.choi@oecd.org +33(0) 145241091 


\section{APPENDIX B}

\section{Workshop Presentations}




\section{Appendix B Workshop Presentations}

\begin{tabular}{|c|c|c|c|}
\hline$\#$ & Presenter & Org/Country & Title \\
\hline 1 & K. Pasamehmetoglu & INL, US & $\begin{array}{l}\text { Workshop on Characterization \& PIE Needs to } \\
\text { Support Science-Based Development of } \\
\text { Innovative Fuels }\end{array}$ \\
\hline 2 & U. Basak & IAEA, Austria & $\begin{array}{l}\text { Joint IAEA HOTLAB Post Irradiation } \\
\text { Examination Facilities Database }\end{array}$ \\
\hline 3 & $\begin{array}{l}\text { T. Wiss } \\
\text { (J. Somers) }\end{array}$ & ITU, Germany & TEM Facility Development in Europe \\
\hline 4 & B. Lee & $\begin{array}{l}\text { KAERI, Republic } \\
\text { of South Korea }\end{array}$ & $\begin{array}{l}\text { Irradiation Status and PIE Plan of Metallic Fuel } \\
\text { for SFR }\end{array}$ \\
\hline 5 & D. Miotla & DOE-NE, US & $\begin{array}{l}\text { United States Perspective on Postirradiation } \\
\text { Examination Capabilities }\end{array}$ \\
\hline 6 & V. Bouineau & CEA, France & $\begin{array}{l}\text { Fuel Performance Code: Characterization and } \\
\text { PIE Needs for Modeling Validation }\end{array}$ \\
\hline 7 & M. Freyss & CEA, France & Atomistic Modeling for Innovative Fuels \\
\hline 8 & S. Hayes & INL, US & $\begin{array}{l}\text { PIE Needs to Support Fuel Design \& Safety } \\
\text { Testing }\end{array}$ \\
\hline 9 & M. Pouchon & PSI, Switzerland & Beam-line Techniques \\
\hline 10 & R. Kennedy & INL, US & $\begin{array}{l}\text { Laser-based Measurement Techniques for } \\
\text { Nuclear Materials }\end{array}$ \\
\hline 11 & L. Snead & ORNL, US & X-Ray Microtomography \\
\hline 12 & J. Lamontagne & CEA, France & $\begin{array}{l}\text { Current and Future Micro-analysis Devices in } \\
\text { the LECA-STAR Facility }\end{array}$ \\
\hline 13 & F. Sudreau & CEA, France & $\begin{array}{l}\text { Post Irradiation Examinations: LECA-STAR } \\
\text { Facility }\end{array}$ \\
\hline 14 & $\begin{array}{l}\text { D. Papaoiannou } \\
\text { (J. Somers) }\end{array}$ & ITU, Germany & $\begin{array}{l}\text { Application of X-ray Absorption to Density } \\
\text { Measurements }\end{array}$ \\
\hline
\end{tabular}




\section{Workshop on characterization \& PIE Needs to support science- based development of innovative fuels}

Kemal Pasamehmetoglu

June 16, 2011 (Paris, France)

OECD/NEA Expert Group on Innovative Fuels 


\section{Background}

- Tradition PIE relies on a limited number of measurements mostly at the engineering-scale

- Traditional PIE provides an integral view of the performance parameters, which is an aggregate of multiple phenomena occurring simultaneously

- The science-based approach aimed at a fundamental understanding of the performance phenomena require measurements at lower length- and time-scales

- Techniques and capabilities aimed at such measurements with highly radioactive samples are being developed at multiple institutions internationally

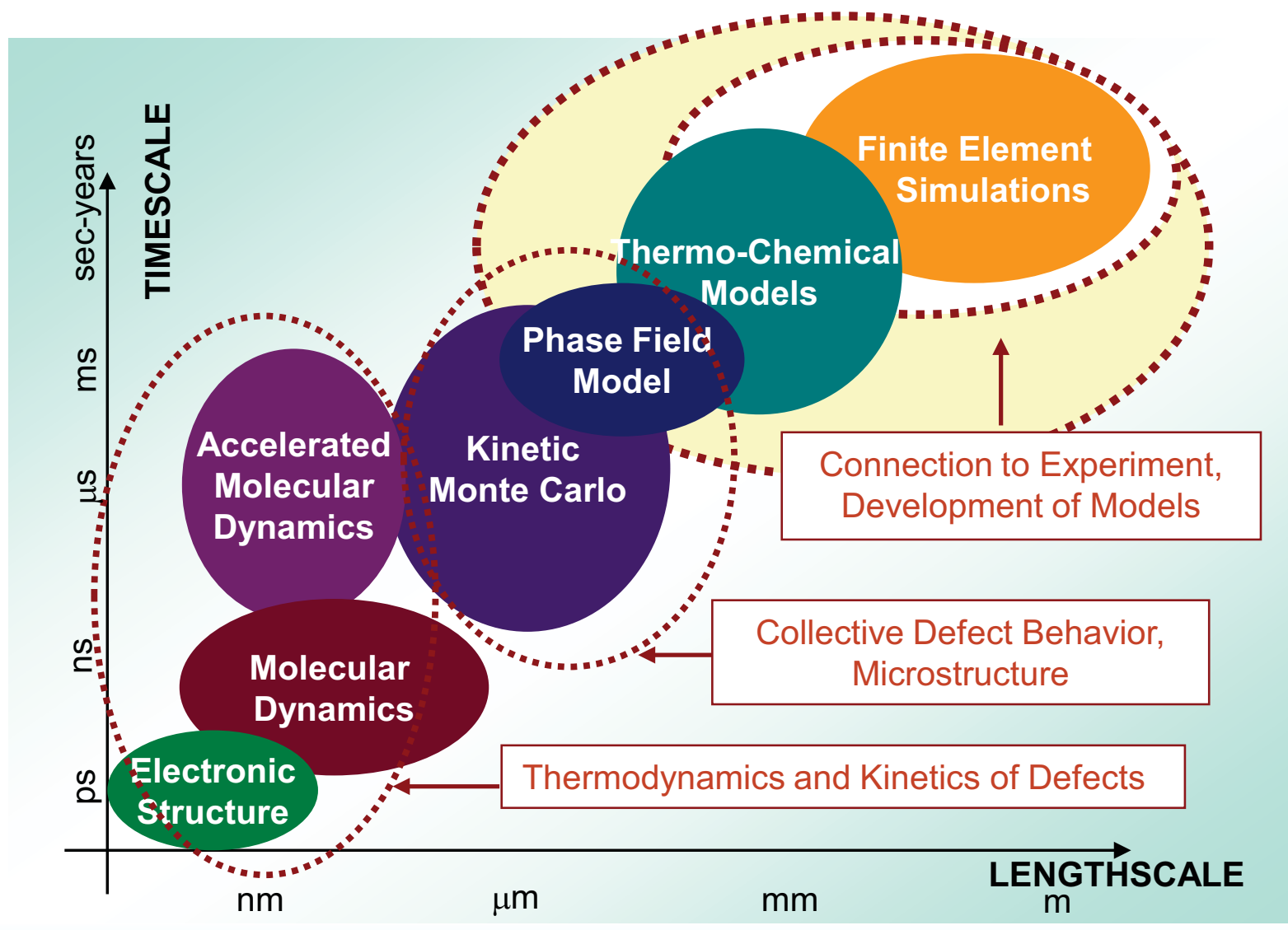




\section{Workshop Objectives}

- To review the existing characterization and PIE capabilities and the novel techniques that are being developed at the international facilities

$>$ To identify the gaps to meet the needs of a $21^{\text {st }}$ century characterization and PIE capabilities 


\section{Workshop Scope}

Presentations by experts from various organizations on the status of existing facilities, capabilities and near-term plans

- sample-sharing possibilities, main features and characteristics of the various facilities and the capability of performing out-of-pile testing on irradiated fuels and material samples

- Presentations on characterization and PIE needs for $21^{\text {st }}$ century fuel development

- Fuel designer and safety analyst perspective

- Modeling and simulation and material science perspective

- New equipment and novel techniques that are being developed at various institutions 


\section{Panel Discussion and Breakout Session}

- Invited experts will comment on

- how the new capabilities, when available, would transform the fuel development paradigm.

- the major gaps and obstacle to achieving a new, science-based paradigm for development

- major areas that were not covered in the presentations that should be focused on during the breakout sessions

2 breakout sessions

- Engineering scale and micro-structure characterization (>1 $\mu \mathrm{m})$

- Lower length scale characterization $(<1 \mu \mathrm{m})$ 


\title{
IAEA Activities:
}

Joint IAEA HOTLAB Post Irradiation Examination Facilities Database

\author{
Presented by \\ U.Basak \\ Nuclear Fuel Cycle and Materials Section \\ International Atomic Energy Agency
}




\section{Integrated Nuclear Fuel Cycle Information System}

\section{Web based}

system with public access from 2001

Initially based on the Agency's electronic databases created in 1990s

Information collected from contact points in Member States, consultants and open sources.

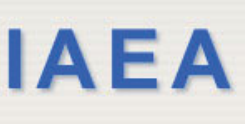

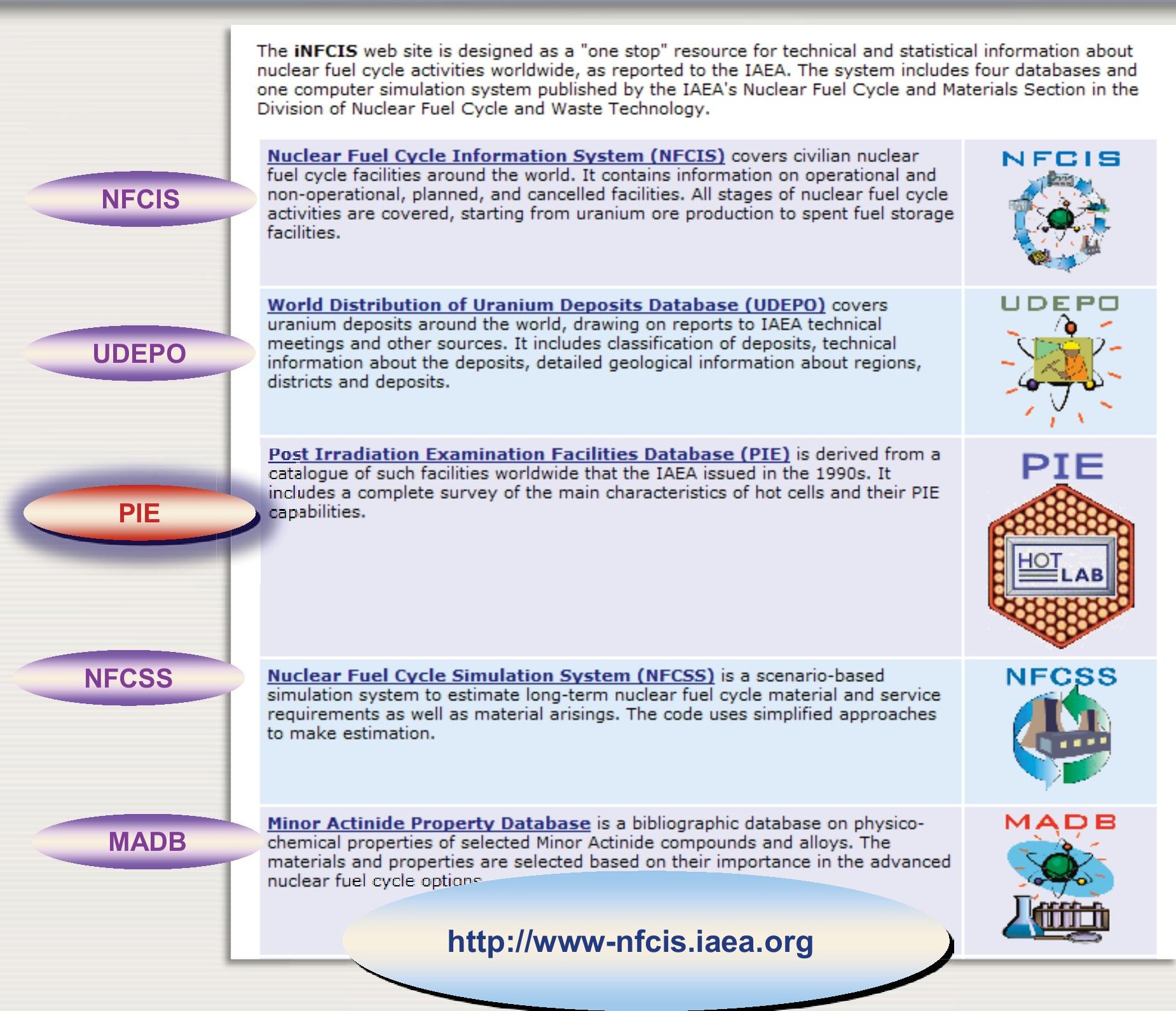

The iNFCIS web site is designed as a "one stop" resource for technical and statistical information about nuclear fuel cycle activities worldwide, as reported to the IAEA. The system includes four databases and one computer simulation system published by the IAEA's Nuclear Fuel Cycle and Materials Section in the activities are covered, starting from uranium ore production to spent fuel storage facilities.

World Distribution of Uranium Deposits Database (UDEPO) covers Wrate deposits around the world, drawing on reports to IAEA technical (

Post Irradiation Examination Facilities Database (PIE) is derived from catalogue of such facilities worldwide that the IAEA issued in the 1990s. It includes a complete survey of the main characteristics of hot cells and their PIE capabilities.

simulation system to estimate long-term nuclear fuel cycle material and service requirements as well as material arisings. The code uses simplified approache make estimation.

Minor Actinide Property Database is a bibliographic database on physicochemical properties of selected Minor Actinide compounds and alloys. The (importance in the advanced http://www-nfcis.iaea.org
NFCIS

UEP

NFCSS

MADE

iniln 


\section{Joint IAEA HOTLAB PIE database: history and status}

- Created in 1990s, published as a working material in 1996

- Transformed into an electronic database in 2003

- Merged with EC HotLab Database in 2008, casks information was added from EC HotLab database

- Modification and update 2009/10

- Wider collaboration with HOTLAB and NULIFE

- Data update by facility coordinators directly, through a web form

- Verification of new data by the DB reviewers

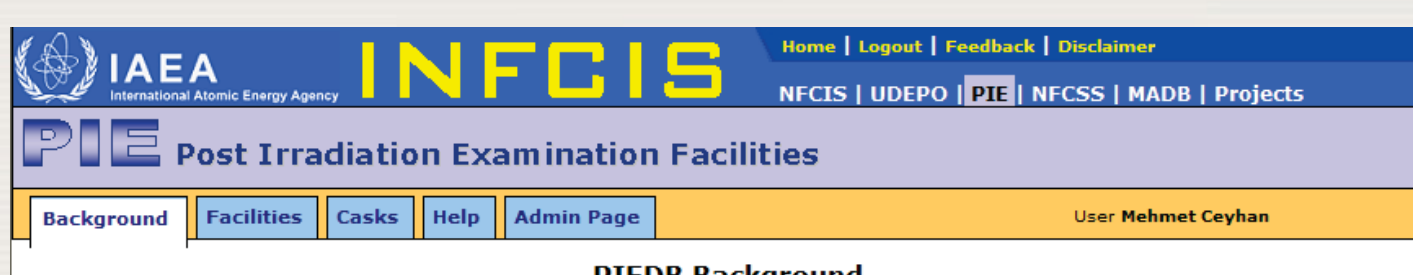

PIEDB Background

While the number of states with nuclear power programmes is growing, the number of hot cells has diminished during the last decades. This creates problems with post-irradiation examination (PIE) for fuel surveillance, safety control and nuclear materials studies, including the development of
new radiation resistant materials for advanced and innovative nuclear applications. It highlights the need for more efficient use of existing PIE facilities relying on wider international exchange of information about their capabilities.

With this in mind, the IAEA initiated a Coordinated Research Project aimed at the development of a PIE Facilities Catalogue, which was published as an IAEA Working Material in 1996. In 2002/03 the catalogue was converted into a database and updated through questionnaires distributed to hot laboratories in the IAEA Member Sates. In 2005/06 an interactive mode of the PIE Database was developed that allowed hot-lab managers to modify and amend its contents on-line via the internet on the IAEA Integrated Nuclear Fuel Cycle Information Systems (iNFCIS) website:
http://Wwww-nfcis.iaea.org. An important advantage of the PIE Database is the procedure of the professional reviewing of all new inputs made on-

In 2007/08, following an agreement with the international HOTLAB Working Group (http://www.sckcen.be/hotlab), the IAEA PIE Database integrated the HOTLAB PIE Catalogue, including transport casks information. So now, the merged data are kept at the iNFCIS website and jointly integrated the HOTLAB PIE Catalogue, including transport casks information. So now, the merged data are kept at the INFC
managed by the IAEA and HOTLAB, representing the only publicly accessible world-wide source of the subject information.

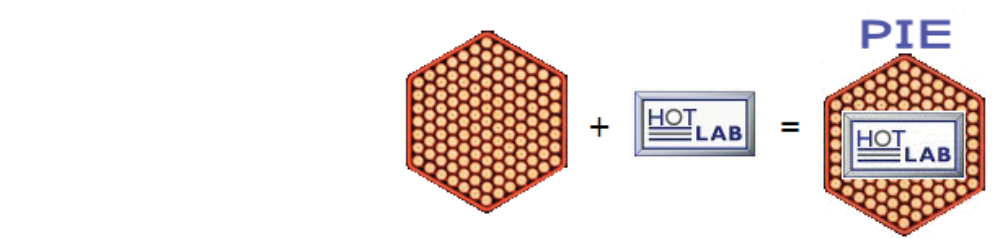

The database consists of five main areas describing PIE facilities (i.e. acceptance criteria for irradiated components, cell characteristics, PIE techniques, re-fabrication/instrumentation capabilities and storage and conditioning capabilities) as well as major technical and licensing data of casks.

The content of the database represen casks and examination technin.
as well as to provide de. the most appropriate facilities,

\section{2 facilities from 22 countries and 19 casks}




\section{Joint IAEA-HOTLAB PIE database: the database}

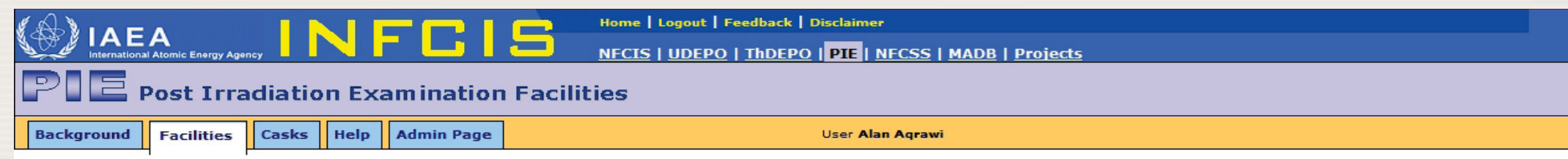

\section{List of PIE Facilities}

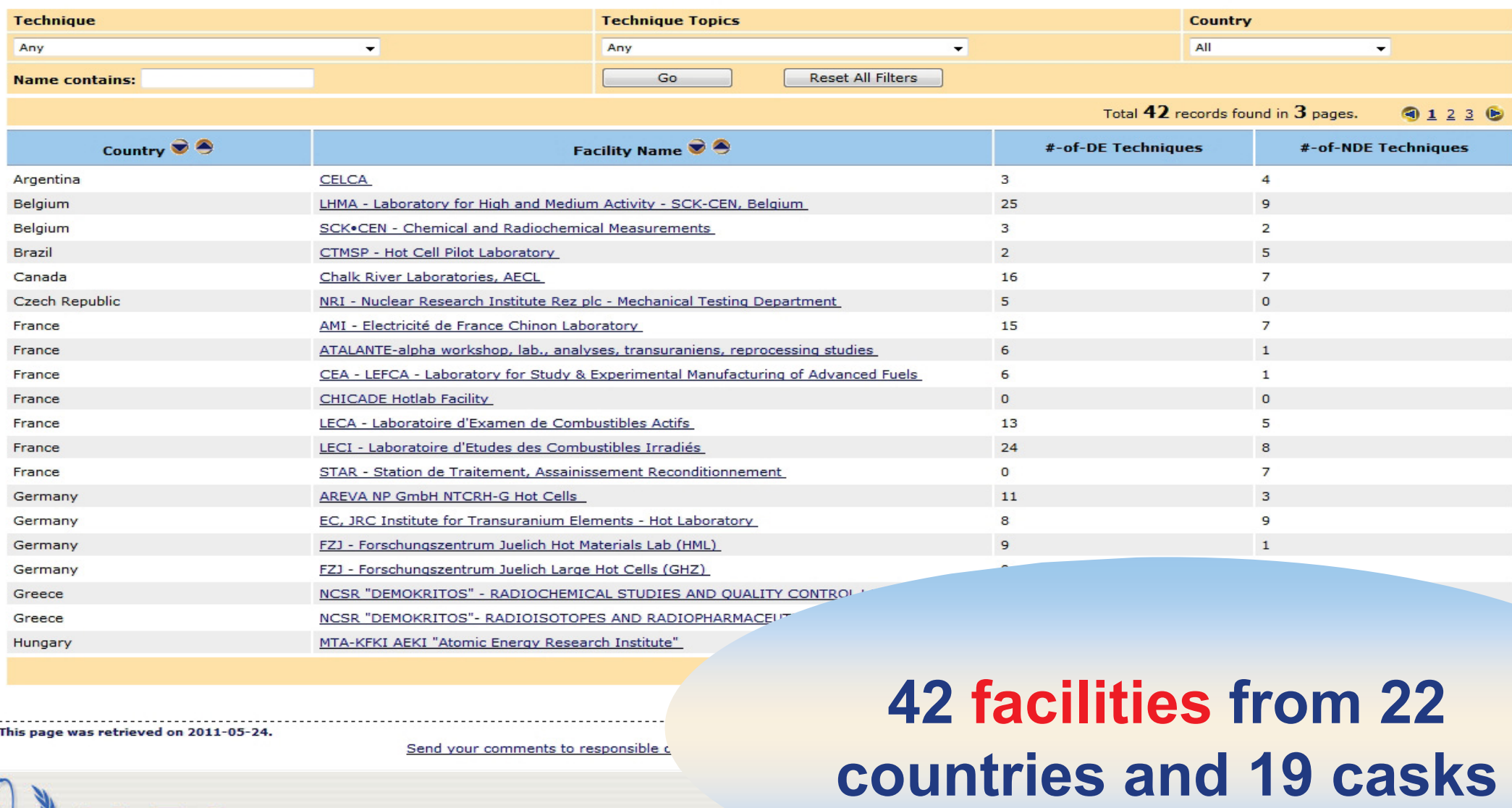




\section{Joint IAEA-HOTLAB PIE database: the database}

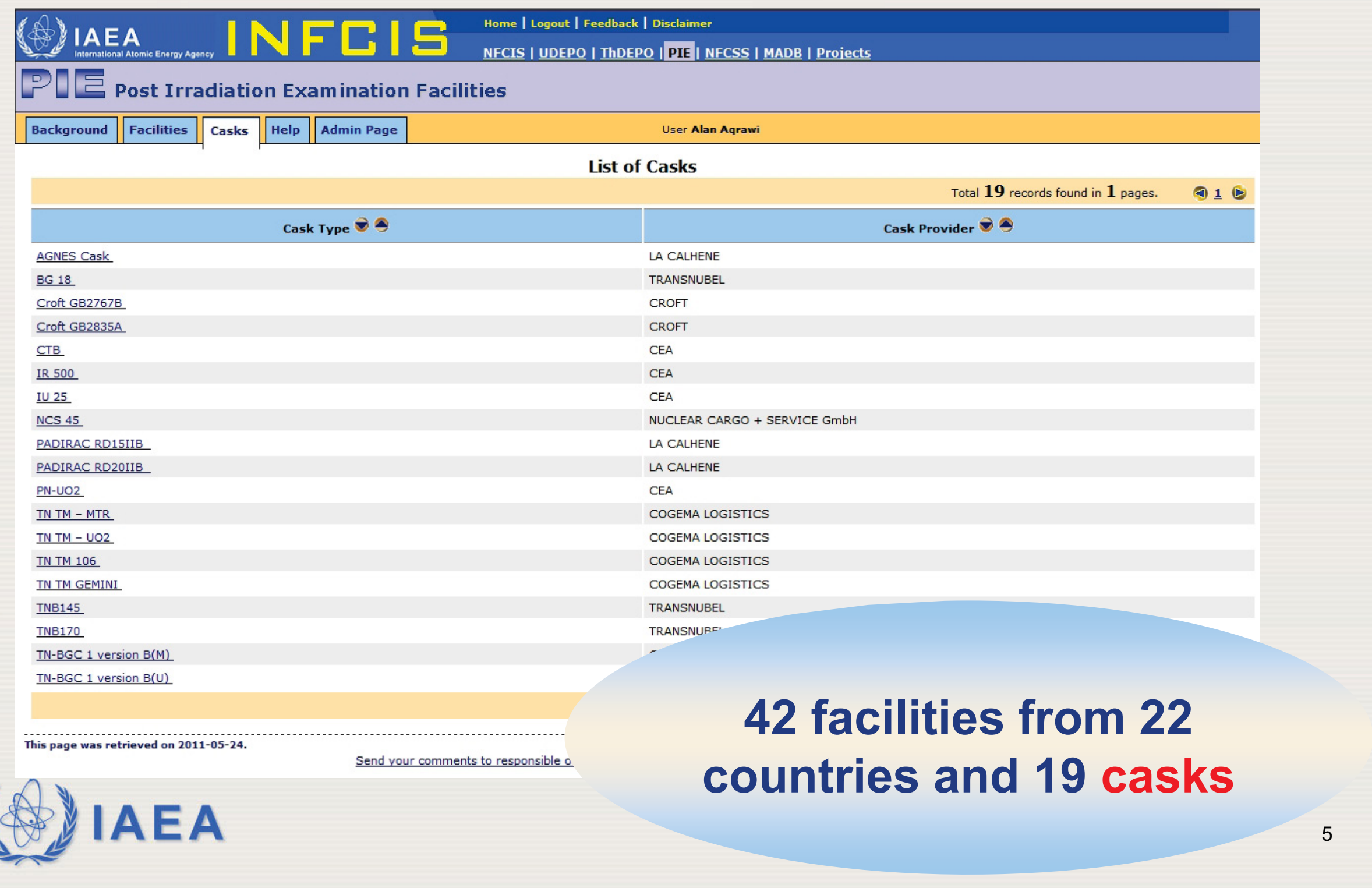




\section{Joint IAEA-HOTLAB PIE database: webform}

1. Register as a contributor with the DB.

2. On-line entry of data by a facility coordinator

3. Verification of new data by the DB reviewers.

4. Release and integration of data into the DB. 


\section{Joint IAEA-HOTLAB PIE database: content}

The DB consists of 5 main areas describing PIE facilities:

- Acceptance criteria for irradiated components.

- Cell characteristics.

- PIE technology.

- Refabrication/instrumentation capabilities.

- Storage and conditioning capabilities.

As well as major technical and licensing data of casks. 


\section{Joint IAEA-HOTLAB PIE database: content}

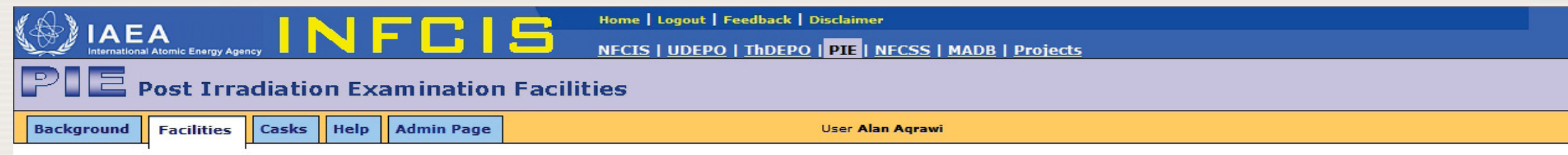

\section{List of PIE Facilities}

\begin{tabular}{|l|l|}
\hline Technique & Technique Topics \\
\hline Any & Any \\
\hline Name contains: & Go \\
\hline
\end{tabular}

\begin{tabular}{|c|c|c|c|}
\hline \multicolumn{4}{|c|}{ Total 42 records found in 3 pages. } \\
\hline Country $\theta \ominus$ & Facility Name $\theta \theta$ & \#-of-DE Techniques & \#-of-NDE Techniques \\
\hline Argentina & CFICA & 3 & 4 \\
\hline Belgium & LHMA - Laboratory for Hiqh and Medium Activity - SCK-CEN, Belaium & 25 & 9 \\
\hline
\end{tabular}

\begin{tabular}{|c|c|c|c|}
\hline Brazil & CTMSP - Hot Cell Pilot Laboratory & 2 & 5 \\
\hline Canada & Chalk River Laboratories, AECL & 16 & 7 \\
\hline Czech Republic & NRI - Nuclear Research Institute Rez plc - Mechanical Testing Department & 5 & 0 \\
\hline France & AMI - Electricité de France Chinon Laboratory & 15 & 7 \\
\hline France & ATALANTE-alpha workshop, lab., analyses, transuraniens, reprocessing studies & 6 & 1 \\
\hline
\end{tabular}

\begin{tabular}{ll}
$\begin{array}{l}\text { France } \\
\text { Germany }\end{array}$ & STAR - Station de Traitement, Assainissement Reconditionnement \\
Germany & AREVA NP GmbH NTCRH-G Hot Cells \\
\hline Germany & EC, JRC Institute for Transuranium Elements - Hot Laboratory \\
\hline Germany & FZJ - Forschungszentrum Juelich Hot Materials Lab (HML) \\
\hline Greece & FZJ - Forschungszentrum Juelich Large Hot Cells (GHZ) \\
\hline Greece & NCSR "DEMOKRITOS" - RADIOCHEMICAL STUDIES AND QUALITY CONTROL, \\
Hungary & NCSR "DEMOKRITOS"- RADIOISOTOPES AND RADIOPHARMACEUTT- \\
\hline & MTA-KFI AEKI "Atomic Eneray Research Institute" \\
\hline
\end{tabular}




\section{Joint IAEA-HOTLAB PIE database: content}

The DB consists of 5 main areas describing PIE facilities:

- General information \& cell characteristics

- Acceptance criteria for irradiated components.

- PIE technology.

- Refabrication/instrumentation capabilities.

- Storage and conditioning capabilities.

As well as major technical and licensing data of casks. 


\section{Joint IAEA-HOTLAB PIE database:}

\section{content}

\section{PIE Facility Report}

\section{Export to PDF}

Facility Name : Chalk River Laboratories, AECL

\begin{tabular}{|c|c|c|c|c|c|}
\hline General \& Cell Charac. $\mid$ Acceptance Info. & Techniques | Refabrication \& Instrumentation | Storage \& Conditioning & \multicolumn{3}{|l|}{ Reference Documents } & \\
\hline \multicolumn{5}{|l|}{ General } & \\
\hline Facility Name & Chalk River Laboratories, AECL & IAEA Ref \# & & \multicolumn{2}{|l|}{ 3-PIE } \\
\hline Country & Canada & Last Update & & \multicolumn{2}{|l|}{2010} \\
\hline Address & \multicolumn{4}{|l|}{ Chalk River Laboratories, St. 17, Chalk River, Ontario, KOJ-1J0, Canada } & \\
\hline Contact Person & Mr Allen Bakewell (Nuclear Facilities Operation Manager) & \multirow{2}{*}{\multicolumn{2}{|c|}{ Last Update }} & & \multirow{2}{*}{2010} \\
\hline Second Contact Person & & & & & \\
\hline Phone & 613-584-8811 ext 46241 & \multicolumn{2}{|l|}{ Fax } & & \\
\hline Email & bakewella@aecl.ca & & & & \\
\hline Web Address & www.aecl.ca & \multicolumn{3}{|c|}{ (Please notify us if you can not reach this web address!) } & \\
\hline \multicolumn{5}{|l|}{ Additional Information } & \\
\hline \multicolumn{5}{|l|}{ Cell Characteristics } & \\
\hline Purpose & \multicolumn{4}{|l|}{ PIE of fuel rods and assemblies } & \\
\hline Gamma Activity Limit (Concrete) (TBq) & 37000 & \# of Concrete Cells & \multicolumn{3}{|c|}{11} \\
\hline Gamma Activity Limit (Steel) (TBq) & 0 & & \multicolumn{3}{|c|}{$a$} \\
\hline Gamma Activity Limit (Lead) (TBq) & \multicolumn{5}{|l|}{0} \\
\hline Cell Atmosphere & \multicolumn{5}{|l|}{ Air } \\
\hline Largest Cell Width (m) & \multicolumn{5}{|l|}{1.8} \\
\hline Largest Cell Length (m) & \multicolumn{5}{|l|}{4.9} \\
\hline
\end{tabular}




\section{Joint IAEA-HOTLAB PIE database: content}

The DB consists of 5 main areas describing PIE facilities:

- General Information \& Cell characteristics

- Acceptance criteria for irradiated components.

- PIE technology.

- Refabrication/instrumentation capabilities.

- Storage and conditioning capabilities.

As well as major technical and licensing data of casks. 


\section{Joint IAEA-HOTLAB PIE database: content}

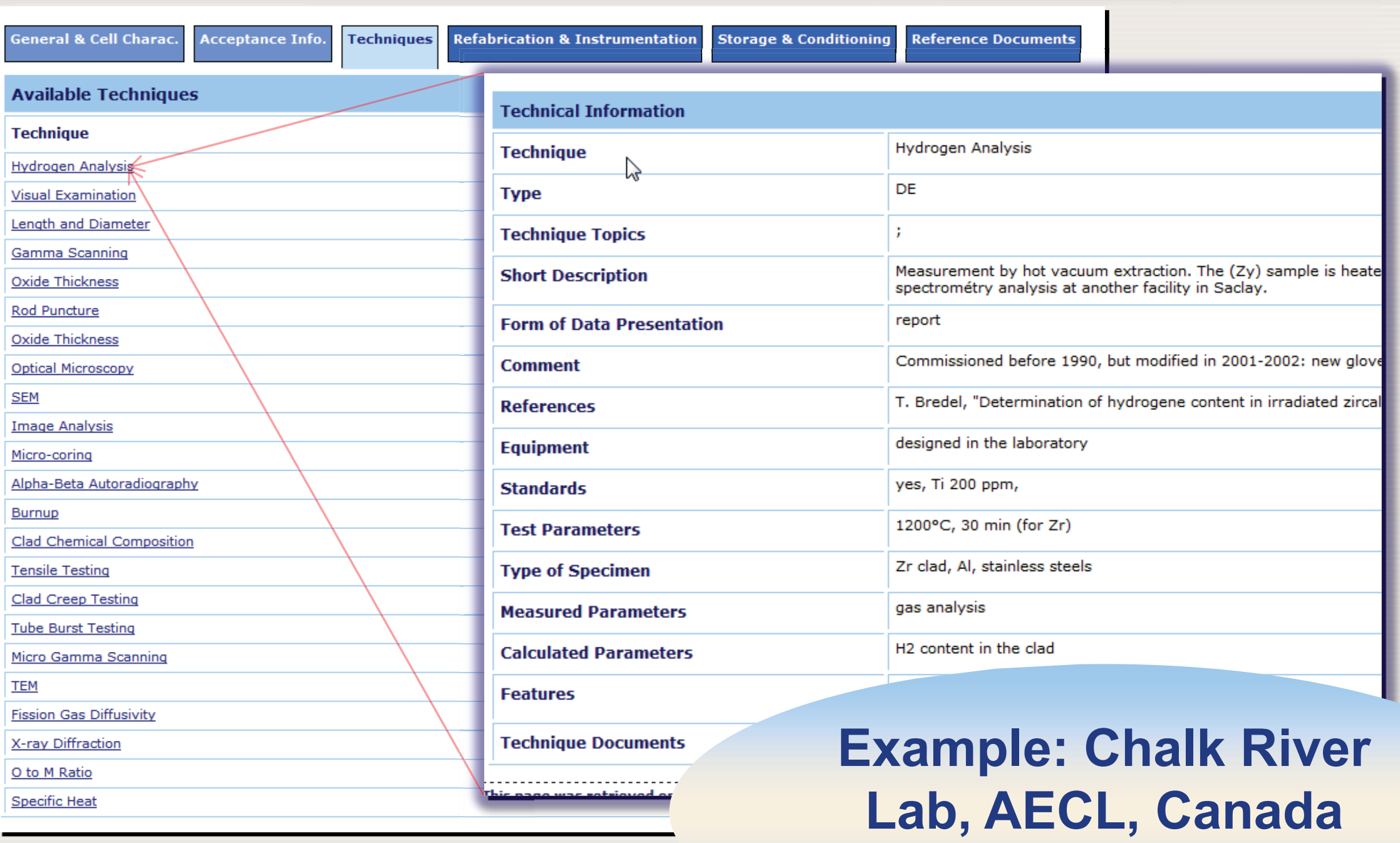




\section{Joint IAEA-HOTLAB PIE database: growth \& statistics}

\section{Year-by-year growth in popularity:}

- Growing collaboration with HOTLAB (http:/hotlab.sckcen.be/)

- In 2010, involvement of the European NULIFE research network for plant life management (launched under the EURATOM framework programme): Instead of developing a new DB, the existing PIEDB is being used and NULIFE facilities are being included.

- Jan-Nov 2010 renewal phase started and completed; with very positive results.

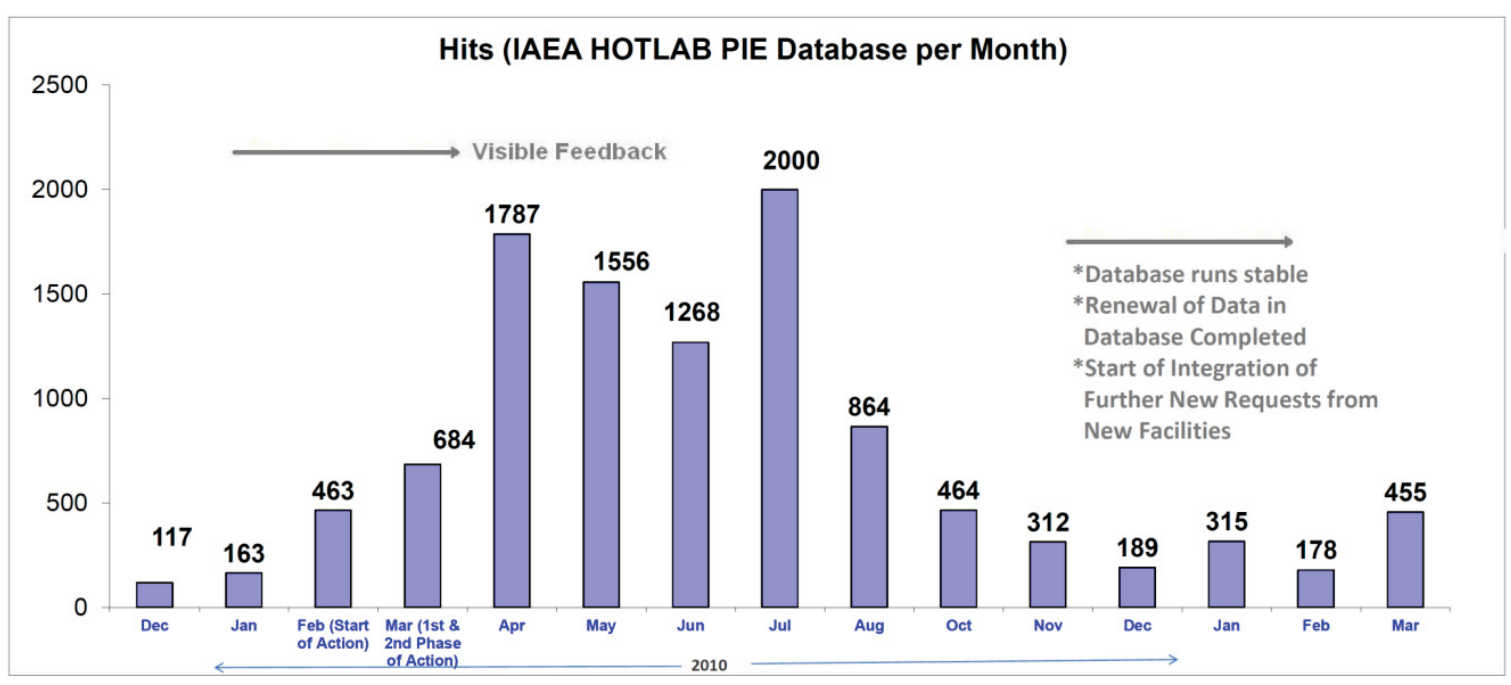




\section{Joint IAEA-HOTLAB PIE database: growth \& statistics}

Names of contributors to the database:

Aqrawi, A. (IAEA, Reviewer)

Inozemtsev, V. (IAEA, DB Custodian)

Jenssen, H. (External Reviewer)

Leenaers, A. (HOTLAB)

Tulsidas, H. (IAEA, Reviewer) 


\section{Joint Research Centre (JRC)}

\section{TEM Facility Development in Europe}

\section{T. WisS (presented by J. Somers)}

ITU - Institute for Transuranium Elements

Karlsruhe - Germany

http://itu.jrc.ec.europa.eu/

http://www.jrc.ec.europa.eu/ 


\section{Hot Cell facility development in Europe}

Refurbishment + replacement of ageing equipment EPMA (CEA, JRC-ITU, SCK CEN SEM (NRG)

SIMS (CEA, JRC-ITU)

TEM (JRC-ITU) 


\section{Future needs / perspectives}

Future needs and perspectives

TEM of MOX (influence of the plutonium)

- gas behaviour

- microstructure

- threshold for restructuring

Behaviour of helium in storage conditions (MOX)

Distribution of metallic FPs and FGs bubbles (tomography) 


\section{Future needs / perspectives}

Future needs and perspectives

New fuels (UC, (U, Pu)C,...)

Phase dispersion

Secondary phases (leaching, corrosion, solubilities)

Forensics (microstructural fingerprint)

Nanoparticles 


\section{Radiation damage studies}
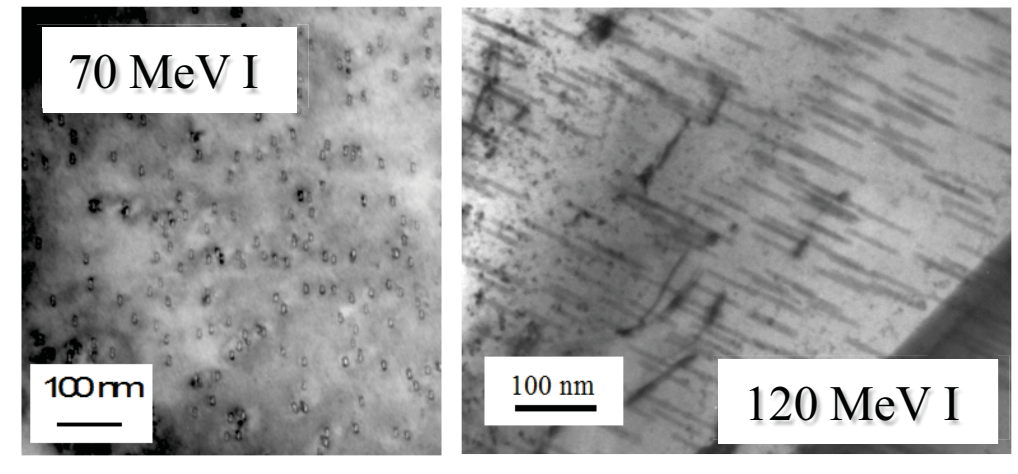

\section{$\mathrm{CeO}_{2}$}

Single effect studies: irradiation with selected ions at given energies

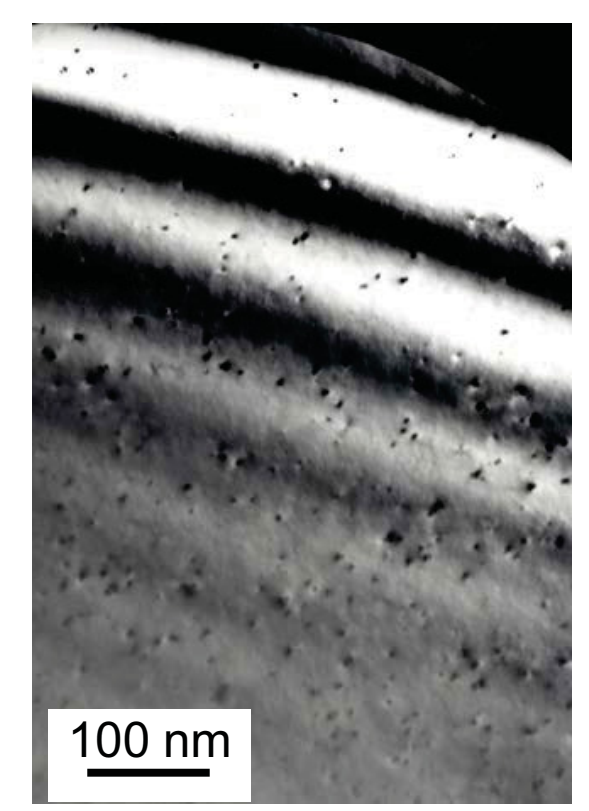

Doping with alpha-emitters for homogeneous damage and helium distribution

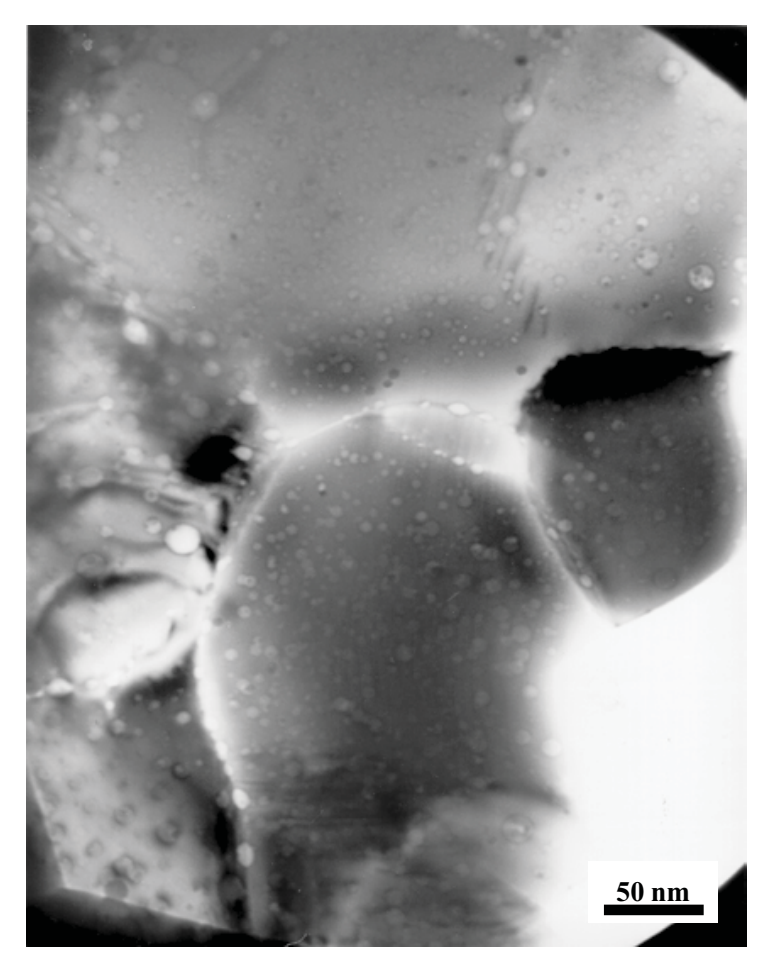

Concomittant effect of different damage sources 
Materials considered

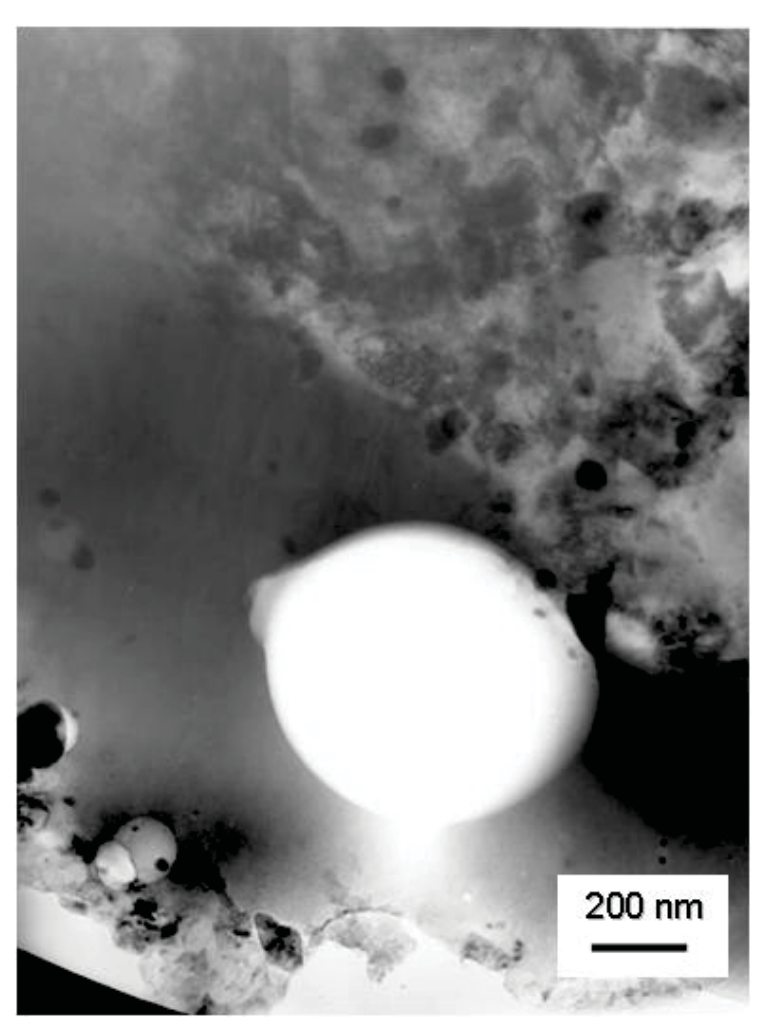

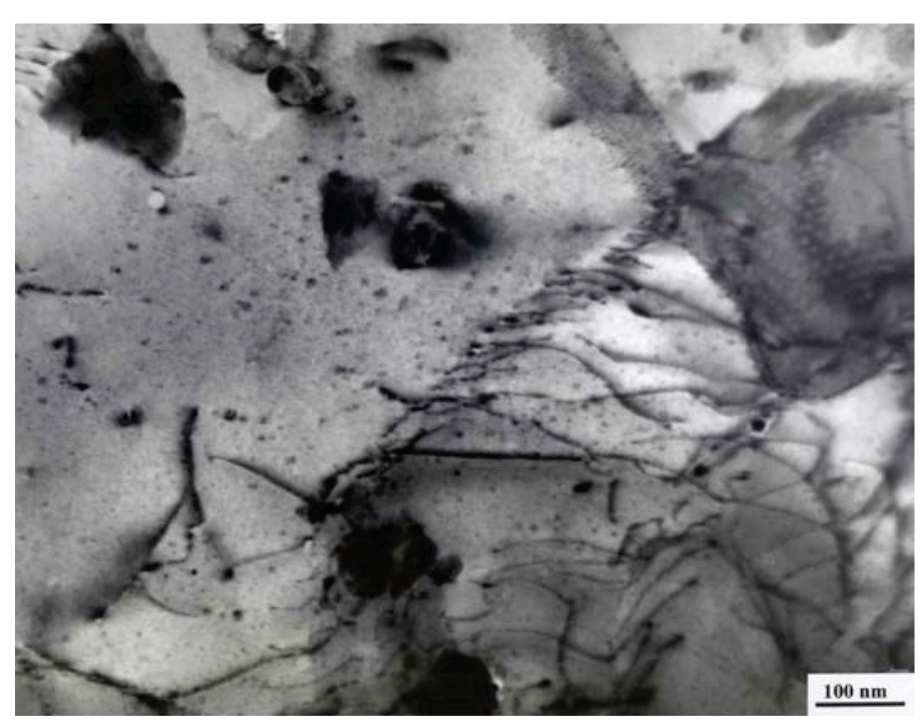

Nuclear fuels

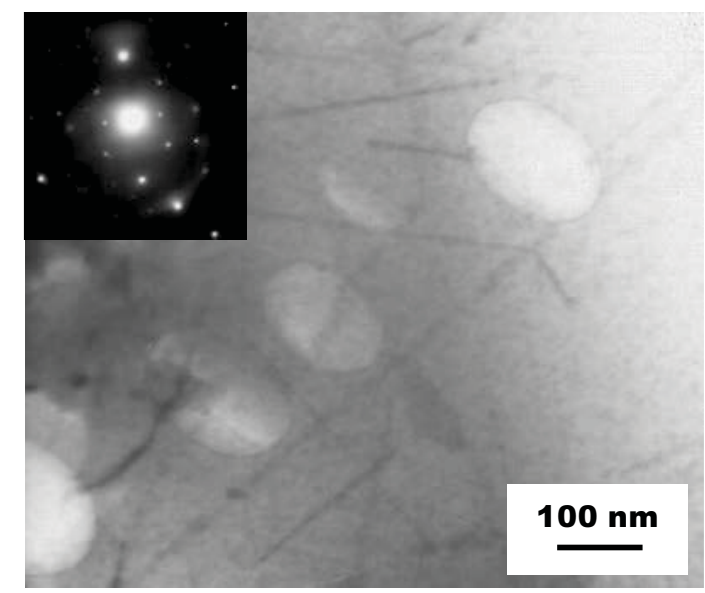

Waste matrices

Transmutation targets - IMF 


\section{Tecnai G² F20 XT}

Nearing end of commissioning 


\section{Tecnai $^{\text {TM }} \mathbf{G}^{2}$ F20 XT}

- Field emission gun (high brightness)

- EDX $20 \mathrm{~mm}^{2}$, Be-window

- EELS, EFTEM, for light elements

- STEM with HAADF, resolution $0.2 \mathrm{~nm}$

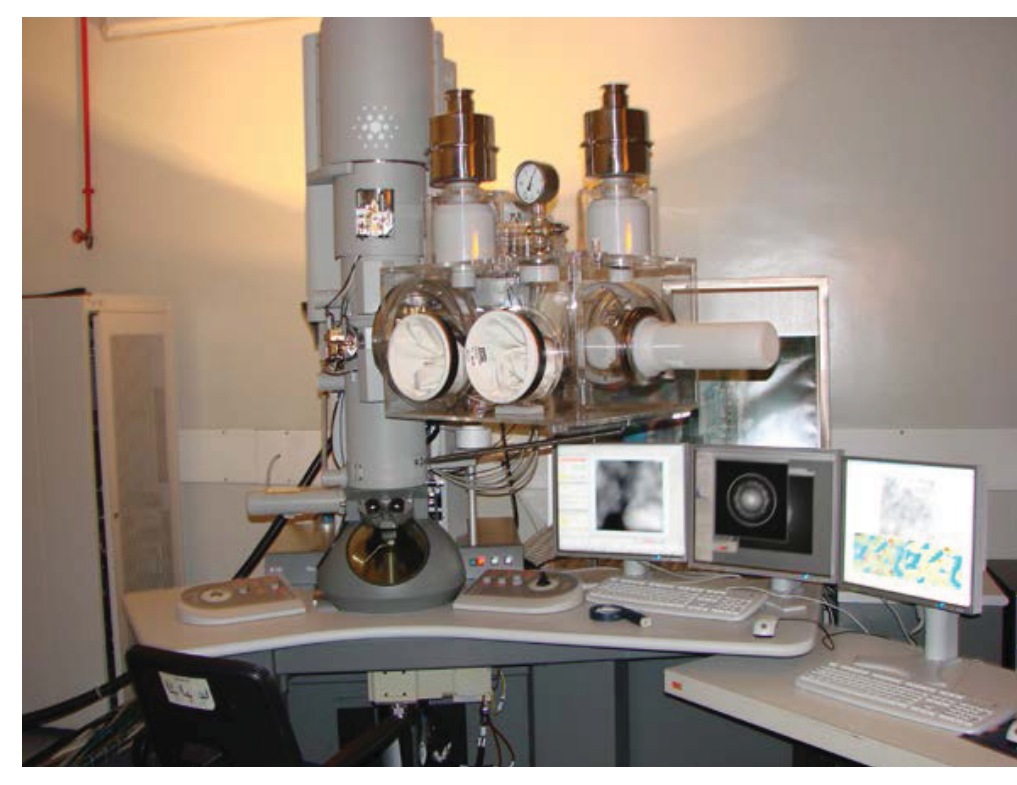

- 3D-tomography (bubbles, crack patterns, phase dispersion, etc)

- 2k-SSCCD camera

- Remote controlled

- Adapted for nuclear materials 


\section{Nanocrystals}
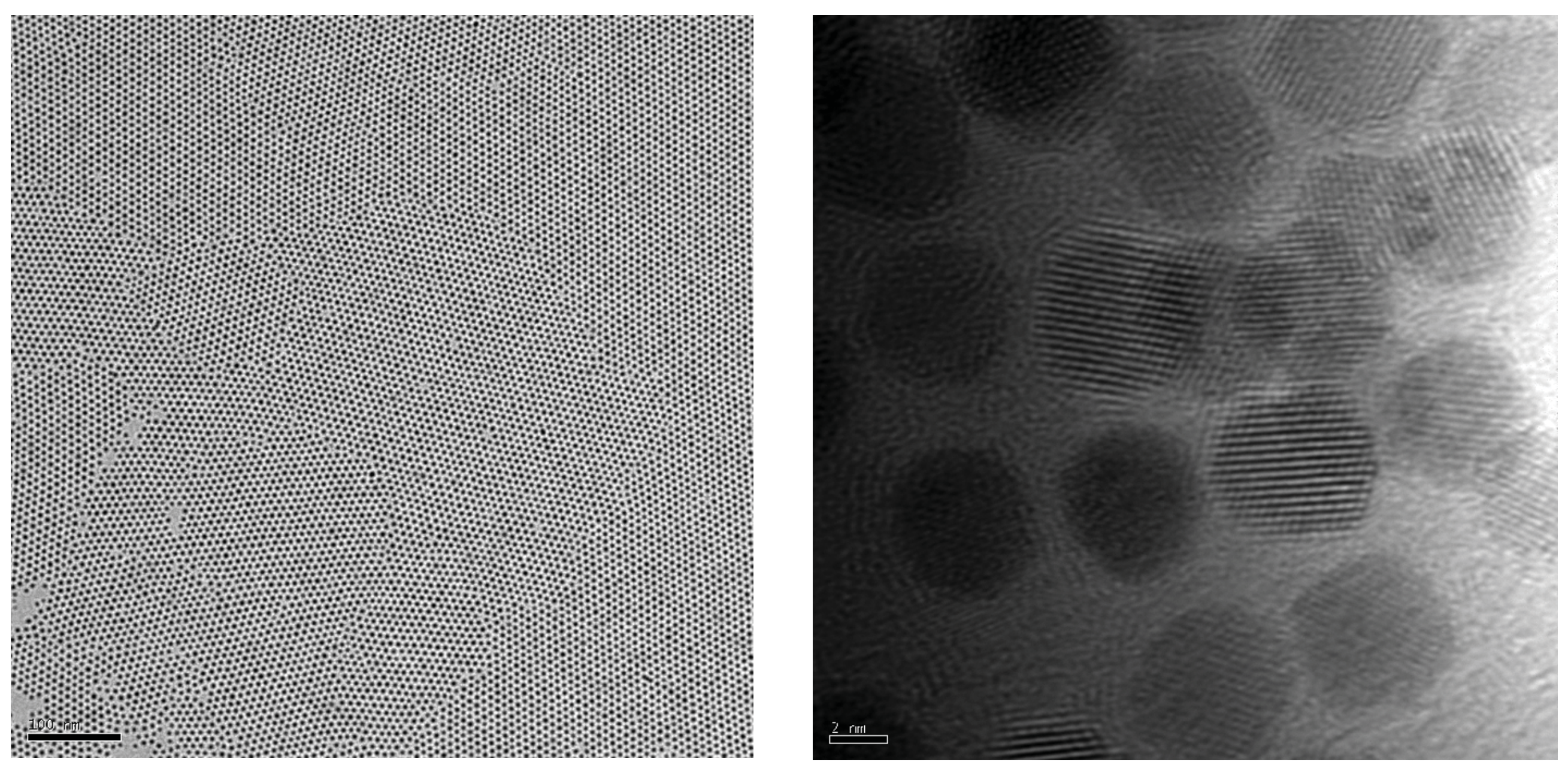


\section{Imaging + elemental analysis and speciation}

\section{EDX}

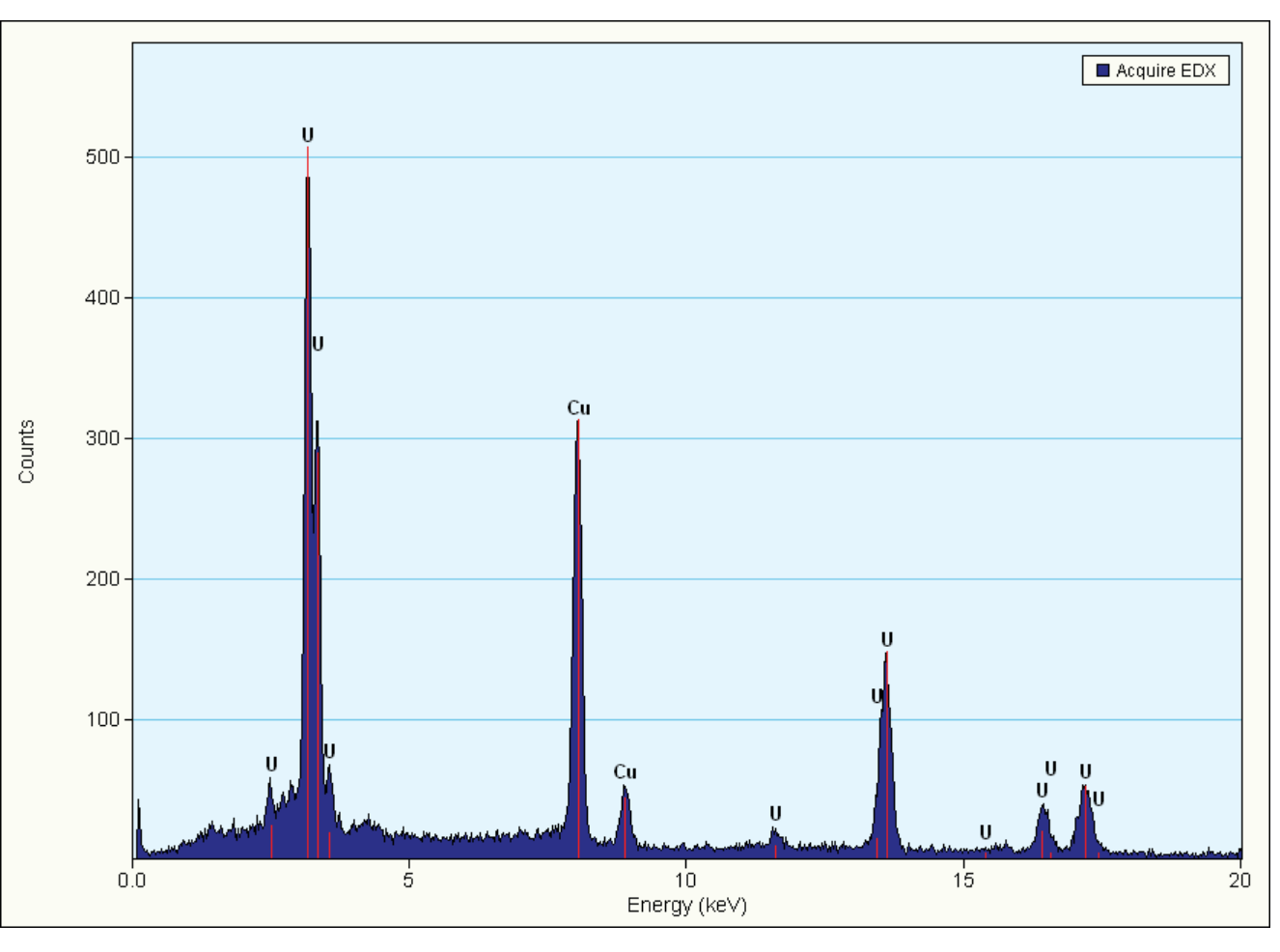

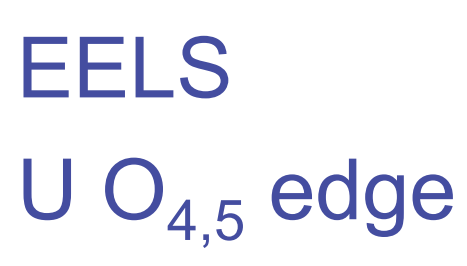

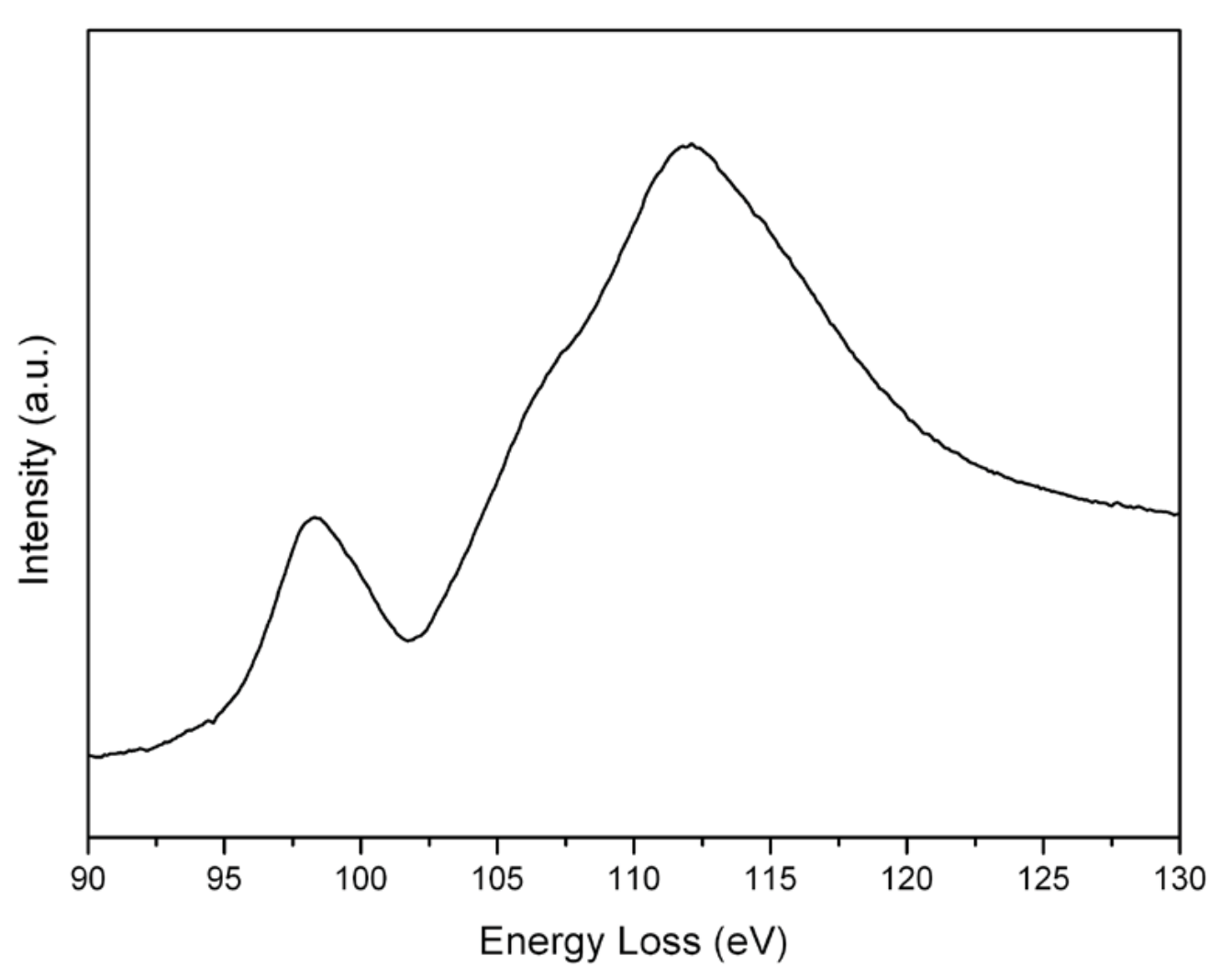




\section{D Tomography}

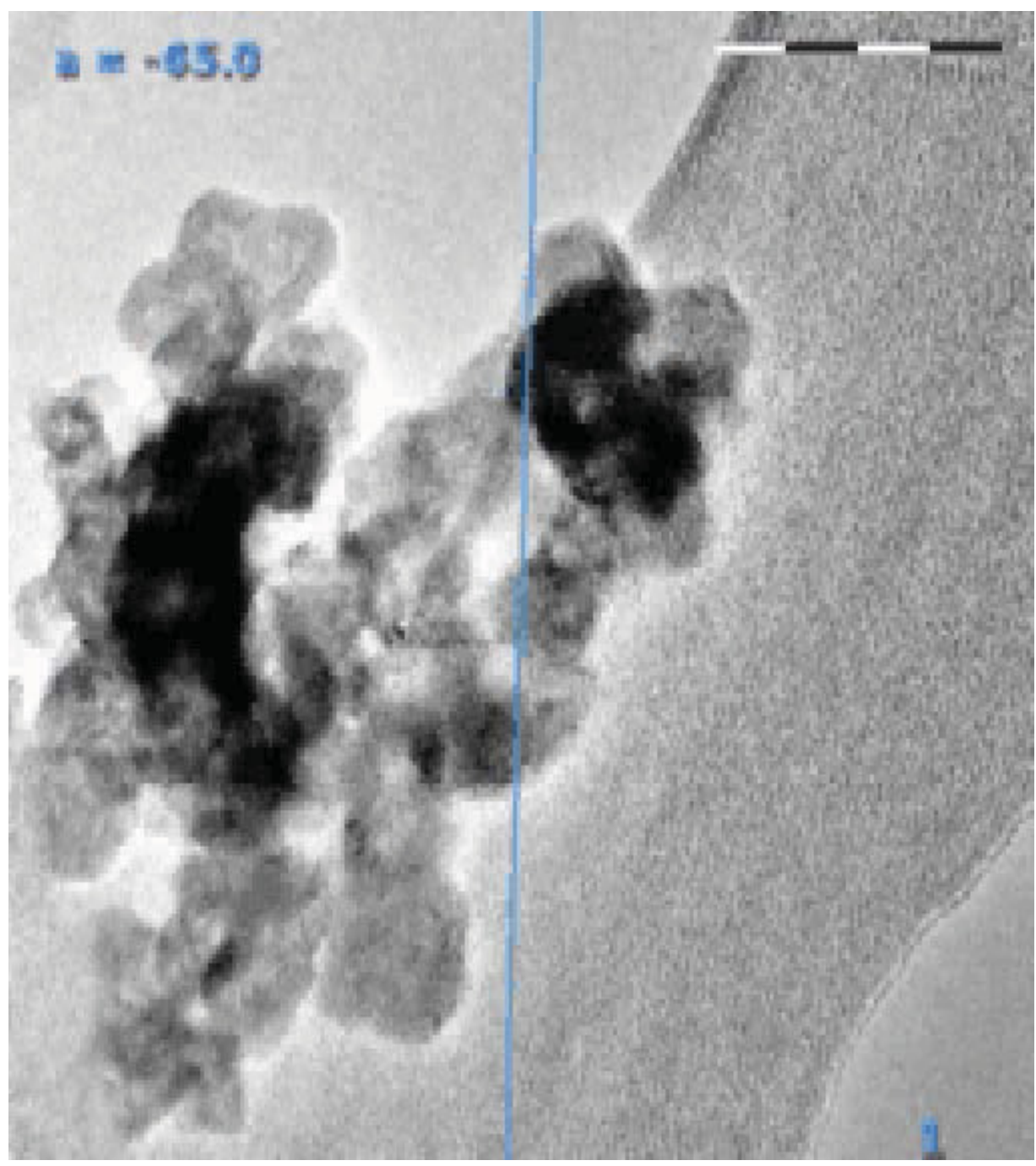




\section{JRC

\section{Performance}

TEM point resolution $(\mathrm{nm}) 0.25$

TEM line resolution (nm) 0.102

Information limit (nm) 0.14

Extended resolution (Truelmage) 0.14

TEM magnification range $22 \times-930$

STEM HAADF resolution (nm) $0.23(0.18)$

STEM magnification range $150 \mathrm{x}-230 \mathrm{Mx}$ Maximum tilt angle -tomography $\pm 70^{\circ}$ EDS energy resolution $134.6 \mathrm{eV}$ Spot drift $1 \mathrm{~nm} \cdot \mathrm{min}^{-1}$

Resolution EELS (ZLP) $0.6 \mathrm{eV}$
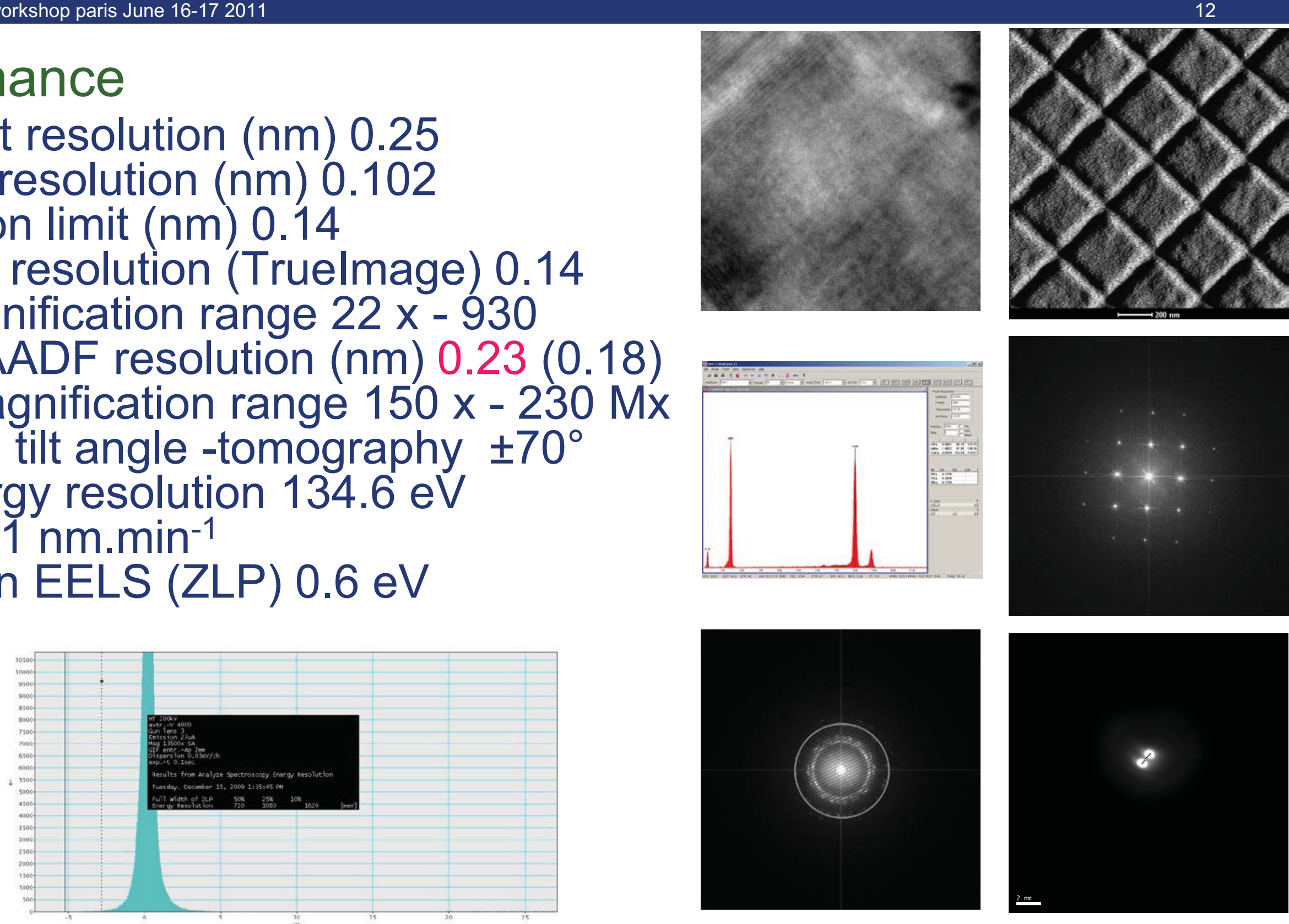


\section{Irradiation Status and PIE Plan of Metallic Fuel for SFR}

OECD/NEA Workshop, NEA HQ, France (characterization and PIE needs to support science-based development of innovative fuels)

$$
\text { 2011. 6. 16-17 }
$$

ByoungOon LEE 


\section{OUTLINE}

1 INTRODUCTION

2 IRRADIATION STATUS

3 PIE PLAN

4. CONCLUSIONS 


\section{Acknowledgments}

\section{- PIE \& Radwaste Division}

$>$ Sangbok Ahn

$>$ Gilsoo Kim

$>$ Byungok Yoo

$>$ Seungjai Baek

$>$ Woongsub Song

$>$ Sangyul Baek

$>$ Woo-Seog Ryu

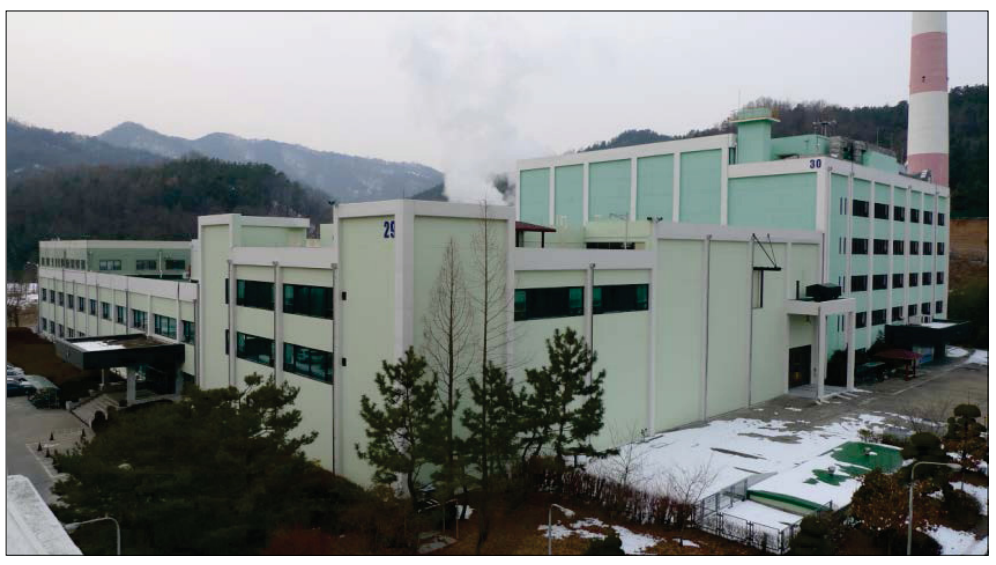


1 INTRODUCTION 


\section{Metallic Fuel for SFR}

* Metallic Fuel Design Concept

- Fuel slug : U-TRU-Zr, U-Zr

- Fuel rod gap filled with sodium

- Cladding and duct : ferritic martensitic steel (HT9)

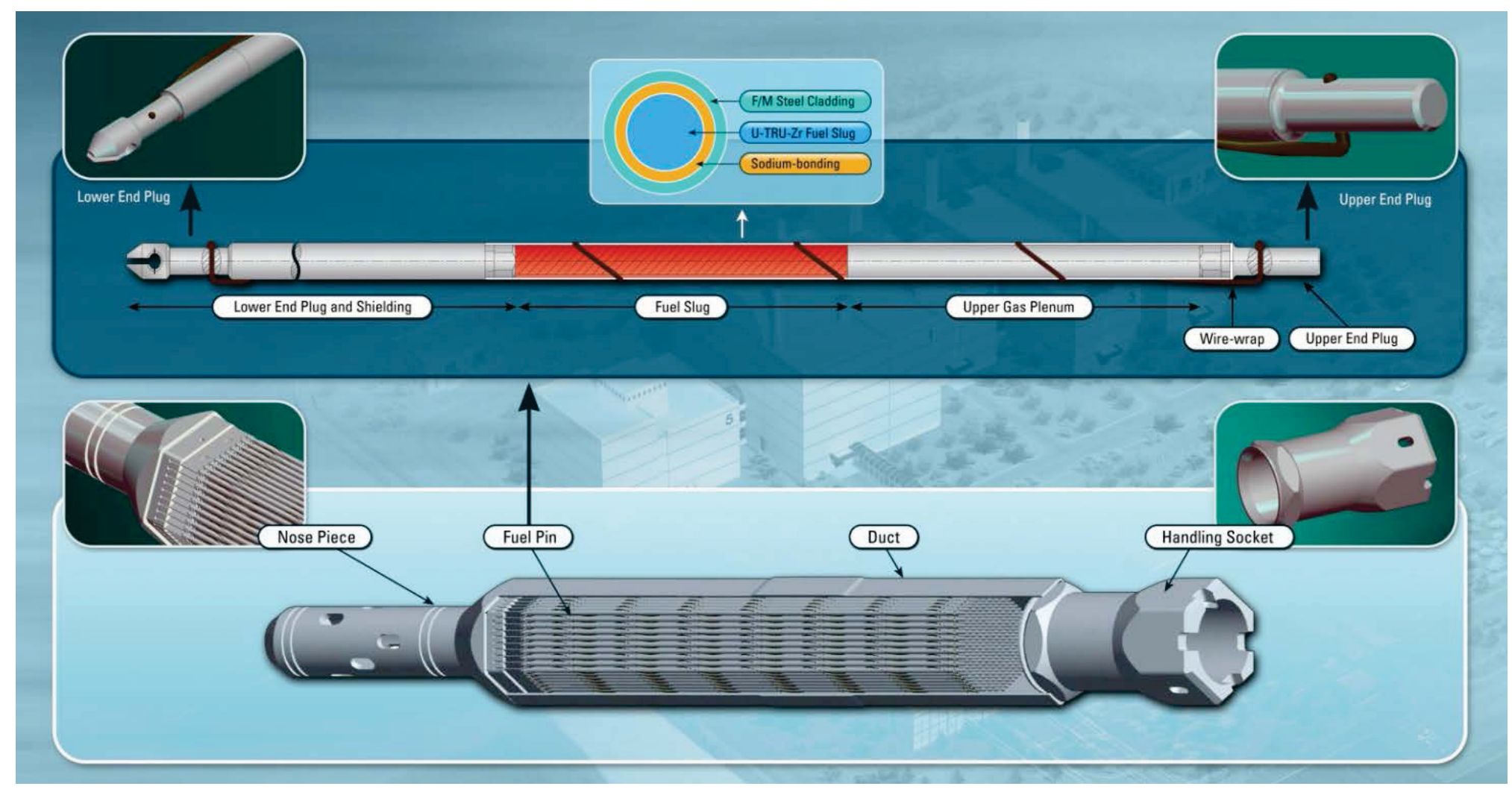




\section{Metal Fuel Development Plan}

- '07 '18 : Fabrication technology development of U-Zr fuel

- '21 '28 : Fuel facility construction \& fabrication for the SFR plant

- '30 : U-Zr fuel transition to U-TRU-Zr after performance verification

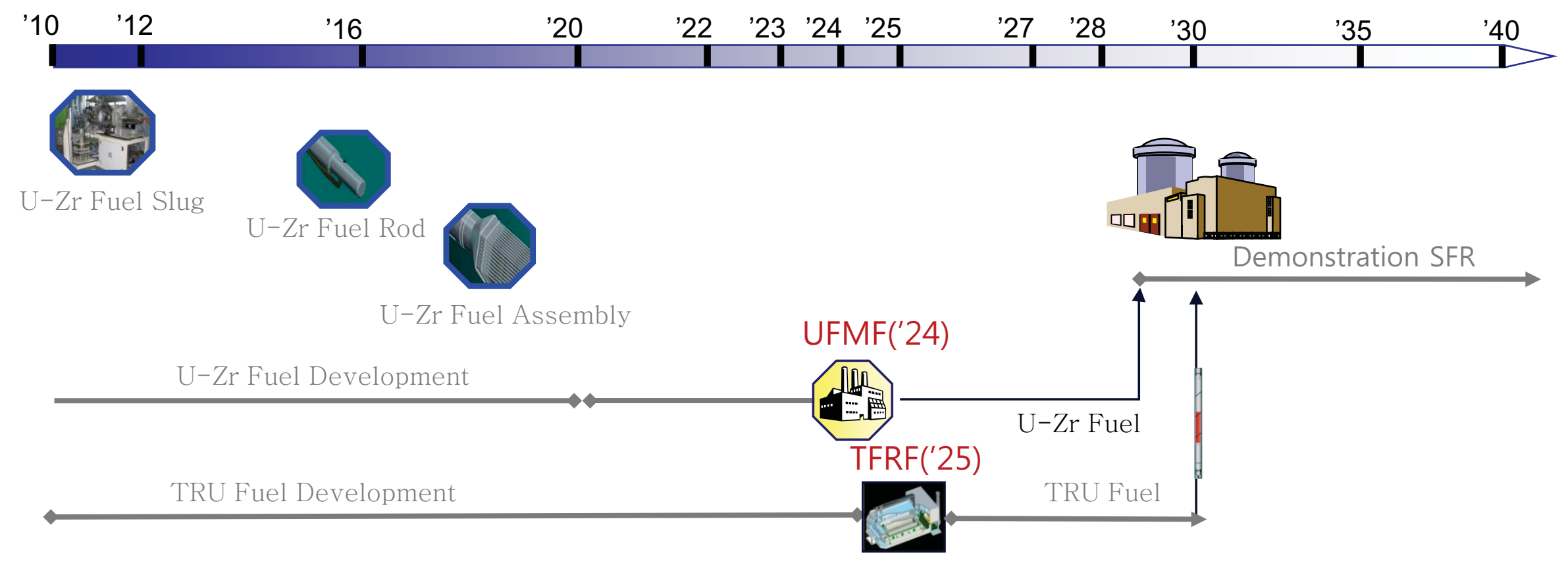

UFMF: U-Zr Fuel Manufacturing Facility

TFRF: TRU Fuel manufacturing Research Facility 


\section{Results of SFR Metal Fuel Development ('07-)}

Fuel Fabrication
- Design and installation of fuel slug
casting system to control volatile
elements
- Fabrication of fuel slugs (U-Zr, U-Ce-
Zr, U-Mn-Zr)
- Fuel rod fabrication with sodium
bonding

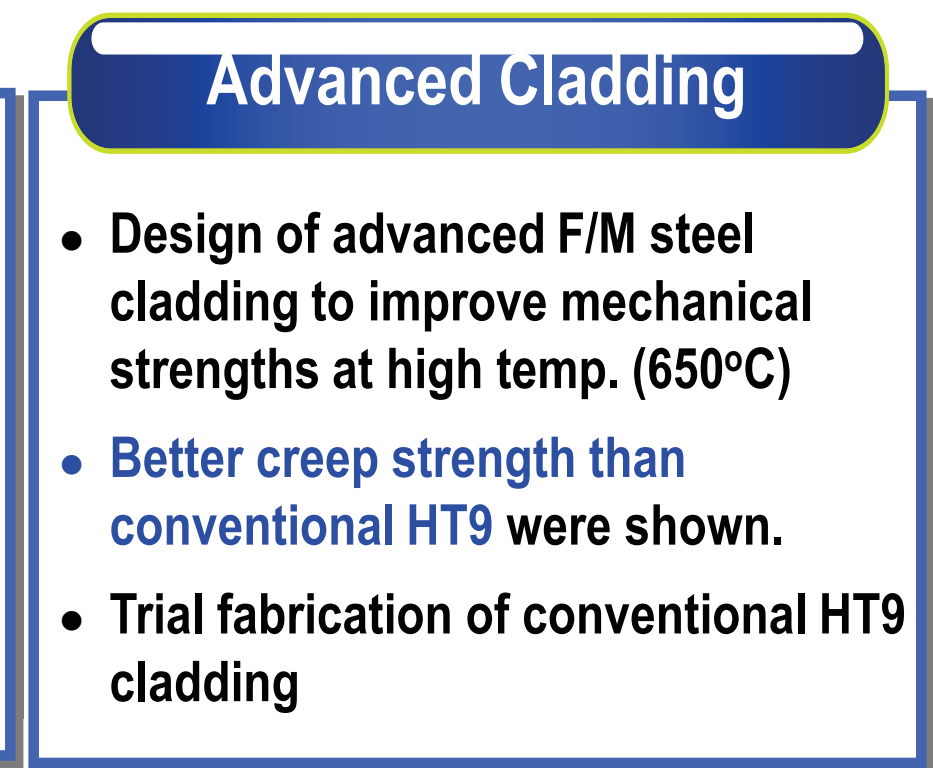

\section{Performance Evaluation}

- Fuel performance analysis and modeling

- Fuel irradiation test in HANARO

- Practical barrier (Cr, V) technology development to prevent fuel cladding chemical interaction
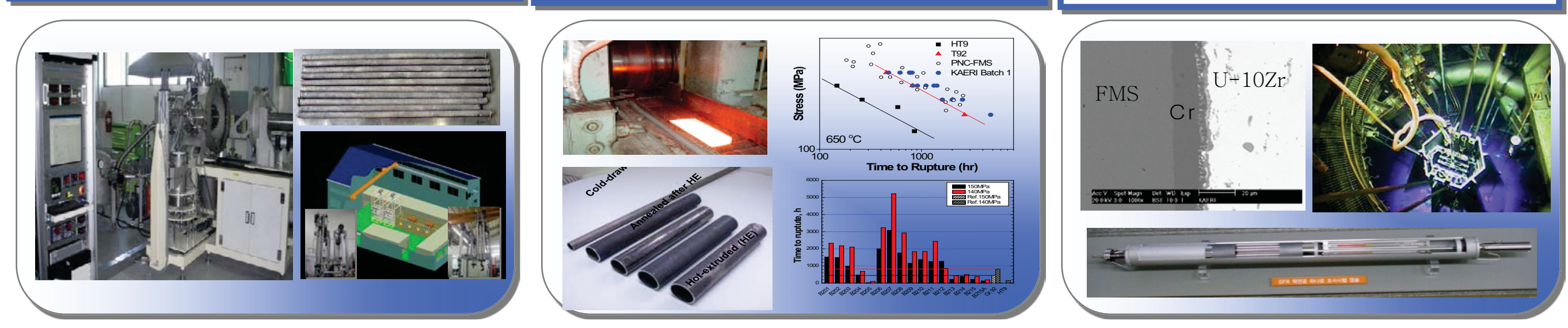
2 IRRADIATION STATUS 


\section{Irradiation in HANARO}

口 2010. 11 : irradiation in HANARO

口 Irradiation condition

$>$ Fuel : U-10wt.\%Zr-(Ce)

$>$ Cladding: FMS

$>$ Fast reactor condition

- Thermal neutron flux filter : Hf

- Fuel temp. control : He gap

- Fuel/cladding gap bonding : $\mathrm{Na}$

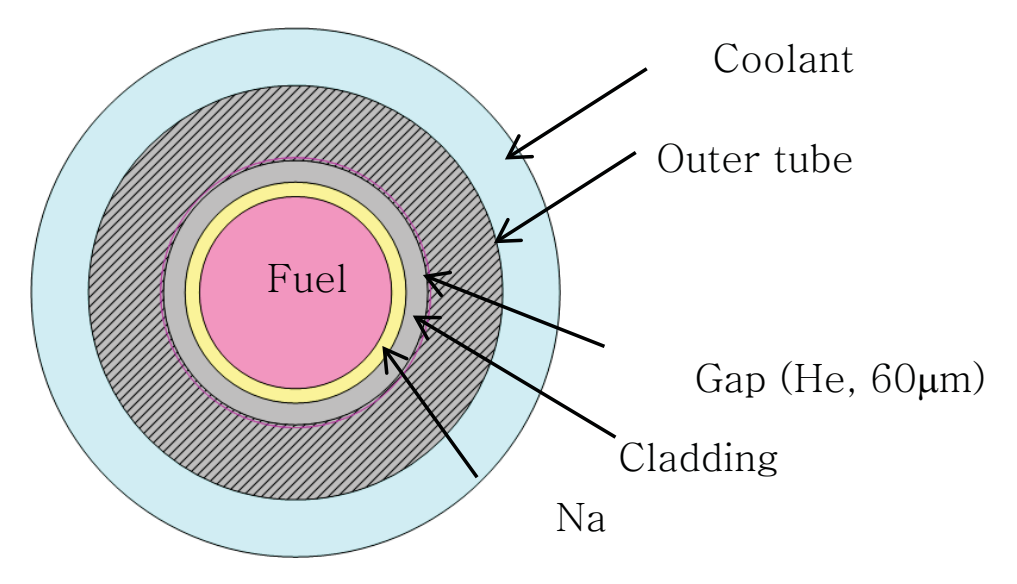

\begin{tabular}{|c|c|c|c|c|c|c|c|c|}
\hline \multicolumn{3}{|c|}{ Fuel slug } & \multicolumn{3}{c|}{ Cladding } & \multicolumn{3}{c|}{ Sealing tube } \\
\hline $\begin{array}{c}\mathrm{OD}, \\
\mathrm{mm}\end{array}$ & $\begin{array}{c}\text { Density, } \\
\mathrm{g} / \mathrm{cc}\end{array}$ & $\begin{array}{c}\text { Length, } \\
\mathrm{mm}\end{array}$ & $\begin{array}{c}\mathrm{OD}, \\
\mathrm{mm}\end{array}$ & $\begin{array}{c}\mathrm{ID}, \\
\mathrm{mm}\end{array}$ & $\begin{array}{c}\text { Length, } \\
\mathrm{mm}\end{array}$ & $\begin{array}{c}\mathrm{OD}, \\
\mathrm{mm}\end{array}$ & $\begin{array}{c}\mathrm{ID}, \\
\mathrm{mm}\end{array}$ & $\begin{array}{c}\text { Length, } \\
\mathrm{mm}\end{array}$ \\
\hline 3.7 & 15.8 & 50 & 5.5 & 4.6 & 193 & 8.62 & 5.62 & 233 \\
\hline
\end{tabular}




\section{HANARO Irradiation Test Goal}

* Objectives

- Investigate the effect of design \& fabrication variables

- Examine the level of impurities

- RE : Ce, Nd, La, Pr

- Other impurities : C, Si

- Identify the characteristics of barriers for preventing eutec reaction

- Barrier material (Cr, V, Zr \& Nitride) and performance

* Requirements for $1^{\text {st }}$ irradiation test

- Ensure the integrity of test fuels and capsule

- Identify the compatibility of capsule with HANARO core

- EOL burnup: 3 at\%
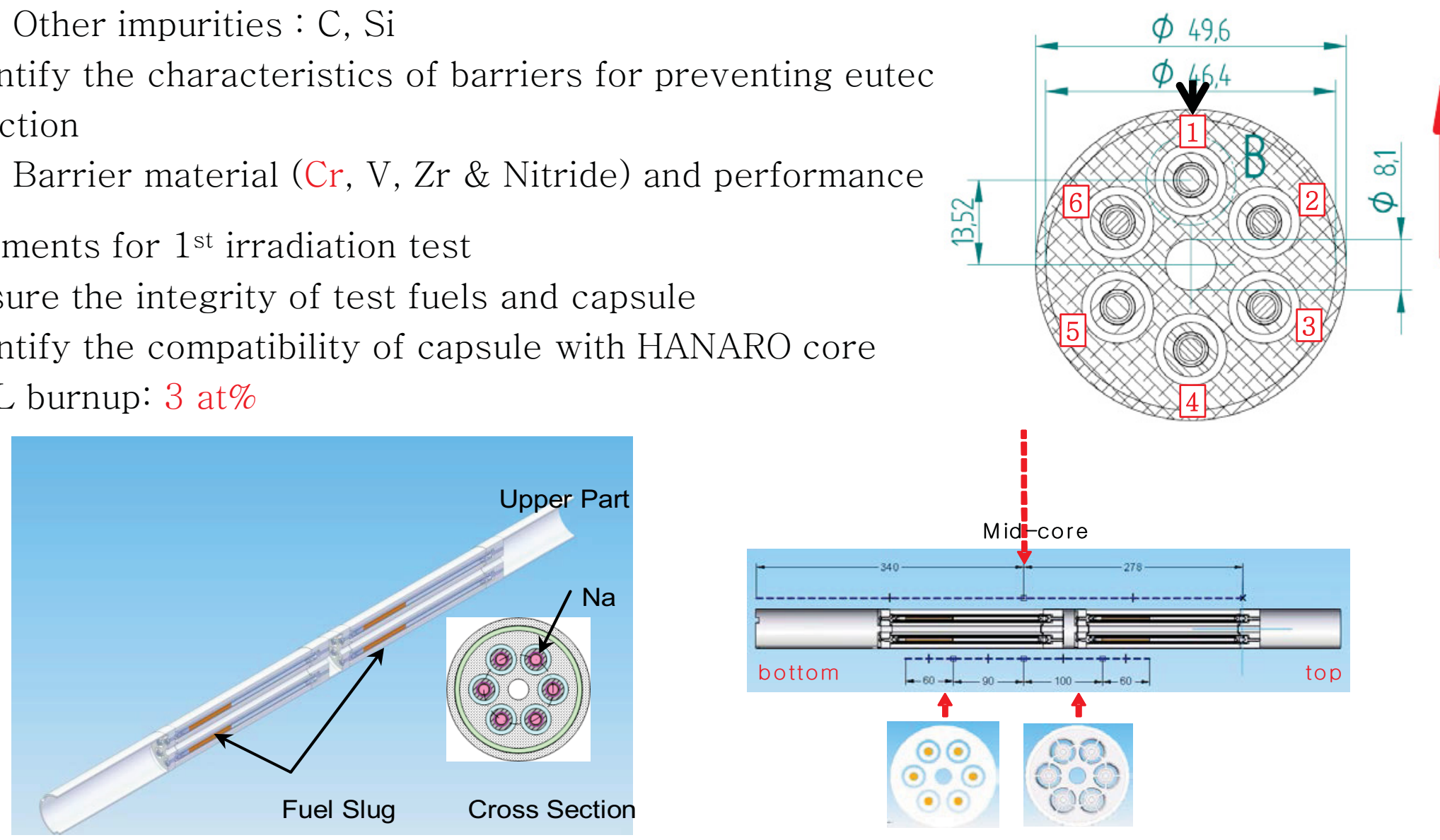

CORE

Top view

Irradiation capsule model 


\section{Irradiation Capsule for HANARO}

Characteristics of irradiation capsule

> 12 rodlets : $6 \mathrm{U}-10 \mathrm{Zr} \& 6 \mathrm{U}-10 \mathrm{Zr}-5 \mathrm{Ce}$

$>$ Barrier : $20 \mu \mathrm{m}$ thick $\mathrm{Cr}$

$>$ Cladding : ferritic-martensitic steel (T92)

$>$ Sealing tube : 316L

> Capsule : total length $961 \mathrm{~mm}$, diameter $56 \mathrm{~mm}$, thickness $3 \mathrm{~mm}$

$>$ Hf tubes : upper $(1.35 \mathrm{~mm}) \&$ lower $(1.58 \mathrm{~mm})$ to limit fuel linear power

\begin{tabular}{|c|c|c|c|c|}
\hline & No. & Fuel slug & Cladding & Barrier \\
\hline $\mathbf{u}$ & 1 & $\mathrm{U}-10 \mathrm{Zr}$ & $\mathrm{T} 92$ & \\
\hline $\mathbf{p}$ & 2 & $\mathrm{U}-10 \mathrm{Zr}$ & $\mathrm{T} 92$ & \\
$\mathbf{p}$ & 3 & $\mathrm{U}-10 \mathrm{Zr}$ & $\mathrm{T} 92$ & $\mathrm{Cr}$ \\
$\mathbf{e}$ & 4 & $\mathrm{U}-10 \mathrm{Zr}-5 \mathrm{Ce}$ & $\mathrm{T} 92$ & \\
$\mathbf{r}$ & 5 & $\mathrm{U}-10 \mathrm{Zr}-5 \mathrm{Ce}$ & $\mathrm{T} 92$ & \\
\hline & 6 & $\mathrm{U}-10 \mathrm{Zr}-5 \mathrm{Ce}$ & $\mathrm{T} 92$ & $\mathrm{Cr}$ \\
\hline & 1 & $\mathrm{U}-10 \mathrm{Zr}$ & $\mathrm{T} 92$ & \\
\hline $\mathbf{L}$ & 2 & $\mathrm{U}-10 \mathrm{Zr}$ & $\mathrm{T} 92$ & \\
\hline $\mathbf{0}$ & 3 & $\mathrm{U}-10 \mathrm{Zr}$ & $\mathrm{T} 92$ & $\mathrm{Cr}$ \\
$\mathbf{w}$ & 4 & $\mathrm{U}-10 \mathrm{Zr}-5 \mathrm{Ce}$ & $\mathrm{T} 92$ & \\
$\mathbf{r}$ & 5 & $\mathrm{U}-10 \mathrm{Zr}-5 \mathrm{Ce}$ & $\mathrm{T} 92$ & \\
\hline & 6 & $\mathrm{U}-10 \mathrm{Zr}-5 \mathrm{Ce}$ & $\mathrm{T} 92$ & $\mathrm{Cr}$ \\
\hline
\end{tabular}

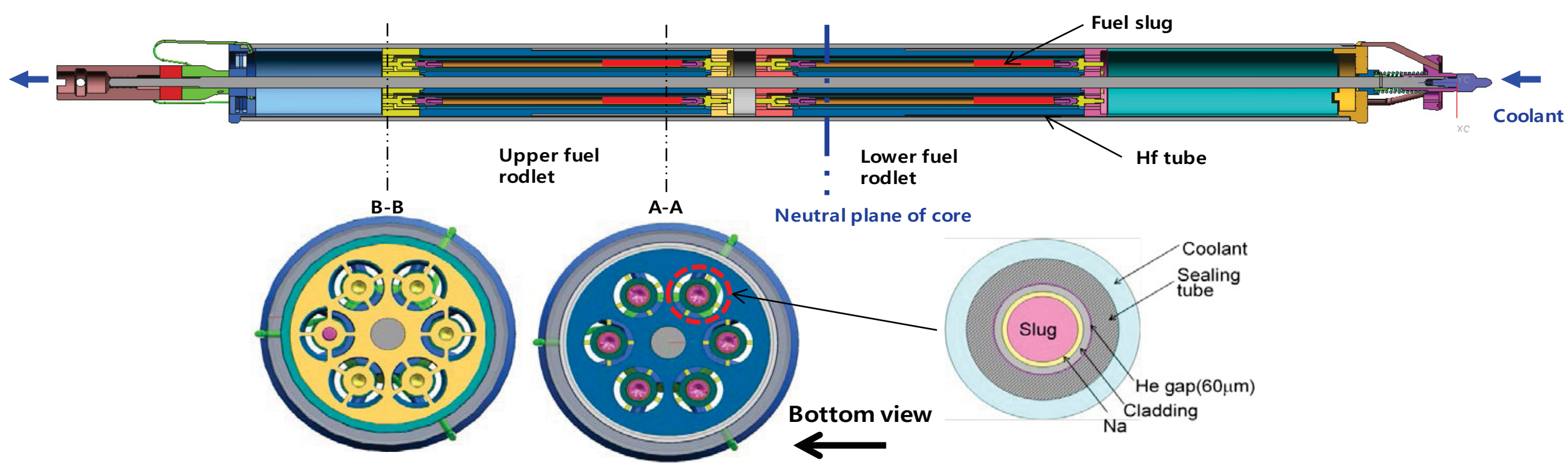




\section{Design of Irradiation Capsule}

* Preliminary evaluation of fuel performance

- MACSIS code was employed

- Cladding inner temperature : $600{ }^{\circ} \mathrm{C}$

- Conservative LHGR : $352 \mathrm{~W} / \mathrm{cm}$

- Fuel integrity is maintained during irradiation : temperature, strain

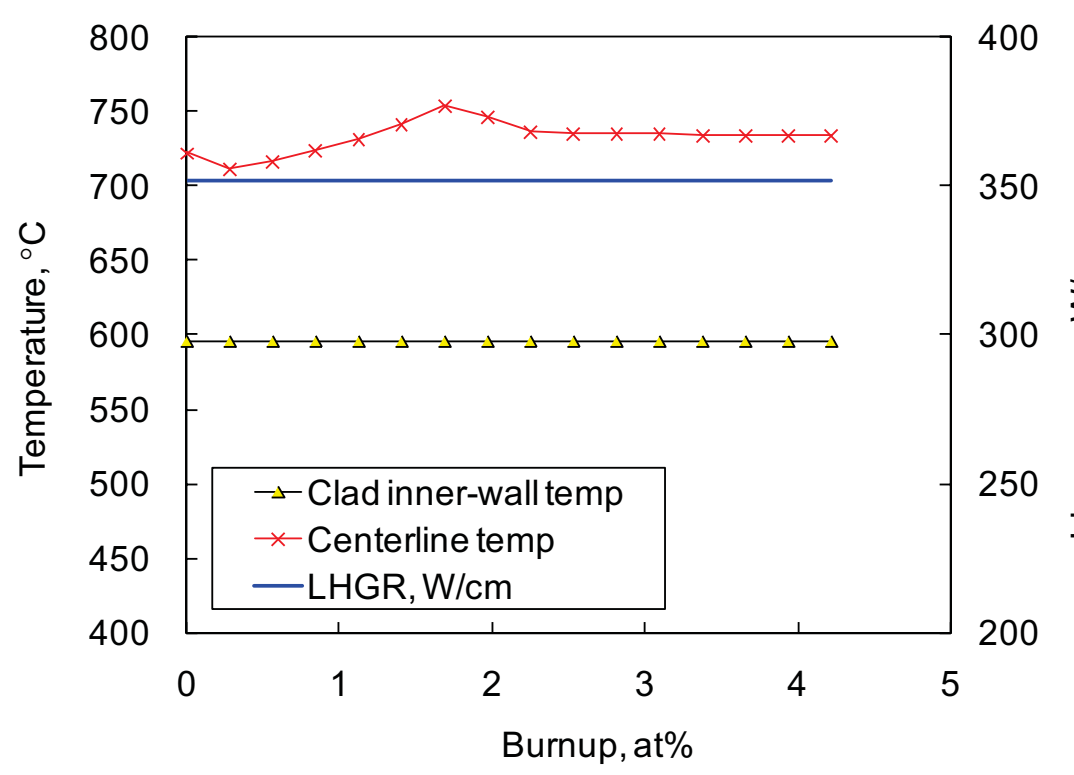

Variation of fuel temperature with burnup

\begin{tabular}{|c|l|}
\hline & $\begin{array}{c}\text { Centerline temperature: } \\
\text { Fuel } \\
755^{\circ} \mathrm{C}<1235^{\circ} \mathrm{C}\end{array}$ \\
temperature & $\begin{array}{r}\text { Surface temperature: } \\
600^{\circ} \mathrm{C}<700^{\circ} \mathrm{C}\end{array}$ \\
\hline $\begin{array}{c}\text { Cladding } \\
\text { Strain, } \\
\text { Stress, } \\
\text { CDF }\end{array}$ & - Rod pressure : 12 bar \\
\hline
\end{tabular}

Fuel performance analysis with MACSIS code 


\section{Status Summary and Planned Activities}

$\square$ Status

$>$ Manufacturing of capsule for HANARO irradiation

$>$ Irradiation began ('10.11.15)

$>$ Burnup at 1st irradiation cycle (29EFPD) : 0.3 at.\%

$>$ Burnup (2011.3.25, 75 EFPD) : 1.2 at.\%

$>$ Burnup (103 EFPD) : 1.6 at\%

ㄱ Planned Activities

$>$ 2011. 9 10: irradiation complete

$>$ PIE ('11 ) will begin

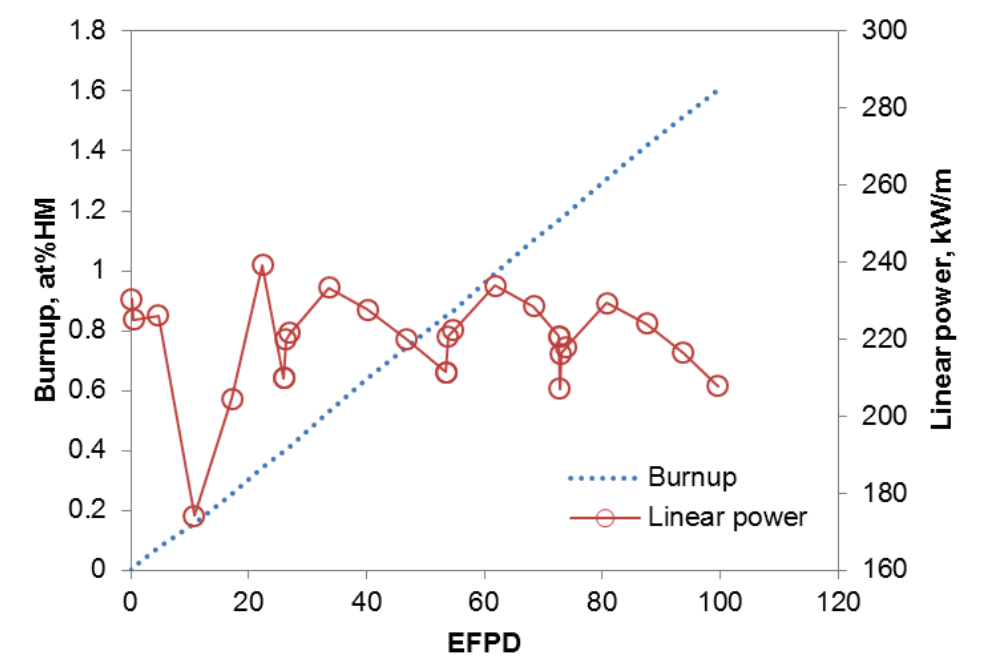

$>2^{\text {nd }}$ and $3^{\text {rd }} \mathrm{U}-\mathrm{Zr}$ HANARO irradiation

> U-TRU-Zr ATR irradiation through Joint Fuel Cycle Studies Collaboration 


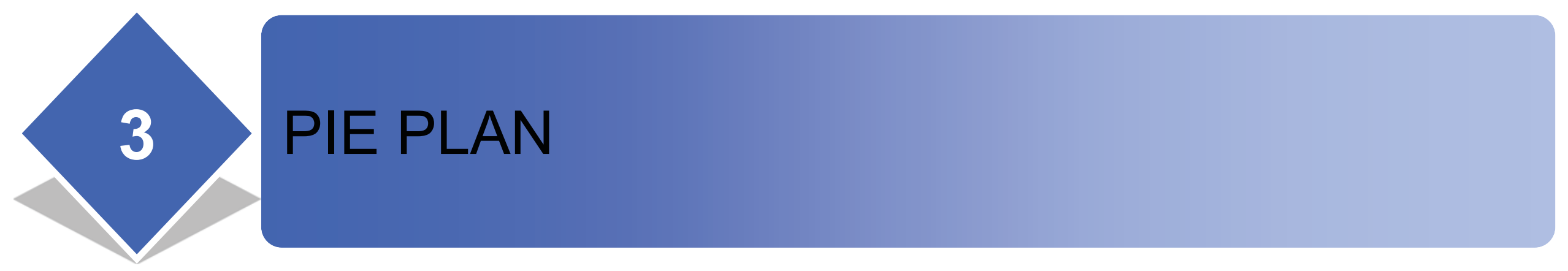




\section{Irradiation and PIE plan}

\section{- Status \& Plan}

$>$ PIE will be performed in IMEF hot cell, and techniques and devices are being developed

- Techniques for disassembling rodlets and dealing with sodium in an air cell

- Laser puncturing system for FGR measurement

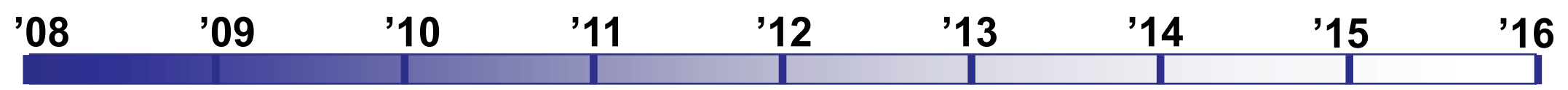

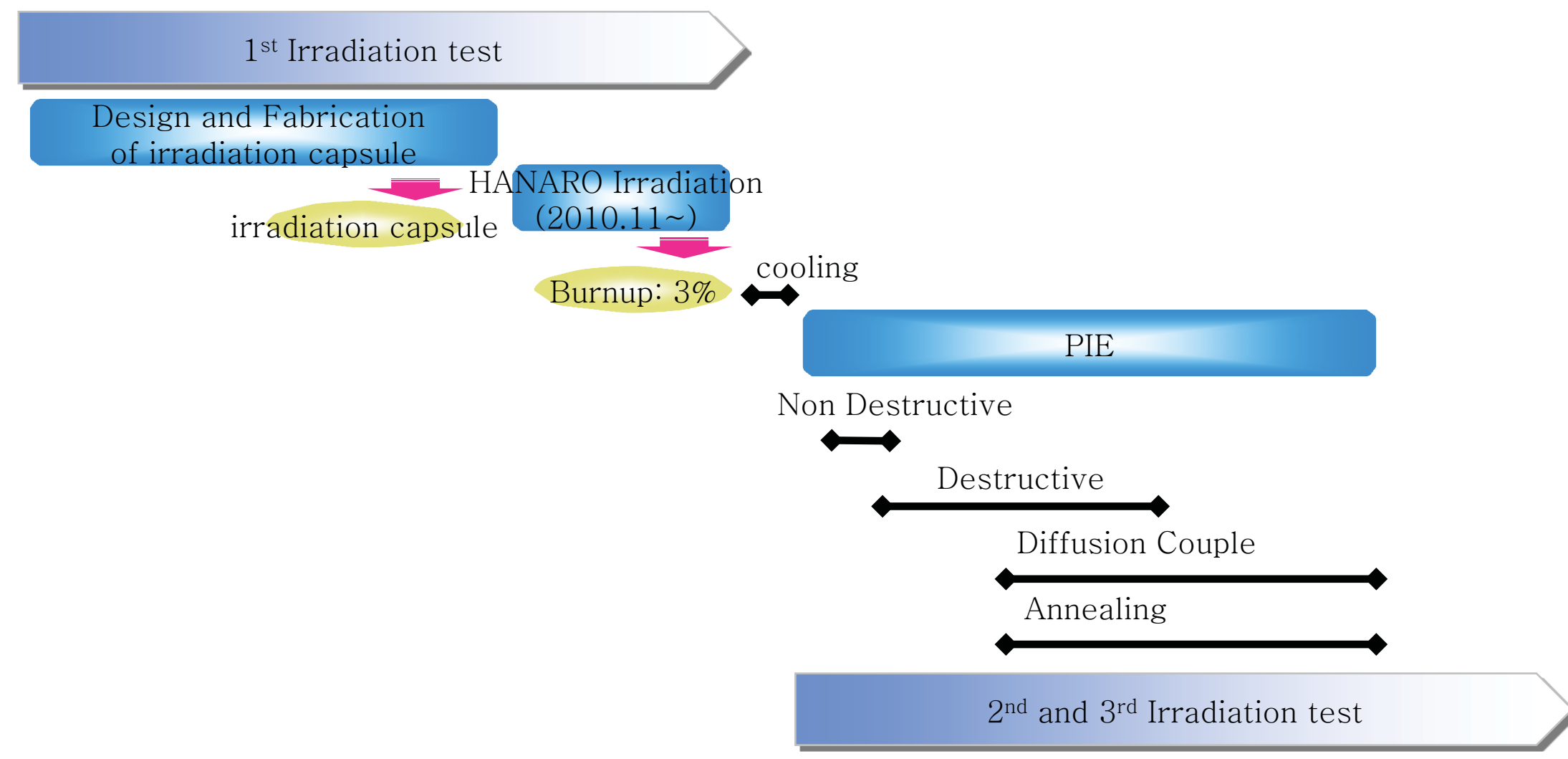




\section{Post-irradiation examination}

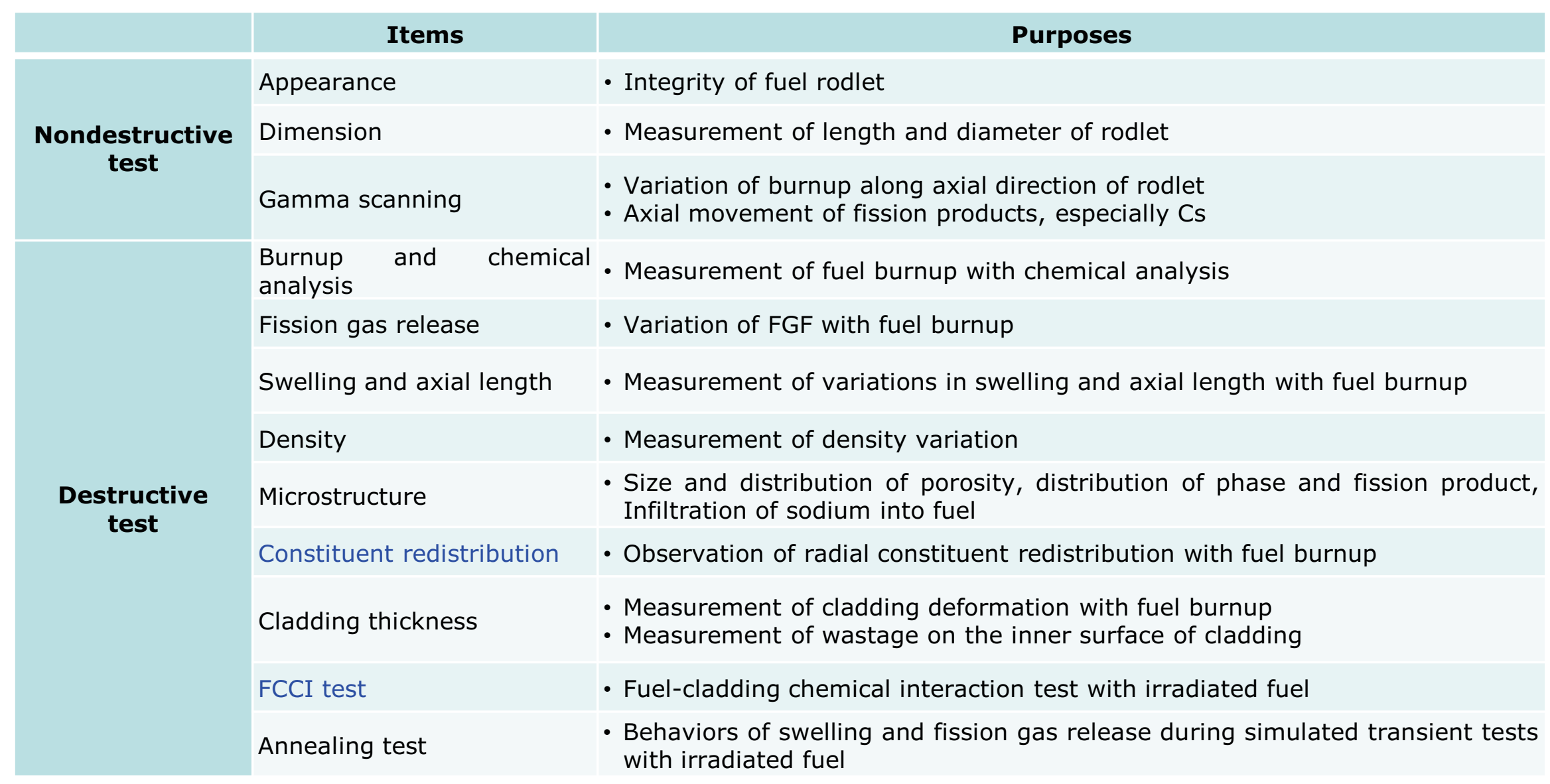




\section{IMEF and PIEF Plan View}

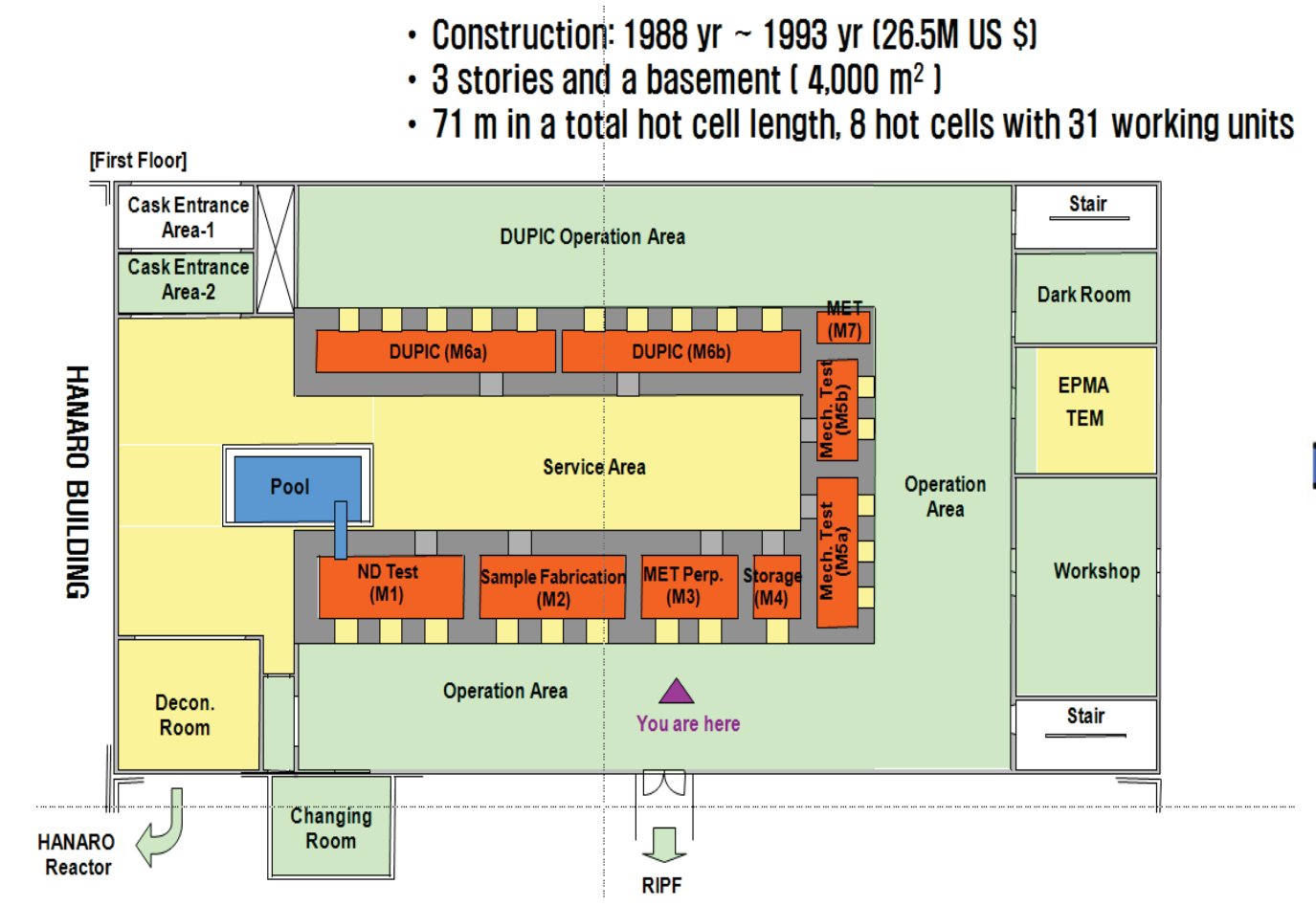

$1^{\text {st }}$ floor plan view in IMEF

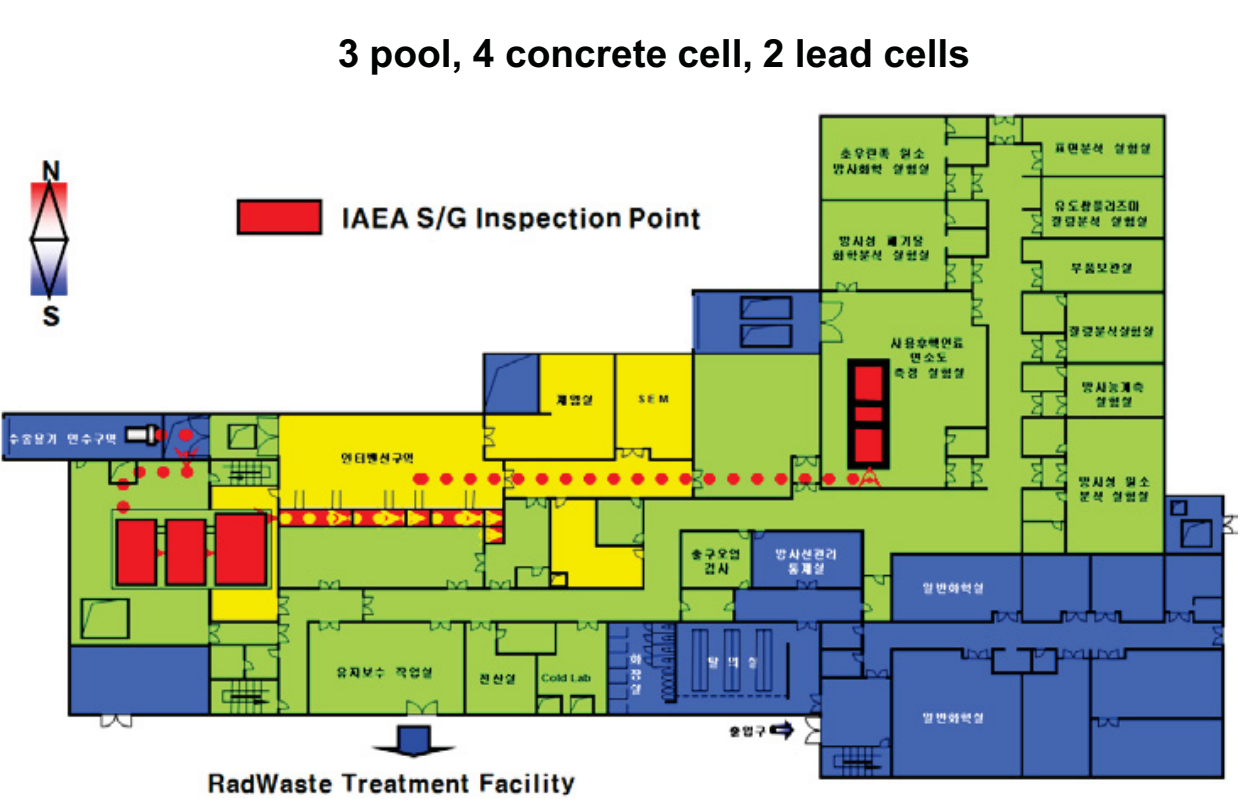

$1^{\text {st }}$ floor plan view in PIEF

The main mission of IMEF is to provide PIE services for the irradiated fuels and materials in the HANARO. And, PIEF is essentially employed for testing and then evaluating the performance and the integrity of nuclear fuels discharged from reactors. 


\section{IMEF and PIEF PIE Flow}

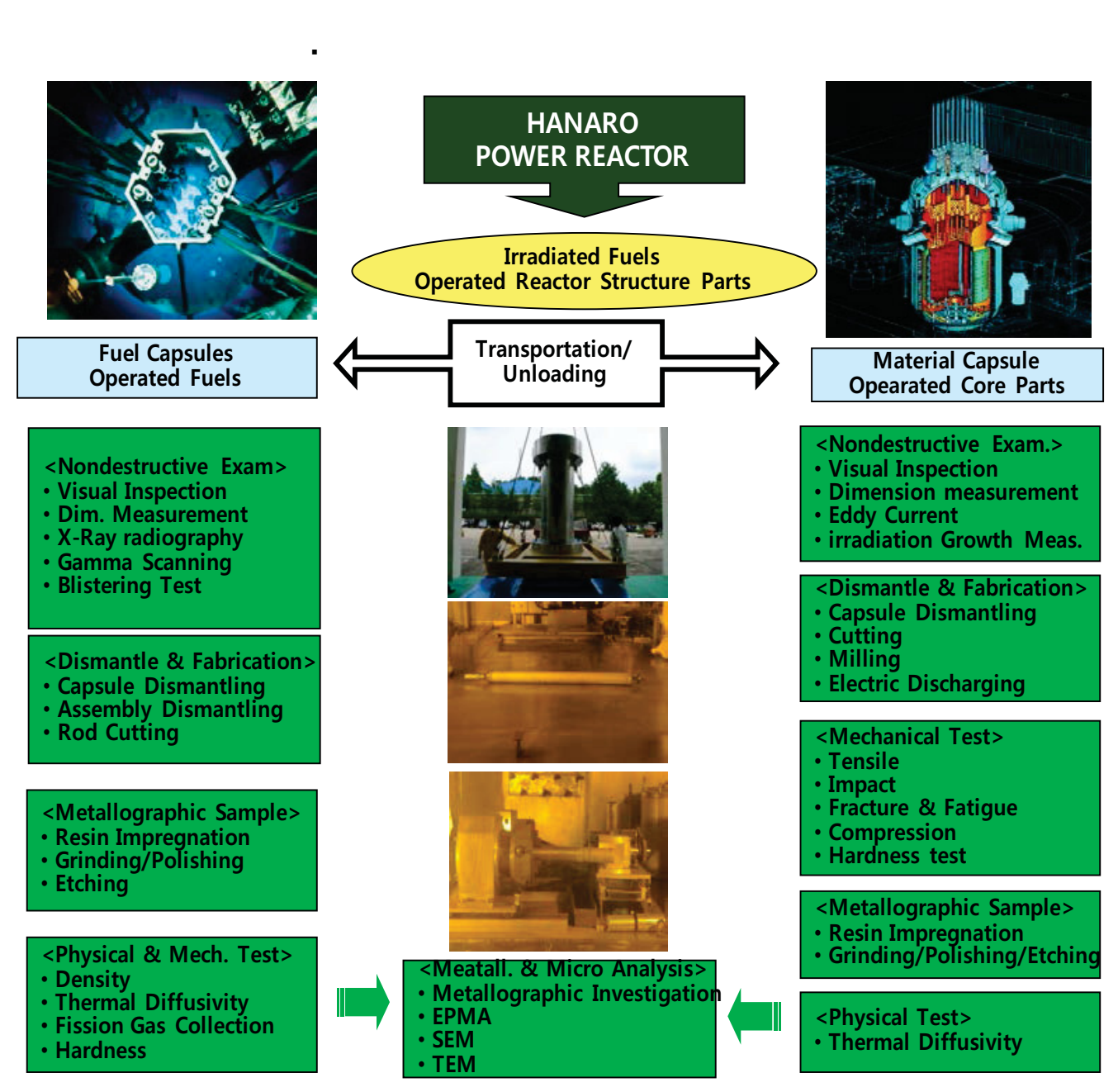

PIE flows for HANARO Capsules \&

NPP core parts in IMEF

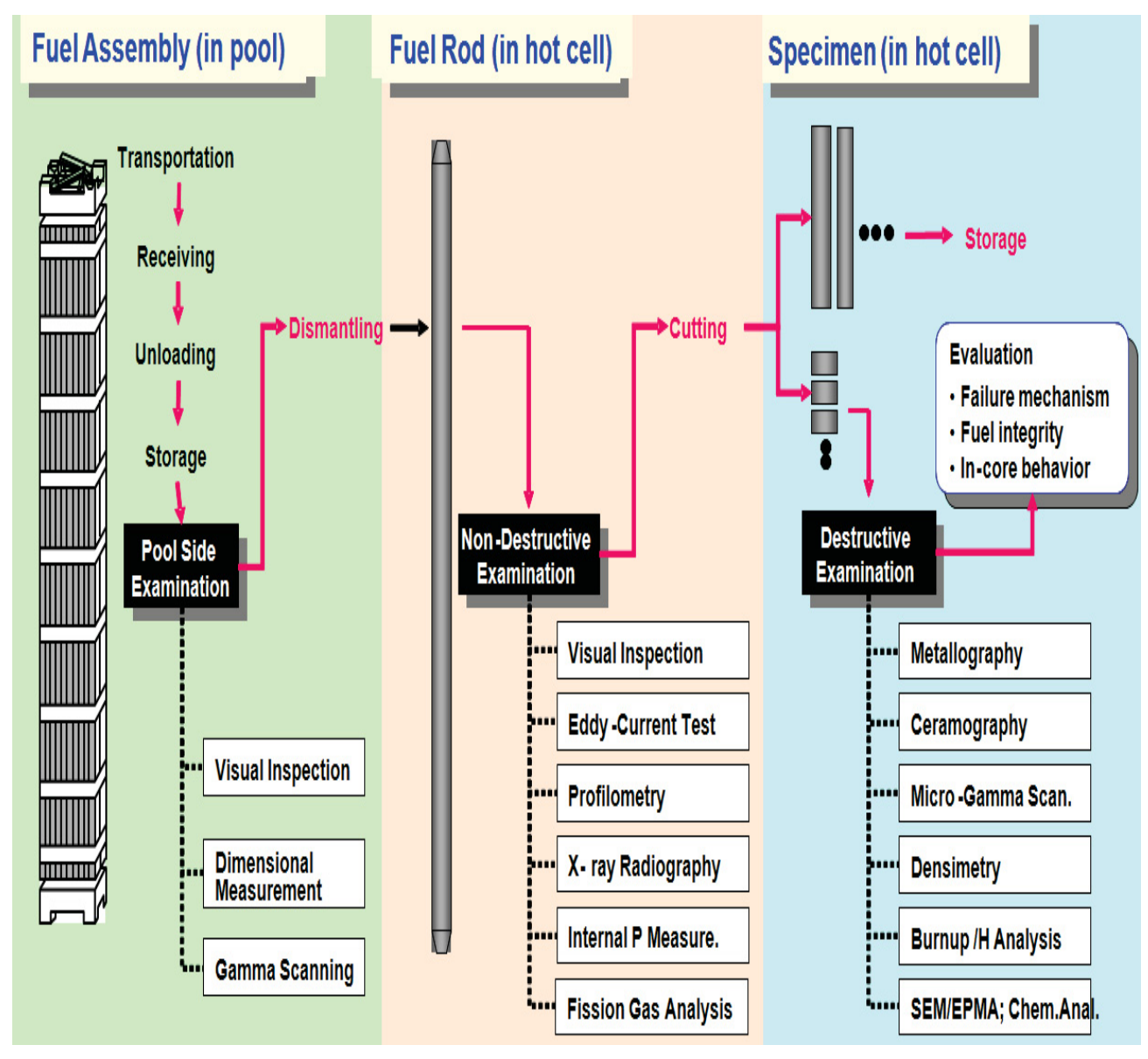

PIE flows for the operated PWR fuels from NPP in PIEF 


\section{Hot cell specifications and equipments in IMEF}

\begin{tabular}{|c|c|c|c|c|c|}
\hline $\begin{array}{l}\text { Pool/ } \\
\text { Cell }\end{array}$ & Function & $\begin{array}{c}\text { Inside } \\
\text { Dimension (m) }\end{array}$ & $\begin{array}{l}\text { Wall } \\
\text { Thickness }\end{array}$ & $\begin{array}{l}\text { Windows } \\
\text { (ea) }\end{array}$ & Major Equipment \\
\hline Pool & $\begin{array}{l}\text { Receiving } \\
\text { Cask }\end{array}$ & $\begin{array}{l}6.0 \times 3.0 \times 10.0 \\
\quad \text { (depth) }\end{array}$ & - & - & -Bucket Elevator \\
\hline M1 Cell & NDT & $7.0 \times 3.0 \times 6.0$ & $\begin{array}{l}\text { Heavy Conc. } \\
1.2 \mathrm{~m}\end{array}$ & 3 & $\begin{array}{l}\text { - Eddy Current - Gamma Scanning System } \\
\text { - X-ray Radiography System - Dia. Measurement System } \\
\text { - Rod Puncturing \& Fission Gas Collection System }\end{array}$ \\
\hline M2 Cell & $\begin{array}{l}\text { Specimen } \\
\text { fabrication }\end{array}$ & $7.0 \times 3.0 \times 6.0$ & " & 3 & $\begin{array}{l}\text { - CNC Machine } \quad \text { - Capsule Cutting Machine } \\
\text { - Cookie Electric Discharge Machine (EDM) }\end{array}$ \\
\hline M3 Cell & $\begin{array}{l}\text { Metallographic } \\
\text { sample prep. }\end{array}$ & $4.7 \times 3.0 \times 6.0$ & " & 2 & $\begin{array}{ll}\text { - Low speed saw } & \text { - Mounting Press } \\
\text { - Grinder/Polisher } & \text { - Periscope }\end{array}$ \\
\hline M4 Cell & $\begin{array}{l}\text { Sample } \\
\text { storage }\end{array}$ & $2.3 \times 3.0 \times 6.0$ & " & 1 & - Specimen Storage Rack \\
\hline M5a Cell & $\begin{array}{l}\text { Mechanical } \\
\text { Test }\end{array}$ & $7.1 \times 2.0 \times 4.0$ & $\begin{array}{l}\text { Heavy Conc. } \\
0.8 \mathrm{~m}\end{array}$ & 3 & $\begin{array}{l}\text { - Impact Tester - Tensile tester for small specimen } \\
\text { - Highscope Dimension Machine }\end{array}$ \\
\hline M5b Cell & $\begin{array}{l}\text { Mechanical } \\
\text { Test }\end{array}$ & $4.8 \times 2.0 \times 4.0$ & " & 2 & - Dynamic Tensile Tester - Static Tensile Tester \\
\hline $\begin{array}{l}\text { M7 Cell } \\
(\mathrm{M7a}, \mathrm{b})\end{array}$ & $\begin{array}{l}\text { Metallographic } \\
\text { Observation }\end{array}$ & $1.5 \times 2.6 \times 4.65$ & $\begin{array}{l}\text { Lead } \\
0.2 \mathrm{~m}\end{array}$ & 2 & $\begin{array}{ll}\text { - Optical Microscope } & \text { - Micro Hardness Tester } \\
\text { - Micro balance } & \text { - Mini SEM }\end{array}$ \\
\hline $\begin{array}{l}\text { Hot } \\
\text { Lab-I }\end{array}$ & $\begin{array}{l}\text { Micro } \\
\text { Analysis }\end{array}$ & $5.8 \times 7.5 \times 8.4$ & $\begin{array}{l}\text { Normal } \\
\text { Conc. }\end{array}$ & - & - EPMA, TEM \\
\hline $\begin{array}{l}\text { Hot } \\
\text { Lab-II }\end{array}$ & $\begin{array}{l}\text { Small Specimen } \\
\text { Testing }\end{array}$ & $6.0 \times 7.0 \times 4.55$ & $\begin{array}{l}\text { Normal } \\
\text { Conc. }\end{array}$ & - & $\begin{array}{l}\text { - Wire EDM - Thermal Diffusivity Tester } \\
\text { - Glove Box - Internal Burst Tester - Creep Tester }\end{array}$ \\
\hline $\begin{array}{l}\text { M6 Cell } \\
(\mathrm{M} 6 \mathrm{a}, \mathrm{b})\end{array}$ & $\begin{array}{c}\text { Sequential Progress } \\
\text { Test }\end{array}$ & $23.4 \times 2.0 \times 4.0$ & $\begin{array}{l}\text { Heavy } \\
\text { Concrete } \\
1.1 \mathrm{~m}\end{array}$ & 10 & $\begin{array}{l}\text { - Use by DUPIC Project } \\
\text { - OREOX Furnace, Mill, Roll Compactor, Mixer, Sintering Furnace, } \\
\text { Center less Grinder, Off Gas Treatment }\end{array}$ \\
\hline $\begin{array}{l}\text { M8 Cell } \\
(\mathrm{M} 8 \mathrm{a}, \mathrm{b})\end{array}$ & $\begin{array}{l}\text { Sequential Progress } \\
\text { Test }\end{array}$ & $10.3 \times 2.0 \times 4.3$ & $\begin{array}{l}\text { Heavy } \\
\text { Concrete } \\
0.9 \mathrm{~m}\end{array}$ & 5 & $\begin{array}{l}\text { - Use by ACP Project } \\
\text { - Slitting Machine, Vol-oxidizer, Metallizer, Smelter, Waste MS } \\
\text { Treatment Device, Off Gas Treatment System }\end{array}$ \\
\hline
\end{tabular}




\section{Procedure and Functions in IMEF}

\section{a Pool}

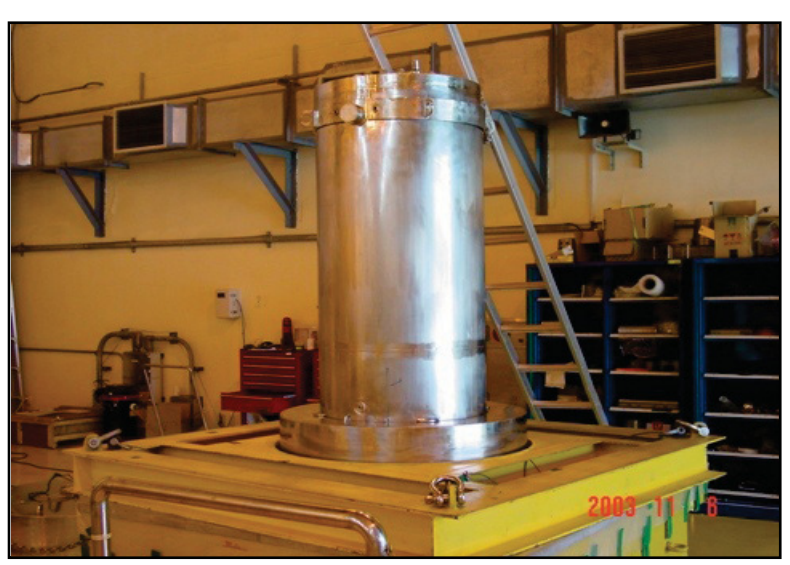

Cask on moving cart

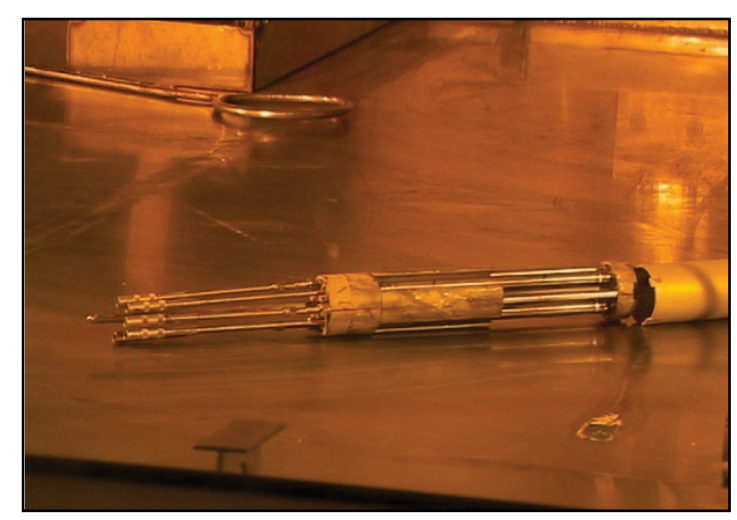

Dismantling capsule

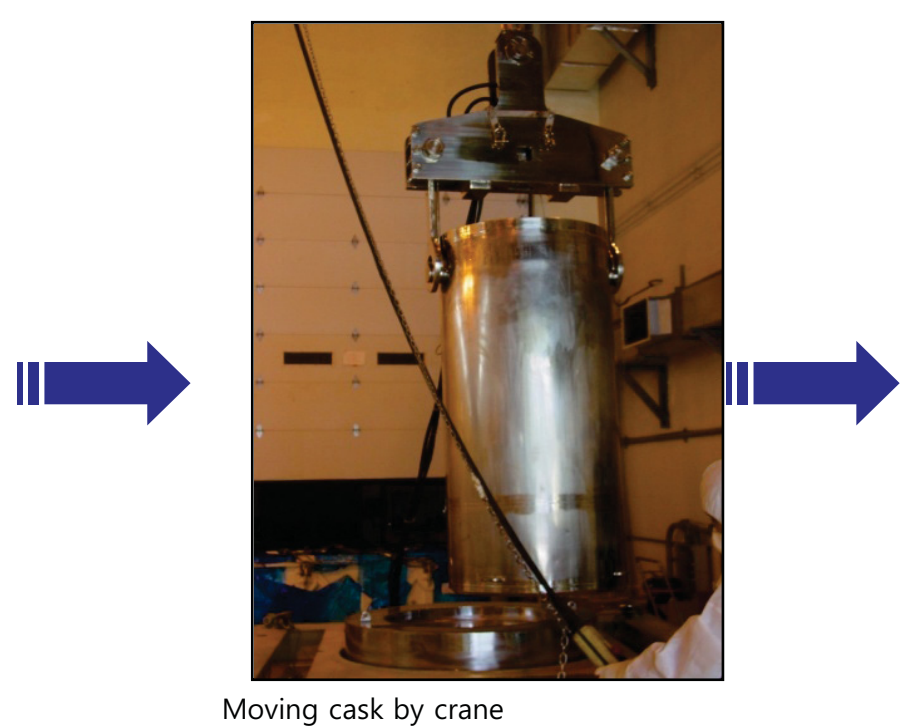

Moving cask by crane

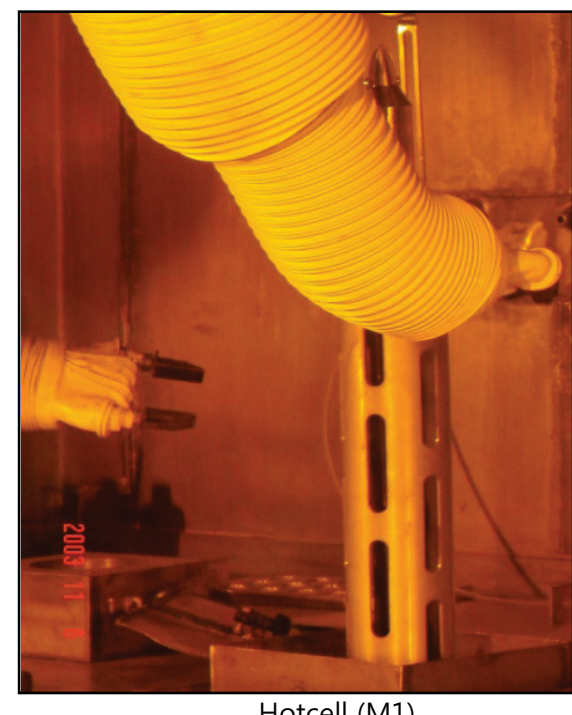

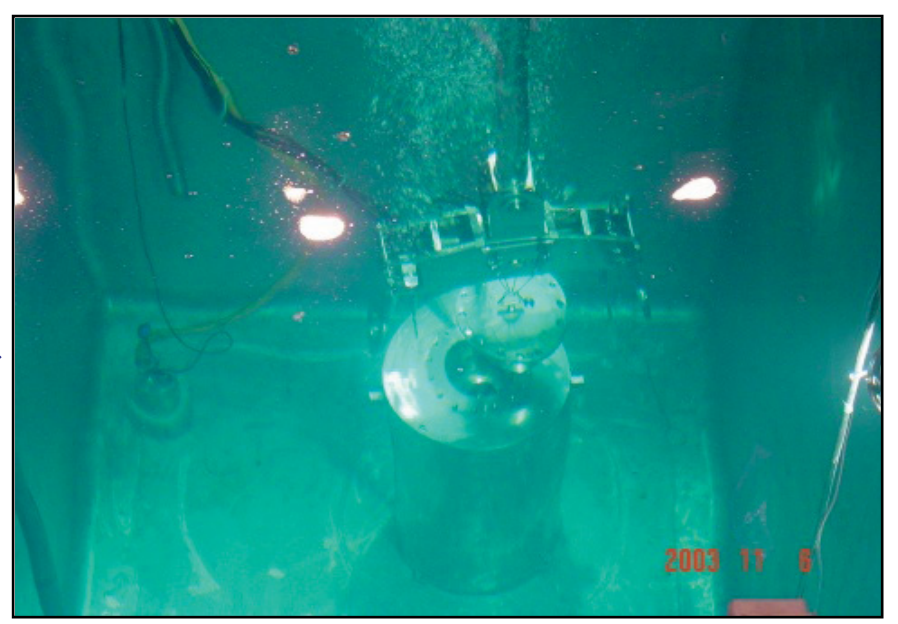

Moving cask into pool

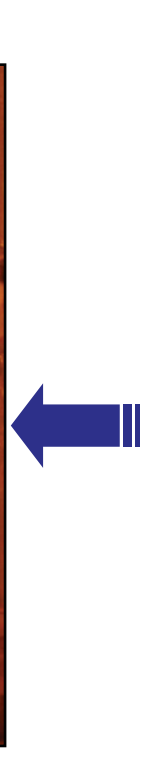

Capsule in the bucket 


\section{Functions in IMEF}

\section{M1 hot cell}

- Main Function: Loading into the Irradiated Capsule, Nondestructive Examination for Fuel Rods

- Equipments: Multipurpose Test Bench (Gamma Scanning, LVDT, Eddy Current Coil)

X-Ray Radiography System, Annealing Furnace Etc

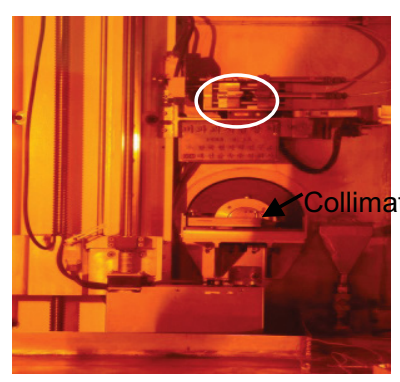

Gamma Scanning System

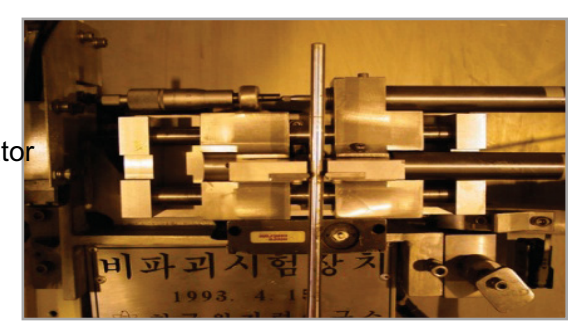

Diameter Measurement System

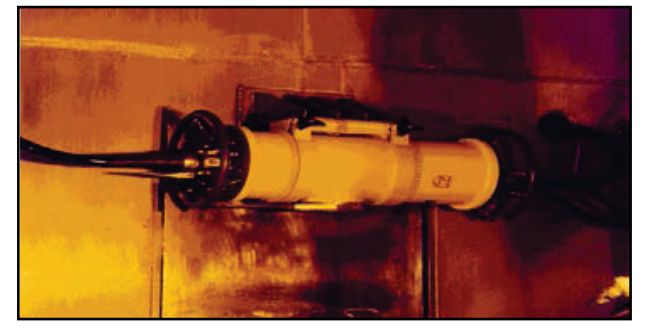

X-ray Radiography System

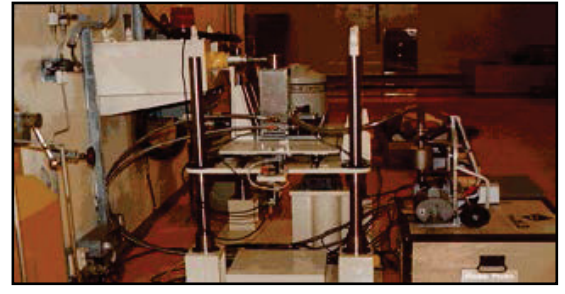

HPGe detector (backyard) for Gamma Scan

\section{M2 hot cell}

- Main Function: Capsule Dismantling, Specimen Fabrication

- Equipments: CNC milling machine, Capsule Cutting Machine, Cookie Type EDM

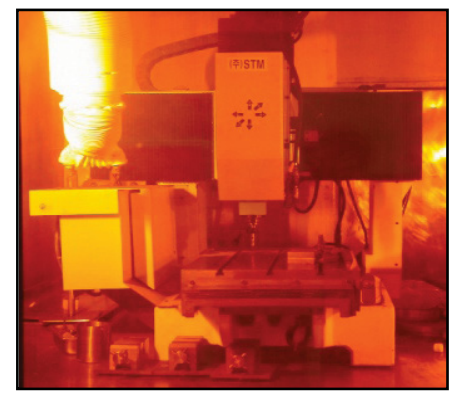

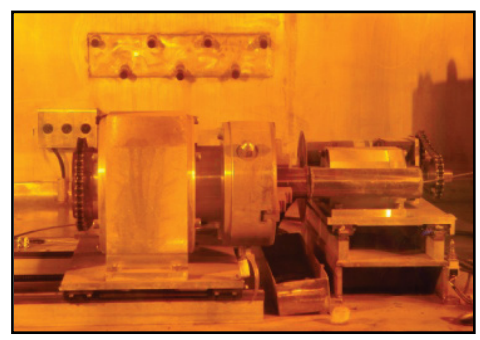

Capsule Cutting Machine

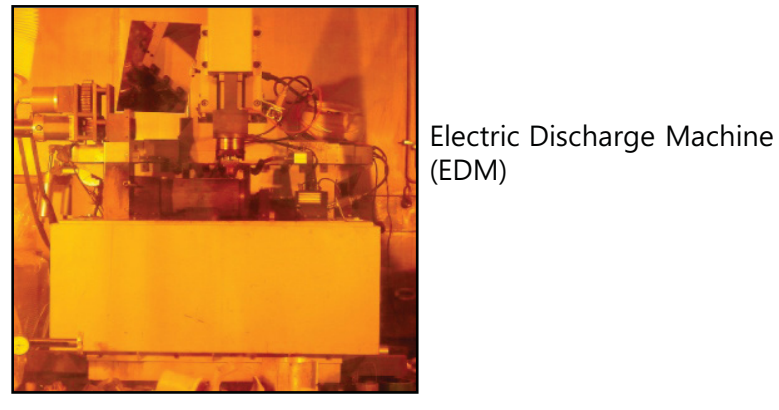




\section{Functions in IMEF}

\section{$\square \mathrm{M} 3$ hot cell}

- Main Functions: Preparation of Metallographic Specimen

- Equipments: Periscope, Mounting Press, Grinder, Polisher, Cutting Saw

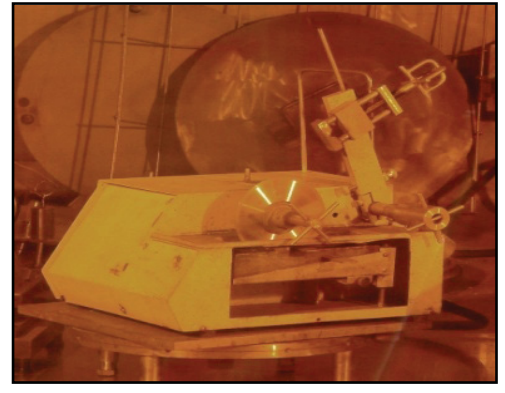

Low Speed Saw

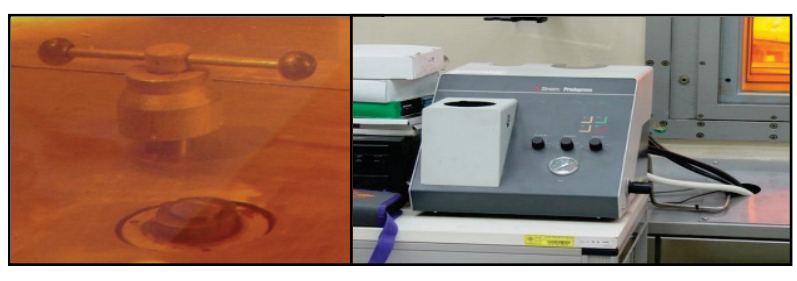

Mounting Press

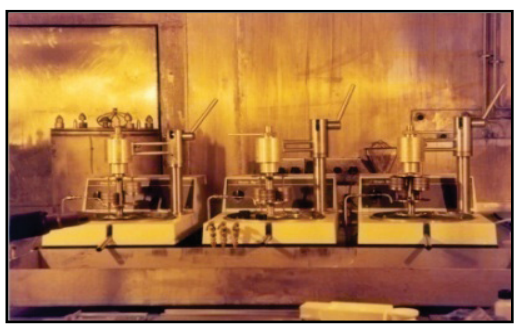

Grinder/Polisher

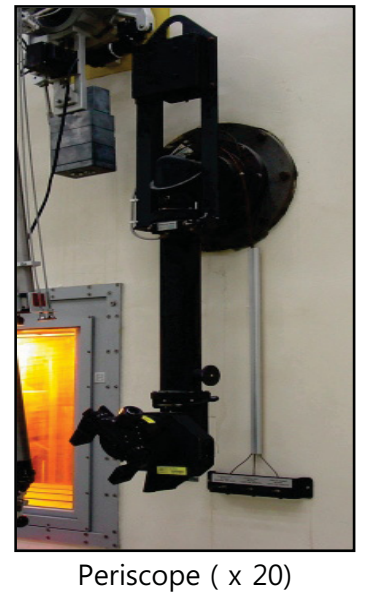

Periscope ( $x$ 20)

\section{M5 hot cell}

- Main Functions: Mechanical Test for Reactor Core Materials

- Equipments: Charpy Impact Tester, UTM for Small Specimen, Static UTM, Dynamic UTM

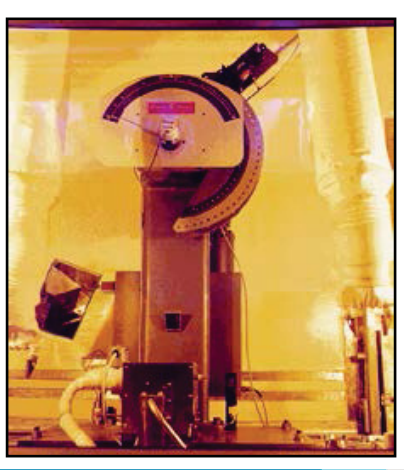

chine

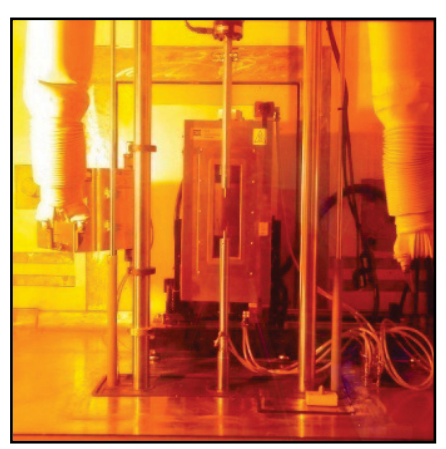

Small Specimen UTM

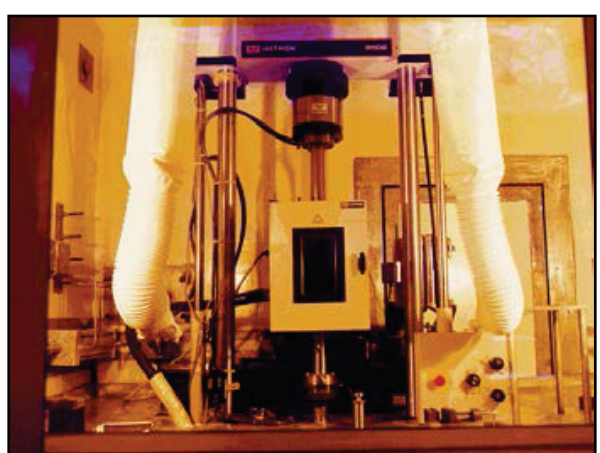

Dynamic Universal Testing Machine

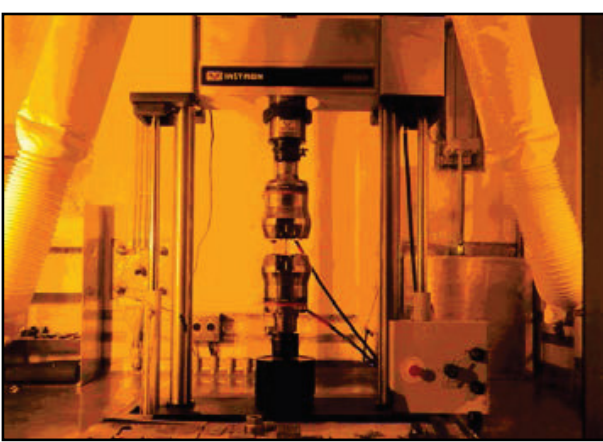

Static Universal Testing Machine 


\section{Functions in IMEF}

\section{M7 hot cell}

- Main Functions: Microscopic Investigation, Micro-hardness Measurement, Density Measurement.

- Equipments : Optical Microscope (LEICA Telatom3), Density Measuring Device

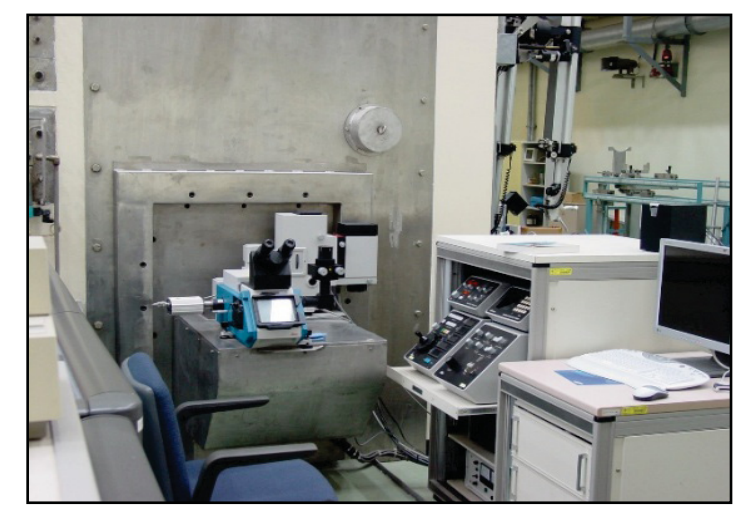

Optical microscope \& Micro Hardness tester

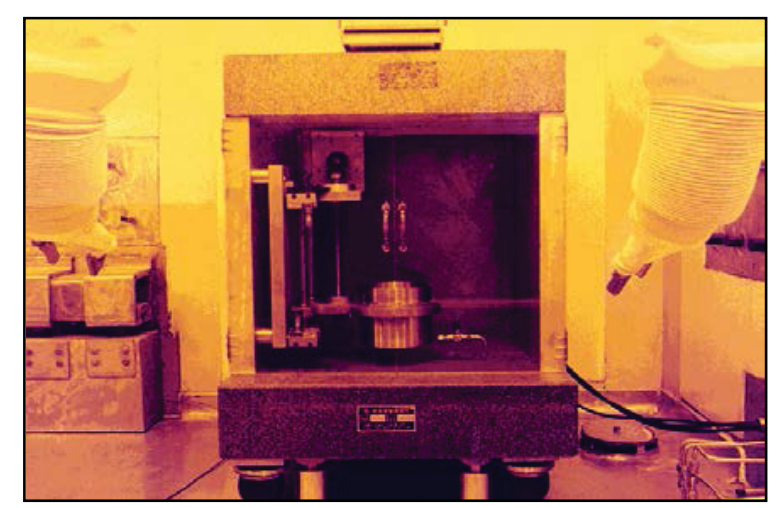

Density measurement device (Immersion method)

\section{Hot laboratory (I)}

- Main Functions: Microscopic Investigation and Chemical Composition Analysis

- Equipment: Shielded EPMA (Cameca SX-50R), TEM (Jeol)

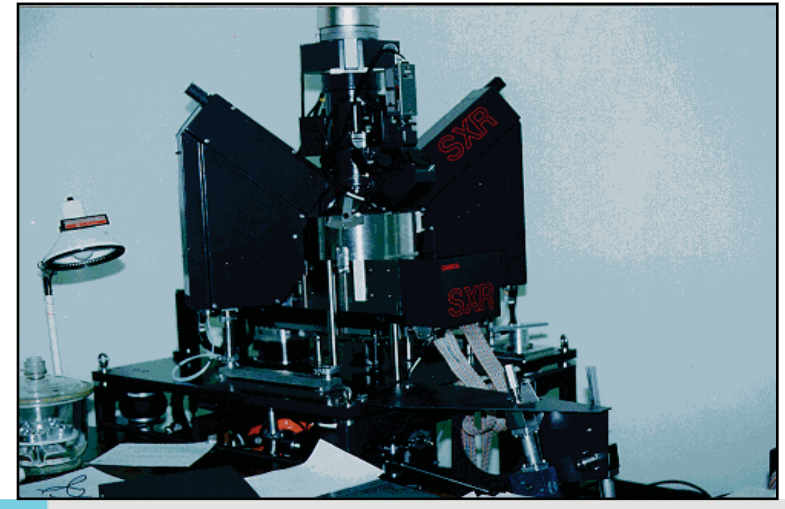

Electron Probe Micro Analyzer (WDS(WDX) -2EA)

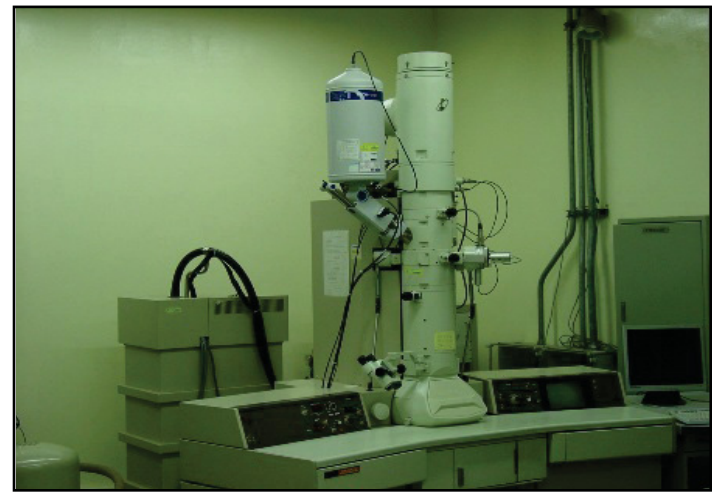

Transmission Electron Microscope 


\section{Functions in IMEF}

\section{M6 hot cell}

- Main Functions: Perform DUPIC Project

- Equipments: Oreox Furnace Etc

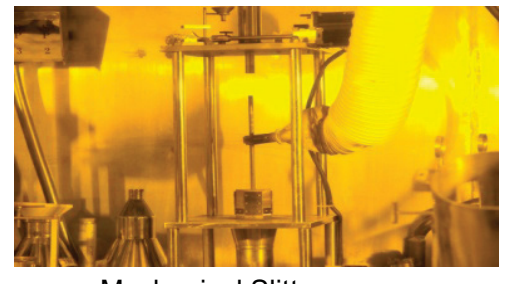

Mechanical Slitter

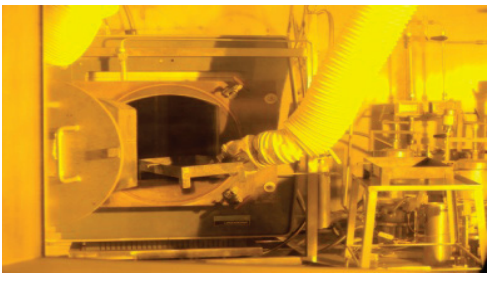

OREOX furnace

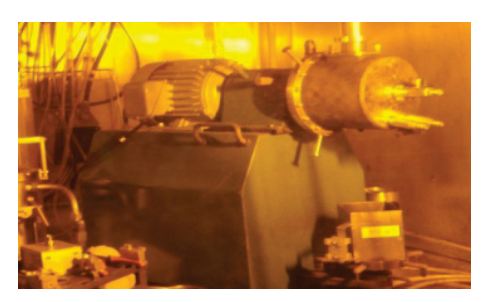

Horizontal rotary ball mill

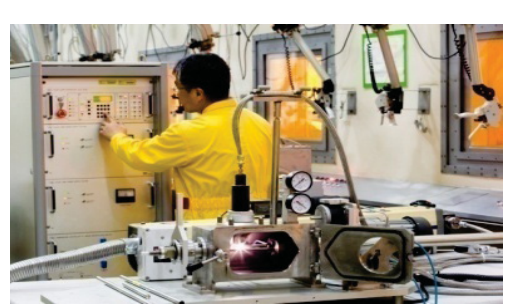

Laser Welder

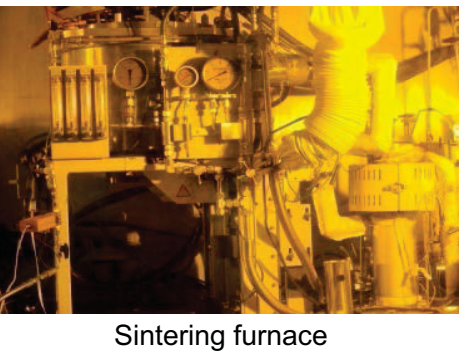

Sintering furnace

$\square$ M8 hot cell

- Main Function: ACP (Advanced spent fuel Conditioning Process) Project

- Equipments: Slitting M/C, Vol-Oxidizer, Metallizer, Smeltzer etc
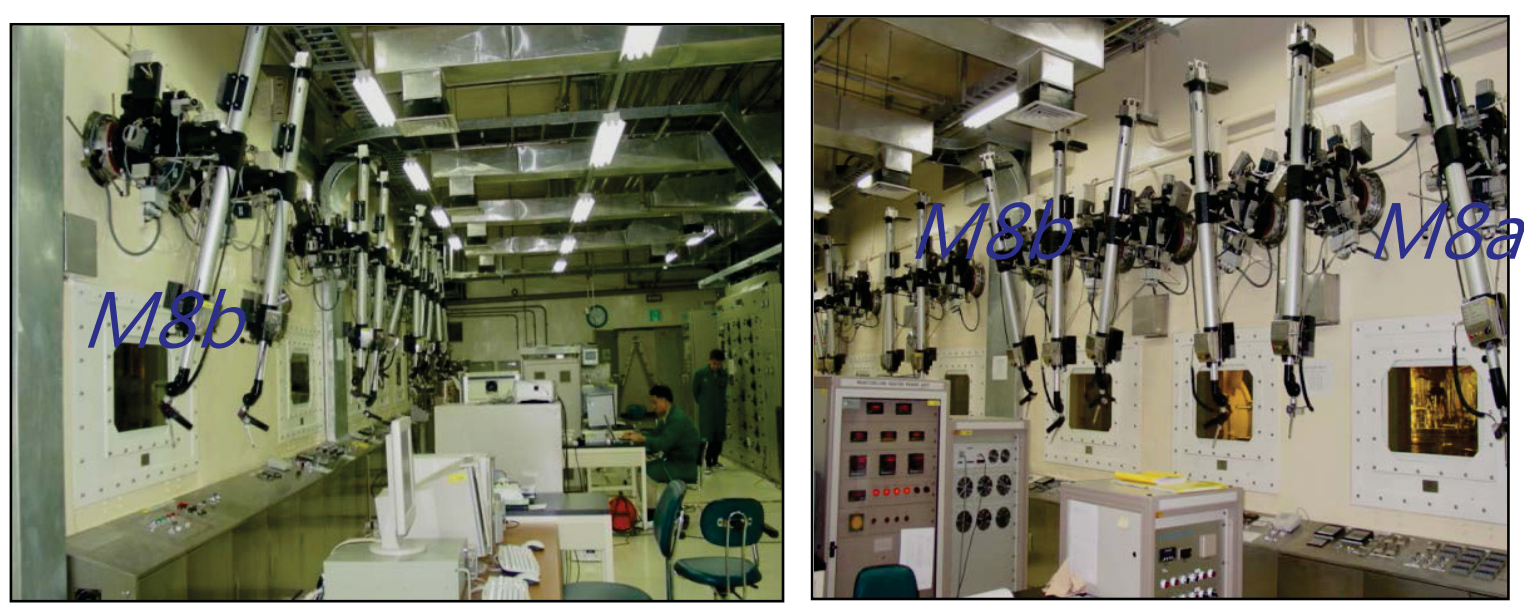


\section{Post-irradiation examination milestone}

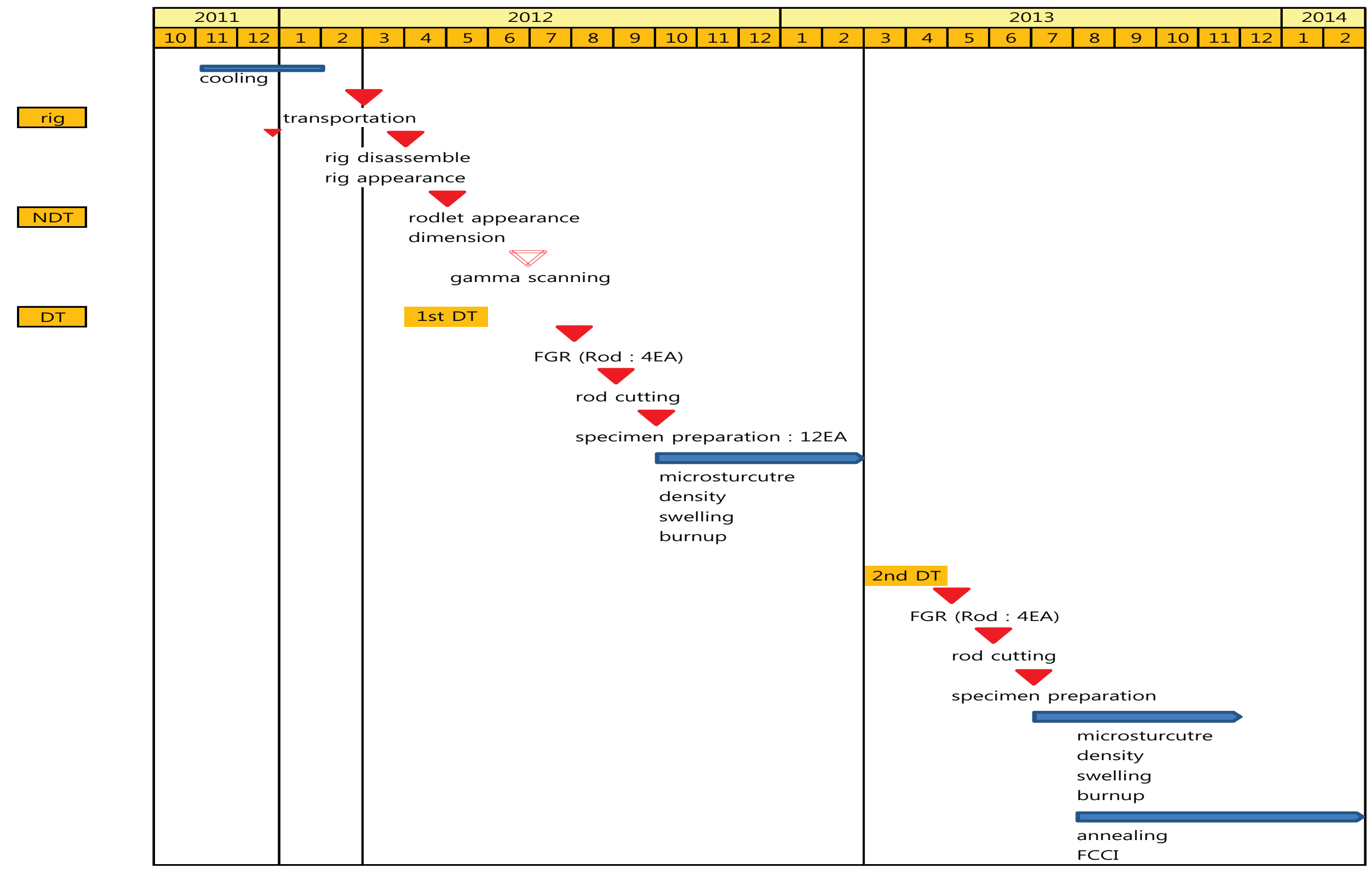




\section{Transportation \& Rig Inspection}

* After irradiation, the capsule is transported from the HANARO pool to the IMEF and PIEF for examination

* Method

- Fuel transfer to hot cell

- The fuel capsule is transferred to the IMEF through the channel connected with the pool by the use of bucket elevator

- The fuel capsule or rods are transferred from the IMEF to the PIEF, if necessary

- Rig Inspection

- Visual Inspection by video \& digital camera

- Disassemble by capsule cutting machine $\checkmark$ Gap tightness between cladding and sealing tube

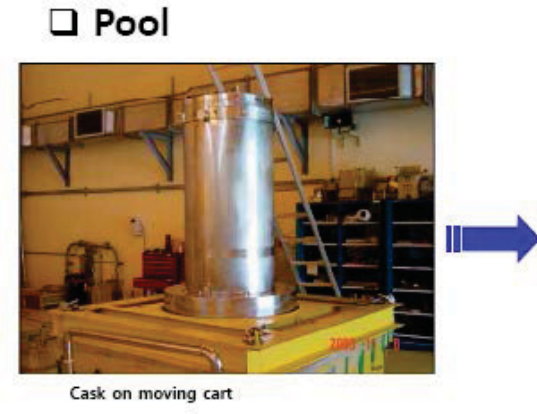

Cask on moving cart

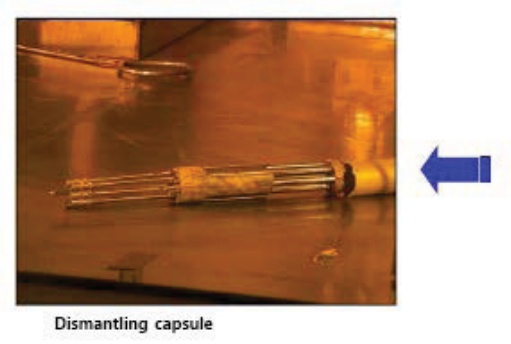

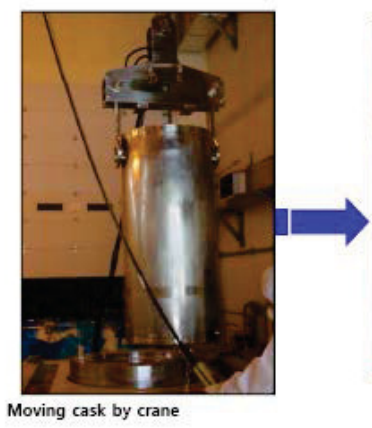

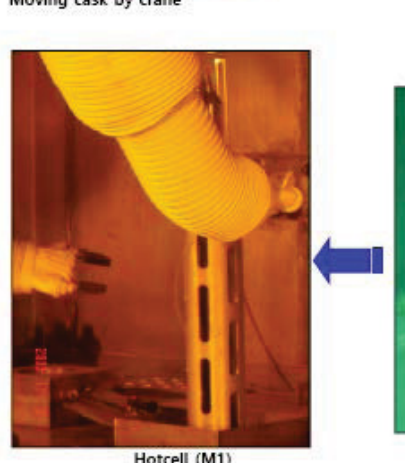

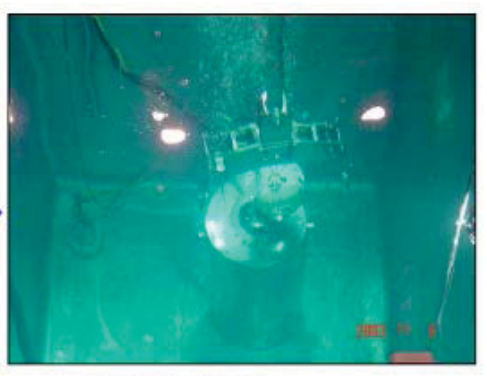

Moving cask into pool

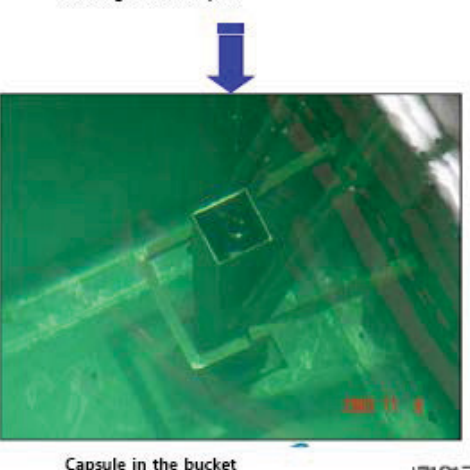




\section{Non destructive test-Visual Inspection}

- Purpose: Integrity of fuel rodlet

口 Application:

$>$ Sodium level and bubble

$>$ Fuel growth

- Equipment and Methods

$>$ Video and digital camera

$>$ X-ray radiography system

- No. of rodlets : 12 EA

- Schedule to Complete Activity

$>$ 2012.04

- Issues for PIE, modeling and design

$>$ Sodium level by X-ray

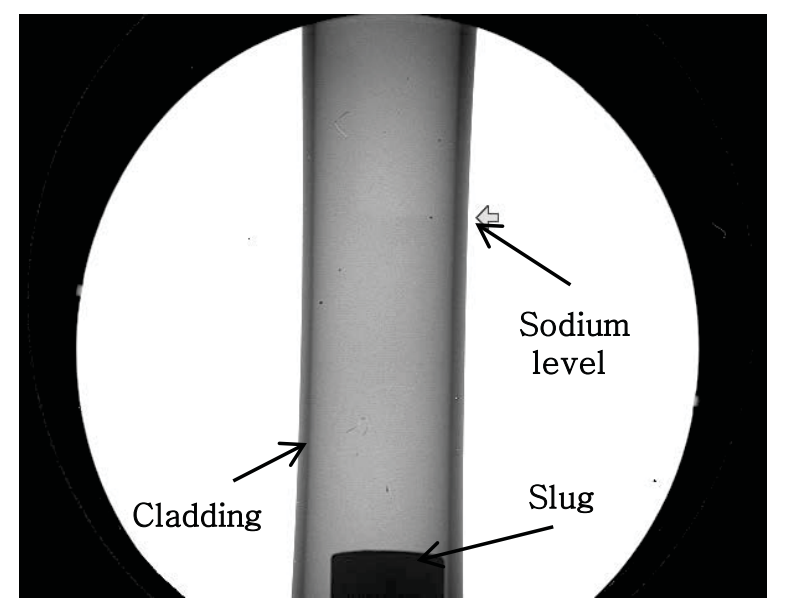

$\mathrm{X}$-ray radiography

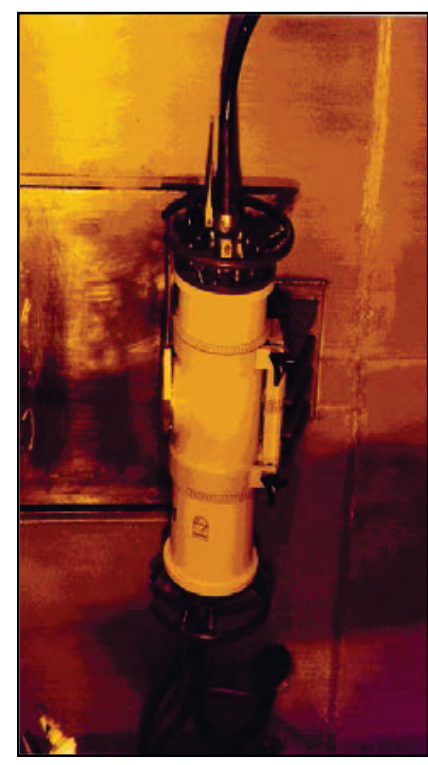

X-ray Radiography System 


\section{Non destructive test-Dimension}

Purpose: Measurement of length and diameter of rodlet

a Application:

$>$ Relationship between FMS cladding strain and Fuel Slug swelling

Equipment and Methods

$>$ Diameter Measurement System (LVDT)

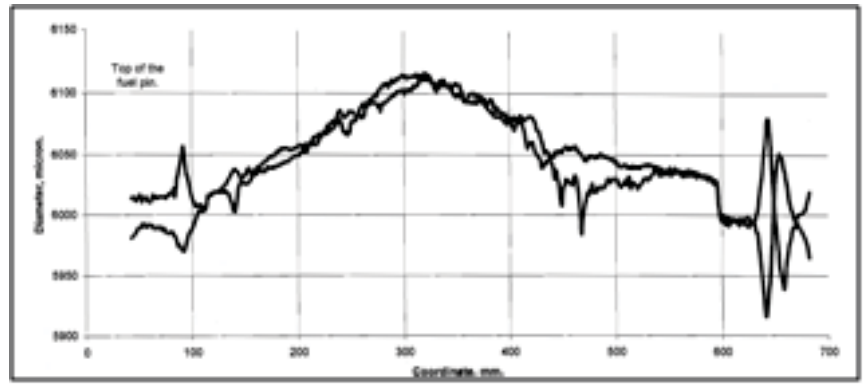

Diameter Change of Cladding

- $\quad 0.5 \mathrm{~mm}$ step, 3 times at 0,60, 120 degree

- No. of rodlets : 12 EA

- Schedule to Complete Activity

> 2012.04 : completed

- Issues for PIE, modeling and design

$>$ Cladding thermal expansion and swelling according to burnup

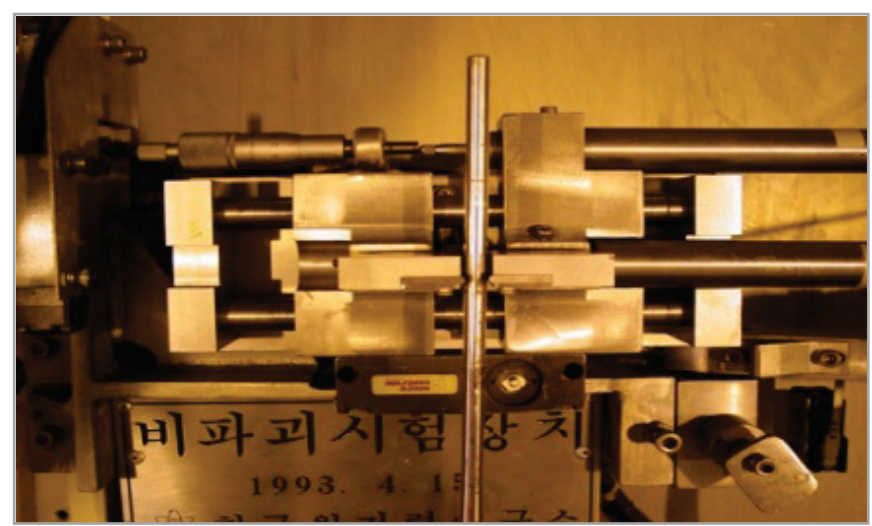

Diameter Measurement System 


\section{Non destructive test-Gamma scanning}

a Purpose

$>$ Variation of burnup along axial direction of rodlet

$>$ Axial movement of fission products, especially Cs

a Application:

$>$ Relative fuel burnup profile

$>$ Relative distribution of various isotopes of interest in fuel

- Equipment and Methods

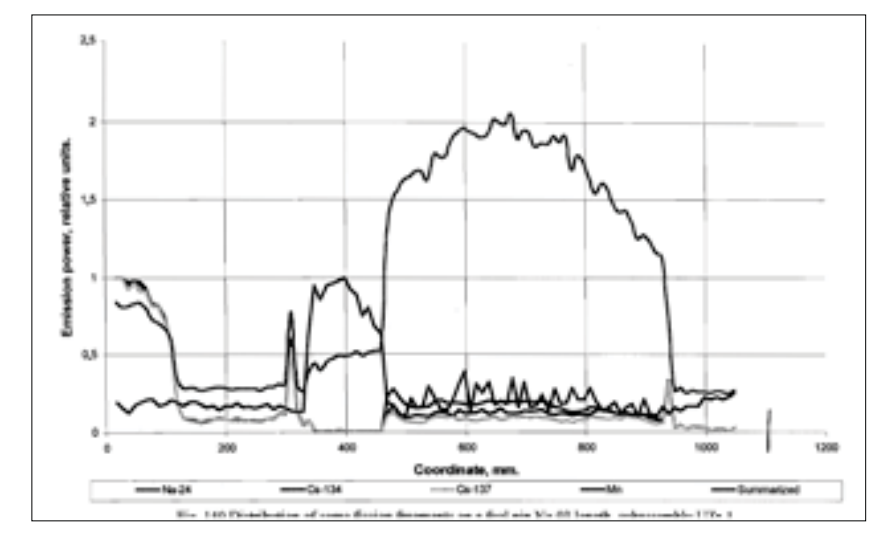

distribution of isotopes

$>$ Gamma scanner in Multipurpose test bench

- Vertical step travel : $2.0 \mathrm{~mm}$ ( $\sim 80$ point)

- No. of rodlets : $12 \mathrm{EA}$

․ Schedule to Complete Activity

> 2012.06: completed

I Issues for PIE, modeling and design

$>$ Cs distribution in Sodium

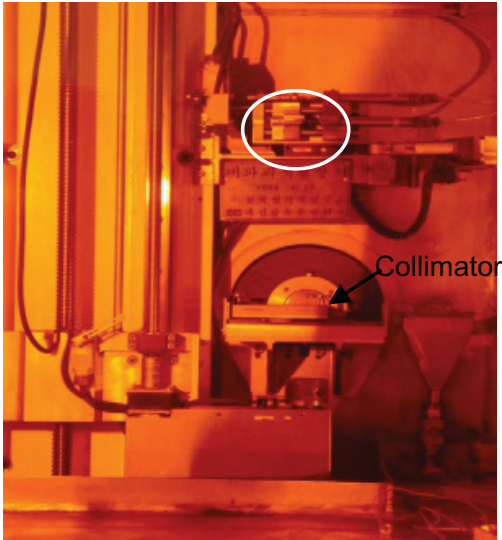

Gamma Scanning System

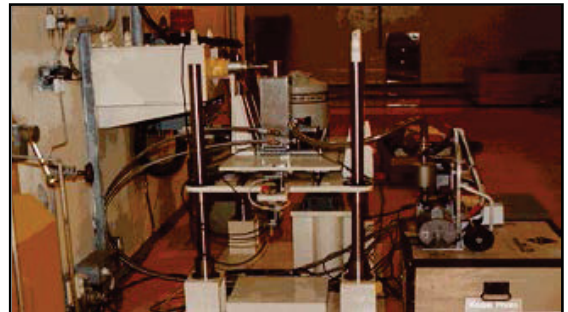

HPGe detector (backyard) for Gamma Scan 


\section{Capsule/Rodlets Disassembly and Specimen preparation}

a Purpose: Disassemble for PIE

- Equipment and Methods

$>$ Capsule cutting system in M2 hot cell

$>$ Preparation of specimen in M3 hot cell

a Schedule to Complete Activity

$>$ 2012. 09 : Rodlets Disassembly completed

I Issues for PIE, modeling and design

$>$ Techniques for disassembling rodlets and dealing with sodium in an air cell

- Steel cell \& coolant $\square$ M2 hot cell

- Main Function: Capsule Dismantling, Specimen Fabrication

- Equipments: CNC milling machine, Capsule Cutting Machine, Cookie Type EDM
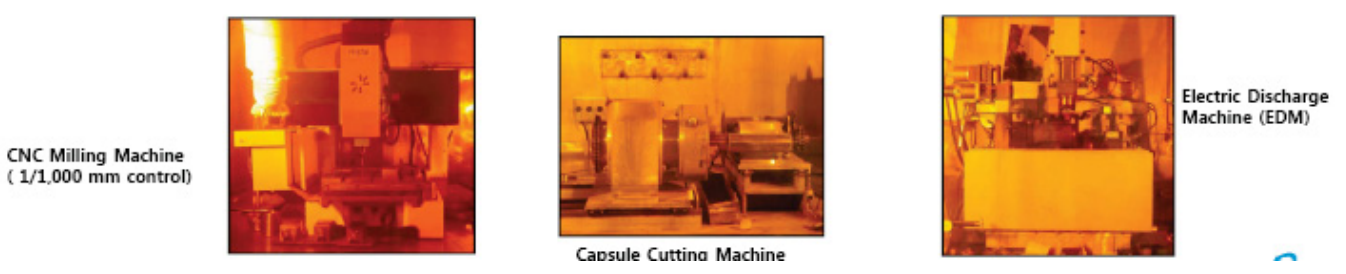

$\sqcup \mathrm{M} 3$ hot cell

- Main Functions: Preparation of Metallographic Specimen

- Equipments: Periscope, Mounting Press, Grinder, Polisher, Cutting Saw
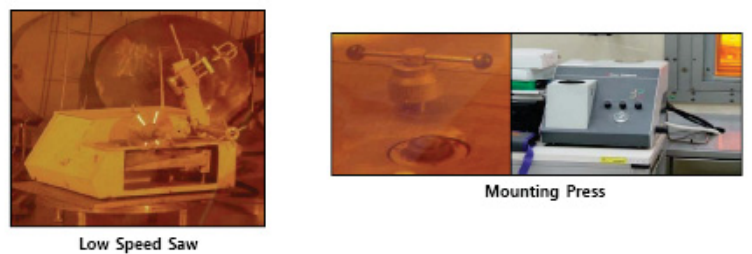

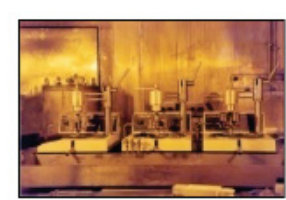

Grinder/Polisher

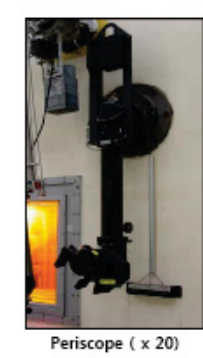




\section{Rodlets Test Group for PIE}

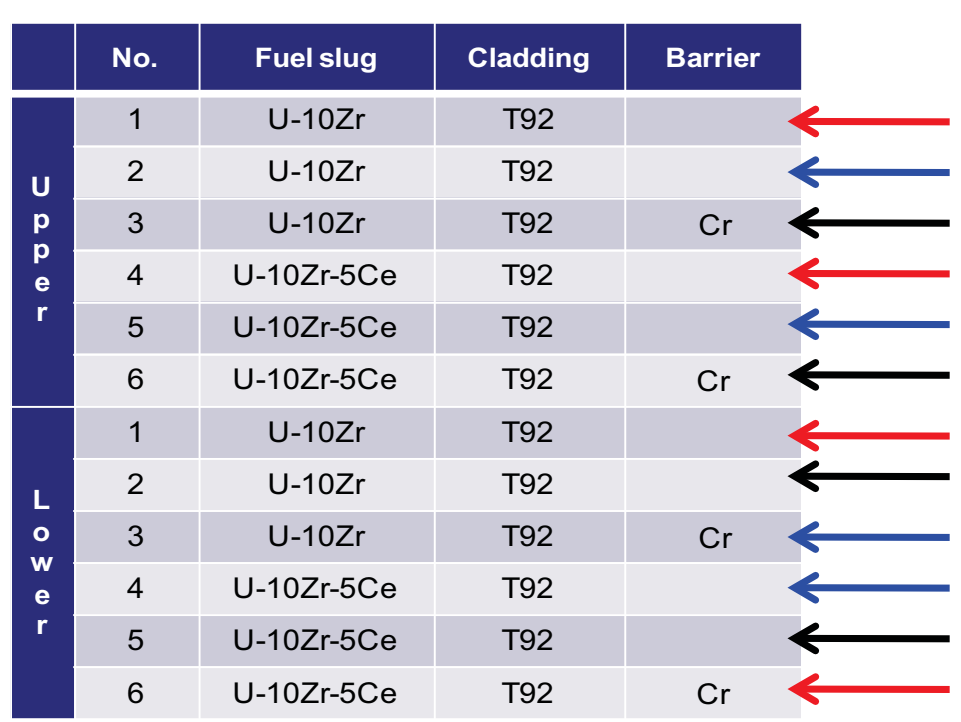

$1^{\text {st }}$ test

$2^{\text {nd }}$ test

Annealing, FCCI

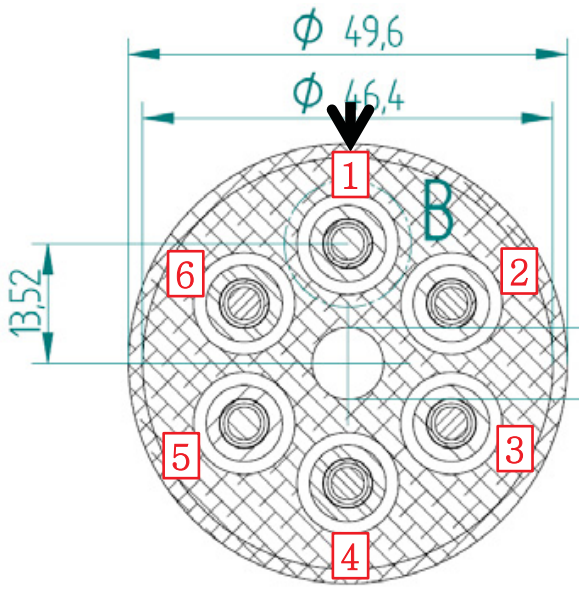

CORE

Top view

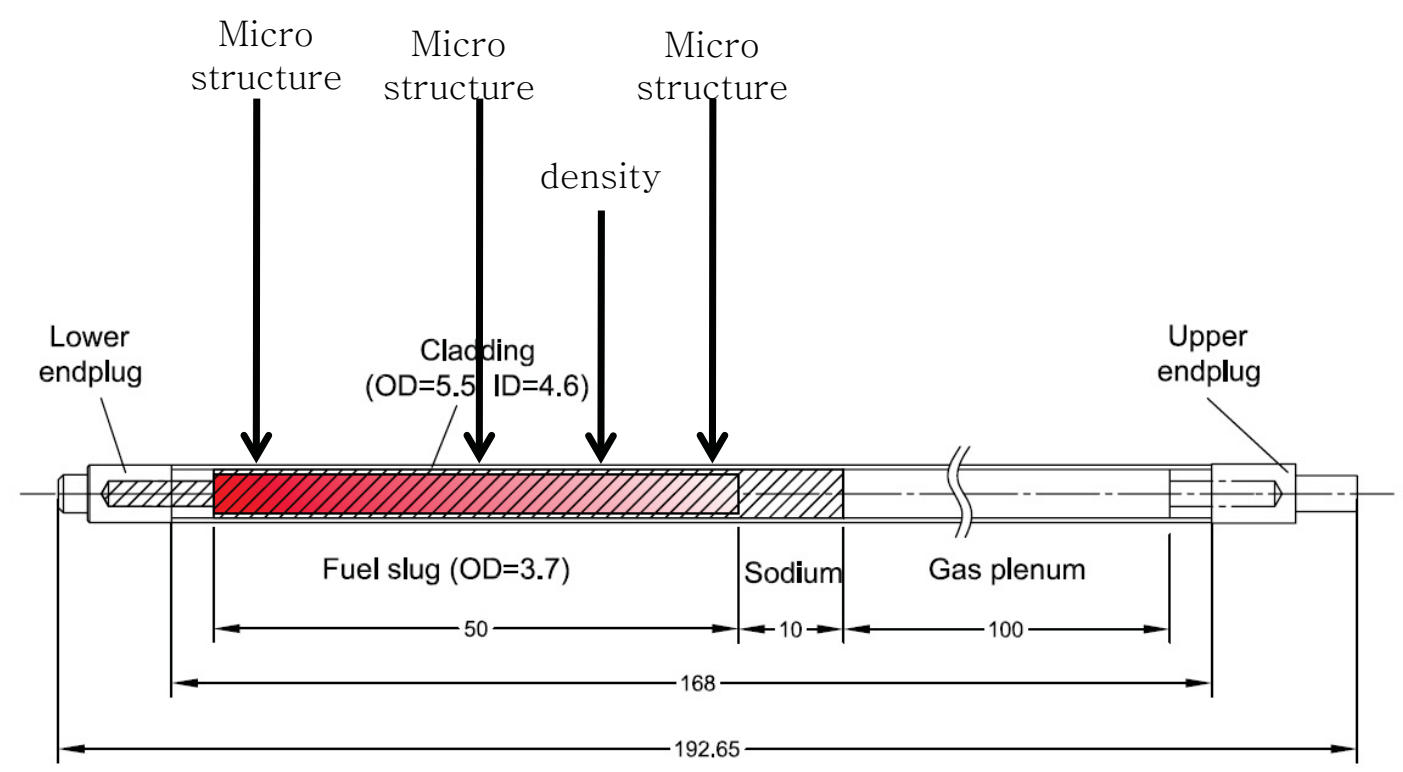




\section{Destructive test- Fission gas release}

- Purpose: Variation of FGR with fuel burnup

a Application:

$>$ Determine fission gas release

- Equipment and Methods

$>$ Puncture system

- System only for SFR metal fuel needed

$>$ No of specimen :

- $1^{\text {st }}: 4 \mathrm{EA}, 2^{\text {nd }}: 4 \mathrm{EA}$

- Schedule to Complete Activity

$>2012.07: 1^{\text {st }}$ test completed

口 Issues for PIE, modeling and design

$>$ Uncertainty in measurement - small system needed

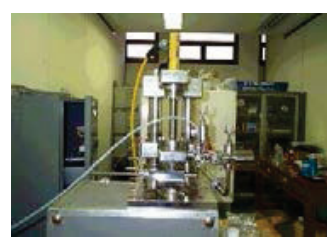

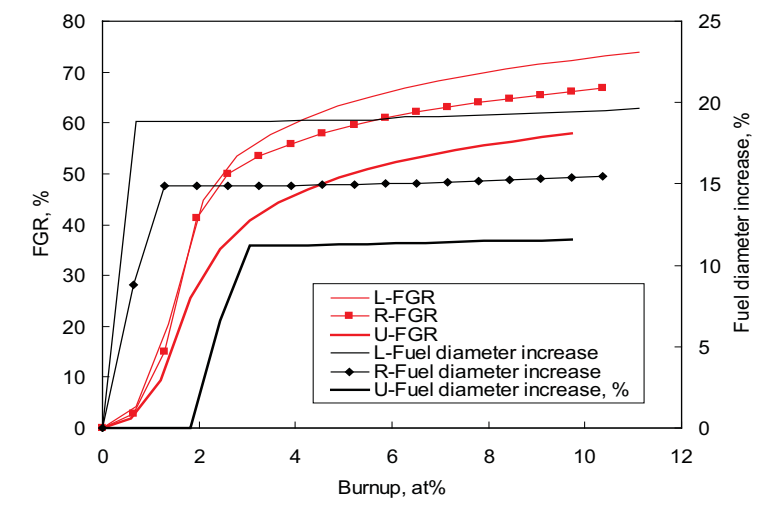

Fission gas release

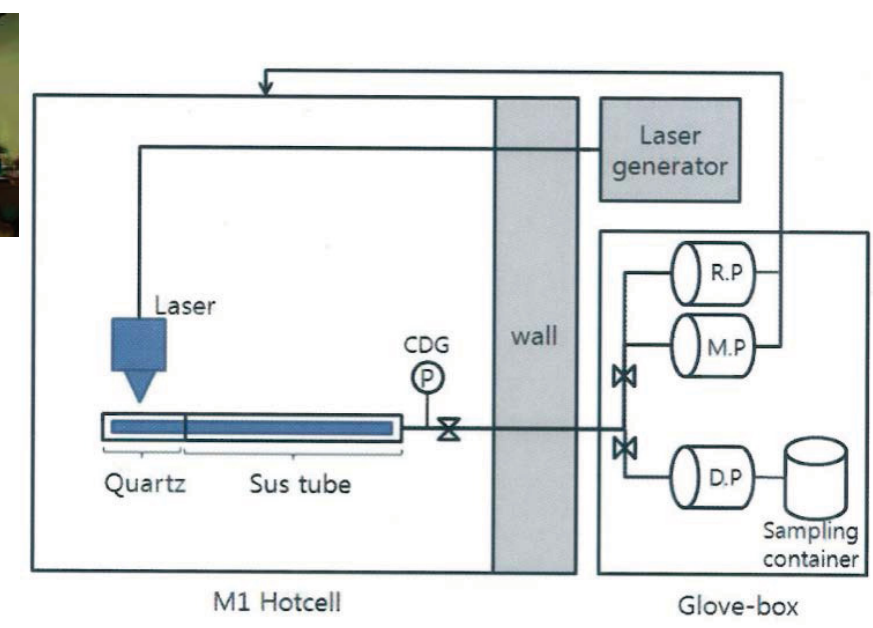

puncture system 


\section{Destructive test-Swelling and axial length}

ㄱ Purpose: Measurement of variations in swelling and axial length with fuel burnup

口 Application:

$>$ Relationship between Fuel irradiation growth and swelling

Equipment and Methods

$>$ Measure by Highscope and OM

- Compare with density

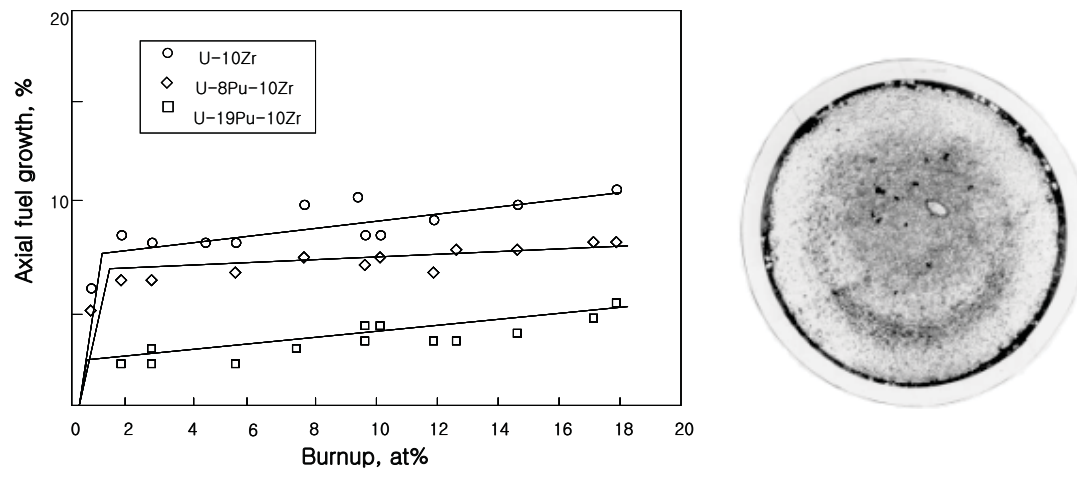

irradiation growth and swelling

$>$ No of specimen

- $1^{\text {st }}: 12 \mathrm{EA}, 2^{\text {nd }}: 12 \mathrm{EA}$

- Schedule to Complete Activity

$>2012.08: 1^{\text {st }}$ test completed

- Issues for PIE, modeling and design

$>$ Measurement according to indirect measurement
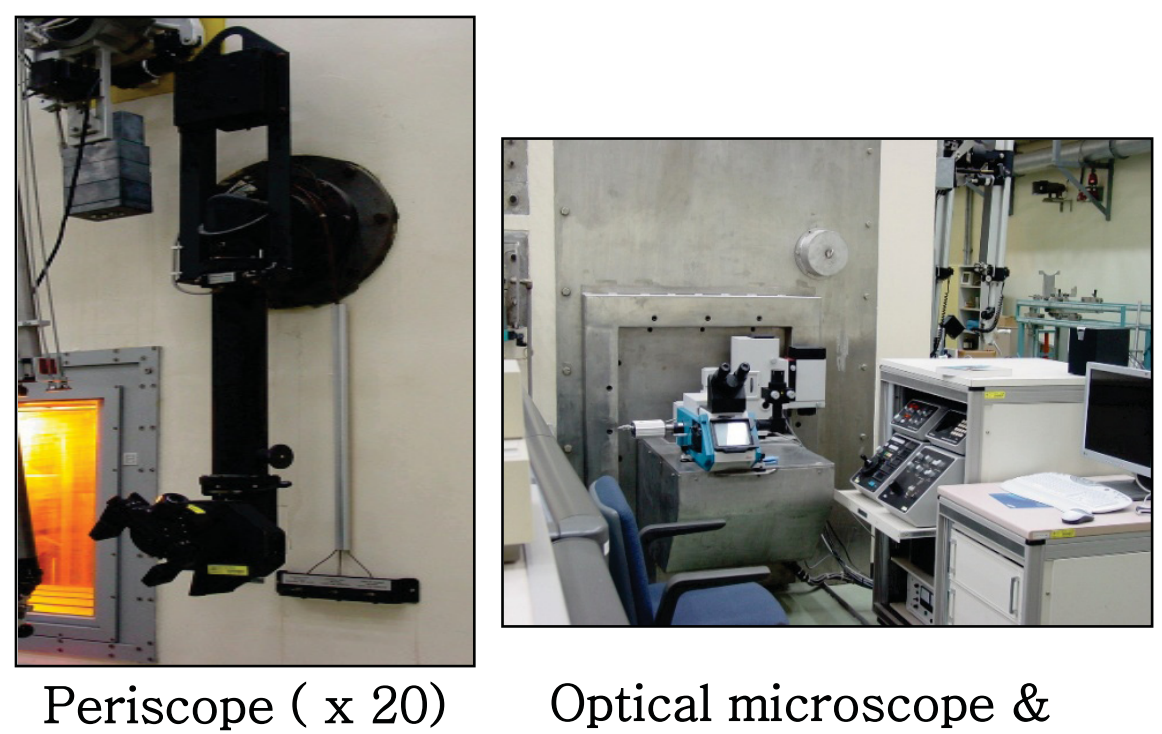

Optical microscope \& Micro Hardness tester 


\section{Destructive test-Density}

- Purpose: Measurement of density variation

口 Application:

$>$ Quantify irradiation swelling

$>$ Derive thermal conductivity

Equipment and Methods

$>$ Immersion method

- Micro-Balance \& toluene

\begin{tabular}{|l|c|c|}
\hline \multicolumn{1}{|c|}{ Parameter } & \multicolumn{2}{c|}{ Value } \\
\cline { 2 - 3 } & $\mathrm{UZr}-1$ & $\mathrm{UZr}-2$ \\
\hline Mean density, $\mathrm{g} / \mathrm{cm}^{3}$ & 15.17 & 15.365 \\
\hline Minimum density, g/cm & 13.68 & 15.21 \\
\hline Maximum density, $\mathrm{g} / \mathrm{cm}^{3}$ & 15.45 & 15.71 \\
\hline Standard deviation, $\mathrm{g} / \mathrm{cm}^{3}$ & 0.102 & 0.423 \\
\hline
\end{tabular}

The standard deviation was defined by the formula: $\left\{\left[n \Sigma x^{2}-(\Sigma x)^{2}\right] / n^{2}\right\}^{1 / 2}$.

$>$ No of specimen

- $1^{\text {st }}: 4 \mathrm{EA}, 2^{\text {nd }}: 4 \mathrm{EA}$

a Schedule to Complete Activity

$>2012.08: 1^{\text {st }}$ test completed

- Issues for PIE, modeling and design

$>$ Measurement considering the porosity of irradiated metal fuel

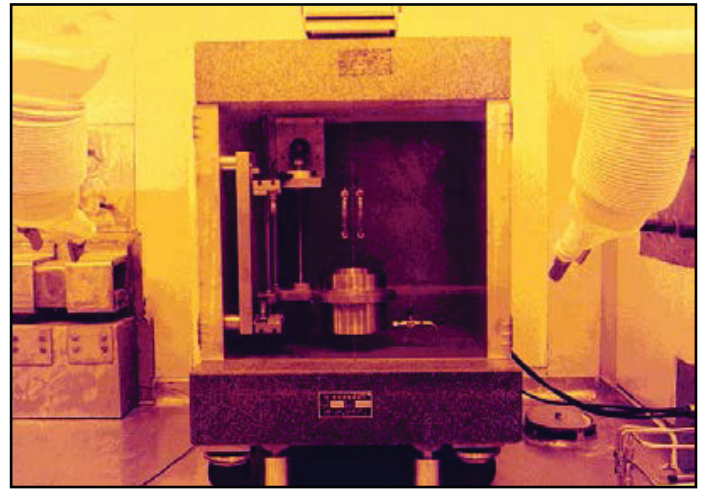

Density measurement device (Immersion method) 


\section{Destructive test-Microstructure}

- Purpose: Size and distribution of porosity, distribution of phase and fission product, Infiltration of sodium into fuel

口 Application:

$>$ Fuel phase and porosity, Fuel constituent migration, sodium infiltration, $\mathrm{FCCl}$ etc

Equipment and Methods

$>$ Optical Microscope (LEICA Telatom3)

$>$ Mini-SEM

$>$ Shielded EPMA

$>$ No of specimen

- $\quad 1^{\text {st }}: 12 \mathrm{EA}, 2^{\text {nd }}: 12 \mathrm{EA}$

- Schedule to Complete Activity

$>2013.02: 1^{\text {st }}$ test completed

I Issues for PIE, modeling and design

$>$ Sample preparation
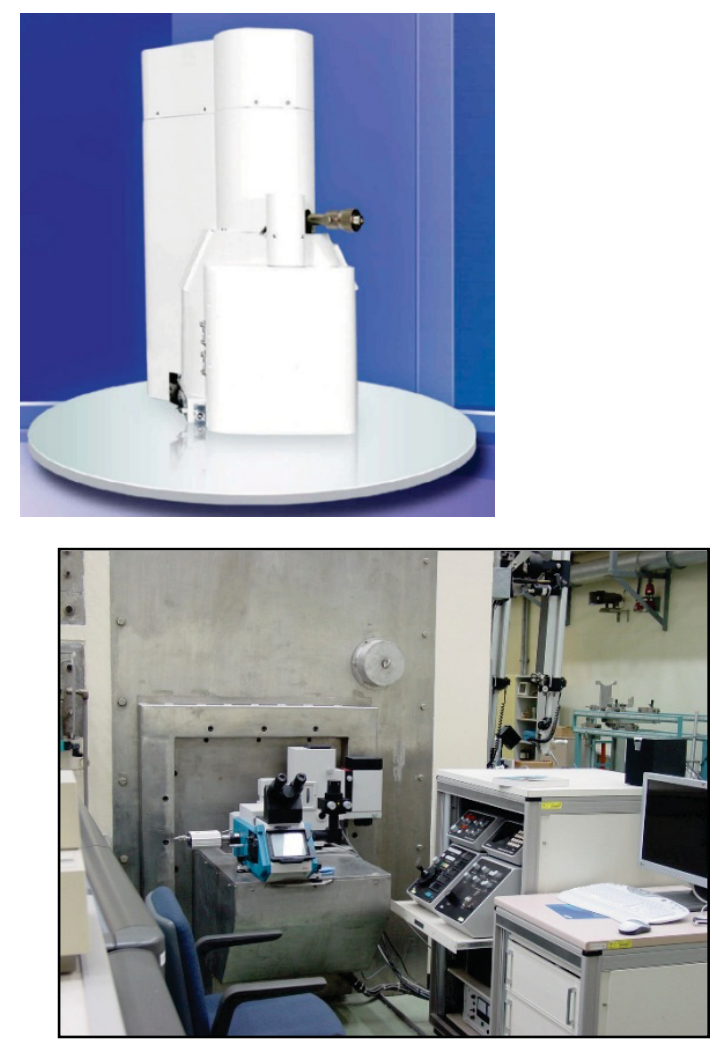

Optical microscope \& Micro Hardness tester
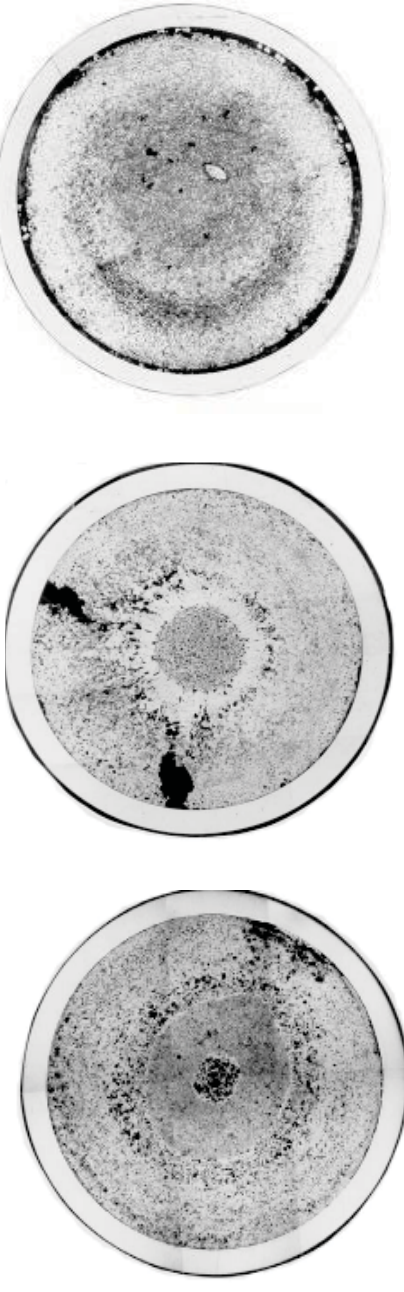


\section{Destructive test- Burnup analysis}

Purpose: Measurement of fuel burnup with chemical analysis

口 Application:

$>$ Derive burnup

Equipment and Methods

$>\quad$ The burnup is determined by the measurement of $148 \mathrm{Nd}$ separated chemically from the fuel sample

$>$ by means of mass spectrometry such as LA-ICP-MS(Laser Ablation Inductively Coupled Plasma Mass Spectrometry).

$>$ Burnup measurement is performed in the Chemical Lab. of the PIEF.

$>$ The samples to be analyzed are transported by a small cask from the IMEF to the Chemical Lab. of the PIEF.

口 Schedule to Complete Activity

$>2013.02: 1^{\text {st }}$ test completed

Issues for PIE, modeling and design

$>$ Standard data in Fast Reactor Conditions

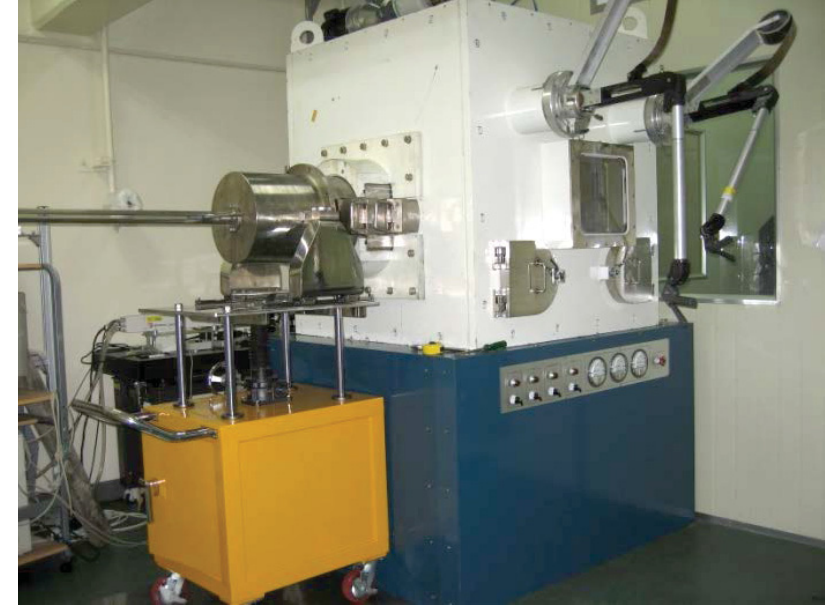

LA-ICP-MS 


\section{Diffusion couple test between fuel and barrier cladding}

\section{Status}

* KAERI fabricated the barrier cladding

* Diffusion couple testing against metal alloys were carried out.

* Barrier(Zr, V metal foil, Cr) and rare earth element(Misch metal, Nd) interaction

* The performance of Barrier such as V \& CrN showed a good result.

* Barrier cladding tubes by electroplating of Cr Under irradiation at HANARO (2010. 11.)

\section{* Planned Activities}

* Focuses on the fabrication of barrier cladding tubes

* Cr plating, Ion Nitride, and combining $\mathrm{Cr}$ plating/Nitride Barrier

* ATR irradiation through Collaboration with INL
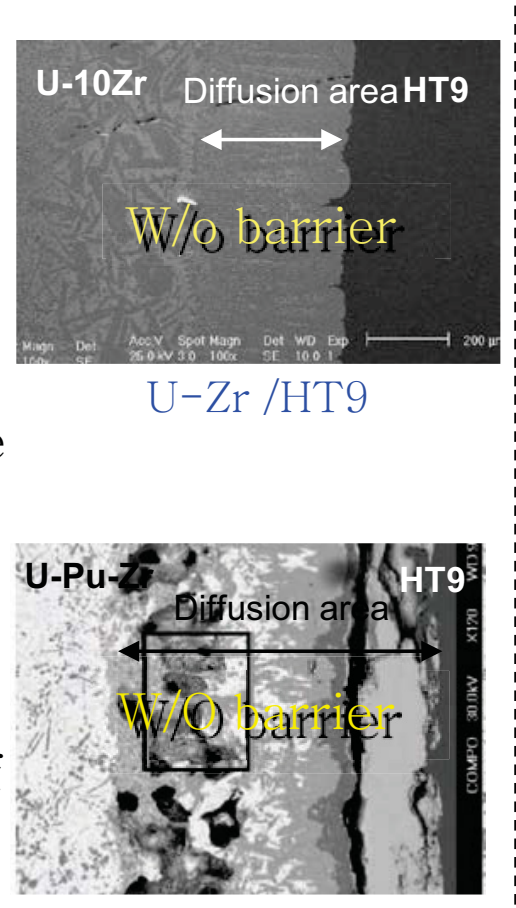

$\mathrm{U}-\mathrm{Pu}-\mathrm{Zr} / \mathrm{HT} 9$

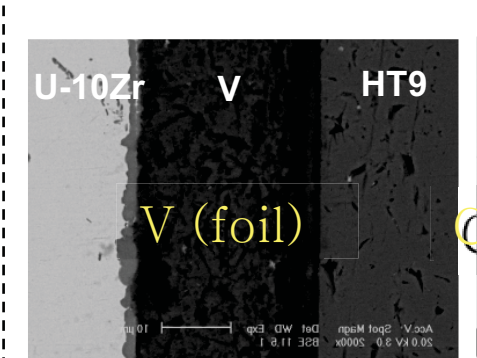

$\mathrm{U}-\mathrm{Zr}$ /barrier

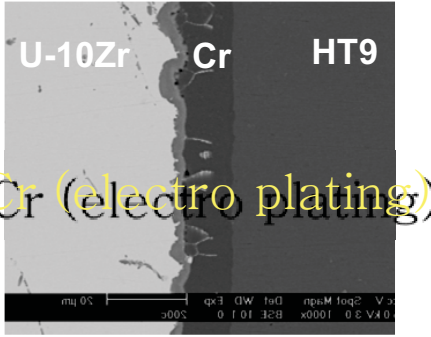

$\left(800^{\circ} \mathrm{C}, 25 \mathrm{hrs}\right)$

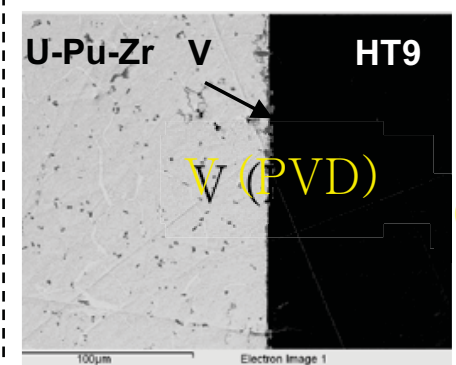

U-Pu-Zr

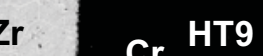

$\mathrm{U}-30 \mathrm{Pu}-20 \mathrm{Zr} /$ barrier $\left(750^{\circ} \mathrm{C}, 24 \mathrm{hrs}\right)$

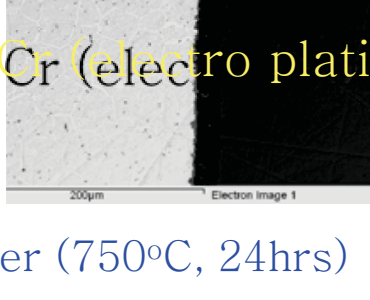

Cr HT9

\section{$\lg )$}
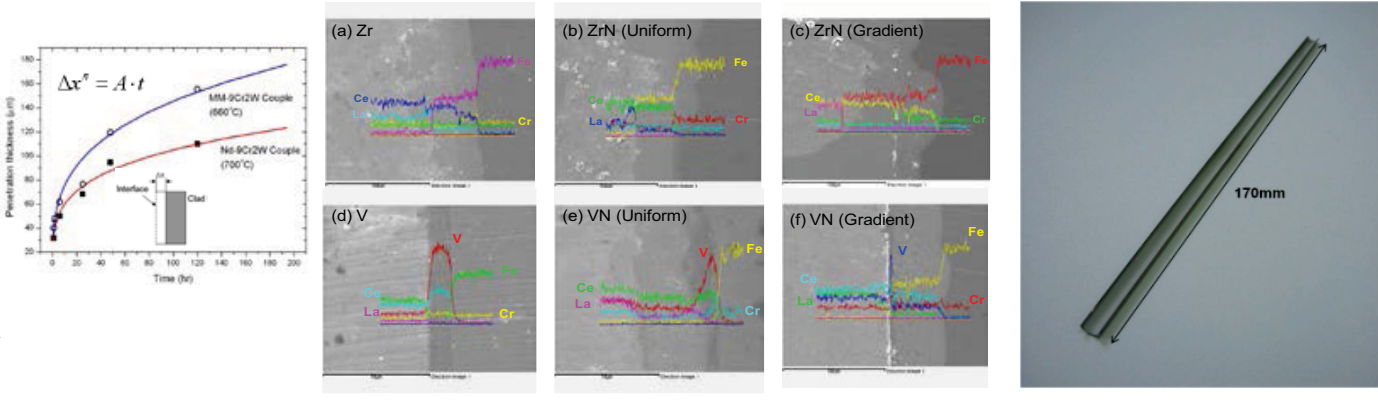

Diffusion couple test of RE/cladding/barrier material
Cr Barrier tube for Irradiation Test 


\section{Destructive test-FCCI test}

- Purpose: Fuel-cladding chemical interaction test with irradiated fuel

- Application:

$>$ Evaluate $\mathrm{FCCl}$ behavior

Equipment and Methods

$>$ Diffusion couple test in shielded globe box

- Schedule to Begin Activity

$>$ 2013.07

Issues for PIE, modeling and design

$>$ Upgrade of Diffusion couple methods

- Design and fabrication of device for diffusion couple test

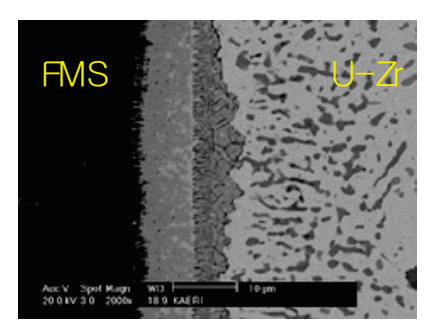

$700^{\circ} \mathrm{C} \rightarrow$ Diffusion layer

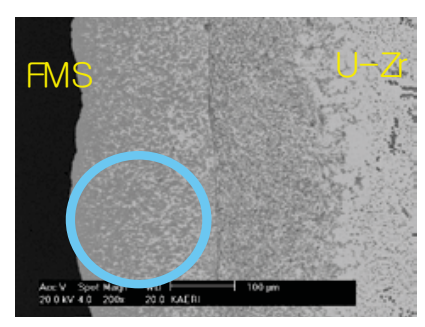

$740^{\circ} \mathrm{C} \rightarrow$ Eutectic

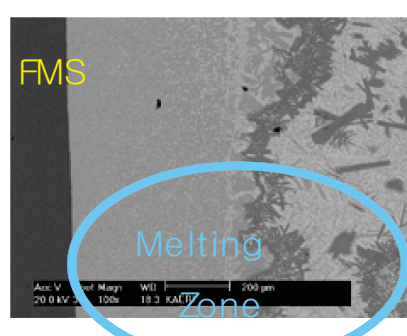

$800^{\circ} \mathrm{C} \rightarrow$ Eutectic
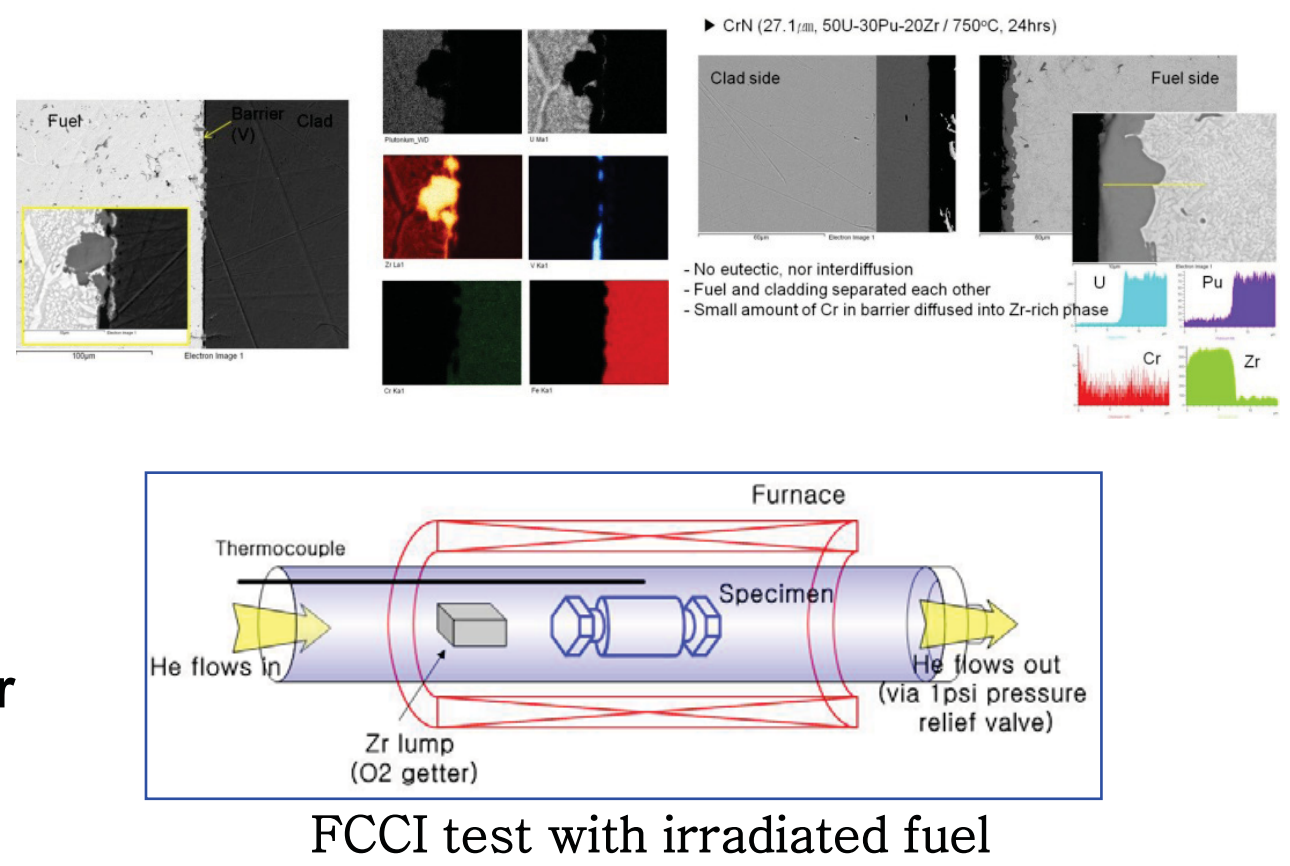


\section{Destructive test- Annealing test}

- Purpose: Behaviors of swelling and fission gas release during simulated transient tests with irradiated fuel

- Application:

$>$ check the fission gas behaviors during transient state.

- Equipment and Methods

$>$ Annealing furnace

$>$ heated up to the high temperature range (less than $1000^{\circ} \mathrm{C}$ )

- Schedule to Begin Activity

$>$ 2013. 07

口 Issues for PIE, modeling and design

$>$ Measurement of swelling behavior related to fission gas bubble behavior
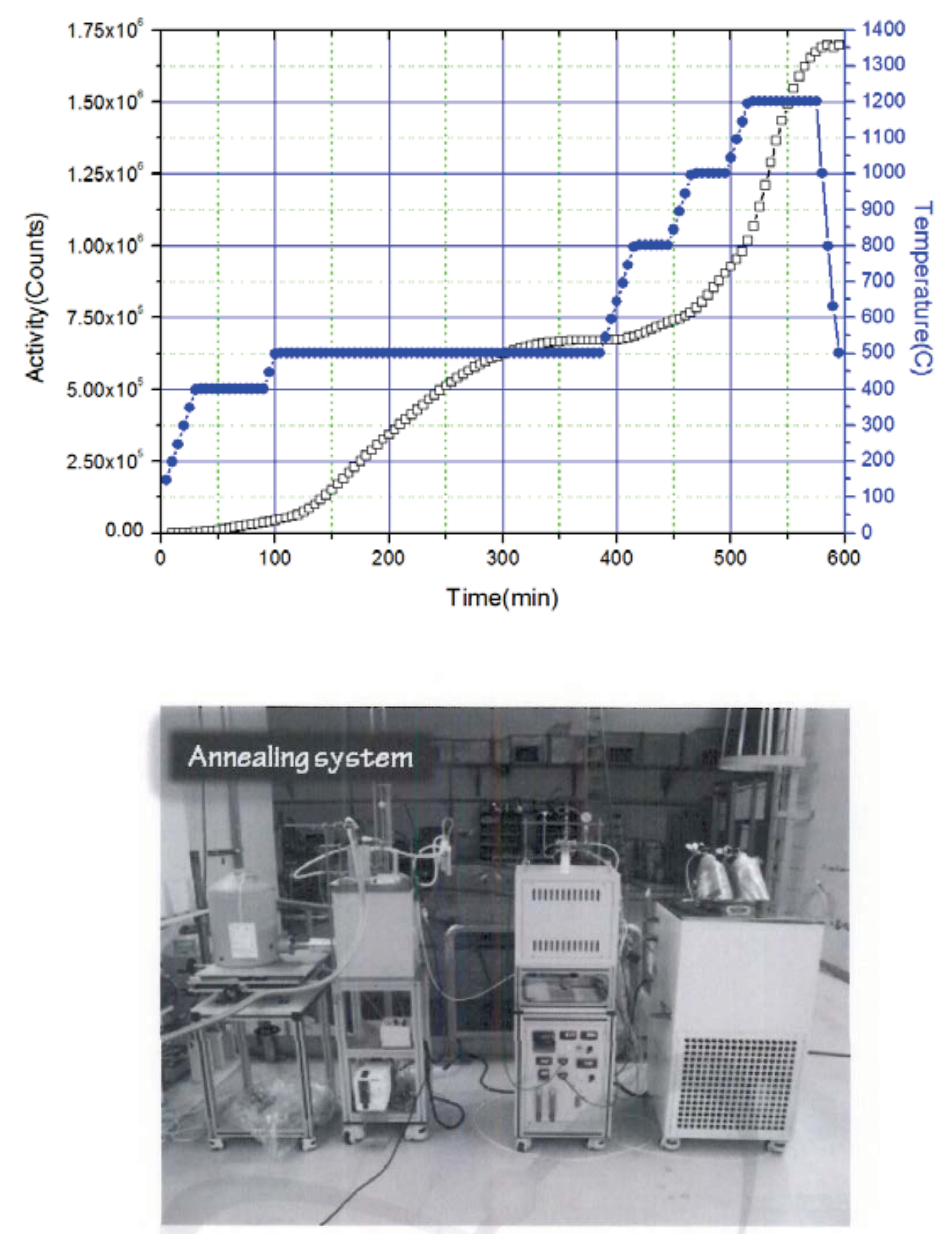


\section{Outstanding results in IMEF and PIEF}

\begin{tabular}{|c|c|c|c|c|}
\hline Origin & Item & $\begin{array}{l}\text { Duration } \\
\text { (yr) }\end{array}$ & Purpose & Remark \\
\hline \multirow{5}{*}{$\begin{array}{l}\text { Fuels } \\
\text { for National } \\
\text { R\&D Projects }\end{array}$} & $\begin{array}{l}\text { Advanced } \\
\text { Research Reactor Fuels }\end{array}$ & $\begin{aligned} & 2001 \\
& \sim \text { Cont'd } \\
&\end{aligned}$ & $\begin{array}{l}\text { - Evaluation of the atomized U-Mo fuels (4 phases) } \\
\text { - Reaction layers, swelling, burn-up measurements etc }\end{array}$ & \\
\hline & HANARO Fuel Assemblies & $\begin{array}{l}1998 \sim ~ \\
2003\end{array}$ & $\begin{array}{l}\text { - Evaluation of the dispersed U-Si fuels ( } 3 \text { assemblies) } \\
\text { - Burn-up distributions, shape deformations etc }\end{array}$ & \\
\hline & DUPIC Fuel Rigs & $\begin{array}{l}2003 \sim \\
2007\end{array}$ & $\begin{array}{l}\text { - Analysis of the irradiation behaviors ( } 6 \text { phases) } \\
\text { - Burn-up, shape deformation, fuel distributions etc }\end{array}$ & \\
\hline & SMART Fuels & $\begin{array}{l}2002 \sim \\
2007\end{array}$ & $\begin{array}{l}\text { - Evaluation of the SMART U-Zr fuels (3 phases) } \\
\text { - Burn-up, composition distribution, blistering etc }\end{array}$ & \\
\hline & Double Cooled Annular Fuels & $\begin{aligned} & 2009 \\
\sim & \text { Cont'd }\end{aligned}$ & $\begin{array}{l}\text { - Analysis of the advanced fuel meat shape fuels } \\
\text { - Dimension, burn-up, composition distribution etc }\end{array}$ & \\
\hline \multirow{2}{*}{$\begin{array}{l}\text { Fuels for } \\
\text { Power Plants }\end{array}$} & $\begin{array}{l}\text { Defected Fuels } \\
\text { from all PWRs in Korea }\end{array}$ & $\begin{aligned} & 1987 \\
\sim & \text { Cont'd }\end{aligned}$ & $\begin{array}{l}\text { - Cause analysis of the defective fuels (10 assemblies) } \\
\text { - Damaged surface investigation, non-destructive etc }\end{array}$ & PIEF \\
\hline & Advanced PWR Fuels & $\begin{aligned} & 2004 \\
\sim & \text { Cont'd }\end{aligned}$ & $\begin{array}{l}\text { - In-reactor behavior analysis ACE-7, PLUS-7 FA's } \\
\text { - Burn-up, cladding integrity, dimensional change etc }\end{array}$ & PIEF \\
\hline \multirow{4}{*}{$\begin{array}{l}\text { Materials for } \\
\text { National } \\
\text { R\&D Projects }\end{array}$} & $\begin{array}{l}\text { Gen-IV Reactor Core \& } \\
\text { Structural Materials }\end{array}$ & $\begin{aligned} & 2001 \\
\sim & \text { Cont'd }\end{aligned}$ & $\begin{array}{l}\text { - Analysis of the future reactor materials ( } 6 \text { times) } \\
\text { - Tensile, creep, facture surface analysis etc }\end{array}$ & \\
\hline & $\begin{array}{c}\text { New } \\
\text { PWR Vessel Materials }\end{array}$ & $\begin{aligned} & 2007 \\
\sim & \text { Cont'd }\end{aligned}$ & $\begin{array}{l}\text { - Analysis of the future PWR vessel materials (4 times) } \\
\text { - Tensile, fracture, impact etc }\end{array}$ & \\
\hline & PWR Fuel Skeletons & $\begin{aligned} & 2008 \\
\sim & \text { Cont'd }\end{aligned}$ & $\begin{array}{l}\text { - Behavior evaluation of the skeleton parts ( } 3 \text { skeletons) } \\
\text { - Mechanical tests for nozzle, control rod, cladding etc }\end{array}$ & \\
\hline & SMART S/G Tube Materials & $\begin{aligned} & 2009 \\
\sim & \text { Cont'd }\end{aligned}$ & $\begin{array}{l}\text { - Irradiation evaluation on the tube materials ( } 3 \text { capsules) } \\
\text { - Tensile, fracture, thermal conductivity etc }\end{array}$ & \\
\hline \multirow{3}{*}{$\begin{array}{l}\text { Materials for } \\
\text { Power Plants }\end{array}$} & $\begin{array}{l}\text { Reactor Vessel } \\
\text { Surveillance Program }\end{array}$ & $\begin{aligned} & 1998 \\
\sim & \text { Cont'd }\end{aligned}$ & $\begin{array}{l}\text { - Reactor vessel aging managements (16 reactors) } \\
\text { - Impact, tensile, chemical composition analysis etc }\end{array}$ & \\
\hline & $\begin{array}{l}\text { Life Extension Assessment } \\
\text { of Kori-1 Reactors }\end{array}$ & $\begin{array}{l}2003 \sim \\
2006\end{array}$ & $\begin{array}{l}\text { - Integrity evaluations of reactor vessel weldments } \\
\text { - Impact, fracture etc }\end{array}$ & \\
\hline & CANDU Pressure Tube Aging & $\begin{array}{l}2001 \sim \\
2005\end{array}$ & $\begin{array}{l}\text { - Evaluation of the operated pressure tubes ( } 2 \text { tubes) } \\
\text { - Tensile, fracture, DHCV etc }\end{array}$ & \\
\hline
\end{tabular}




\section{Future PIE plan of IMEF}

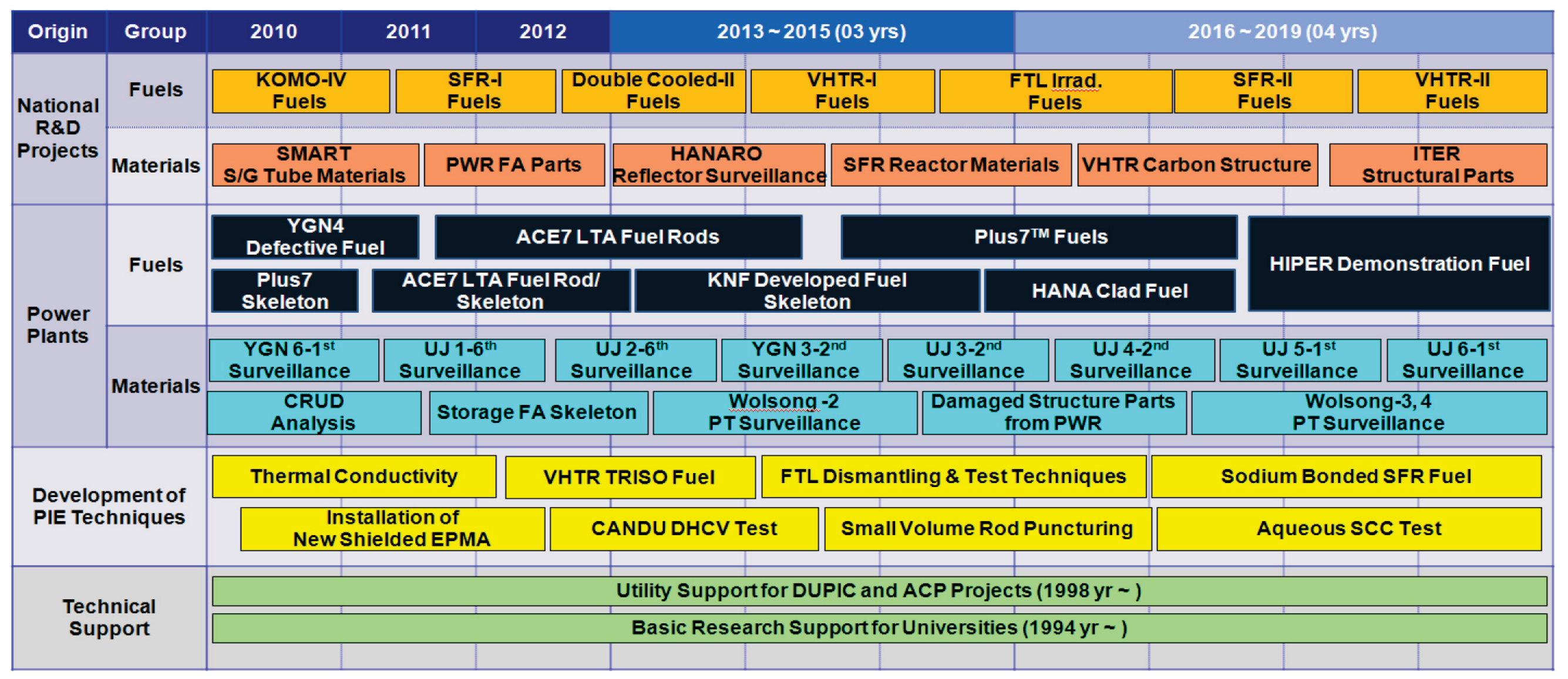


4 CONCLUSIONS 


\section{Conclusions}

DMetallic fuel development for SFR started in 2007

$\square$ Irradiation in HANARO : 2010.11

$\square$ PIE will be carried out in IMEF

$>$ Totally 8 hot cells with $72 \mathrm{~m}$ in a hot cell length, 1 pool, 2 hot lab's and 31 working units ( 31 windows)

DPIE of SFR metal fuel

$>$ PIE considering $\mathrm{Na}$ treatment

$>$ System for FGR measurement

$>$ In-reactor Behavior only for SFR metal fuel such as FCCI, Fuel constituent migration etc

$\square$ Continuous experimental tests needed

$\rightarrow$ for verifying the performance of metal fuel

$\rightarrow$ International collaborations are essential 


\title{
United States Perspective on Post-Irradiation Examination Capabilities
}

OECD/NEA International Workshop

\author{
Dennis Miotla \\ Deputy Assistant Secretary for \\ Nuclear Facility Operations \\ U.S. Department of Energy
}

June 16, 2011 
- We are in the stage of identifying what capabilities are needed; what are the gaps in the United States (U.S.) and international research communities

- We want to complement, not compete, with capabilities that already exist or are planned world-wide

- We plan to invest in PIE capabilities and facilities that are:

- adaptable to changing technologies,

- sustainable, given the constant demand on limited resources, and

- accessible to researchers world-wide

DOE-Office of Nuclear Energy is working to establish an enduring capability for nuclear energy research in the U.S. 


\section{Advancements in PIE Capabilities}

Nuclear Energy

-During the past 15 years, stunning advancements in analytical research instrumentation have been made

- Nano-scale (10-9 meter) characterization of materials is becoming routine, with capabilities for sub-angstrom (10-10 meter) investigation increasing

- Examples of new capabilities of interest to Department of Energy include:

- Nano-indenter (have)

- Laser Resonant Ultrasonic Spectroscopy

- Dilatometer

- Scanning Thermal Diffusivity Microscope

- Analytical Transmission Electron Microscope (have)

- Dual Beam Focused Ion Beam (have)

- Local Electron Atom Probe (have)

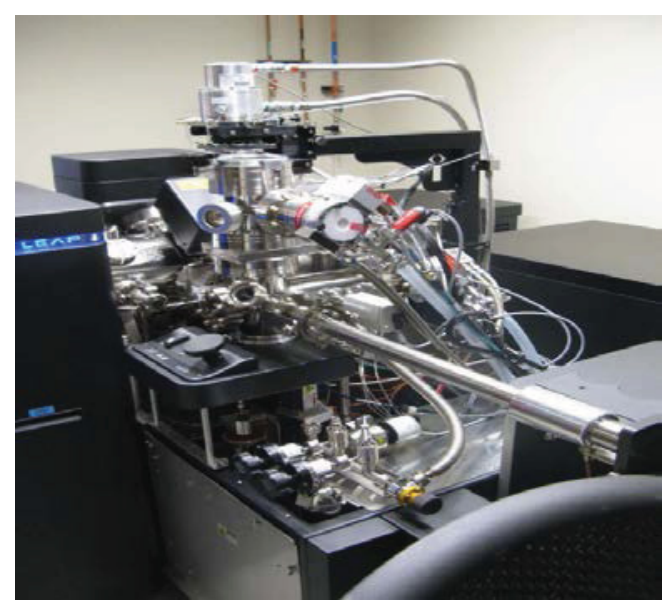

Atom Probe 
- Concentration on restoring the U.S. nuclear energy research capability to world-class status

- Consolidate and maximize existing capabilities wherever they may exist

- Co-locate new capabilities with existing infrastructure

- Increase international collaboration and make greater use of university capabilities

- Focus on the core capabilities, such as hot cell facilities, and specialized facilities needed to conduct post-irradiation examination and related mechanical testing
Examples of Existing PIE Capabilities at U.S. National Laboratories

\begin{tabular}{|l|l|}
\hline \multicolumn{1}{|c|}{ U.S. Location } & \multicolumn{1}{|c|}{ PIE Capabilities } \\
\hline $\begin{array}{l}\text { Idaho National } \\
\text { Laboratory }\end{array}$ & $\begin{array}{l}\text { - On-site irradiation capability at } \\
\text { the Advanced Test Reactor } \\
\text { - Large, heavily shielded hot cells } \\
\text { capable of handling full-size fuel } \\
\text { assemblies and elements } \\
\text { - Analytical laboratories with fuel } \\
\text { examination capabilities } \\
\text { - Specialized PIE equipment }\end{array}$ \\
\hline $\begin{array}{l}\text { Los Alamos } \\
\text { National }\end{array}$ & $\begin{array}{l}\text { accommodate research quantities } \\
\text { of materials } \\
\text { - Analytical laboratory capabilities }\end{array}$ \\
\hline $\begin{array}{l}\text { Oaboratory } \\
\text { Oational }\end{array}$ & $\begin{array}{l}\text { - On-site irradiation capability at } \\
\text { the High Flux Isotope Reactor } \\
\text { - Hot cells with ability to } \\
\text { Laboratory }\end{array}$ \\
$\begin{array}{l}\text { accommodate research quantities } \\
\text { of materials } \\
\text { - Analytical capabilities for } \\
\text { material characterization }\end{array}$
\end{tabular}


Nuclear Energy

- Re-baselined PIE capabilities to ensure linkages to Research and Development needs

- Procured state of the art PIE equipment to support missions

- Constructing Irradiated Materials Characterization Laboratory to house state-of- the art PIE/analytical equipment with environmental control

- Refurbishing hot cells and supporting infrastructure
Irradiated Materials Characterization Laboratory

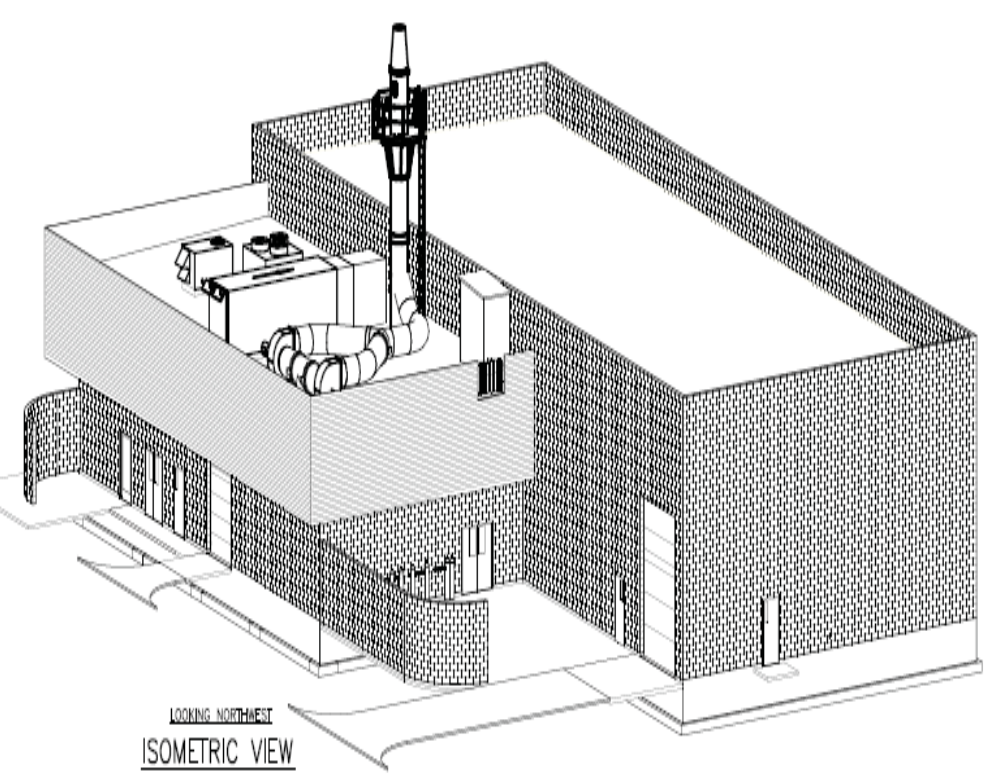

Goal: By 2013 provide comprehensive PIE capabilities to match current world status 
- Formally identified the gap in long-term PIE needs in January 2011

- Requested funds to conduct exploratory studies to assess possible advanced PIE capability options

- Held a United States PIE Workshop March 29-30, 2011, in Gaithersburg, Maryland, to identify the domestic needs for PIE to support advanced fuels and nuclear material development.

- Conclusions of workshop will be used to identify alternatives

- National PIE needs were identified from various perspectives, including universities, industry, vendors, Nuclear Regulatory Commission (NRC), Department of Energy (DOE), and DOE national laboratories

\section{We are interested in knowing the international perspective}




\section{Historical Funding Trend for Nuclear Energy Research and Development Activities}

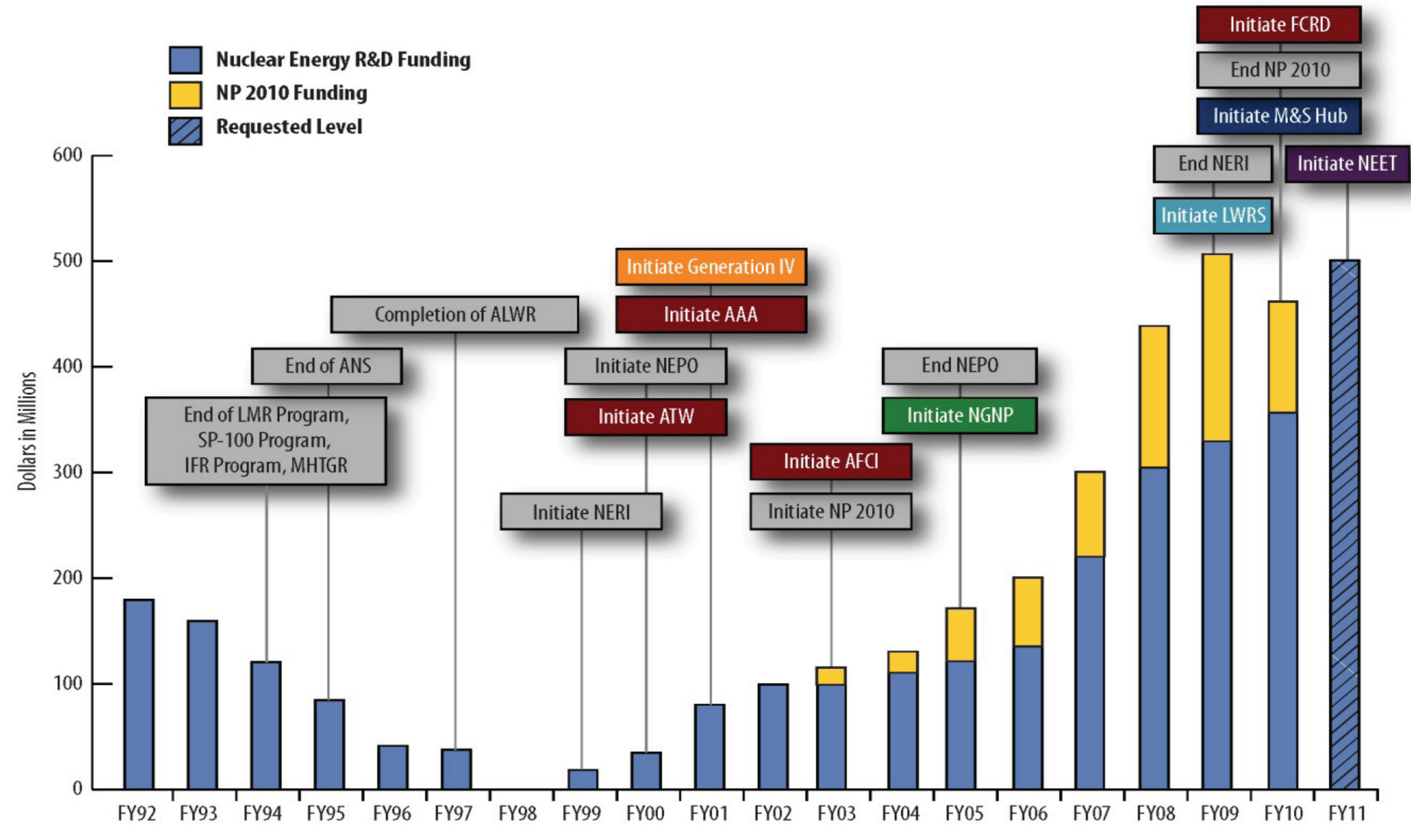




\section{Proposed Timeline for Establishing New Core and Enabling Capabilities at the Idaho National Laboratory} Nuclear Energy

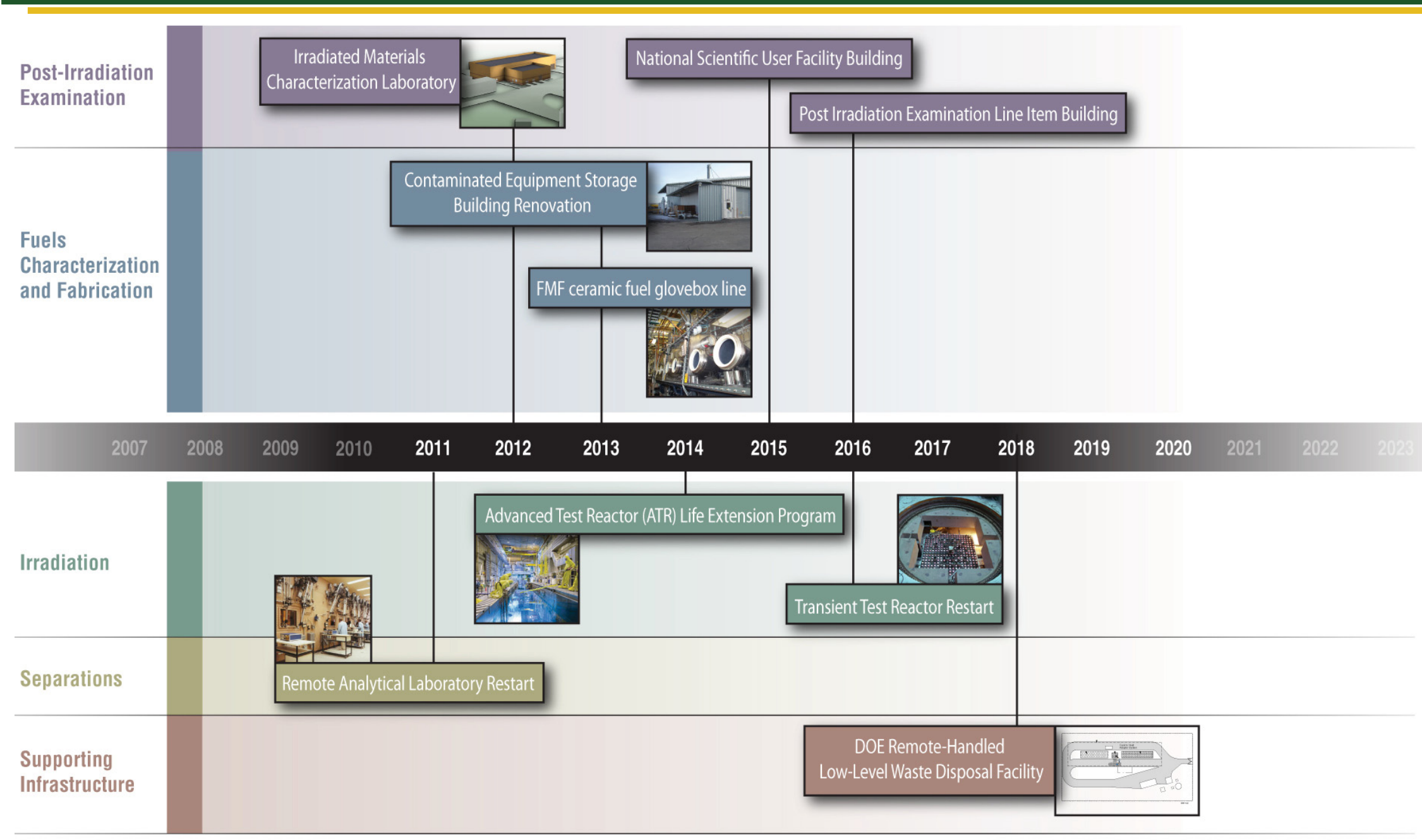


Nuclear Energy

- United States is engaging in PIE capabilities and is investing in near-term activities to complement the existing international suite

- Interested in looking toward the next generation of PIE capabilities to make smart investment decisions 
Nuclear Energy

\section{Questions?}




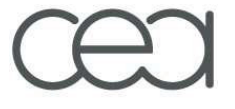

\section{Fuel performance code : \\ characterization and PIE needs for modeling validation.}

V. Bouineau,

CEA-Cadarache, Fuel studies department 


\section{Simulation: main issues}

- Interpretations of experiments conducted on nuclear fuel:

- Out of pile experiments

- In pile experiments

- Design of fuel elements:

- Fuel behavior improvements

- Innovative designs (fuel or nuclear systems)

- Design of experimental studies on irradiated fuels:

- Irradiation in SFR (Phenix, ...) and MTRs

- Out of pile experiments

- $\quad$ Capitalization of acquired knowledge:

- Fuel Performance code like Germinal (SFR) 


\section{Modeling: main challenges}

Physics and modeling to describe the behavior of fuel pins with mixed oxide fuel $(\mathrm{U}, \mathrm{Pu}) \mathrm{O}_{2}$

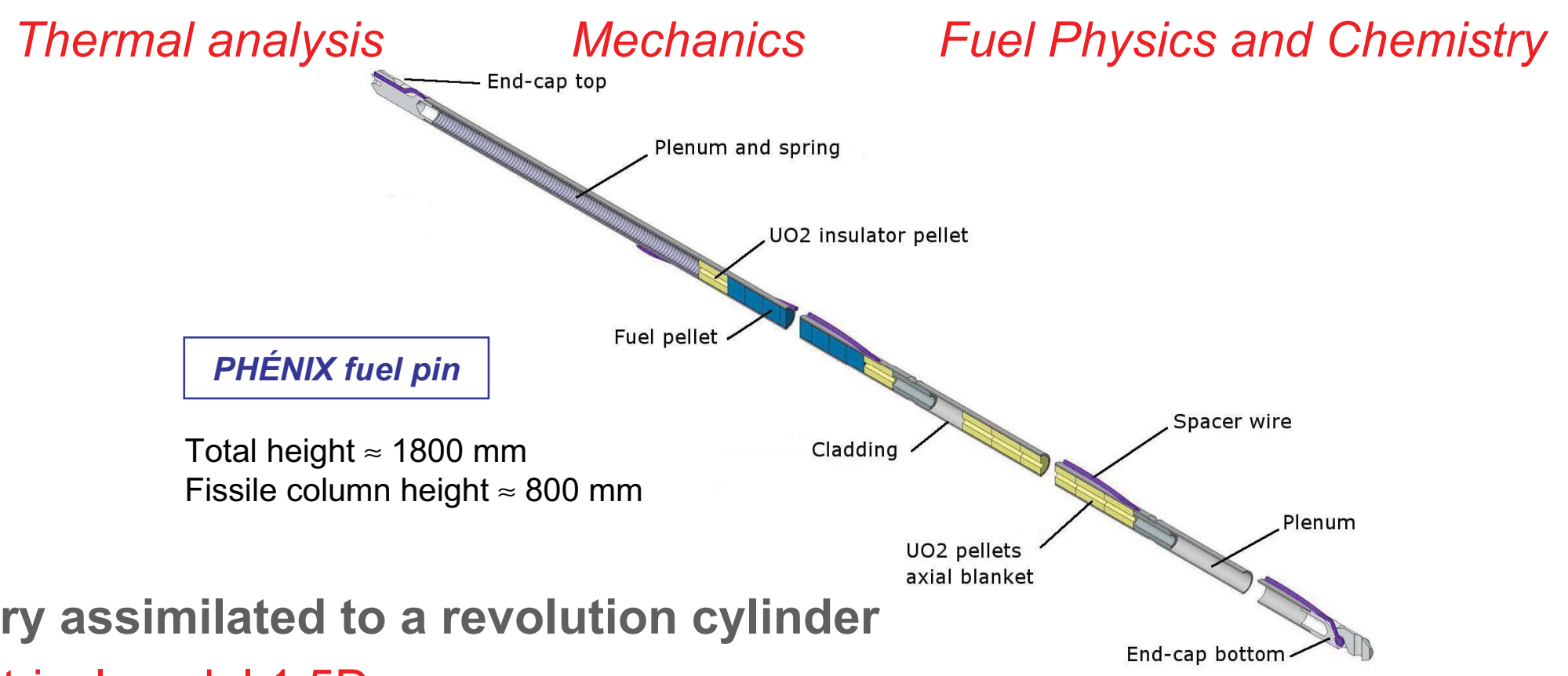

Geometry assimilated to a revolution cylinder

Axisymetrical model 1,5D :

End-cap bottom

$\checkmark$ Radial resolution coupling axial slices by thermalhydraulics in coolant

$\checkmark$ Similar as the model for PWR fuel rods

$\Rightarrow$ Benefits of recent work on PWR fuel rods simulation 


\section{Modeling: main challenges}

Physics and modeling to describe the behavior of fuel pins with mixed oxide fuel $(\mathrm{U}, \mathrm{Pu}) \mathrm{O}_{2}$

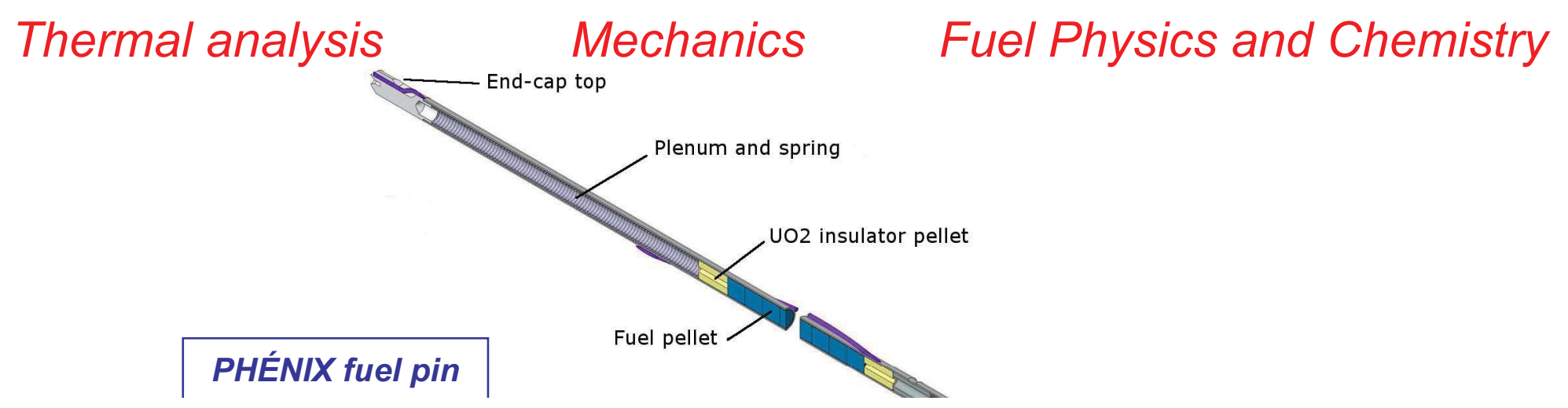

- Fuel element structural integrity

\section{Structural computation}

Thermo-mechanical state of the fuel element

- Fuel behavior

\section{Physico-chemical of irradiation}

Inventory and localization of fission products in the pellet 


\section{GERMINAL V2}

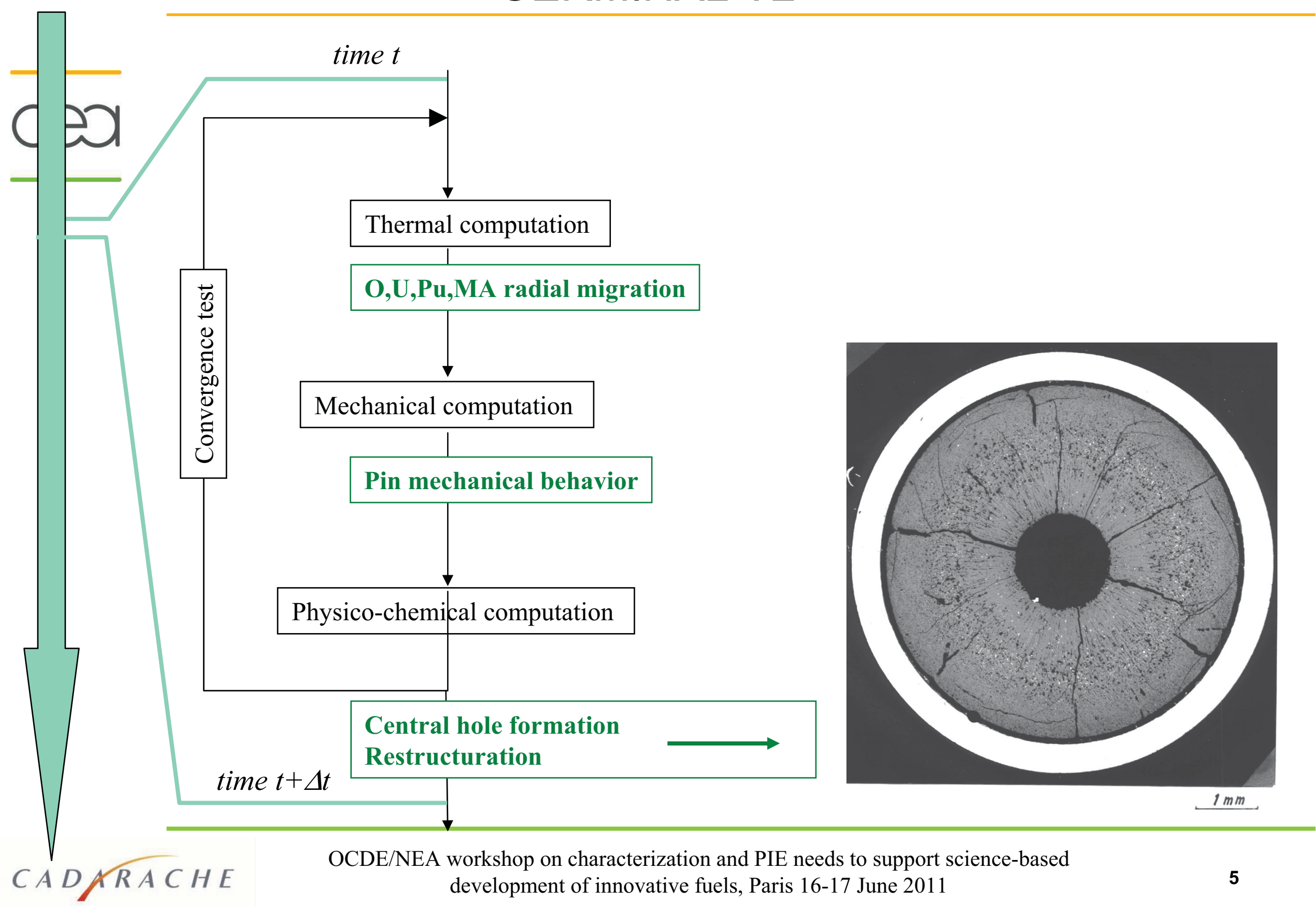




\section{Synthesis of couplings}

cen

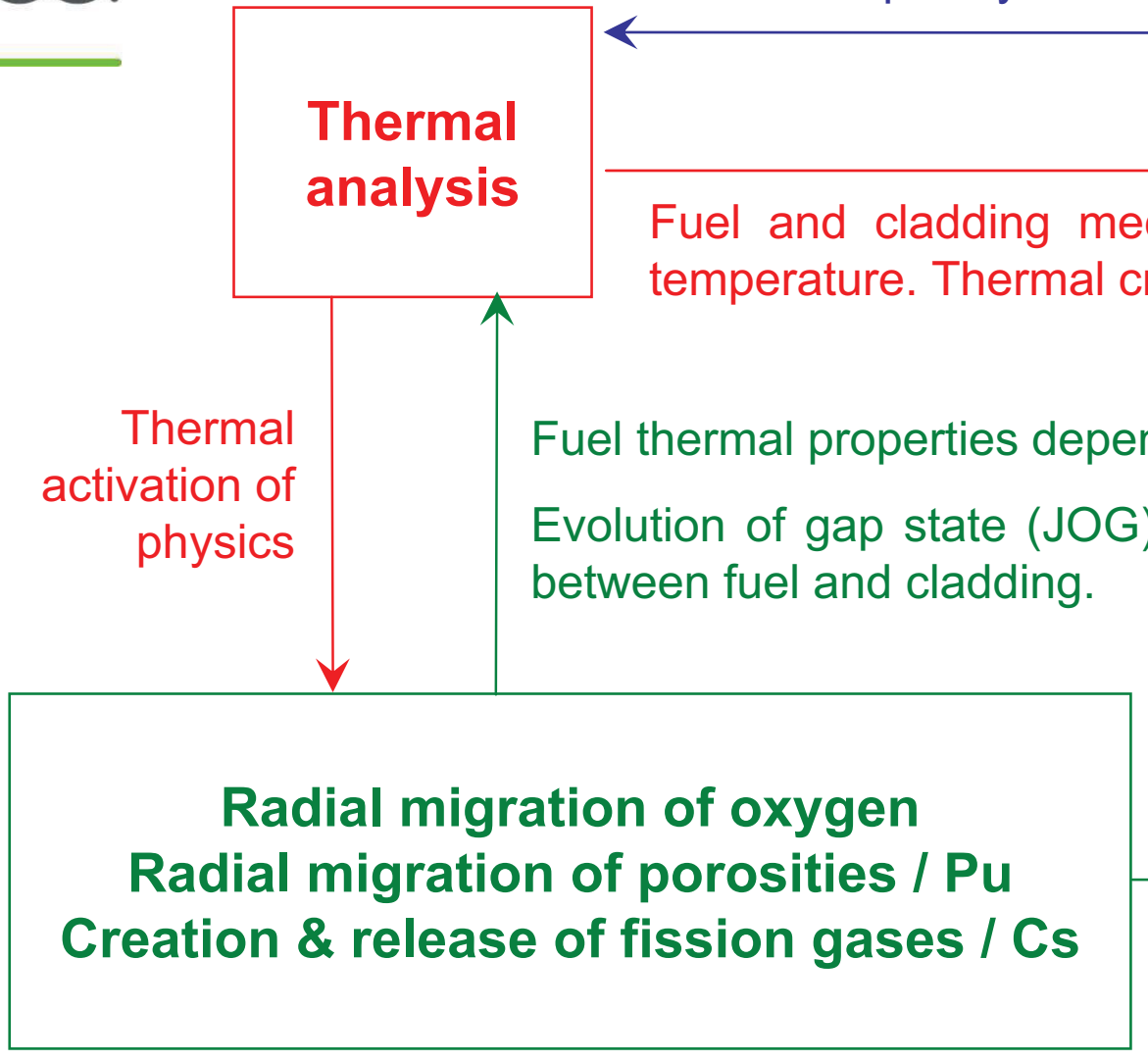

Fuel and cladding deformations modify the gap thickness

and consequently heat exchange.

Fuel mechanical properties depend on (O/M) and porosity.

Fuel swelling is modified by porosity migration and fission products release. 


\section{GERMINAL in PLEIADES}

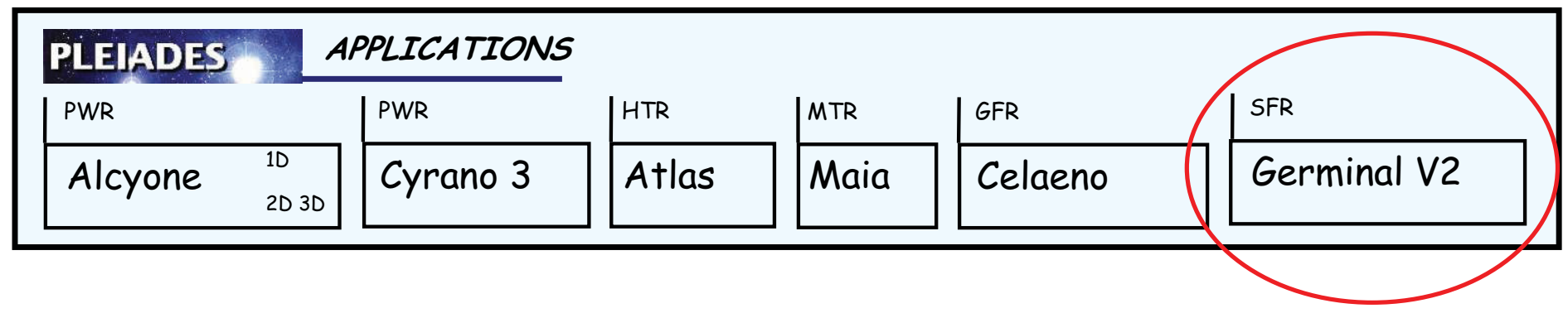

$>$ Federative unified framework to develop fuel performance codes Co-developed by CEA and eDF

Allows modeling advancement to be shared among all applications

Involves connexions with Data Bases :

$\checkmark$ Physical Data Base : Sirius $\Rightarrow$ Material properties

$\checkmark$ Validation Data Bases : CRACO (PWR rods), BREF (SFR pins)

Benefit of PLEIADES platform : Inheritance of mechanical behaviors modeling of PWR fuel rods materials 
- Homogeneous mode : 1-5\% MA in mixed oxide fuel $(\mathrm{U}, \mathrm{Pu}) \mathrm{O}_{2}$

- In core with high temperature

- Heterogeneous mode : $10-20 \%$ MA in uranium oxide fuel

- At the periphery of the core with low temperature

- On Inert Matrix : $10-20 \%$ MA on typically MgO

- At the periphery of the core with low temperature

- Main differences

- Higher production of Helium

- Modification of physical properties (oxygen potential, thermal conductivity, temperature of fusion, ...) 


\section{Experimental results on Am transmutation}

- SUPERFACT-1 in PHENIX (1988)

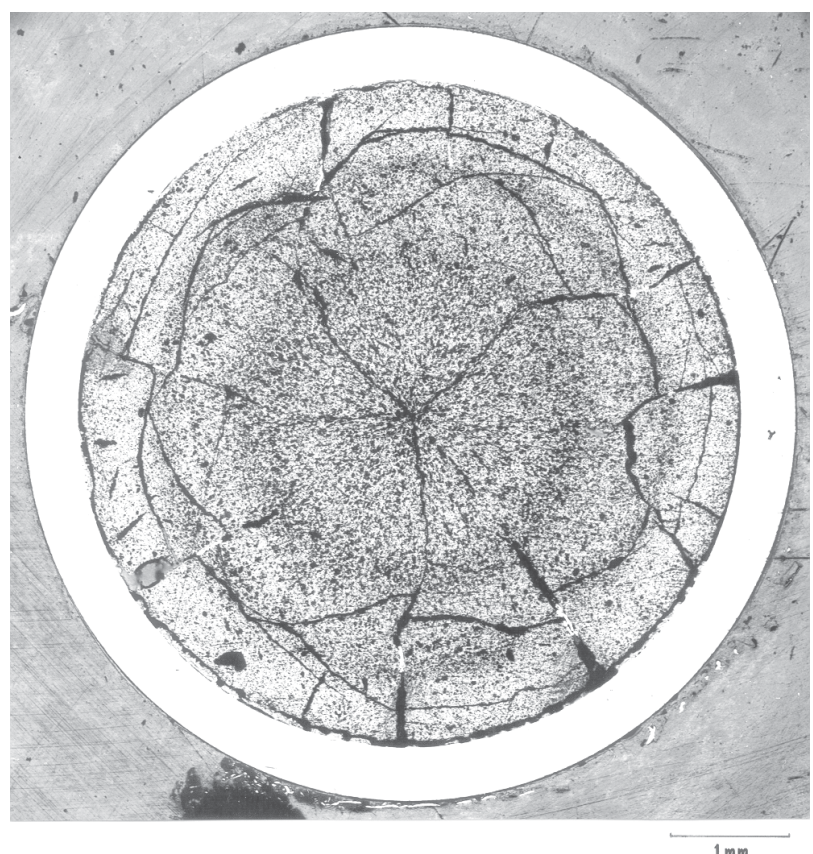

- Heterogeneous pin U,Am(20\%), Np(20\%)O $\mathrm{O}_{2}$ up to 4 at $\%$

- Cladding-fuel mechanical interaction ( cladding strain + circumferential cracks)

- No classical restructuration but large central region with porosity

$\rightarrow$ No correct fuel properties in actual code

- Experimental data are capitalized in database BREF (fabrication, irradiation and PIE) 


\section{Experimental results on Am transmutation}

- Experiment in inert matrix

- EFTTRA T4 and T4bis in HFR

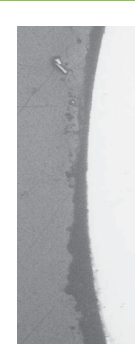

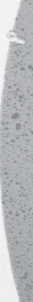

Edge

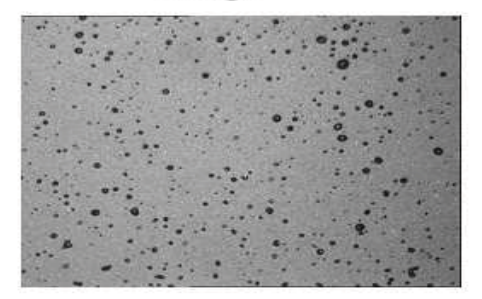

$\underline{50 \mathrm{\mu m}}$

Area porosity:

$\sim 5 \%$ $\sim 32 \%$
- Large swelling of 18 to $24 \%$

- Large helium retention $(80 \%)$

- Up to $32 \%$ of porosity locally 


\section{Specific development for Fuels with minor actinide}

- Homogeneous mode : $1-4 \% \mathrm{MA}$ in mixed oxide fuel $(\mathrm{U}, \mathrm{Pu}) \mathrm{O}_{2}$

- In core with high temperature
» Helium release
» Modification of Oxygen Potential
"Modification of $\mathrm{O}, \mathrm{Pu}, \mathrm{MA}$ Redistribution
"Impact on thermal conductivity
» Impact on cladding internal corrosion
» Impact on melting temperature

- Needs for physical properties on fresh and irradiated fuels

»Feed the Physical Data Base : Sirius 


\section{Specific development for Fuels with minor actinide}

- Heterogeneous mode : $10-20 \%$ MA in uranium oxide fuel

- On Inert Matrix : 10-20\% MA on typically MgO

- At the periphery of the core with low temperature

» Retention of Helium

"Impact on Gaseous Swelling

» No large Modification of Oxygen Potential

» No large Modification of $\mathrm{O}, \mathrm{Pu}, \mathrm{MA}$ Redistribution

" Impact on thermal conductivity

- Needs to model retention / release of helium and associated swelling

- Needs mechanical behavior of inert matrix

" Mechanics of heterogeneous microstructure

" He (and FP) implantation in inert matrix

- Very long irradiation time

» Impact on material properties of high damage 
He retention in $\mathrm{UO}_{2}$

On He implanted UO2 and NRA characterization

Labrim et al. NIMB 261 (2007)

At low dose

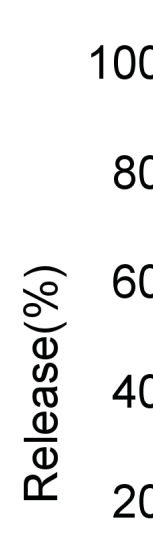

$00 \quad 0800^{\circ} \mathrm{C} 1 \mathrm{~h}$

- $1000^{\circ} \mathrm{C} 1$ minute

$80-$

$1000^{\circ} \mathrm{C} 1 \mathrm{~h}$

- Below $800{ }^{\circ} \mathrm{C}$ : Iow He mobility

- Above $800^{\circ} \mathrm{C}$ :

- Near grain boundary : defects annealing and large He mobility

- In grain : bubble formation

At large dose

- Below $1000^{\circ} \mathrm{C}$ : low He mobility - bubble formation

- Above $10000^{\circ}$ : large He mobility 


\section{Needs for code improvement and validation}

\section{- Models needs physical properties and behavior laws}

- Analytical experiments

- On simulated fuels to understand basic physico-chemicals behavior

- Analytical irradiation

- Some characteristics are fixed or adjusted during the irradiation and must be known also as function of radial (and axial) position.

- Integral or semi-integral irradiation

- Characteristics needed as function of radial and axial position.

- in the worse case after the fabrication and during PIE and in the best case all along the irradiation. 
- Irradiation conditions:

- Flux, spectrum, dose, power, temperature and thermal gradient, temperature and flow rate of the coolant

- Composition :

- Fuel composition : wt \% TRU, fission products, gases (helium and fission gases), impurities, stoechiometry $(\mathrm{O} / \mathrm{M})$

- Chemical form of each component : inside the fuel (single or multiple phases), interaction with others components (specially cladding), clad wastage

- Gas composition and pressure in the gap

- Microstructure:

- Density, porosity (open, closed, shape of porosity), grain size, columnar grain diameter, bubbles interconnection, cracks,

- Geometry:

- Fissile column length, pellet diameter, inner/outer clad diameter, fuel central hole, gap closure

- Properties (mainly but may be completed):

- Thermal conductivity and thermal expansion, melting point, eutectics, Young modulus, creep. 


\section{Conclusion for modeling fuel with MA}

- Improvement on modeling MUST BE COMPLETED with

- More accuracy on fabrication data and irradiation conditions

- Analytical experiments

- More instrumentation in core, especially in MTR (also in prototype?)

- More characterizations in hot cell

"To have good assessment of physical properties and behavior laws 


\section{Atomistic modeling for innovative fuels}

M. Freyss, B. Dorado, M. Bertolus, G. Martin R. Skorek, S. Maillard, P. Garcia,

Commissariat à l'Energie Atomique et aux Energies Alternatives (CEA)

Centre de Cadarache Fuel Study Department

Saint-Paul lez Durance, France 


\section{Context}

$>$ Increasing expectations for the modelling in order to improve existing nuclear fuels (U-Pu oxides,...) or to develop new innovative fuels (U-Pu carbides, transmutation targets...)

$>$ Atomistic modeling to get insight into elementary mechanisms of the behavior of point defects, fission products... at the atomic scale
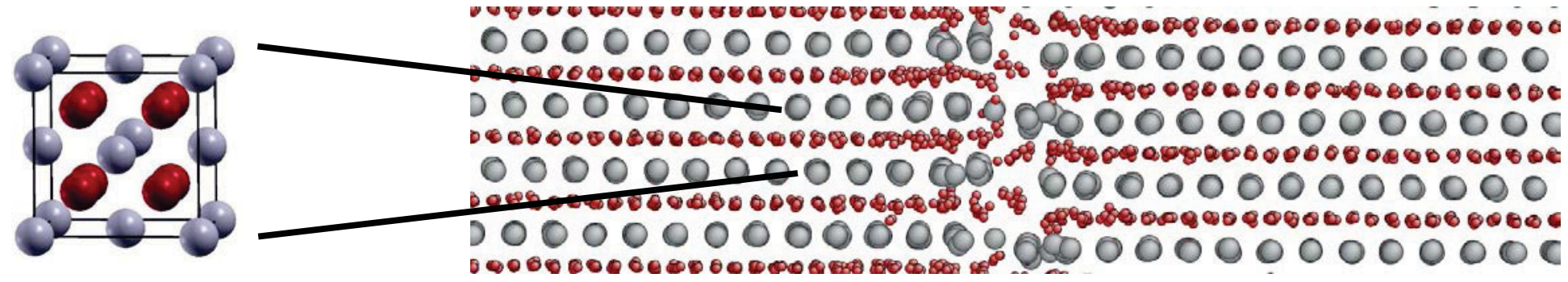

$>$ Direct links between methods (ab initio, MD, KMC, CD...) to take more realistically into account the microstructure of the material (grain boundaries, fission gas clusters, ....). Multi-scale approach needed for the material modeling

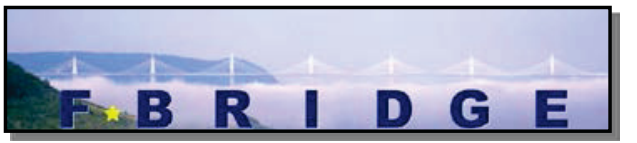

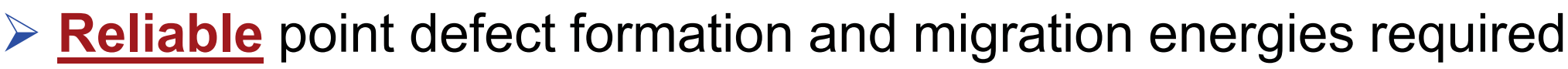




\section{Fission gas diffusion in nuclear fuels}
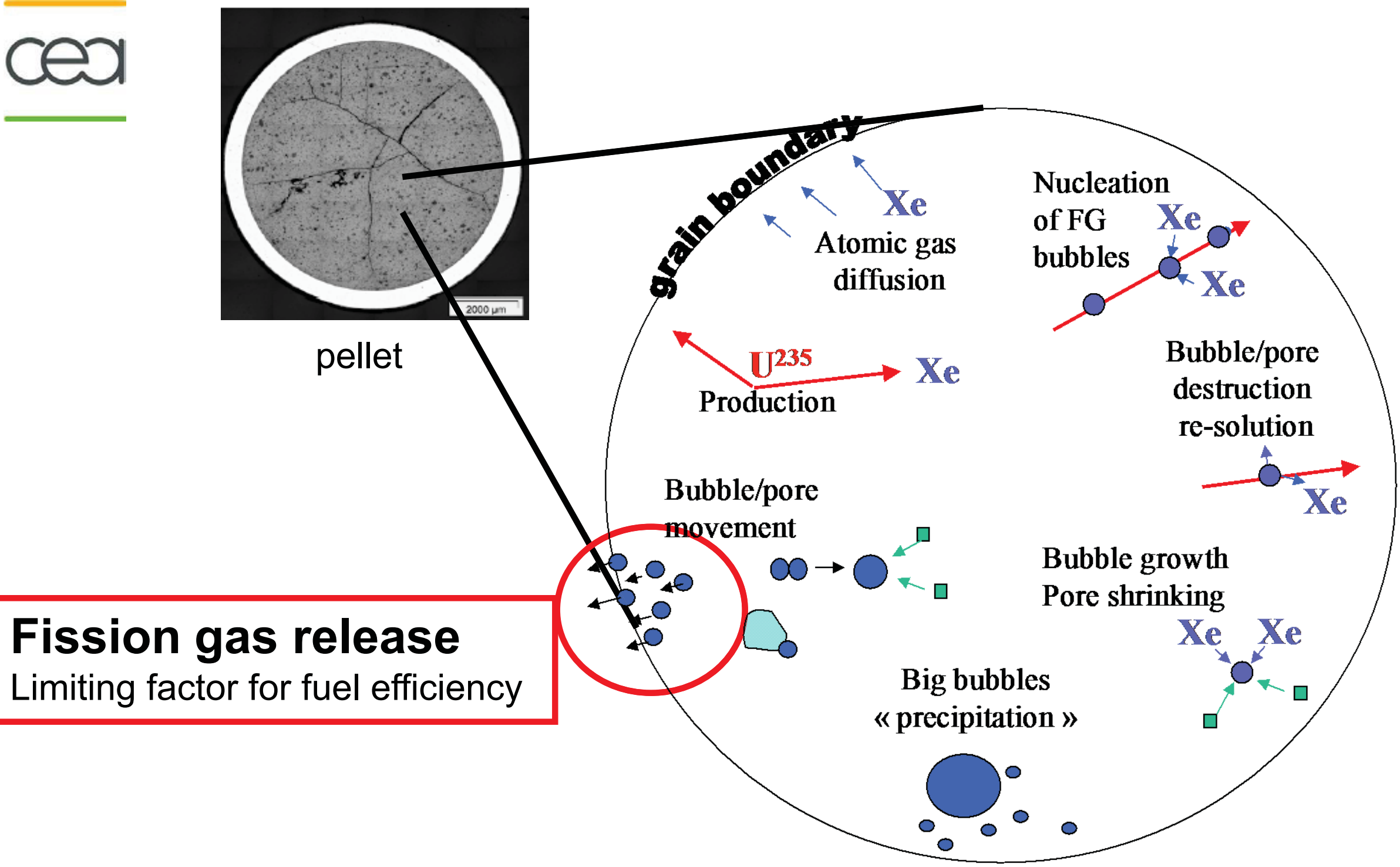


\section{Fission gas diffusion in nuclear fuels}

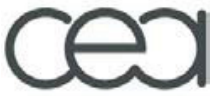

\section{Tendency of fission gases to migrate in the grain}

Atomistic calculations to get insight into the behaviour of fission gases at the atomic scale
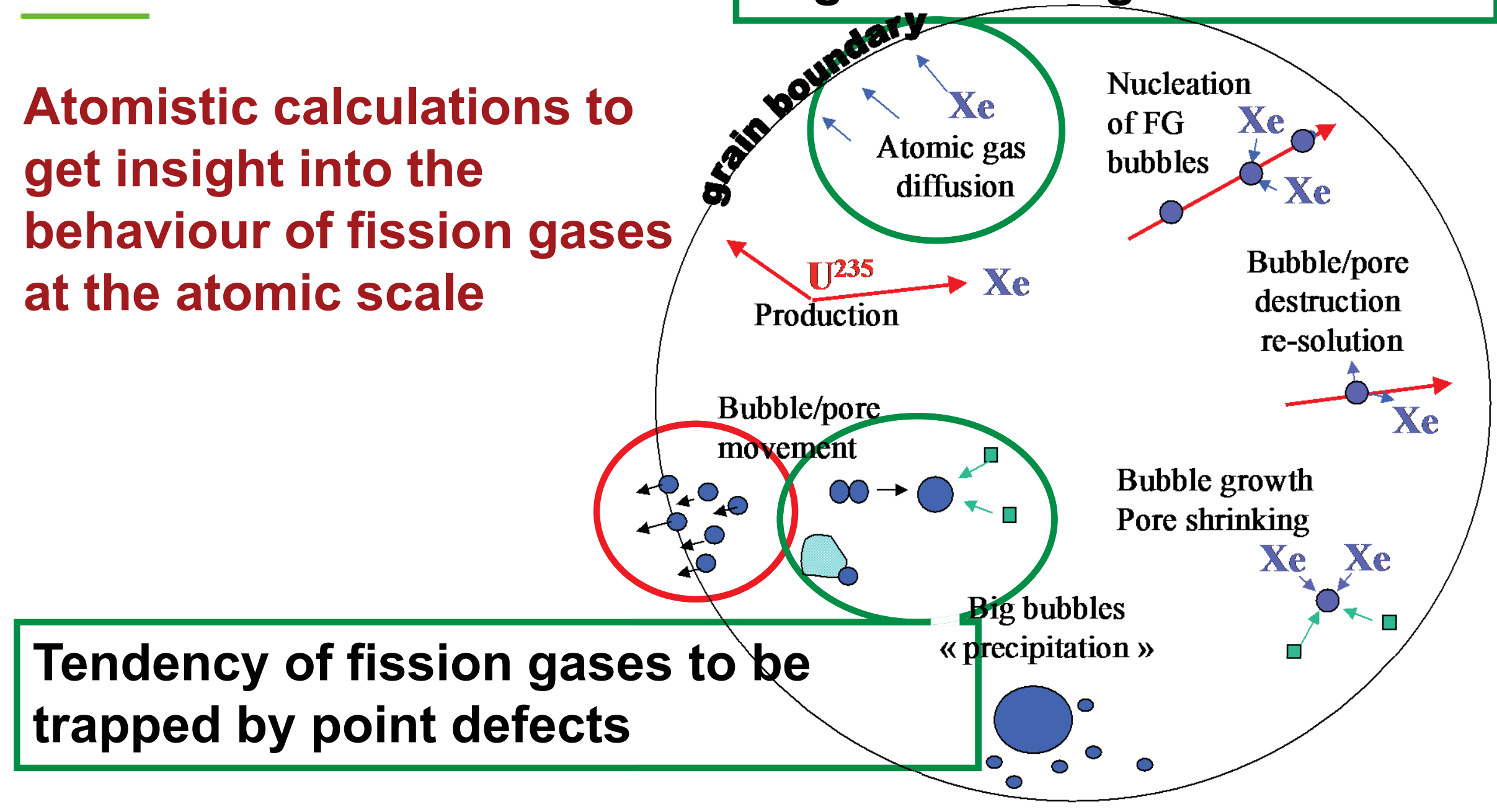


\section{Multi-scale modeling of nuclear fuels}

\section{Macroscopic scale \\ Microscopic scale}

- Thermodynamics

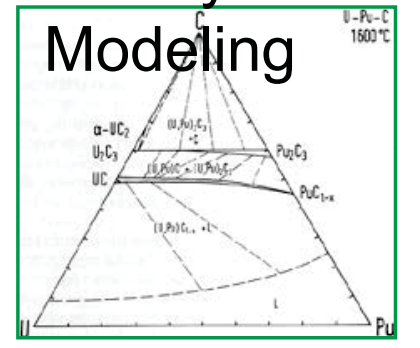

- Modeling of fission

-Modeling of fuel

behavior

Atomic scale

- Atomistic modeling of nuclear fuels:

structure, defect stability and fission gas behavior

gas behavior
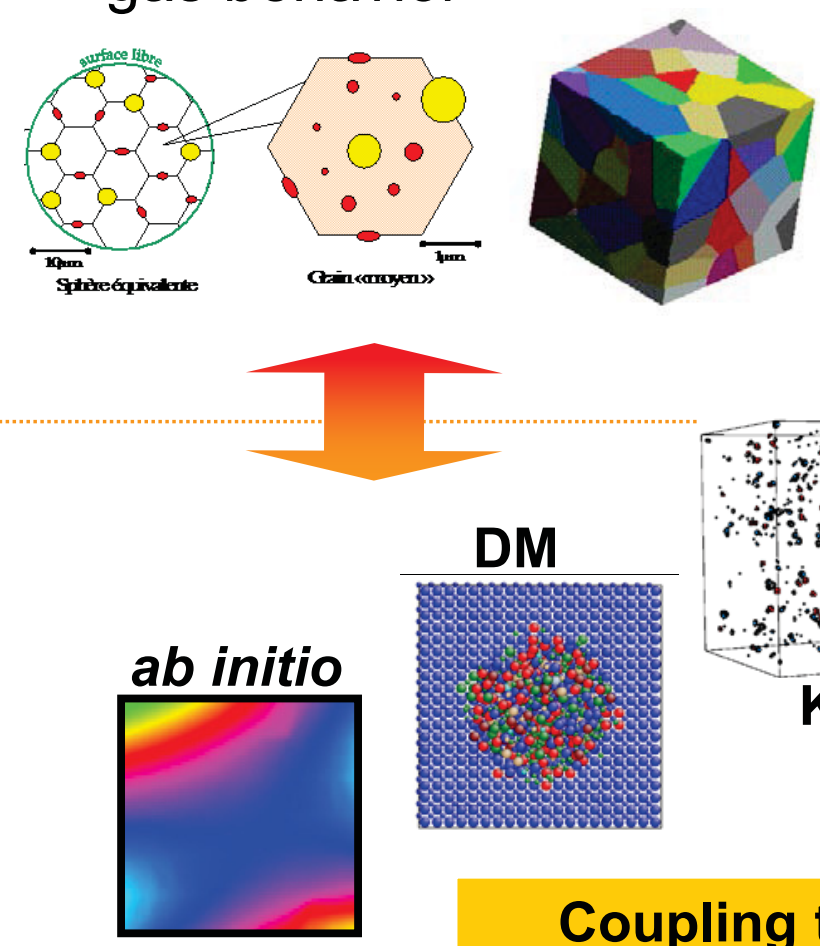

- Thermomechanical behavior laws of nuclear fuels

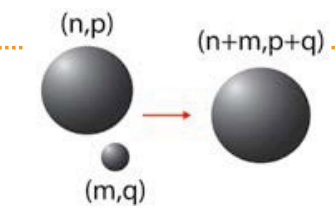

Cluster dynamics

Coupling to experimental studies 


\section{Multi-scale modeling of nuclear fuels}

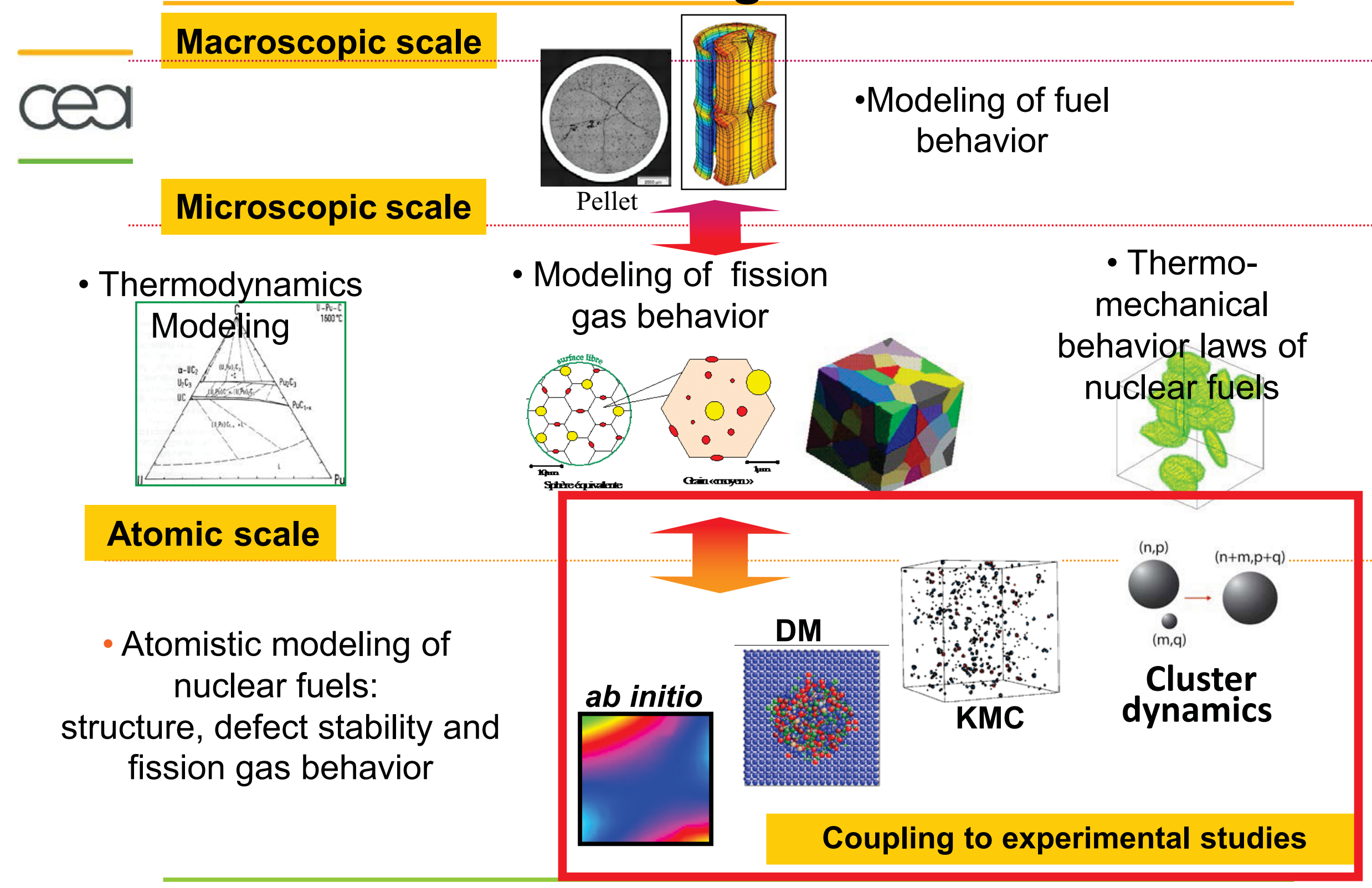




\section{Ab initio modeling: Density Functional Theory}

Quantum description of interaction between nuclei and electrons Schrödinger equation

$$
H \Psi(\vec{r})=E \Psi(\vec{r})
$$

Impossible to solve for systems with more than 1 electron !

\section{Method to solve it: transform it into a single electron problem}

Wave function $\psi$ for $N$ electrons $\rightarrow$ Wave functions for 1 electron $\varphi_{i}$

But retain description of the electronic interaction: important in bonding

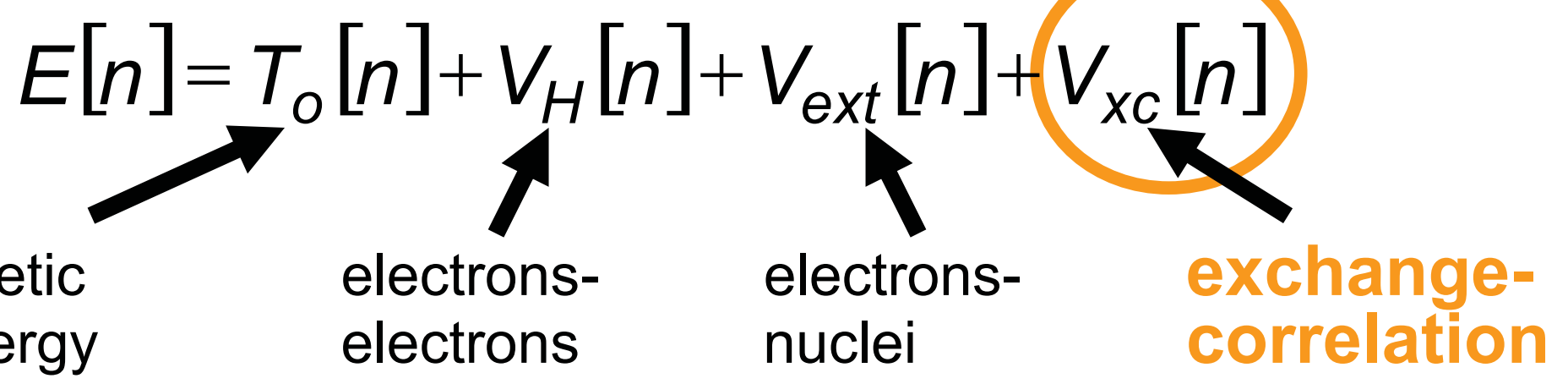
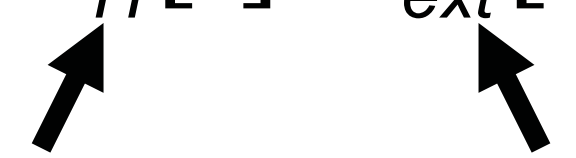

\section{exchange=}

kinetic energy 


\section{$A b$ initio modeling: Density Functional Theory}

\section{$5 f$ electron spatial localization in the actinide series}

ceal delocalized localized
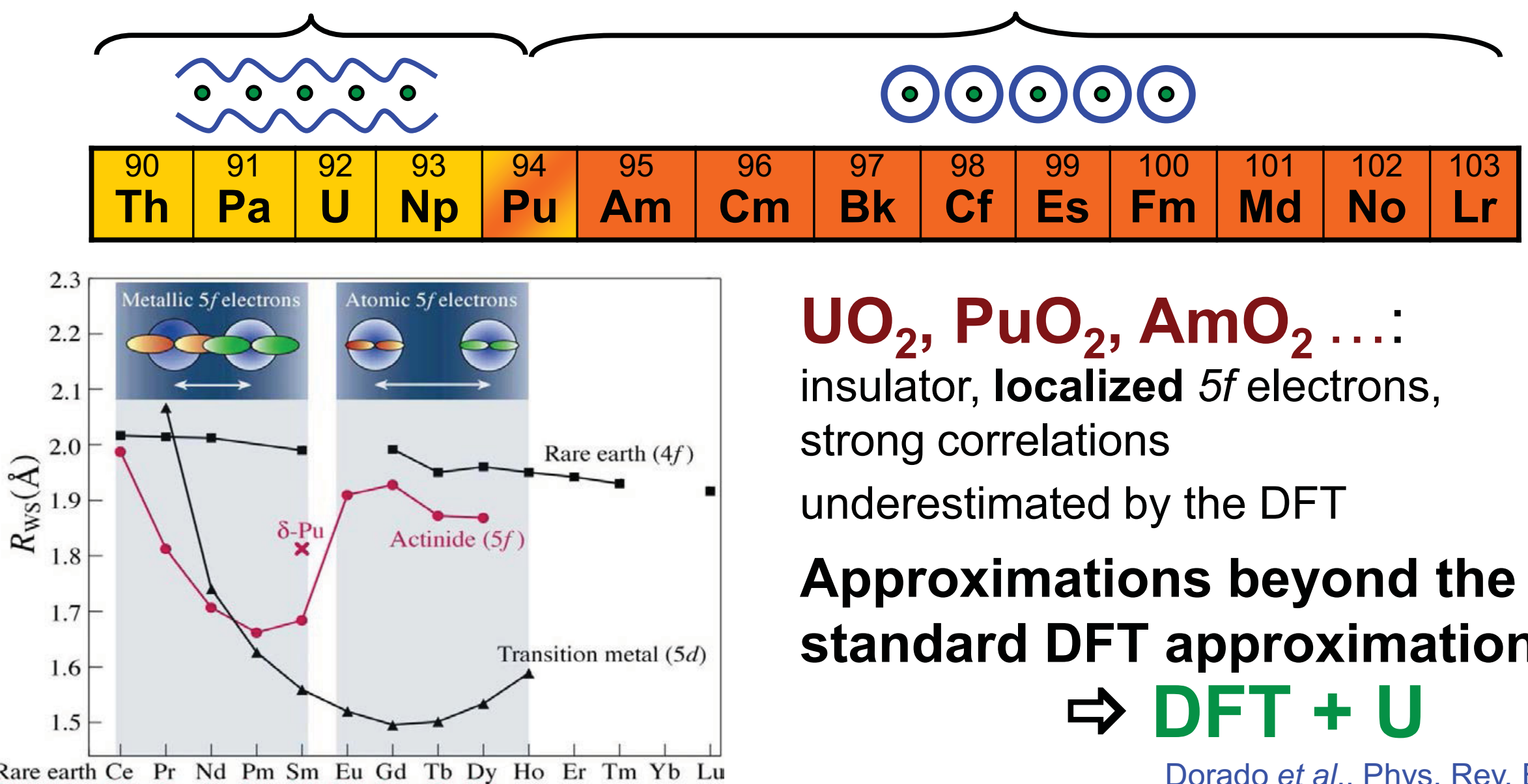

Actinide Th Pa U Np Pu Am Cm Bk Cf From Moore et al. Rev. Mod. Phys. 81, 235 (2009) $\begin{array}{lllllll}\text { Actinide } & \text { Th } & \text { Pa } & & \text { Np } & \text { Pu Am } \\ \text { Transition } & \text { La Hf Ta } & \text { W Re Os Ir Pt Au and Albers, Nature 410, 759 (2001). }\end{array}$

\section{$\mathrm{UO}_{2}, \mathrm{PuO}_{2}, \mathrm{AmO}_{2} \ldots$ :} insulator, localized $5 f$ electrons, strong correlations underestimated by the DFT

Approximations beyond the standard DFT approximations

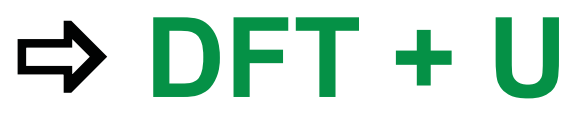

Dorado et al., Phys. Rev. B 79,235125 (2009) 


\section{Point defects and fission products in $\mathrm{AnO}_{2}$}

\section{-Type of defects}

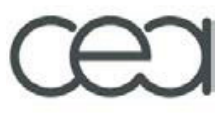

Vacancies, interstitials

Frenkel pairs (1 int. +1 vac.) Schottky defects

(1 vac. $A n+2$ vac. O)

Fission gases and helium kryton, xenon, iodine

Stability: formation energies, incorporation energies Migration: migration energies using the nudge elastic band (NEB) method

$\mathrm{UO}_{2}$ : Dorado et al., Phys. Rev. B 83, 035126 (2011) UC: Freyss, Phys. Rev. B 81, 014101 (2010)

Extension to other An oxides:

$\mathrm{PuO}_{2}, \mathrm{AmO}_{2}$ Freyss et al. JNM (2006)

$\mathrm{PuO}_{2}, \mathrm{NpO}_{2}$ Tiwary et al. Phys. Rev. B 83, 094104 (2011)
$2 \times 2 \times 2$ cubic supercells
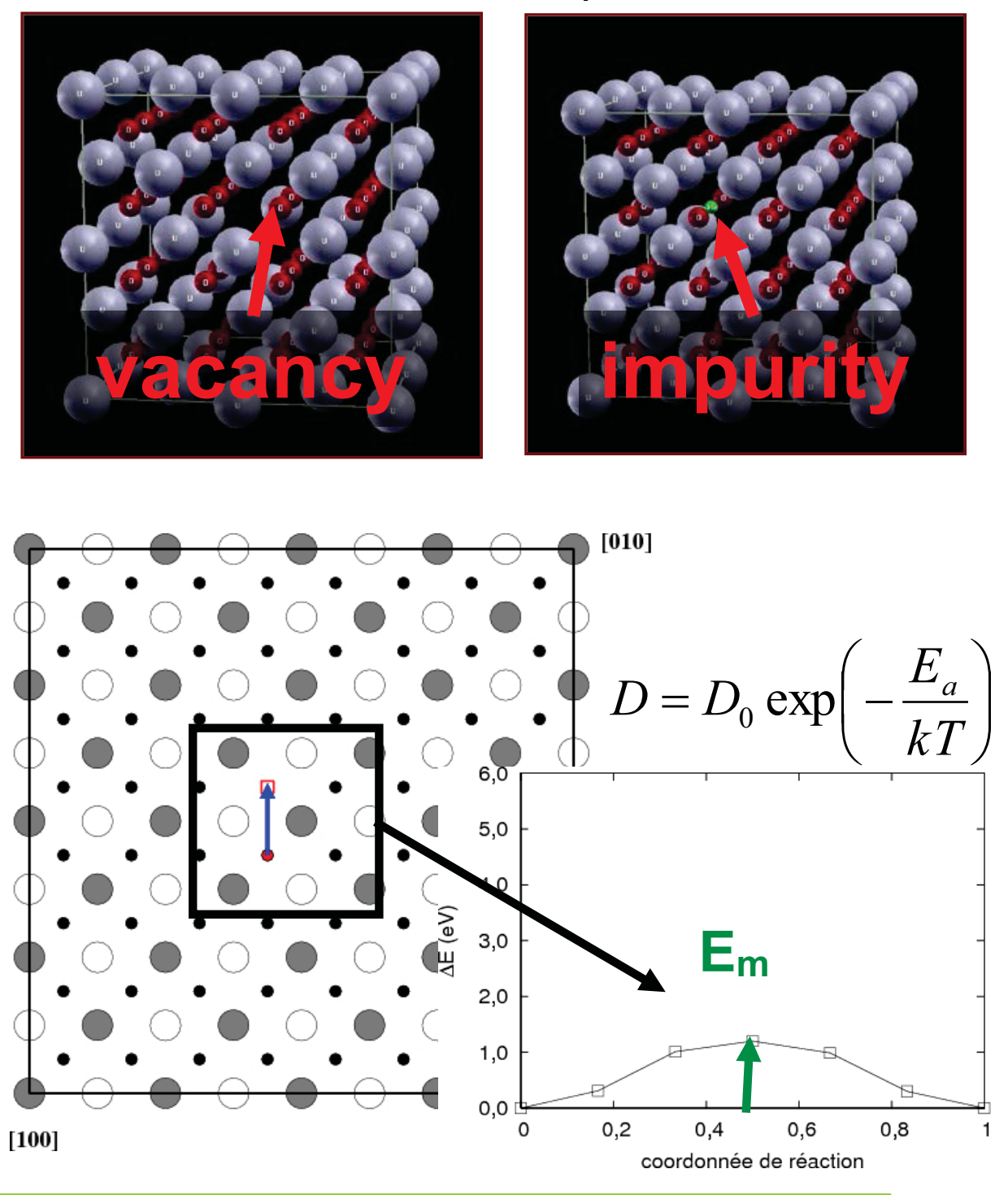


\section{Empirical potentials for $\mathrm{UO}_{2}$}

\section{Empirical potentials : rigid ions model (fixed point charges)}

\section{Buckingham interatomic pair potential:}

Thermal expansion

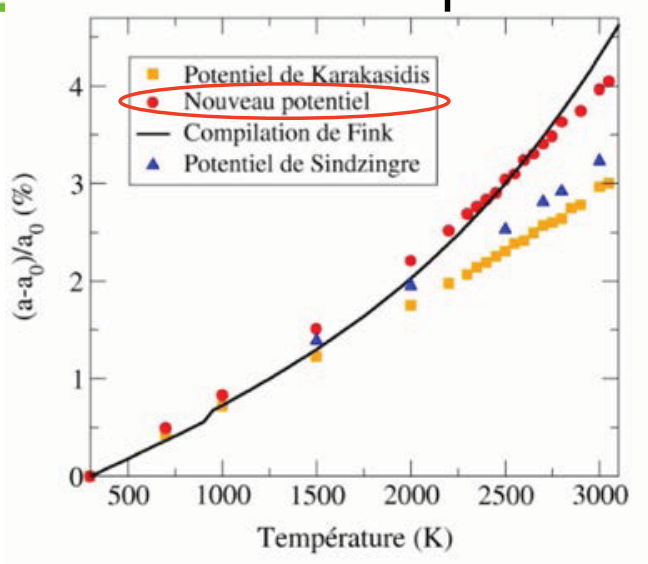

\begin{tabular}{|c|c|c|c|c|}
\hline \multirow{2}{*}{ Energy [eV] } & \multirow{2}{*}{ Experimental } & \multicolumn{2}{|c|}{ Ab initio } & \multirow{2}{*}{$\begin{array}{l}\text { Rigid ions } \\
\text { Morelon }\end{array}$} \\
\hline & & GGA & GGA+U & \\
\hline Formation Frenkel O & \multirow{4}{*}{$\begin{array}{c}3.5 \pm 0.5 \\
0.5 \\
0.8-1.0\end{array}$} & 3.3 & 5.3 & 3.9 \\
\hline Migration vac. O & & 1.2 & 0.7 & 0.3 \\
\hline Migration int. $\mathrm{O}$ (direct) & & 3.6 & 3.2 & 1.4 \\
\hline Migration int. $\mathrm{O}$ (indirect) & & 1.1 & 0.9 & 0.7 \\
\hline Formation Frenkel U & 9.5 & 9.3 & 15.8 & 15.7 \\
\hline Migration vac. $U$ & 2.5 & 4.4 & 5.5 & 3.9 \\
\hline Migration int. U & 2.0 & 5.8 & I & 4.2 \\
\hline Formation Schottky & $6.5 \pm 0.5$ & 4.1 & 2.5 & 3.9 \\
\hline
\end{tabular}

$V(r)=A \exp \left(-\frac{r}{B}\right)-\frac{C}{r^{6}}$

repulsion

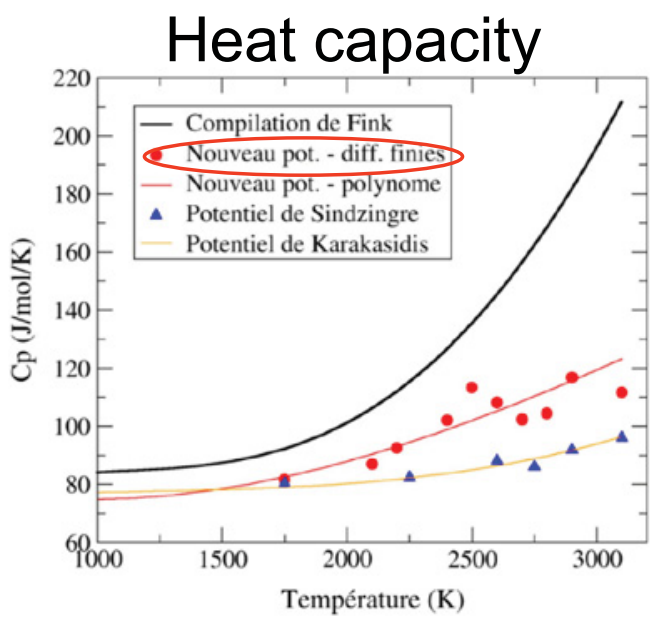

Parametrization (A, B, C) by Morelon (CEA):

bulk properties, ab initio

formation energies of point defects, thermo-elastic data... Morelon et al., Phil. Mag. 83, 1533 (2003)

GGA: M. Freyss et al. J. Nucl. Matter. 347, 44 (2005)

GGA+U: B. Dorado, PhD Thesis, CEA Cadarache (2010)

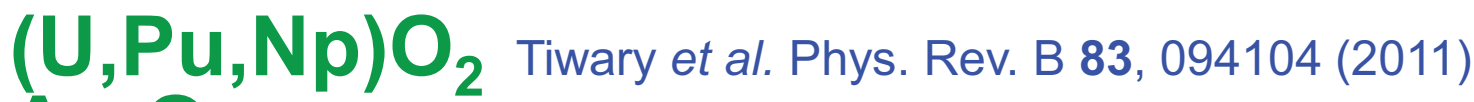
$\mathrm{AmO}_{2}$ Uchida et al. JNM 400, 3 (2010) 


\section{Empirical potential modeling}
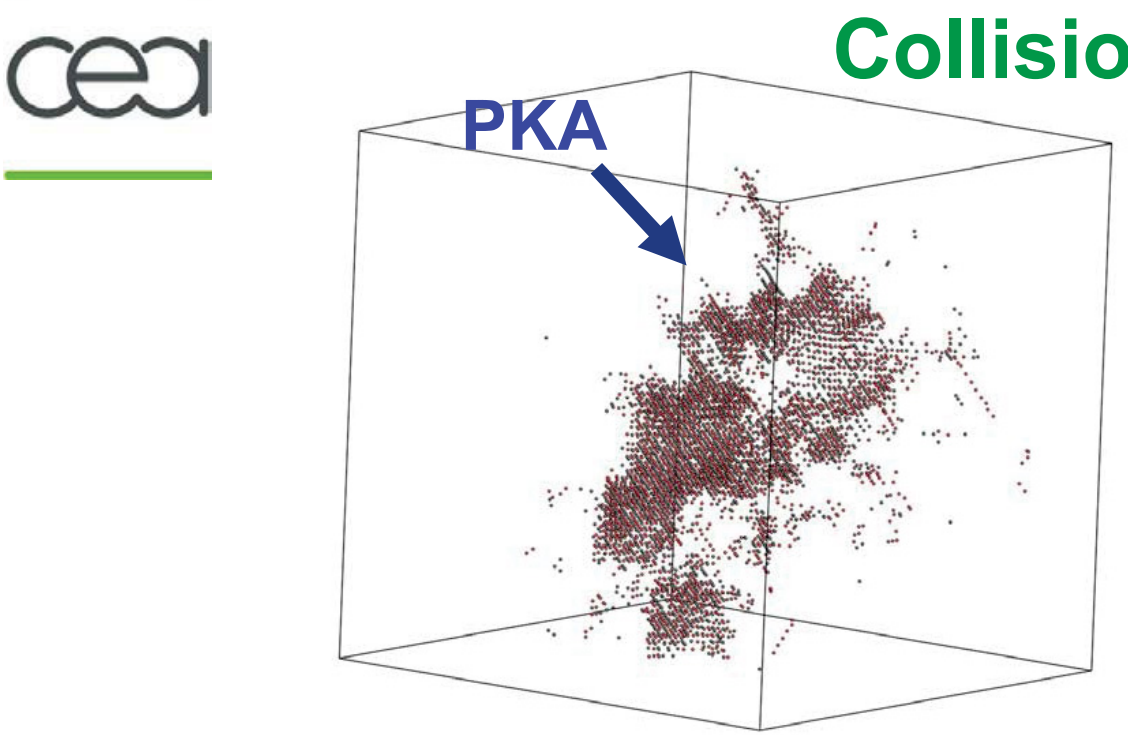

Defects at grain boundaries

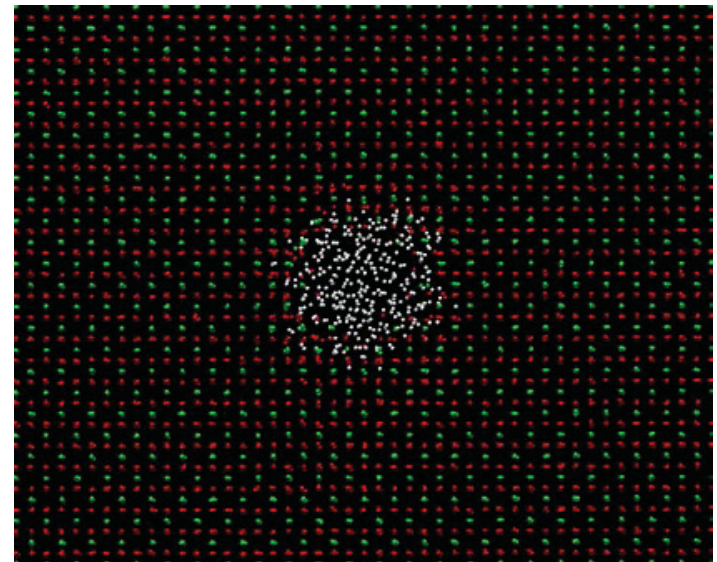

Gas bubble nucleation 


\section{Radiation damage and stability of Xe clusters in $\mathrm{UO}_{2}$}

Xenon incorporation energies in different void shapes, as a function

$c e^{-}$of the number $p$ of Schottky defects, which contain $p$ Xe atoms

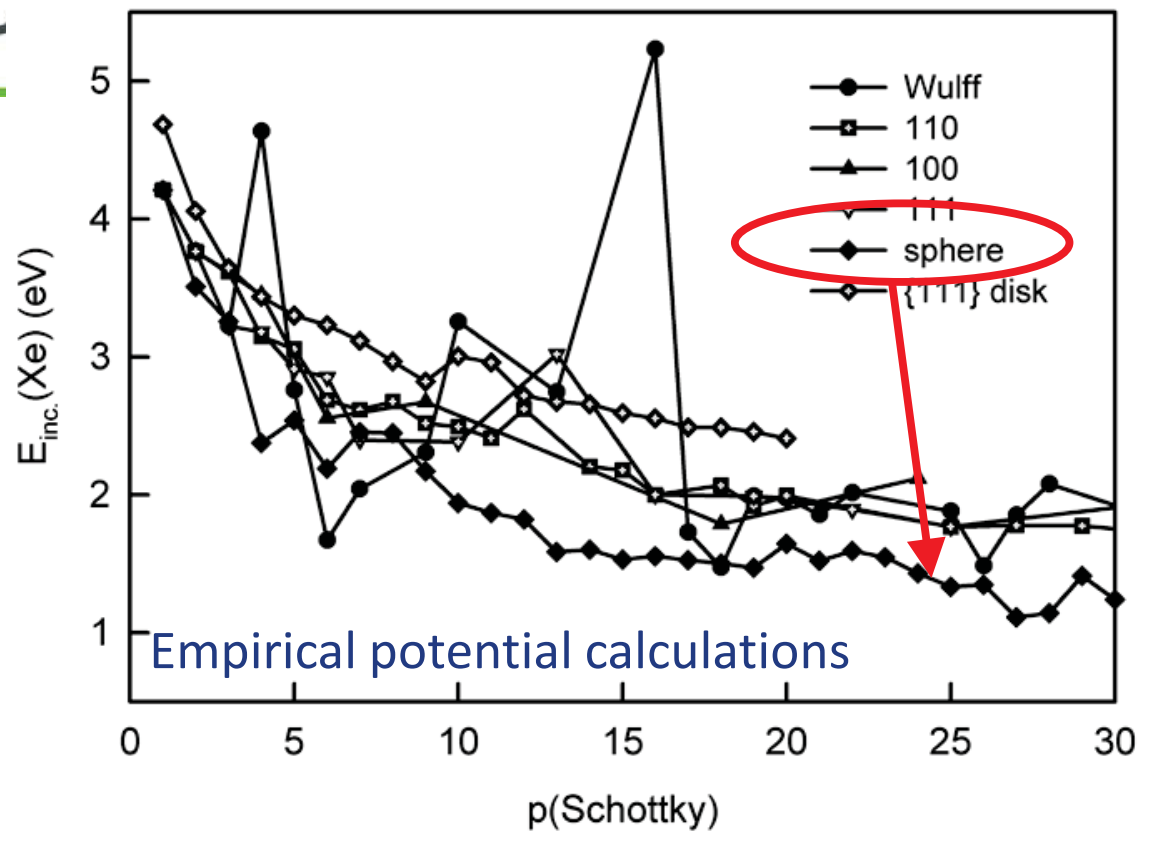

$\rightarrow$ Spherical xenon clusters with radius of $\sim 1.3 \mathrm{~nm}$. In agreement with TEM and SAX analysis

A. Chartier, L. van Brutzel. M. Freyss, Phys. Rev. B 81, 174111 (2010)

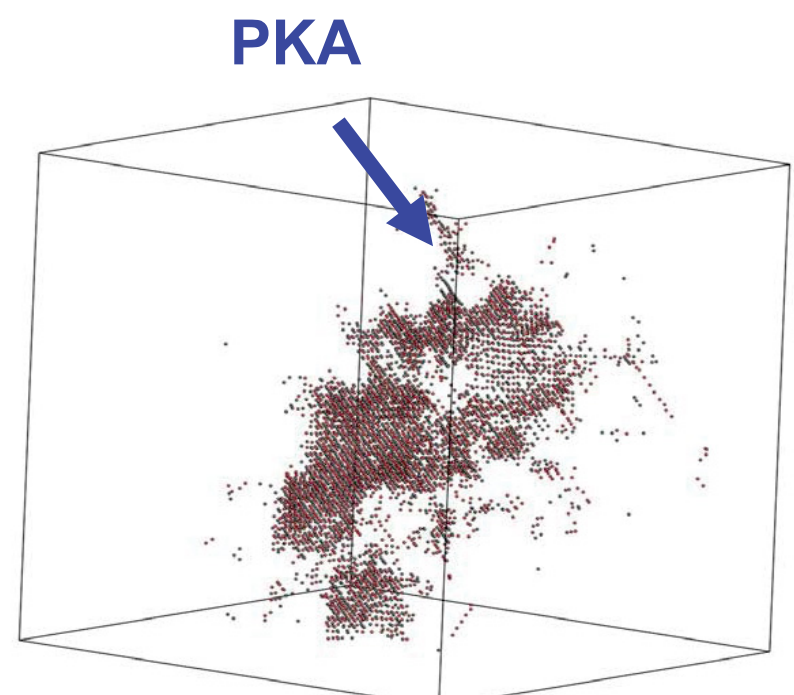

Ballistic damage created by the slowing-down of recoil nuclei G. Martin et al., Journal of Nuclear Materials 385, 351 (2009) 


\section{Damage production after cascades in $\mathrm{UO}_{2}$}

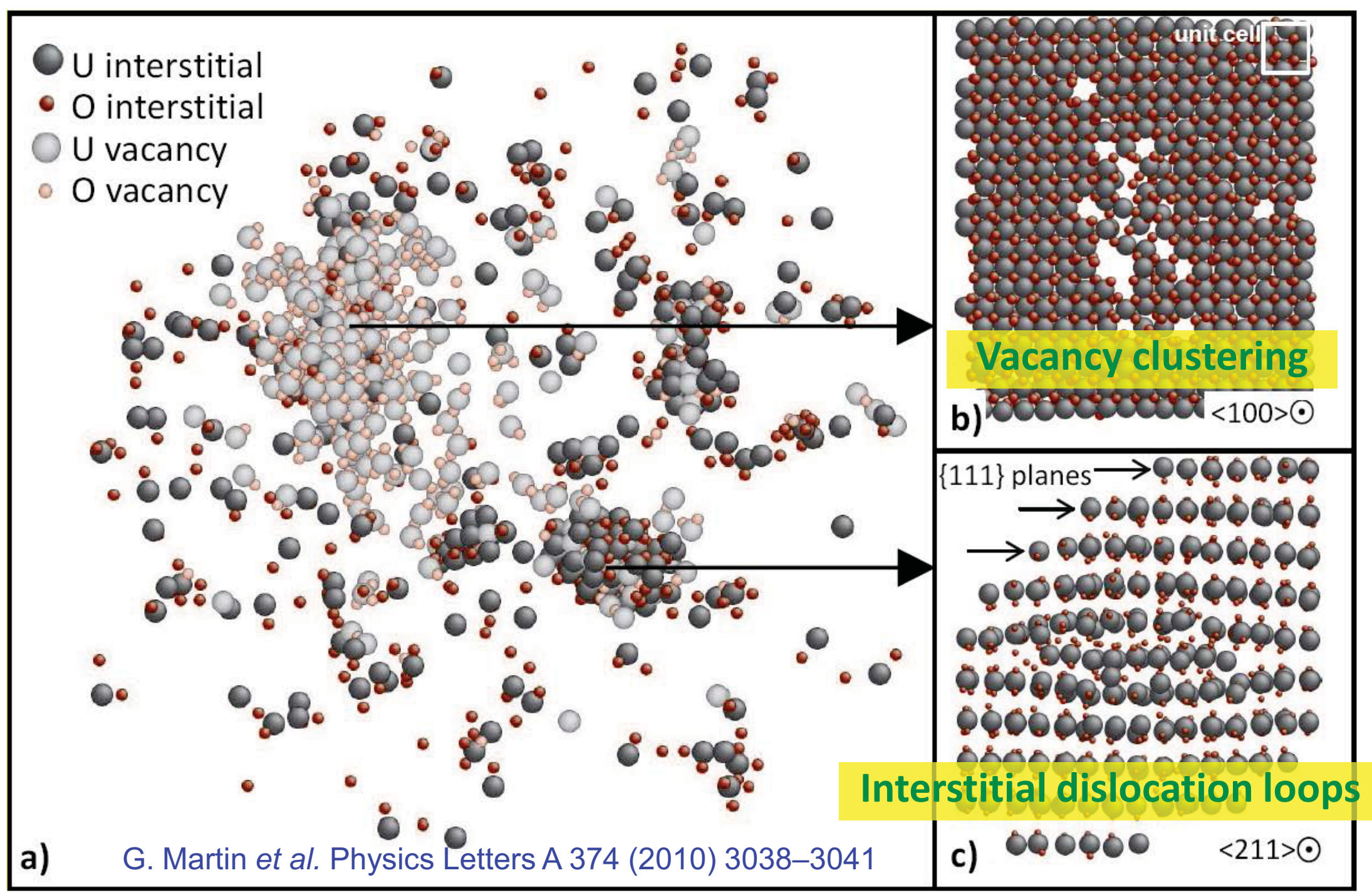

Coupled with MET analysis of ion implanted $\mathrm{UO}_{2}$ samples (thesis of Amélie Michel) 


\section{Cluster dynamics}

Several models exist to model FG behaviour $\rightarrow$ e.g. MARGARET at CEA

Most observation are correctly simulated but some phenomena are empirically modelled (not based on a mechanistic comprehension), in particular bubble sink strength is empirically changed for annealing simulations

\section{$\Rightarrow$ Cluster Dynamics (= rate theory model)}

Comprehensive framework to calculate defect and defect clusters (bubbles / loops) concentrations over time, with time scale and length scale appropriate for fuel study (years, grains)

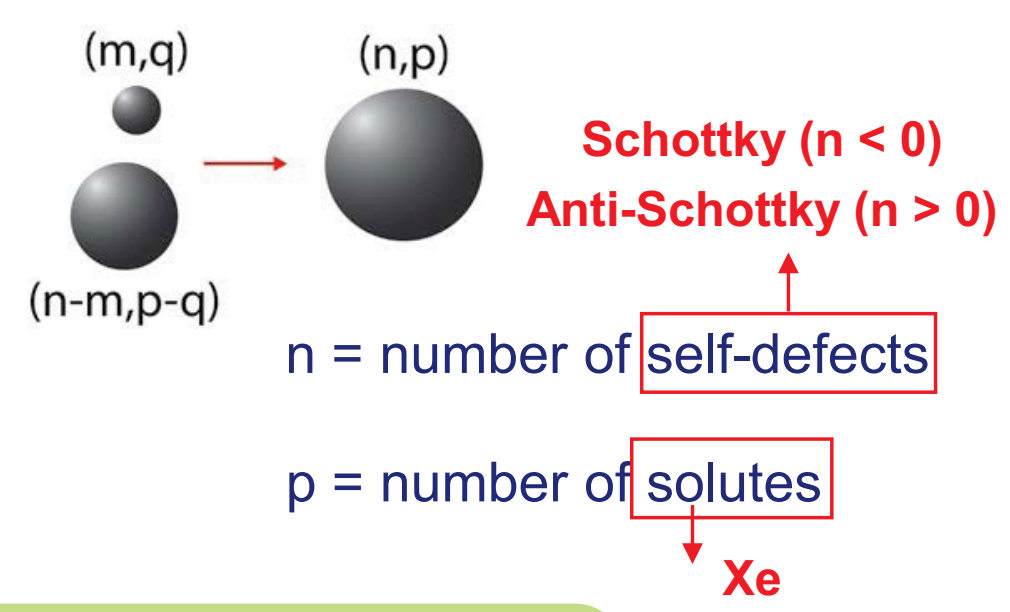

$$
\frac{\partial C(n, p, t)}{\partial t}=\sum_{n^{\prime}, p^{\prime}} J_{\left(n^{\prime}, p^{\prime}\right) \rightarrow(n, p)}-\sum_{n^{\prime}, p^{1^{\prime}}} J_{(n, p) \rightarrow\left(n^{\prime}, p^{\prime}\right)}+\underset{\text { Source term }}{G(n, p)-\underset{\downarrow}{\text { Sink term }}}
$$

Transition rate of reactions

toward $(n, p)$

Transition rate of reactions

from $(n, p)$
Input parameters : $D, E_{b}, E_{m}, \ldots$ 


\section{Cluster dynamics: gas bubble growth}

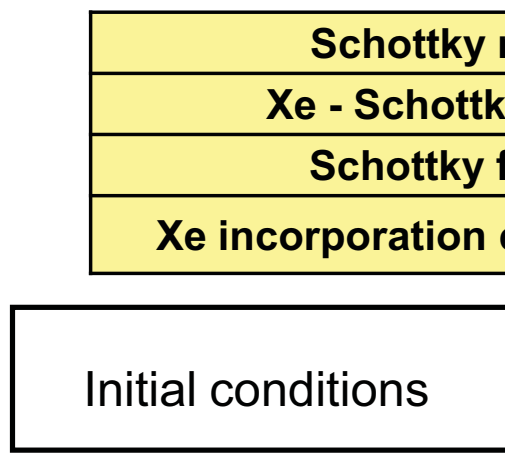

$C(-40,18)=10^{17} \mathrm{~cm}^{-3}$

No source term and no sink term

Mobile clusters: $(-1,0)$ and $(-1,1)$
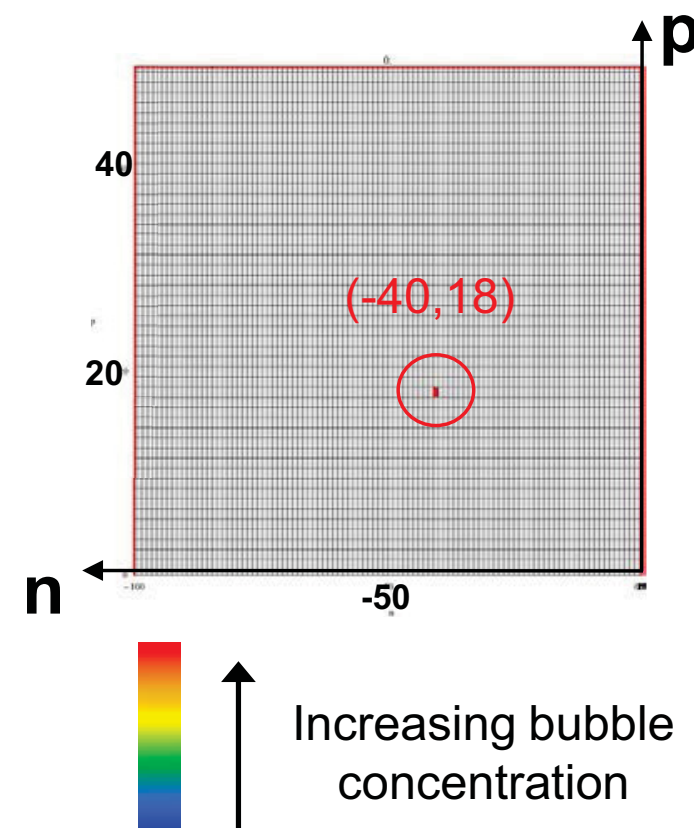

40

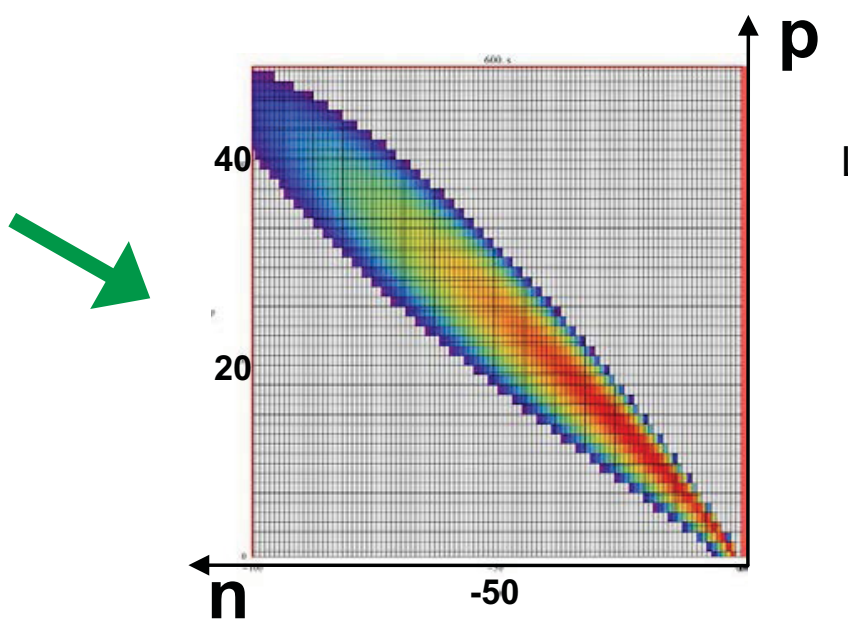

\begin{tabular}{|c|c|}
\hline Annealing time & $10 \mathrm{~min}$ \\
\hline Temperature & $1400^{\circ} \mathrm{C}$ \\
\hline
\end{tabular}

$C(-1,1)$ over time

†p

$\log _{10} C_{14}$

$\uparrow \mathbf{p}$
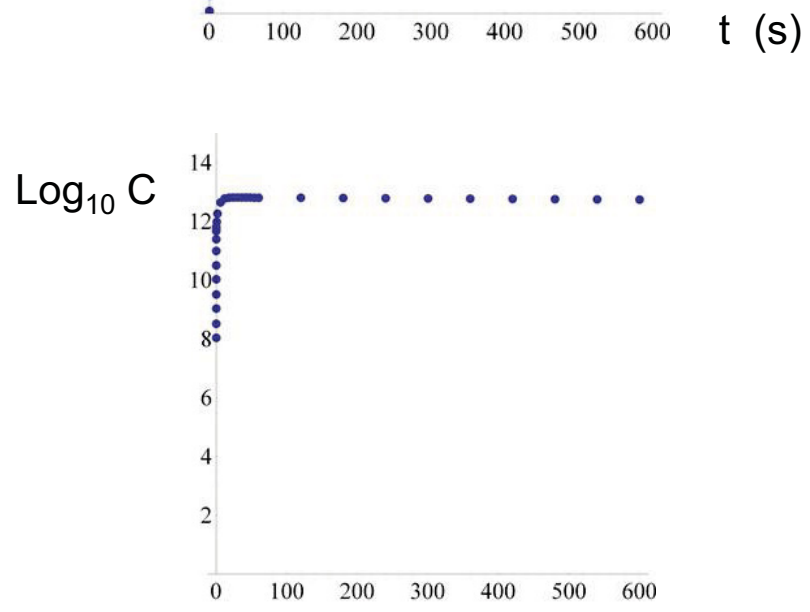

t (s) 


\section{Need of experiments for validation}

Each modeling technique requires experimental validation:

- for the approximations or models used

- for the physical data used as input material properties

Not much data available for mixed oxide fuels such as (U,Pu,MA)O $\mathrm{O}_{2}$ and for the fission gas behavior in those materials

\begin{tabular}{|c|c|c|}
\hline $\begin{array}{c}\text { Modeling } \\
\text { approaches }\end{array}$ & Observations & techniques \\
\hline Ab initio & $\begin{array}{l}\text { - location of fission products } \\
\text { - activation energies of diffusion (self- } \\
\text { diffusion and gases) }\end{array}$ & $\begin{array}{l}\text { - TEM, XAS, ... } \\
\text { - SIMS, ... }\end{array}$ \\
\hline $\begin{array}{l}\text { Empirical } \\
\text { potentials }\end{array}$ & $\begin{array}{l}\text { - material thermo-mechanical properties } \\
\text { - radiation damage, microstructure } \\
\text { evolution } \\
\text { - fission gas and helium bubbles }\end{array}$ & $\begin{array}{l}\text { - SEM-FIB, MET, } \\
\text { PAS, EBSD,... } \\
\text { - SAX, TEM,... }\end{array}$ \\
\hline $\begin{array}{l}\text { Cluster } \\
\text { dynamic }\end{array}$ & $\begin{array}{l}\text { - atomic diffusion coefficients } \\
\text { - size and density of fission gas and } \\
\text { helium bubbles, ... }\end{array}$ & $\begin{array}{l}\text { - TDS, SIMS,... } \\
\text { - SAX, TEM,... }\end{array}$ \\
\hline
\end{tabular}




\section{Seperate effect studies of nuclear fuels}

- Non active model materials such as depleted $\mathrm{UO}_{2}$

- Ion implantation to simulate fission products

- Thermal treatment or heavy ion irradiation

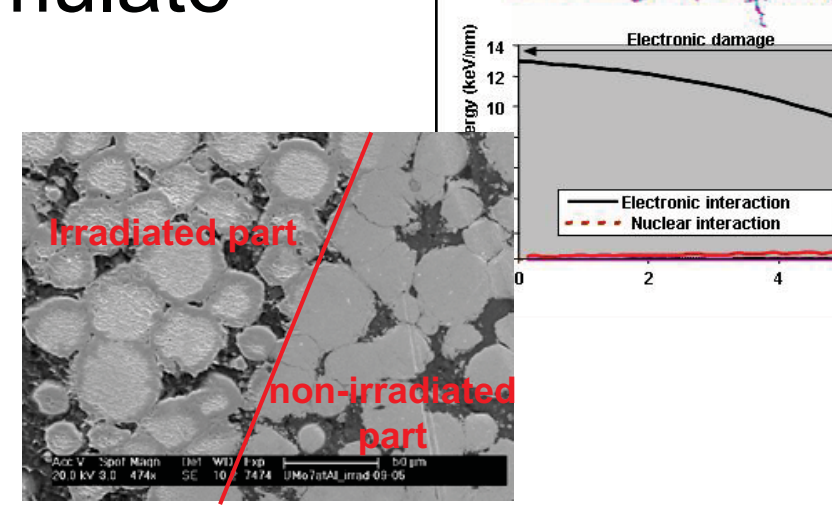

- Characterization with a large panel of dedicated techniques (SIMS, RBS, NRA, TEM, XAS)
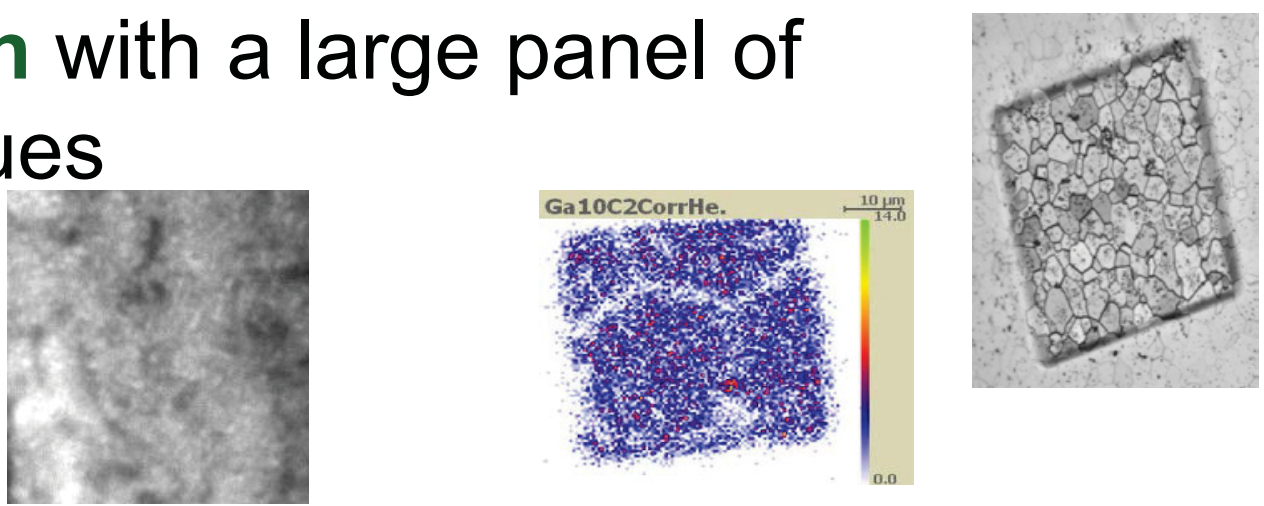

- Large scientific facilities (particle accelerators and synchrotron radiation) 


\section{Oxygen migration: comparison to experimental results}

Comparison to experimental results: Electrical conductivity measurements + SIMS experiments + control of parameters that affect the material (oxygen partial pressure and impurity content):

$>$ Oxygen diffusion occurs via interstitial mechanism Garcia et al., J. Nucl. Mater. 400, 112 (2010)

$>\mathrm{DFT}+\mathrm{U}$ calculations show that oxygen diffusion in $\mathrm{UO}_{2}$ occurs via an interstitialcy mechanism when $\mathrm{O}$ diffusion is governed by interstitials

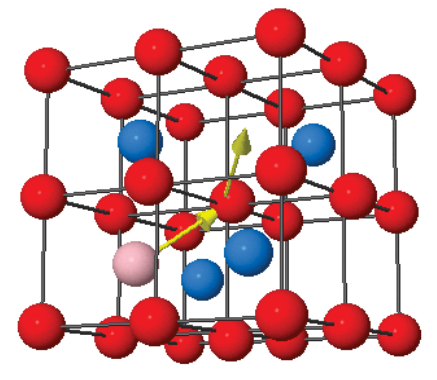

Experimental value of the diffusion activation energy $\mathrm{E}_{\mathrm{a}}$ :

$$
\frac{D}{\sqrt{p_{O_{2}}}} \propto \exp \left(-\frac{E_{a}}{k T}\right)=\exp \left(-\frac{E_{F}+E_{m}}{k T}\right)
$$

Experimental value $E_{a}=0.75 \pm 0.08 \mathrm{eV}$

Calculated migration energy: $E_{m}=0.93 \mathrm{eV}$ Dorado et al., Phys. Calculated formation energy: $E^{F}=-0.05 \mathrm{eV}$ Rev. B 83, 035126 (2011)

Calculated activation energy: $E_{a}=E^{F}+E_{m}=0.88 \mathrm{eV}$

Good agreement between experimental and calculated values 


\section{XAS and TEM characterization of Xe bubbles in $\mathrm{UO}_{2}$}

$\mathrm{Ced} 2$ at $\%$ Xe implantation in $\mathrm{UO}_{2}$ polycrystalline samples

annealing $20-30$ minutes at $600^{\circ} \mathrm{C}$

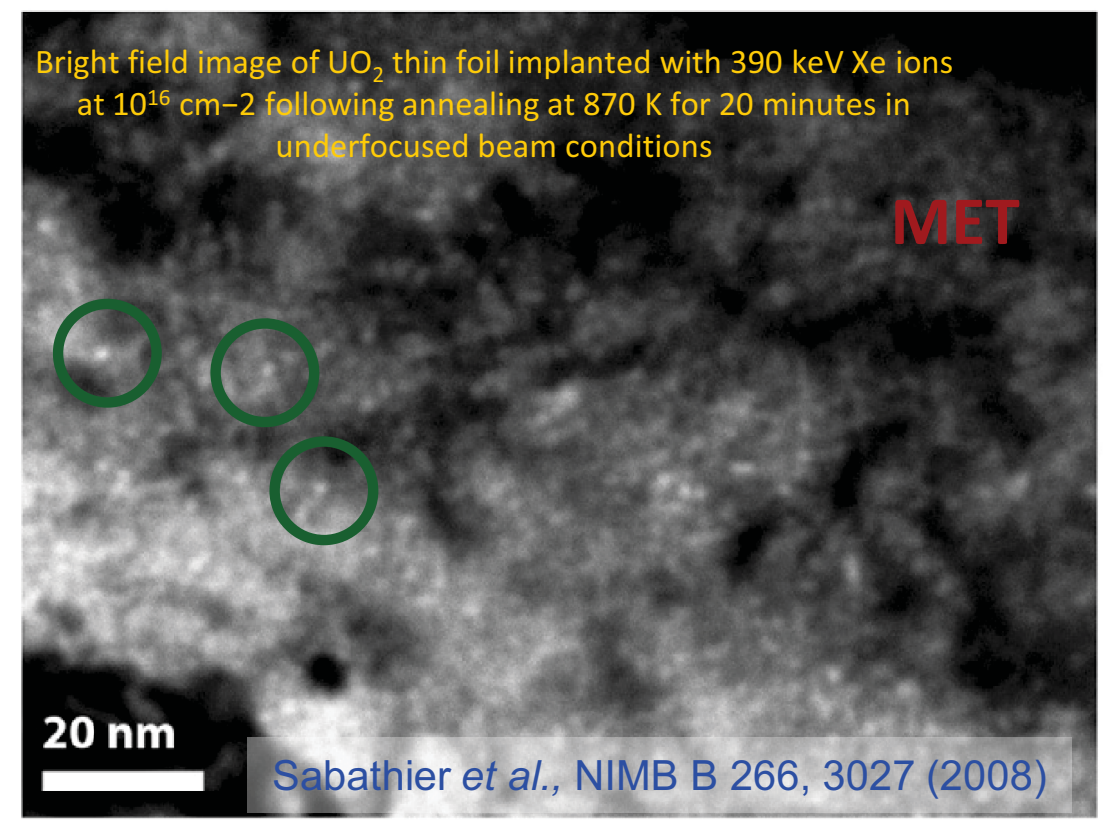

Xe aggregate size $2 \mathrm{~nm}$

In agreement with empirical potentials calculations Chartier, van Brutzel, Freyss, Phys. Rev. B 81, 174111 (2010)

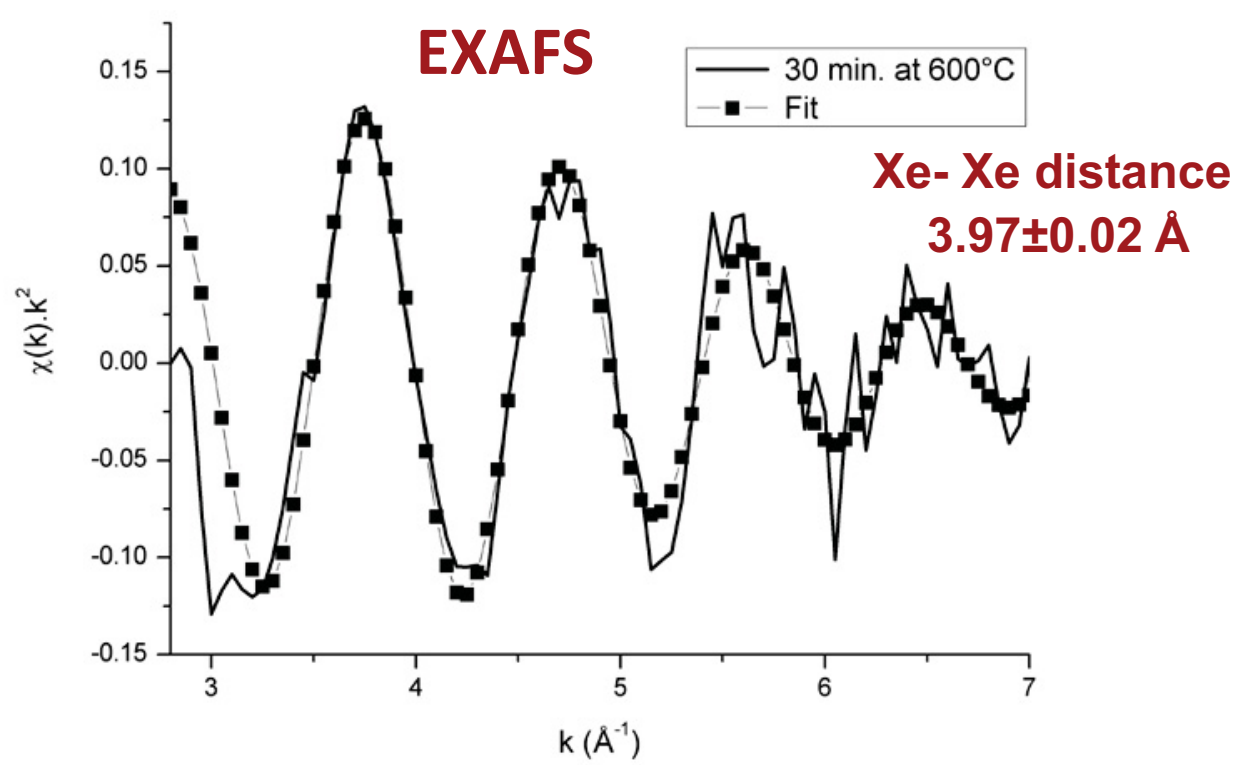

$$
\begin{gathered}
\mathbf{d}_{\mathbf{R g}-\mathbf{R g}} \begin{array}{c}
\text { lattice E.O.S. } \\
\text { parameter }
\end{array} \\
\begin{array}{c}
\text { aggregate internal } \\
\text { pressure }
\end{array} \\
\mathrm{P}(\mathrm{V}, \mathrm{T}) \text { by K. Asaumi, Phys Rev. B 29(1984)) } \\
\mathbf{2 . 8} \pm \mathbf{0 . 3} \mathbf{G P a} \\
\text { P. Garcia et al., J. Nucl. Mater. 352, 136 (2006) } \\
\text { P. Martin et al NIMB. B 266, } 2887(2008)
\end{gathered}
$$




\section{Conclusions}

$>$ Modeling of the standard $\mathrm{UO}_{2}$ fuel behavior much improved

> Atomistic modeling of fuels has much benefited from the improvement of the methods/approximations and of the increasing computing power

> Already very favourable and encouraging confrontation of atomistic calculations and experimental results for $\mathrm{UO}_{2}$ (oxygen migration, xenon bubble nucleation, ...)

$>$ Data transfer between modeling techniques

$>$ Similar modeling for $(\mathrm{U}, \mathrm{Pu}, \mathrm{MA}) \mathrm{O}_{2},(\mathrm{U}, \mathrm{MA}) \mathrm{O}_{2},(\mathrm{MA}) \mathrm{O}_{2}+\mathrm{IM}$ and carbides

$>$ Quality and accuracy of the calculated results can only be ensured provided some experimental data are available 


\section{Acknowledgments}

CEA: B. Amadon, G. Jomard, M. Torrent, F. Jollet, L. van Brutzel, A. Chartier, A. Barbu

Experiments on oxygen diffusion: G. Baldinozzi, D. Siméone, C. Petot, G. Petot (CEA-CNRS-Ecole Centrale de Paris, Gif-sur-Yvette, France), B. Pasquet (CEA Cadarache, France), C. Davoisne (CEA Cadarache / Lille Univ., France)

Los Alamos National Lab: D. Andersson

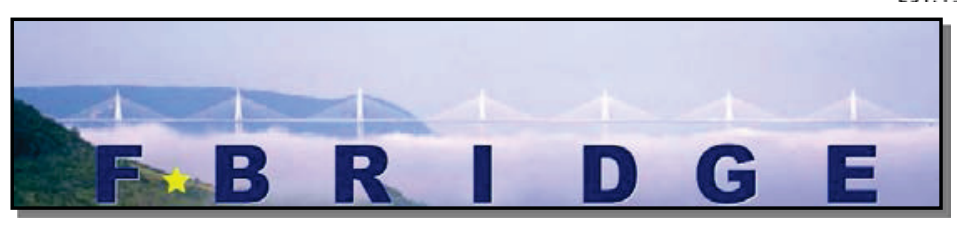

F-BRIDGE project

Basic Research for Innovative Fuel Design for GEN IV systems

Computing facilities:

GENCI

Grand Equipement National de Calcul Intensif CCRT

Centre de Calcul Recherche et Technologie

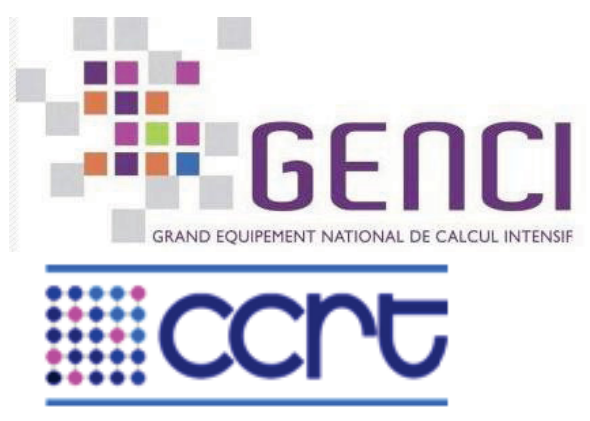




\title{
PIE Needs to Support Fuel Design \& Safety Testing
}

\author{
Steven L. Hayes, PhD
}

Nuclear Fuels \& Materials Division Idaho National Laboratory 


\section{Outline of Presentation}

- Fuel Development \& Safety Testing

- Historic process

- US (DOE) development and qualification of a new fuel

- Postirradiation Examination Needs

- Traditional suite of exams (largely macroscopic)

- Non-traditional microscopic characterization

- Emerging need for nano-scale characterization

Conclusion 


\section{FUEL DEVELOPMENT 8}

SAFETY TESTING 


\section{Fuel Development \& Safety Testing}

Crawford, et al., Journal of Nuclear Materials, 371: 232-242 (2007).

- Review of 4 phases of fuel development process

1) Fuel candidate selection

2) Concept definition and feasibility

3) Design improvement and evaluation

4) Fuel qualification and demonstration

- Process has decades of experience for EBR-II \& FFTF fuel qualification/confirmation testing

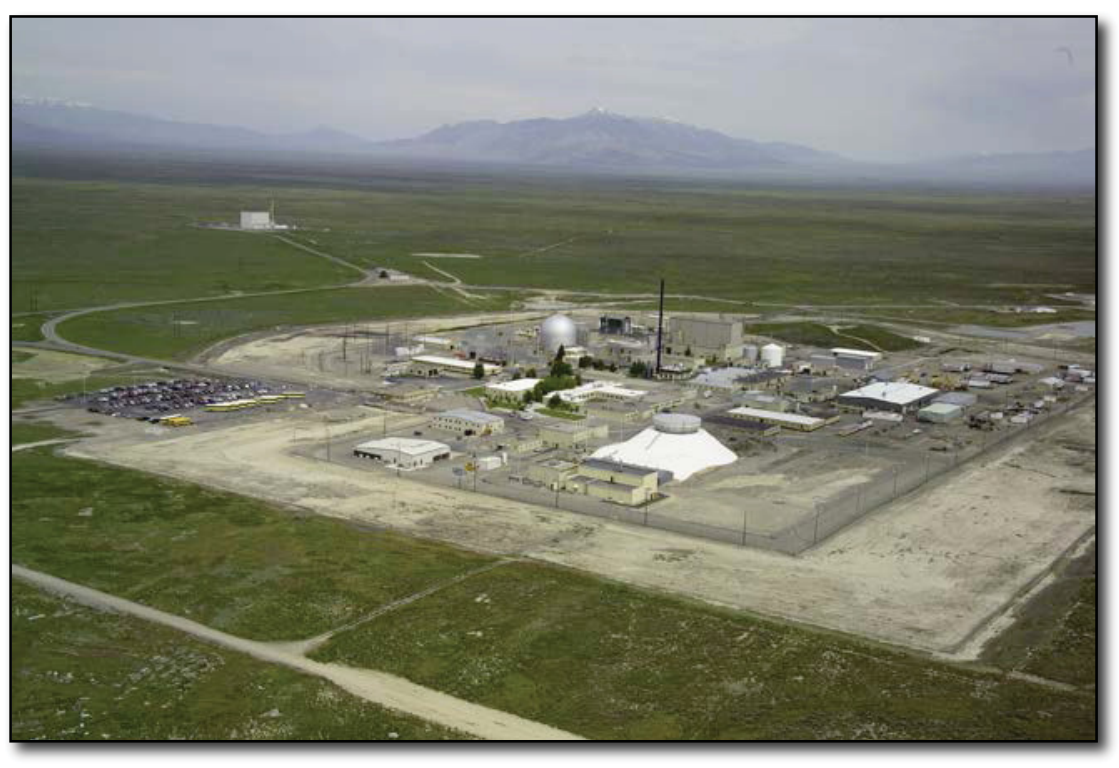




\section{TRL Objective in Fuel Qualification}

Idaho National Laboratory

\begin{tabular}{|c|c|c|}
\hline TRL & Function & Definition \\
\hline 1 & \multirow[t]{3}{*}{ 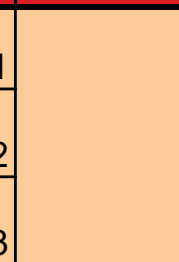 } & $\begin{array}{l}\text { A new concept is proposed. Technical options for the concept are } \\
\text { identified and relevant literature data reviewed. Criteria developed. }\end{array}$ \\
\hline 2 & & $\begin{array}{l}\text { Technical options are ranked. Performance range and fabrication } \\
\text { process parametric ranges defined based on analyses. }\end{array}$ \\
\hline 3 & & $\begin{array}{l}\text { Concepts are verified through laboratory-scale experiments and } \\
\text { characterization. Fabrication process verified using surrogates. }\end{array}$ \\
\hline 4 & & $\begin{array}{l}\text { Fabrication of samples using stockpile materials at bench-scale ( 100 } \\
\text { gram batches). Irradiation testing of small-samples (rodlets) in relevant } \\
\text { environment. Design parameters and features establsihed. Basic } \\
\text { properties compiled. }\end{array}$ \\
\hline 5 & & $\begin{array}{l}\text { Fabrication of pins using prototypic feedstock materials at laboratory- } \\
\text { scale }(10 \mathrm{~kg}) \text {. Pin-scale irradiation testing at relevant environment. } \\
\text { Primary performance parameters with representative compositions } \\
\text { under normal operating conditions quantified. }\end{array}$ \\
\hline 6 & & $\begin{array}{l}\text { Fabrication of pins using prototypic feedstock materials at laboratory- } \\
\text { scale }(1 \mathrm{~kg}) \text { and using prototypic fabrication process. Pin-scale } \\
\text { irradiation testing at relevant and prototypic environment (steady-state } \\
\text { and transient testing). Safety basis establis }\end{array}$ \\
\hline \multirow[t]{2}{*}{7} & \multirow{3}{*}{-} & $\begin{array}{l}\text { Fabrication of test assemblies using prototypic feedstock materials at } \\
\text { engineering-scale }(100 \mathrm{~kg}) \text { and using prototypic fabrication process. } \\
\text { Assembly-scale irradiation testing at prototypic environment. Safety } \\
\text { basis established for full-core operations. }\end{array}$ \\
\hline & & $\begin{array}{l}\text { Fabrication of a few core-loads of fuel (tons) and operation of a } \\
\text { prototype reactor with such fuel. }\end{array}$ \\
\hline 9 & & Routine commercial-scale operations. Multiple reactors operating \\
\hline
\end{tabular}




\section{Fuel Development Phase 1: Fuel Candidate Selection}

Objective: Based on previous experience, identify candidate fuel forms/concepts that appear capable of meeting mission needs.

- Selection criteria might include:

- Ability to accommodate desired fuel compositions

- Experience with similar fuel types or analogues

- Suitability of established fabrication techniques, or the potential for successful innovative techniques

- Anticipated performance capabilities (e.g., temperature, burnup, or fluence)

- Anticipated safety-related behavior (which may be quite speculative at an early stage)

- Suitability of design, considering issues such as fuel-cladding compatibility, fuelcoolant compatibility, and fuel properties

- Compatibility with envisioned back-end fuel cycle technology

- Expected cost of fabrication

- Achieves TRL 2 


\section{Fuel Development Phase 2: Concept Definition and Feasibility}

- Objective: Establish a reference concept/design

- Determine how the fuel can be fabricated

- Process scoping \& feasibility

- Fabricate characterization and test samples

- Determine and assess key properties

- Feasibility issues for irradiation testing

- Use scoping irradiation tests to assess phenomena envisioned to impact feasibility and fuel lifetime

- Simple experiments

- Prototypic conditions as much as possible

- Achieves TRL 4 


\section{Fuel Development Phase 3: Design Improvement and Evaluation}

- Objectives:

- Optimize the fuel design for economics, performance and safety

- Produce a Fuel Specification and a Fuel Safety Case for a core of fuel

- Establish predictive fuel performance code (or codes)

- Develop engineering-scale fabrication processes and equipment

- Assess fuel properties vs. composition or processing variations

- Irradiation testing to:

- Determine sensitivity of performance to fuel design and fabrication variables and to operating conditions

- Establish burnup limits and safety margins for various operating conditions (normal and off-normal)

- Develop fuel behavior models and predictive codes

Achieves TRL 6 


\section{Fuel Development Phase 4: Fuel Qualification and Demonstration}

- Objectives:

- Qualify production-line fuel as the driver fuel for a demonstration reactor

- Demonstrate the safety and reliability of a core of fuel through successful operation of the demonstration reactor

- Validate predictive fuel performance code (or codes)

- Demonstrate production of fuel in conformance with Fuel Specification

- Demonstrate through LTA irradiation that fuel/fuel assembly behavior is within the bounds of the Fuel Safety Case

- Accumulate reactor performance data and operating experience with a core of fuel to support licensing of first-of-a-kind unit

- Achieves TRL 7 or 8 
POSTIRRADIATION EXAMINATION NEEDS 


\section{Traditional Suite of (PIE) Examinations}

1) Non-Destructive Examinations

2) Destructive Examinations
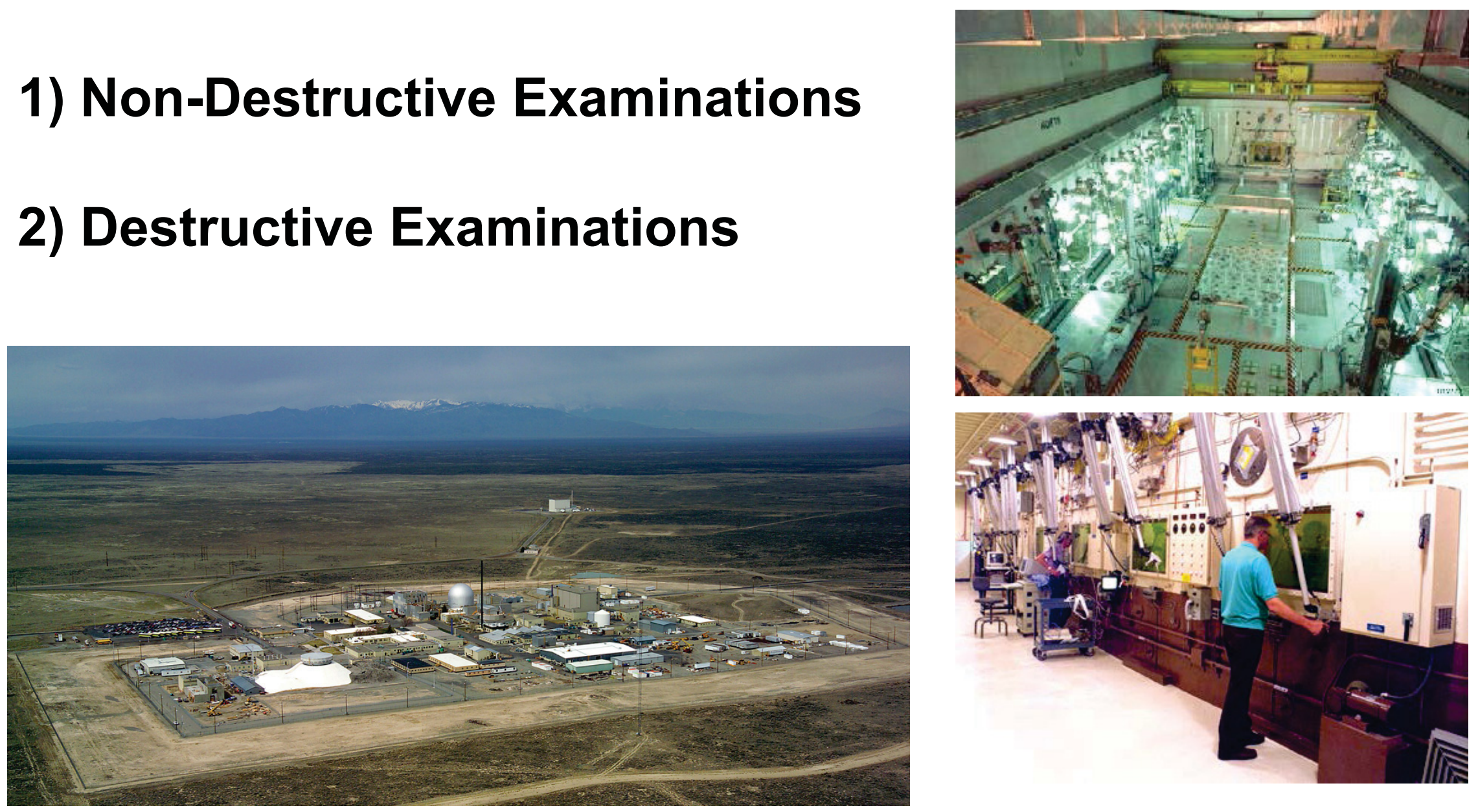


\section{Non-Destructive Examinations}

Idaho National Laboratory

$\checkmark$ Visual Inspection

$\checkmark$ Neutron Radiography

$\checkmark$ Dimensional Inspection

$\checkmark$ Gamma Ray Spectroscopy

$\checkmark$ Eddy Current Oxide Layer Tester

$\checkmark$ Eddy Current Cladding Integrity Tester
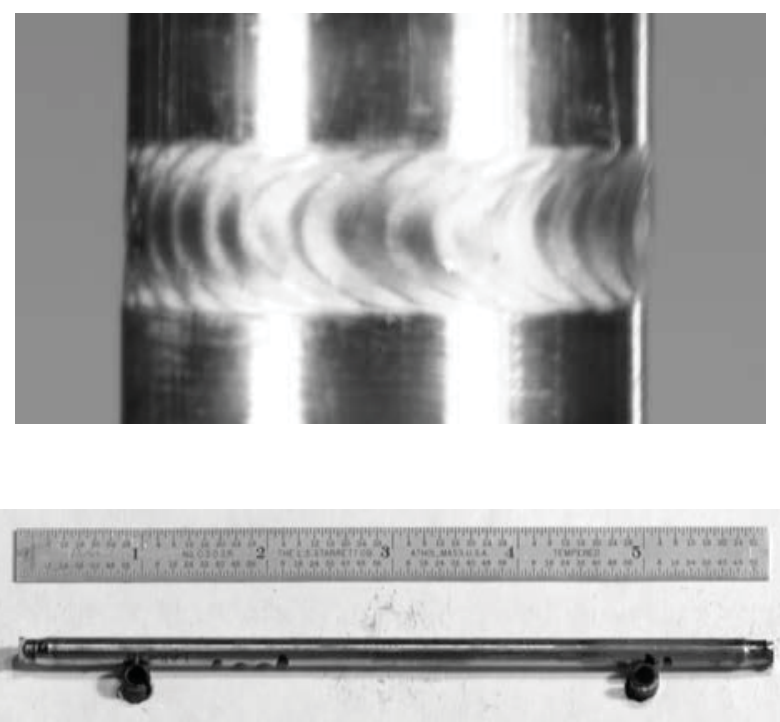
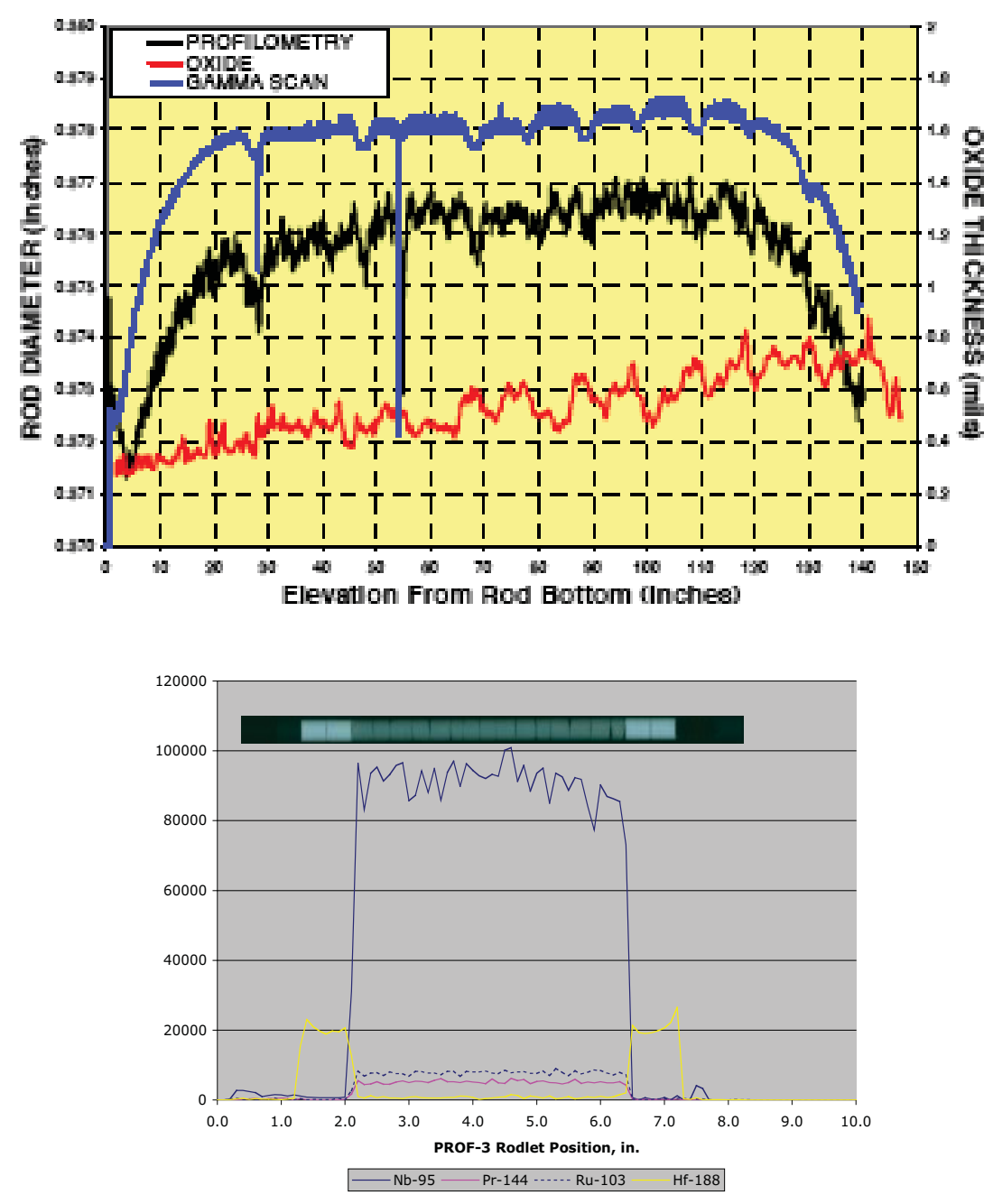


\section{Destructive Examinations}

$\checkmark$ Plenum Puncture \& Gas Analysis

$\checkmark$ Isotopic \& Burnup Analysis

$\checkmark$ Metallography/Ceramography

$\checkmark$ Physical Properties

- Fuel Density

- Cladding Hydrogen Analysis

- Cladding Mechanical Properties

$\checkmark$ Support for Safety Testing

- Handle/disassemble loops?

- Fuel Annealing Furnace
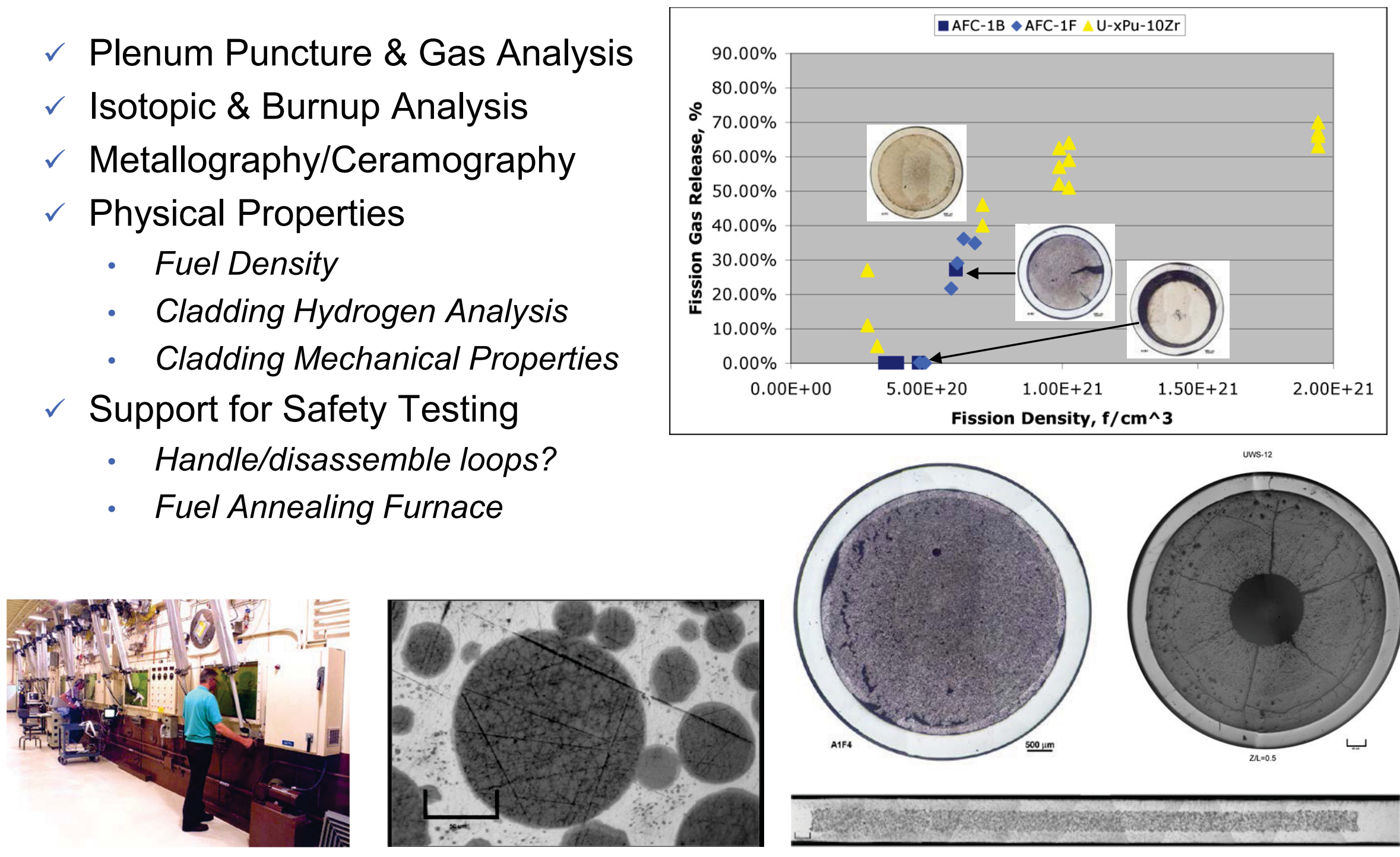

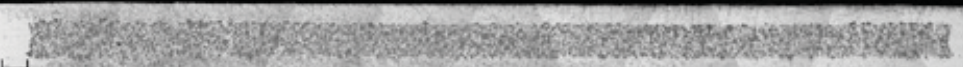




\section{Non-Traditional Microscopic Characterization}

$\checkmark$ Scanning Electron Microscopy

$\checkmark$ Transmission Electron Microscopy

$\checkmark$ Electron Micro-Probe Analysis

$\checkmark$ Physical Properties

- Thermal Conductivity/Diffusivity

- Melting Point
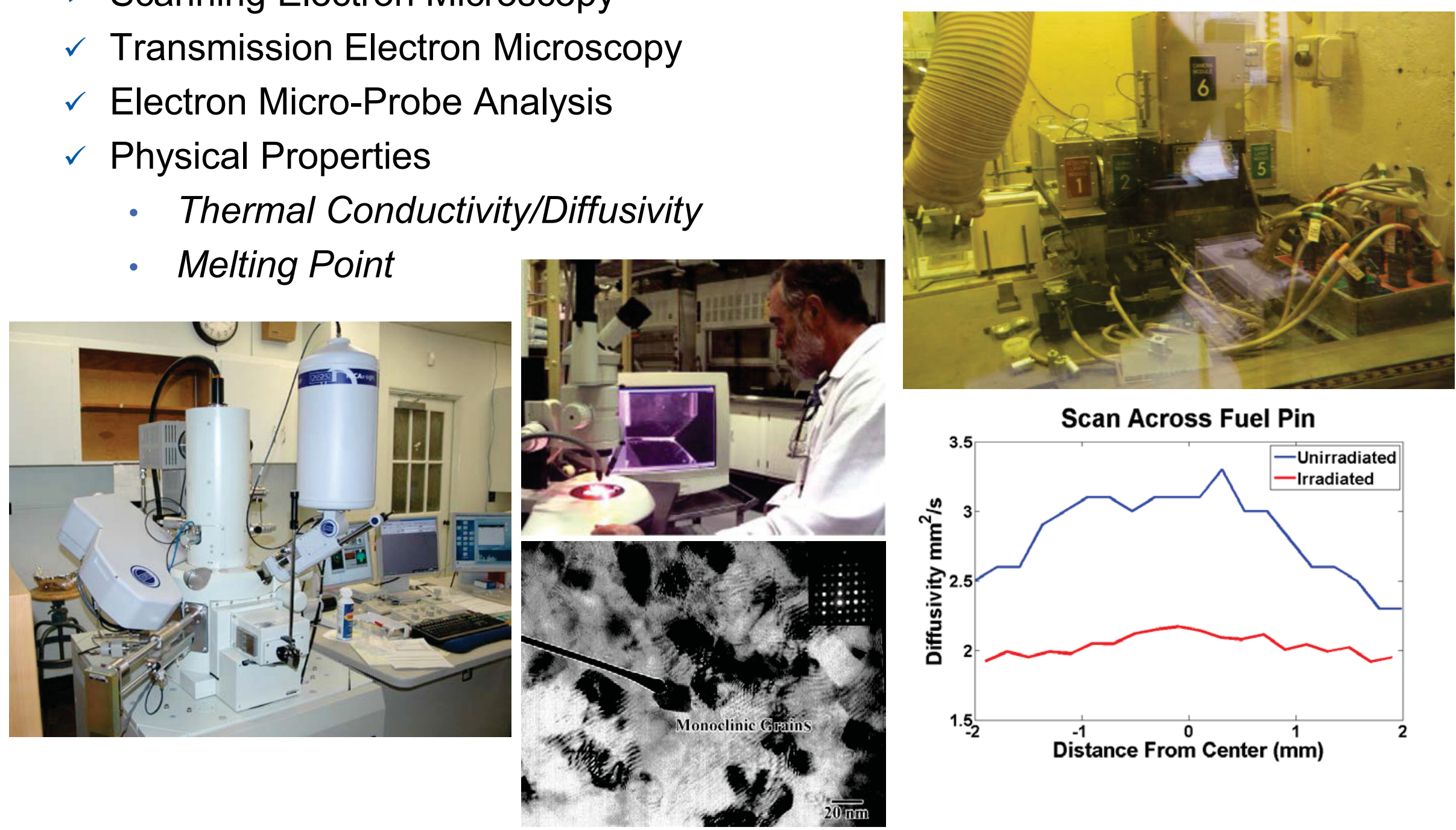


\section{Emerging Need for Nano-scale Characterization}

Why needed/desired?

- Prototypic test environments no longer available (i.e., fast reactors, transient reactors)

- Historic, empirically-based approach costly and time-consuming

- Characteristics of approach

- Develop/apply theory to fuel behavior

- Perform separate effects testing

- Guided, informed by theory

- Extensive pre-irradiation characterization

- Simulated with advanced M\&S

- Detailed postirradiation examinations

- Inform models, validate theory

- Potential results

- Faster, less costly fuel development

- Number of experiments reduced, but more effective

\section{Science-Based Approach}

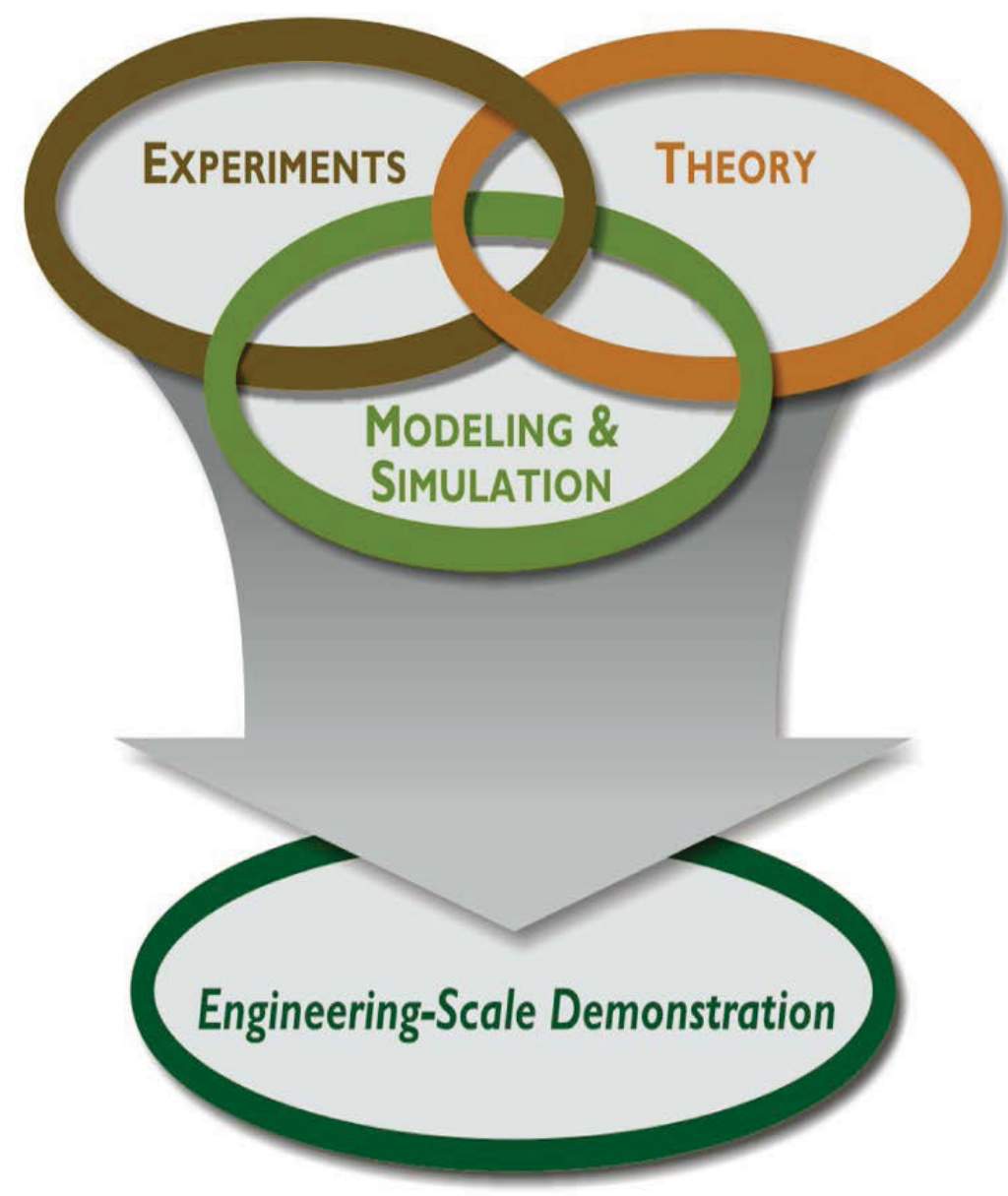




\section{Conclusion}

- Historic process to develop/qualify new fuels is proven

- Costly and time-consuming process

- Necessary infrastructure (in some cases) no longer exists

- Future development of new fuels will likely evolve

- Historic (empirically-based) process will continue to be used

- Supplemented with increasing dependence on tools developed under advanced modeling and simulation efforts

- Conclusion

- Traditional PIE processes will still be needed

- Development of micro- and nano-scale methods of characterizing irradiated nuclear fuels and materials will be increasingly important 
$\mathrm{Ft}$

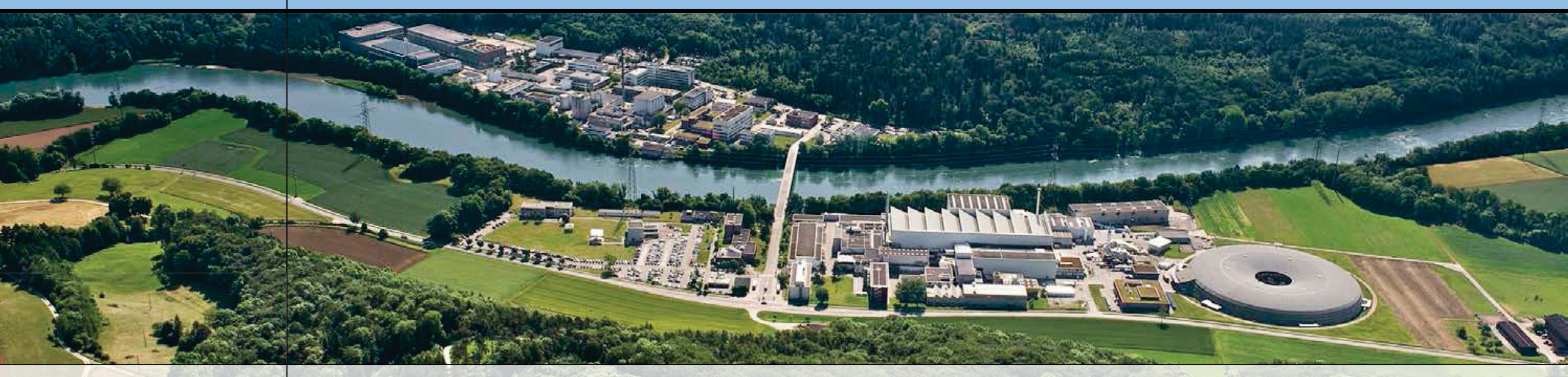
Wir schaffen Wissen - heute für morgen

\section{Paul Scherrer Institut Manuel A. POUCHON Beam-line techniques}




\section{Table of contents}

- Introduction

- Aspects of beamlines / Types of beamlines

- X-Ray beamlines

- Synchrotron light sources

- Basics / Beamlines in the world

- Selection of analysis techniques

- Examples

-PIE of MOX by $\mu X R D$, EXAFS

$-X R D$ of ODS after He irradiation

- Free electron laser (FEL)

- Special aspects/Possible application

- Neutrons

- Sources / Features

- One example 


\section{Table of contents}

- Introduction

- Aspects of beamlines / Types of beamlines

- X-Ray beamlines

- Synchrotron light sources

- Basics / Beamlines in the world

- Selection of analysis techniques

- Examples

-PIE of MOX by $\mu X R D$, EXAFS

$-X R D$ of ODS after He irradiation

- Free electron laser (FEL)

- Special aspects/Possible application

- Neutrons

- Sources / Features

- One example 


\section{Aspects of beamlines}

\section{Advantages, special features:}

- High flux (e.g. Synchrotron light, FEL)

- Special particles for analysis (e.g. neutrons, electrons, ions, muons ,...)

- Large range of energies (up to very high ones)

- Special features as

- polarization

- coherency (e.g. for X-Ray from FEL),

- pulsed sources (e.g. FEL, neutrons, ...)

- high beam quality for superior focalization (for $\mu$ analysis) $\rightarrow$ option of scanning

$\rightarrow$ Evolving of new experimental techniques exploring more material features, physical/chemical effects

\section{Disadvantages:}

- Experiment requires long preparation time (with application phase) for a couple of hours up to a few days of experimental time (low flexibility)

- Beamlines often do not accept radioactive samples

- if proprietary research, then very expensive 


\section{Types of beam-lines}

- X-Ray

- Synchrotron light sources $\leftarrow$

- Free electron laser $\leftarrow$

- Neutron

- Reactors

- Spalation $\leftarrow$

- Muons (Muon spectroscopy)

- Electrons (TEM, ...)

- Ions (RBS, ERDA, .....) 


\section{Table of contents}

- Introduction

- Aspects of beamlines / Types of beamlines

- X-Ray beamlines

- Synchrotron light sources

- Basics / Beamlines in the world

- Selection of analysis techniques

- Examples

-PIE of MOX by $\mu X R D$, EXAFS

$-X R D$ of ODS after He irradiation

- Free electron laser (FEL)

- Special aspects/Possible application

- Neutrons

- Sources / Features

- One example 


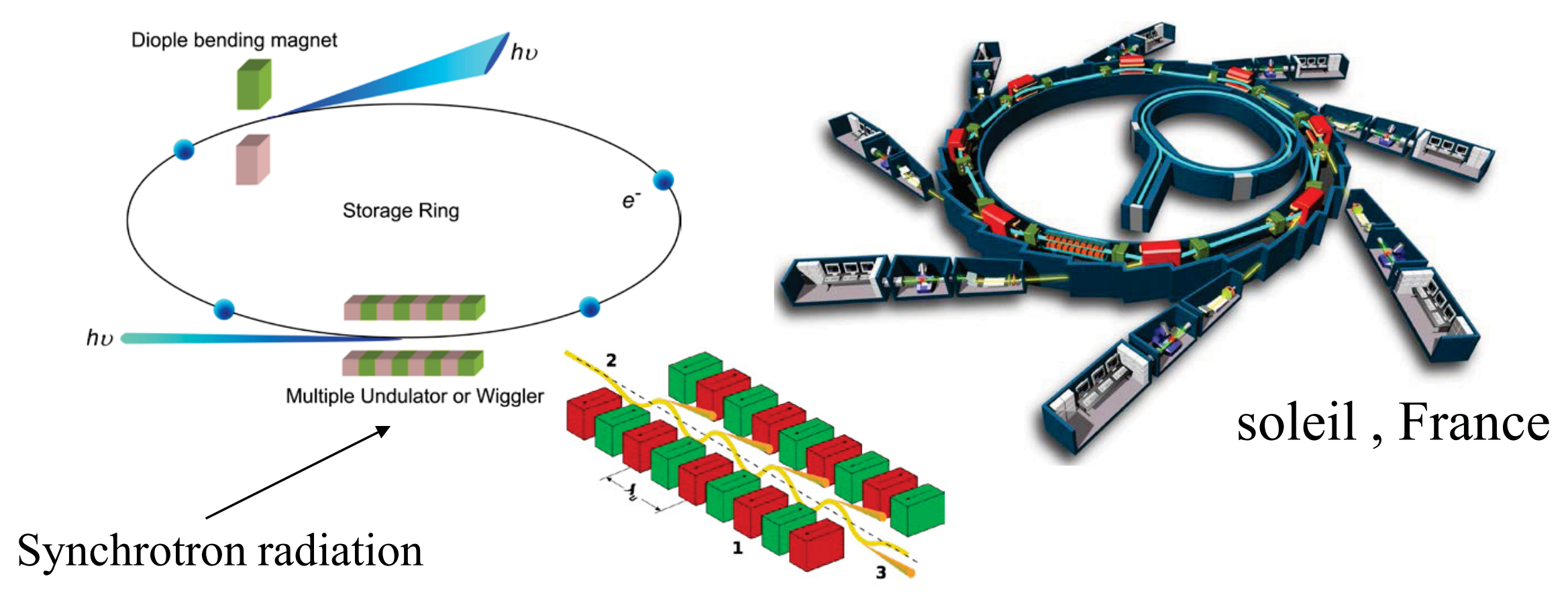

\section{Synchrotron}

- Intense light

- Infrared - Hard X-Ray (huge range) 


\section{Synchrotron radiation experiments}

\section{Beamlines for radioactive samples}

- ANL/APS - (USA)

- Berkeley Lab/ALS- (USA)

- BNL/NSLS - (USA)

- ESRF - (France) - element specific

- KIT/ANKA - INE - (Germany) - element specific C-Lab

- SLS - Microxas - (Switzerland) - 100 LA

- Soleil - Mars - (France) - <1 LA

- Spring8/JAEA - Actinide Science - (Japan)

- Stanford University/SSRL - (USA)

\section{Sample downsizing}

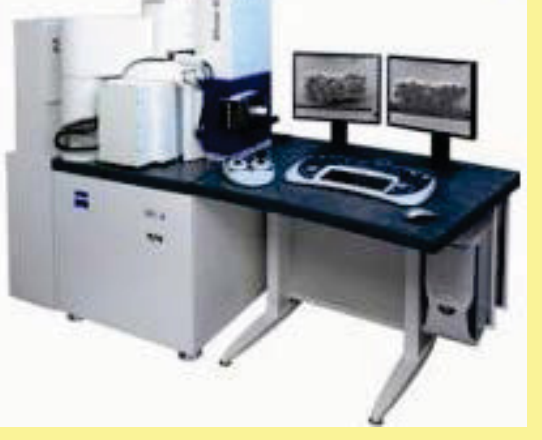

Local shielding

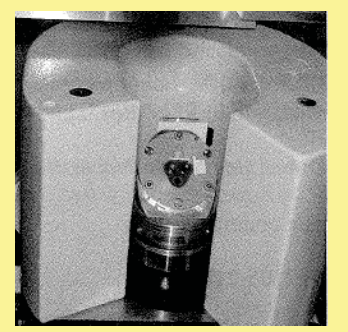




\section{Possible techniques}

- $X$ ray absorption techniques

- EXAFS / XANES $\leftarrow$

- $\mu$-XRD $\leftarrow$

- Tomography (high(er) resolution, penetration)

- Fluorescence 


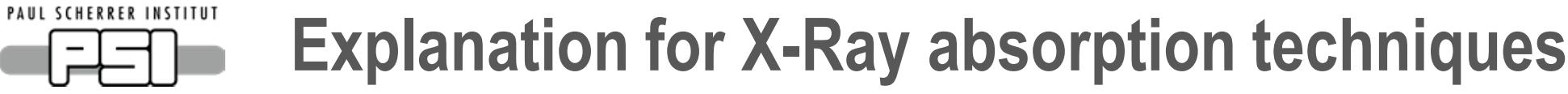

\section{XANES/EXAFS}

Absorption of incoming beam
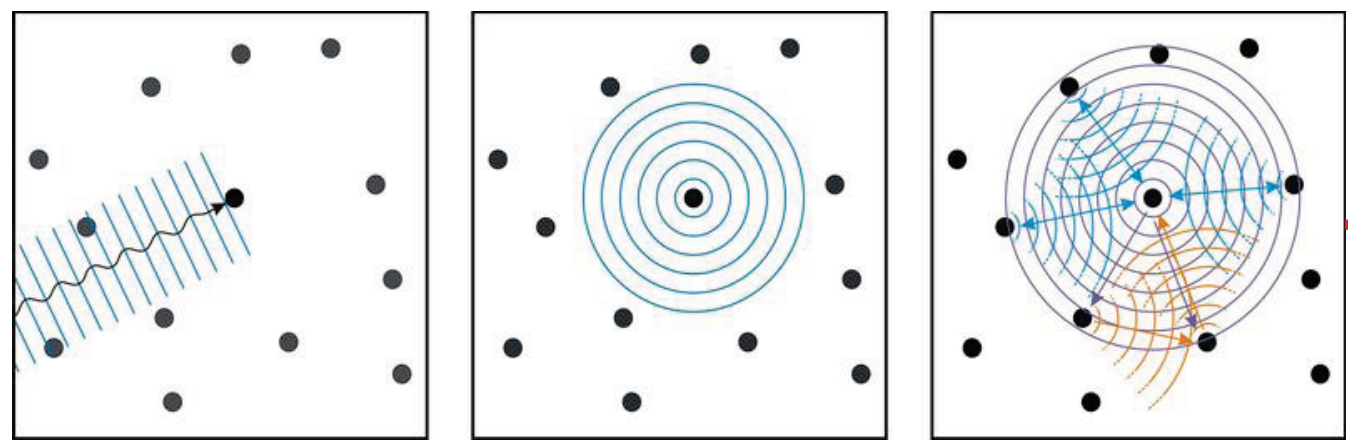

Resulting absorption spectrum

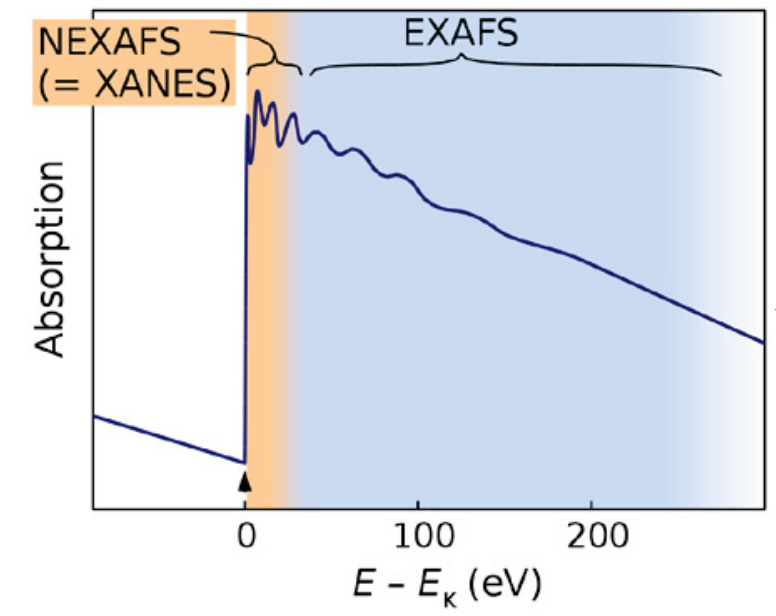




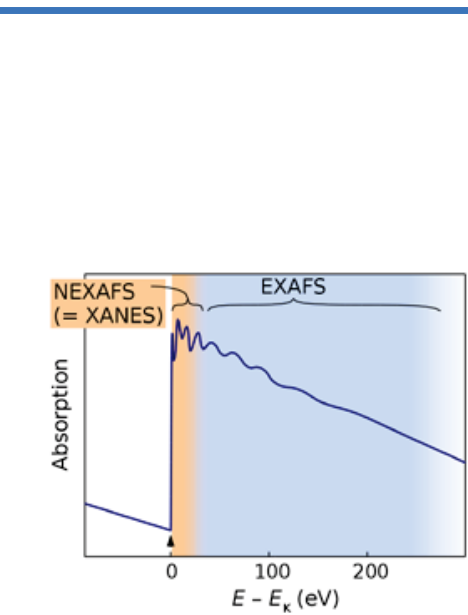

Extraction of

\section{fine structrue}

(substraction of atomic absoption)

Fourier trsf.
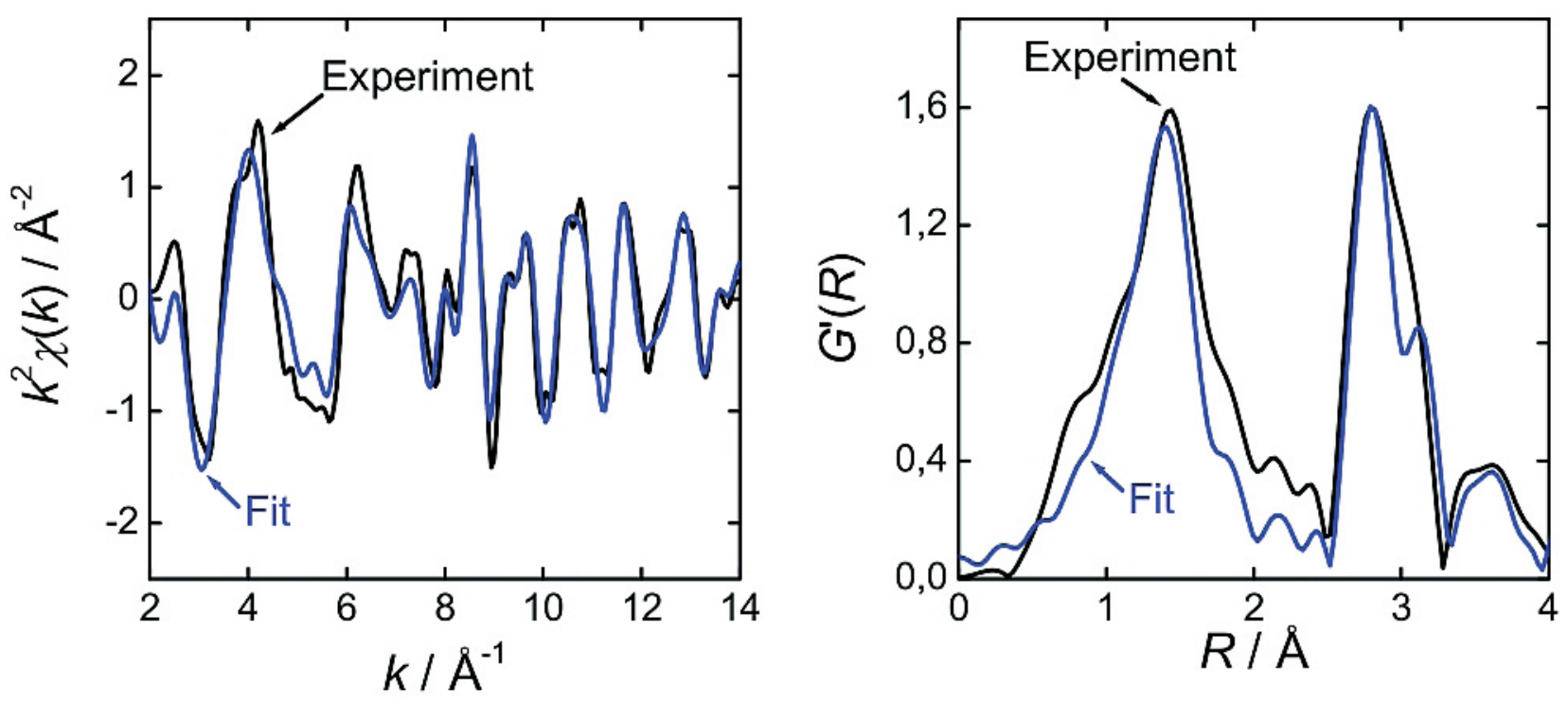

Example for $\mathrm{GaO}_{1.2}$ 


\section{Paul scherrer institut}

\section{Effect of Redox on White line}

White line

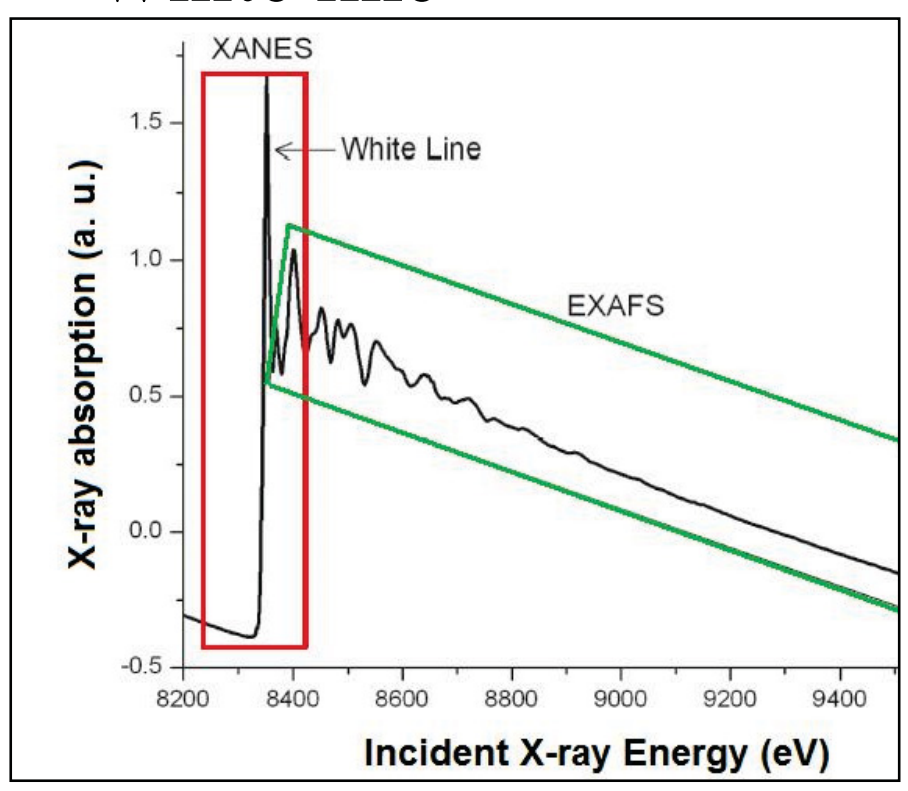

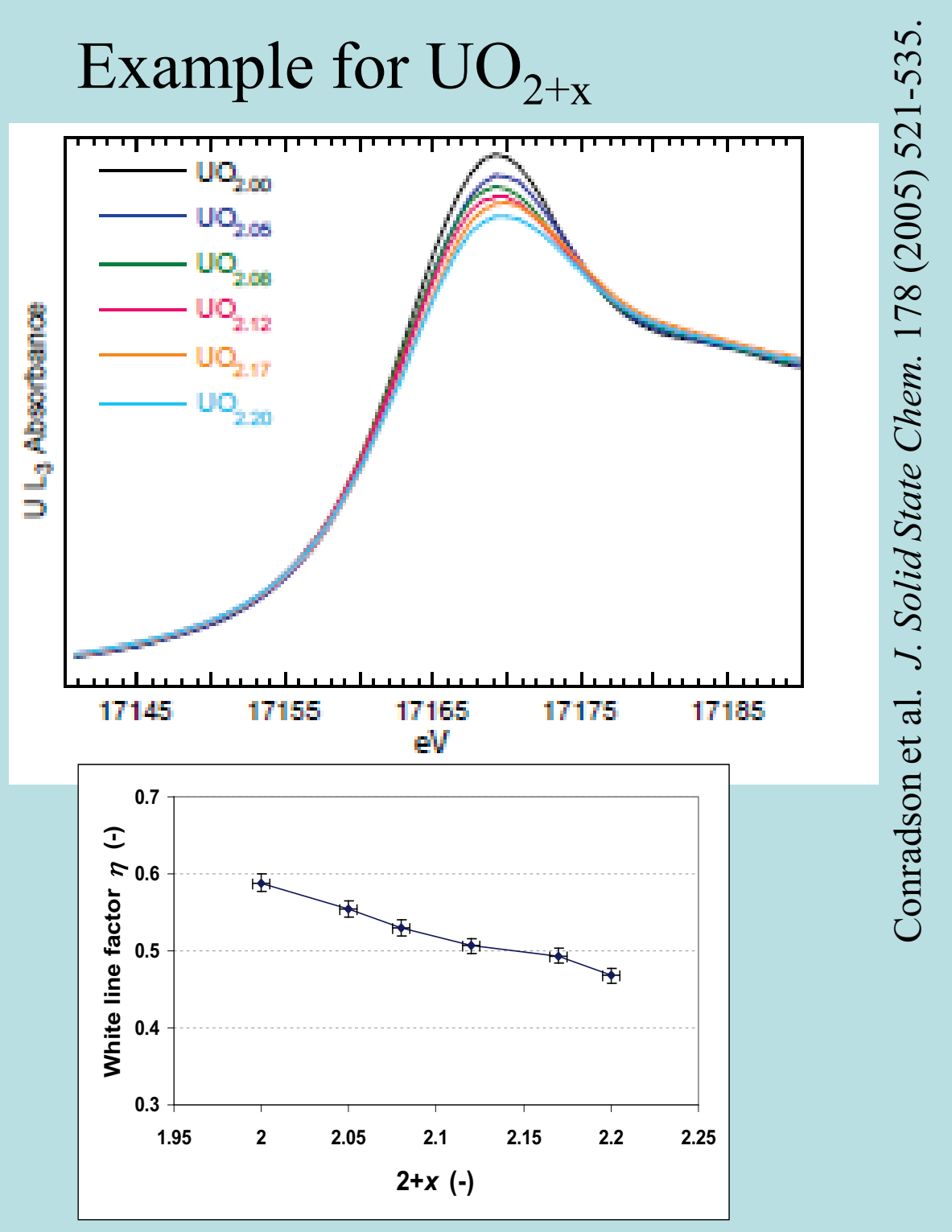




\section{Table of contents}

- Introduction

- Aspects of beamlines / Types of beamlines

- X-Ray beamlines

- Synchrotron light sources

- Basics / Beamlines in the world

- Selection of analysis techniques

- Examples

-PIE of MOX by $\mu$ XRD, EXAFS

$-X R D$ of ODS after He irradiation

- Free electron laser (FEL)

- Special aspects/Possible application

- Neutrons

- Sources / Features

- One example 


\section{MOX sample: SpherePack 60 MWd kg-1 @ KKB-I}

\section{Beta and gamma autoradiography done on the sample}

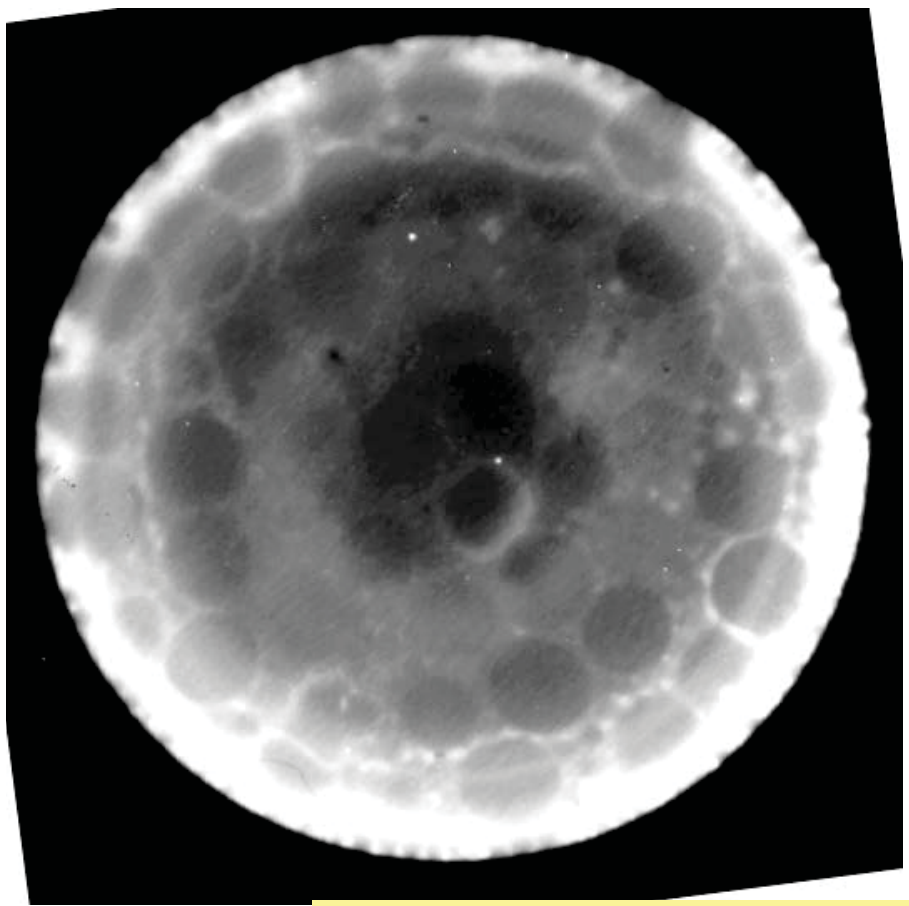

C. Degueldre*, M.A. Pouchon, G. Kuri, C. Borca, C. Cozzo, White line of actinide $\mathrm{x}$-ray absorption spectra as a tool for their atomic environment description, 40emes Journées des actinides, CERN, 27-30 March 2010

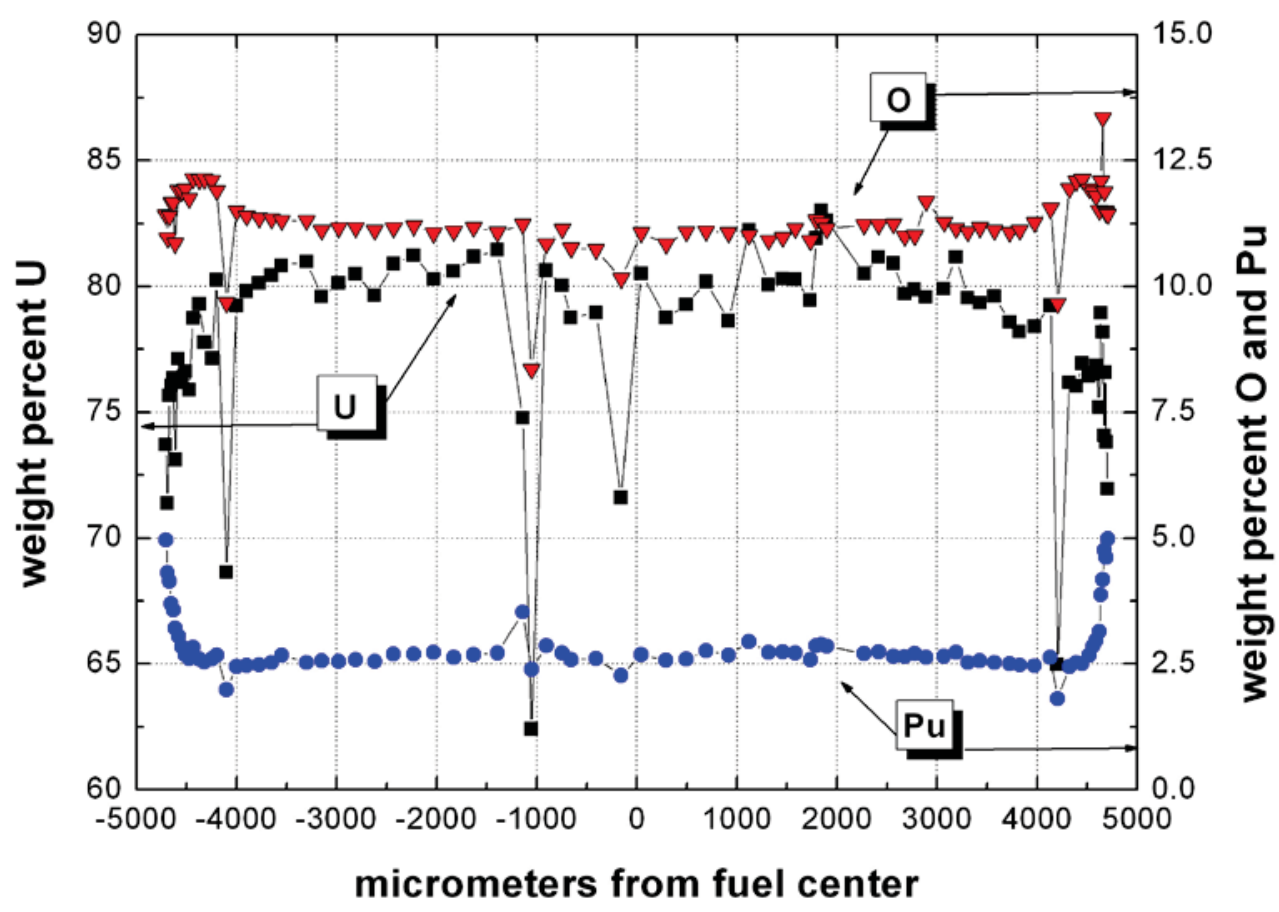

We also have: diametrical concentration profiles of the fission products $\mathrm{Nd}, \mathrm{Zr}, \mathrm{Cs}, \mathrm{Xe}, \mathrm{Ba}, \mathrm{Mo}$ and $\mathrm{Ru}$. 


\section{PAUL SCHERRER INSTITUT \begin{tabular}{|l|l|}
\hline &
\end{tabular} \\ Example for $\mu$ XRD and EXAFS - Setup}

\section{MOX XAFS analysis}

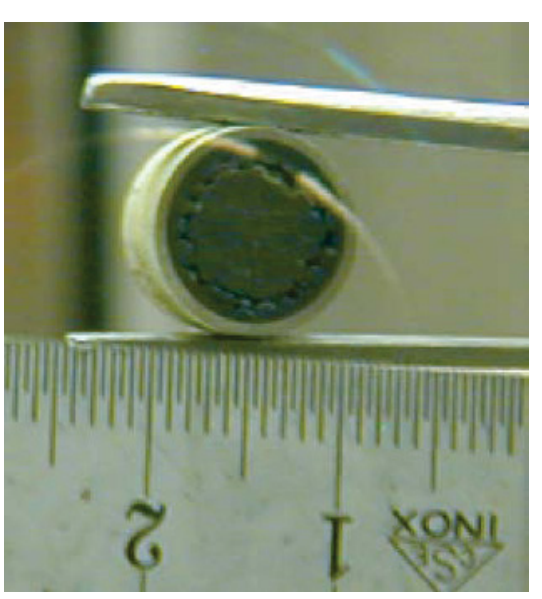

Kapton foil

peeling and selection of subsample with activity

$<100$ LA
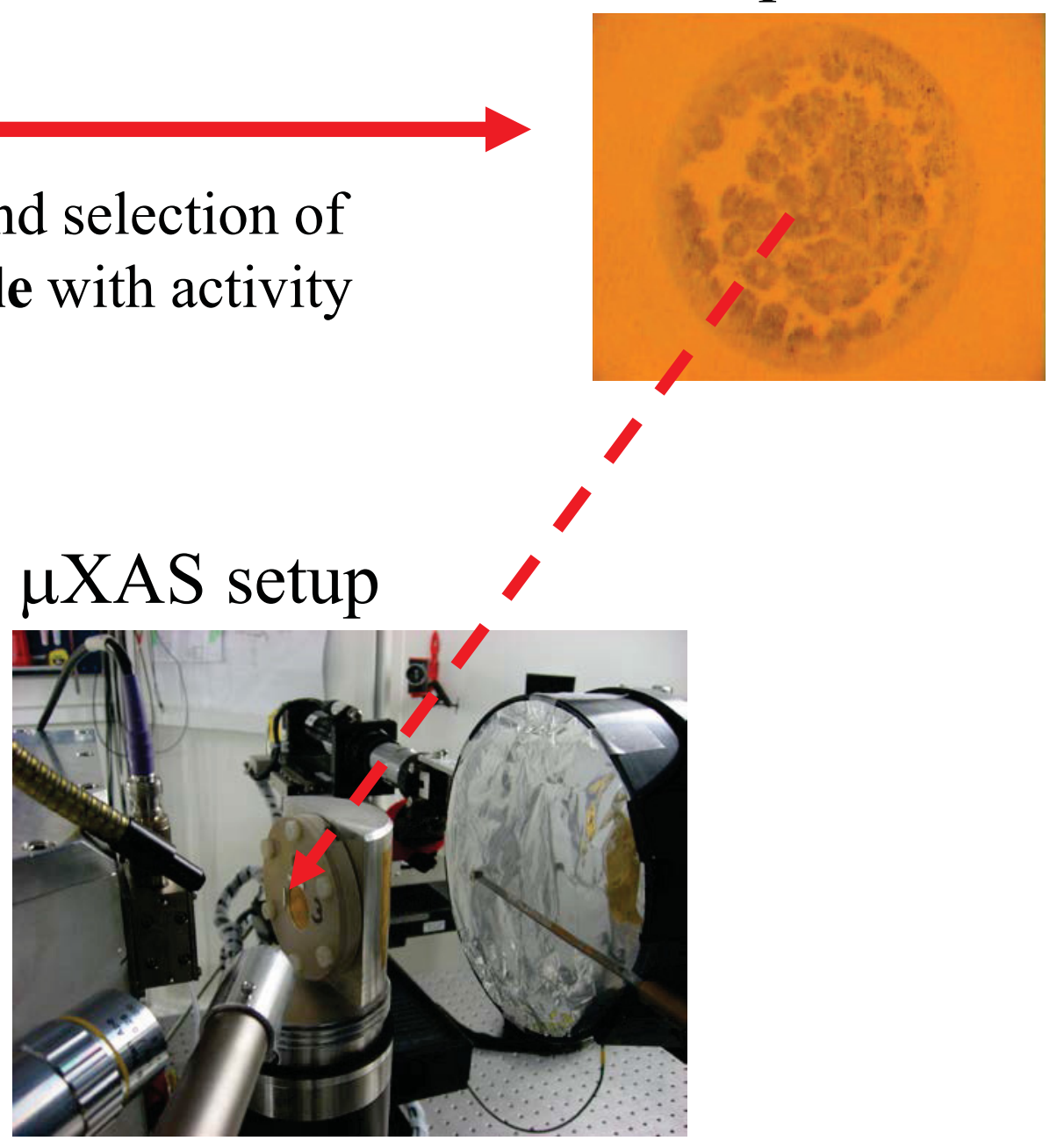

C. Degueldre et al., J. Nucl. Mater. (2011), doi:10.1016/j.jnucmat.2010.11.096 


\section{MOX $\mu$ XRD conditions: $E_{0} 18600 \mathrm{eV}, \lambda=0.666 \AA, v \sim 300 \mu \mathrm{m}^{3}$}

\section{Pristine MOX}

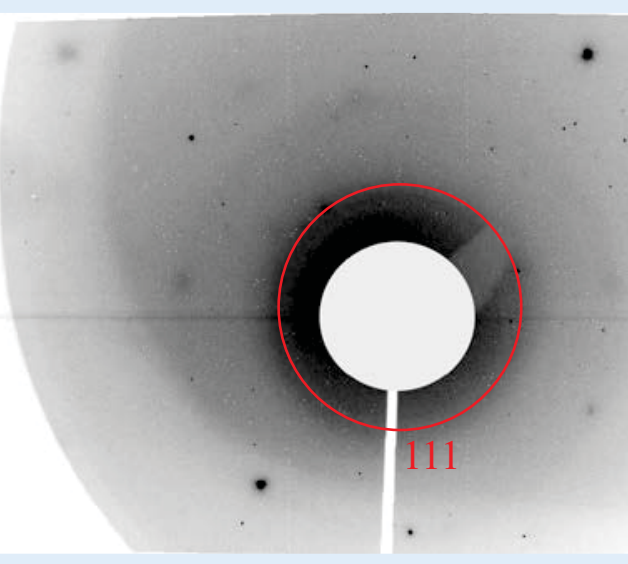

MOX center

MOX RIM

Local crystalline changes during burnup

- Center: lower burnup (1700dpa) limits damage \& high $\mathrm{T}(\sim 1400 \mathrm{oC})$ increases healing

- RIM: larger burnup (2500dpa) increases damage \& lower T ( 600oC) limits healing 


\section{Example for $\mu$ XRD and EXAFS - White line}

\section{MOX $\mu$ XAFS conditions: Pu L3 Edge, $v \sim 300 \mu \mathbf{m}^{3}$}

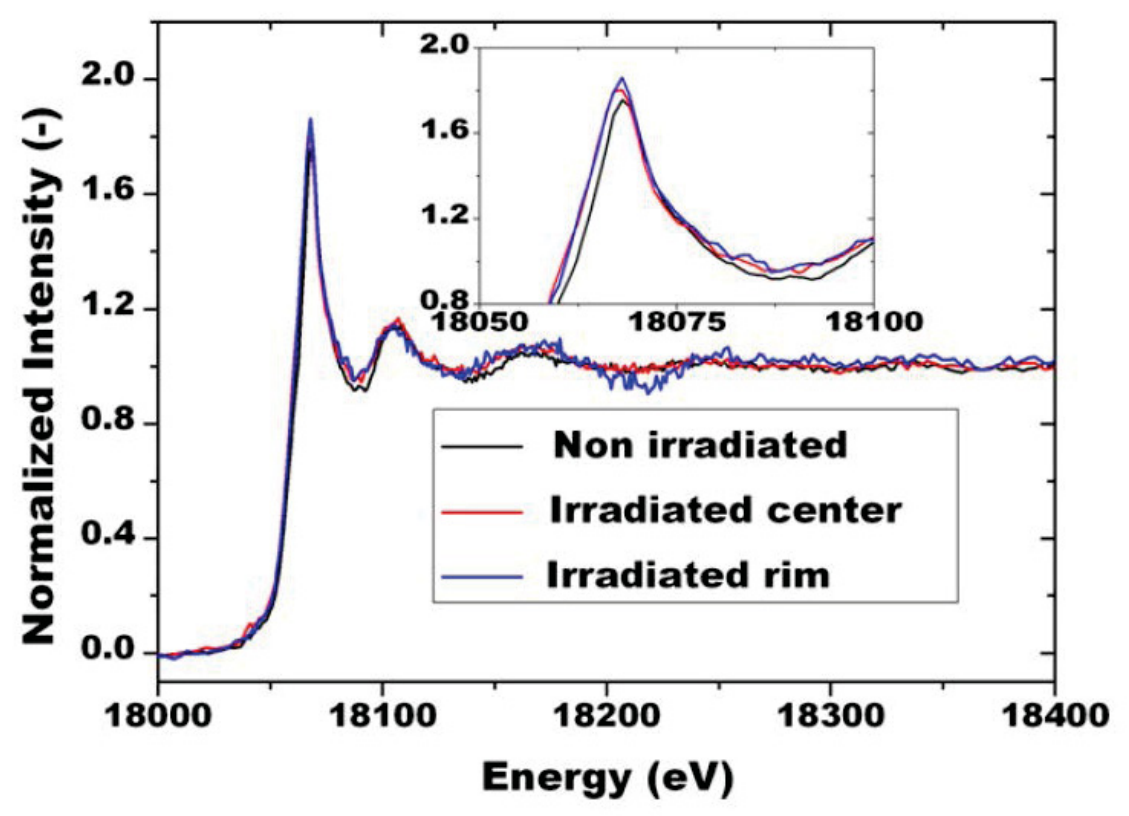

Pu redox in MOX fuel is likely to remain unchanged during burnup

In MOX center, lower burnup (Eo $=18062 \pm 2 \mathrm{eV}$ ).

In MOX RIM, larger burnup but PCI, (Eo = 18062 $\pm 2 \mathrm{eV})$. 


\section{EXAFS of irradiated ODS - Material}

Chemical composition

\begin{tabular}{|c|ccccc|}
\hline elements & $\mathrm{Fe}$ & $\mathrm{Cr}$ & $\mathrm{Al}$ & $\mathrm{Ti}$ & $\mathrm{Y}_{2} \mathrm{O}_{3}$ \\
\hline wt \% & 73.5 & 20 & 5.5 & 0.5 & 0.5 \\
\hline
\end{tabular}

$\mathrm{Y}_{2} \mathrm{O}_{3}$ particle size distribution

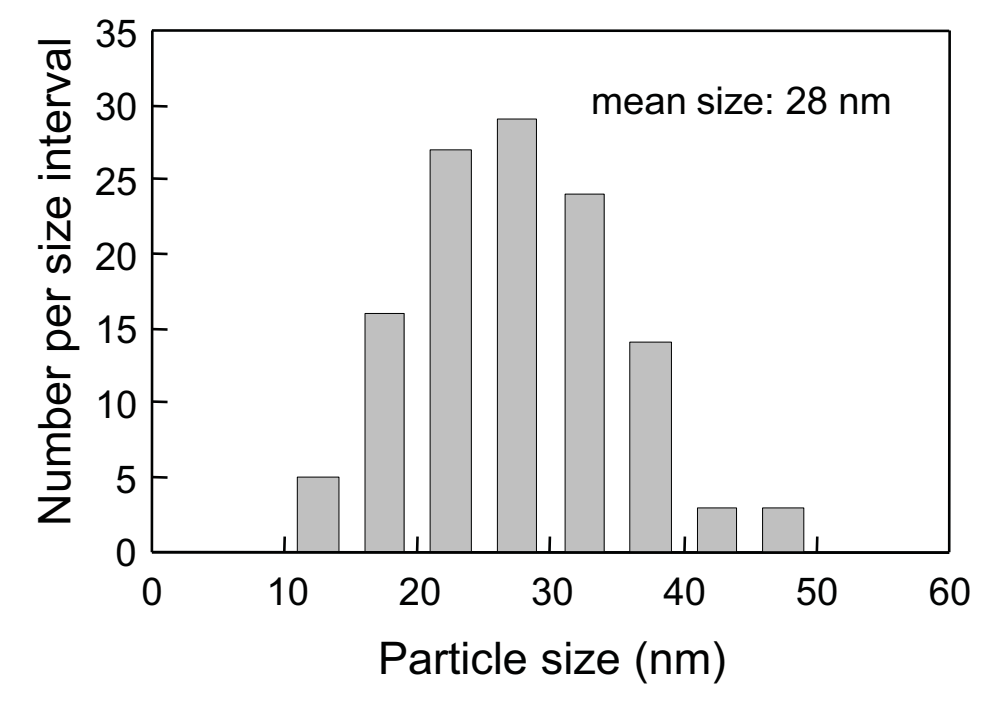

\section{PM2000}

Grain size: $1 \times 1 \times(>12) \mathrm{mm}^{3}$
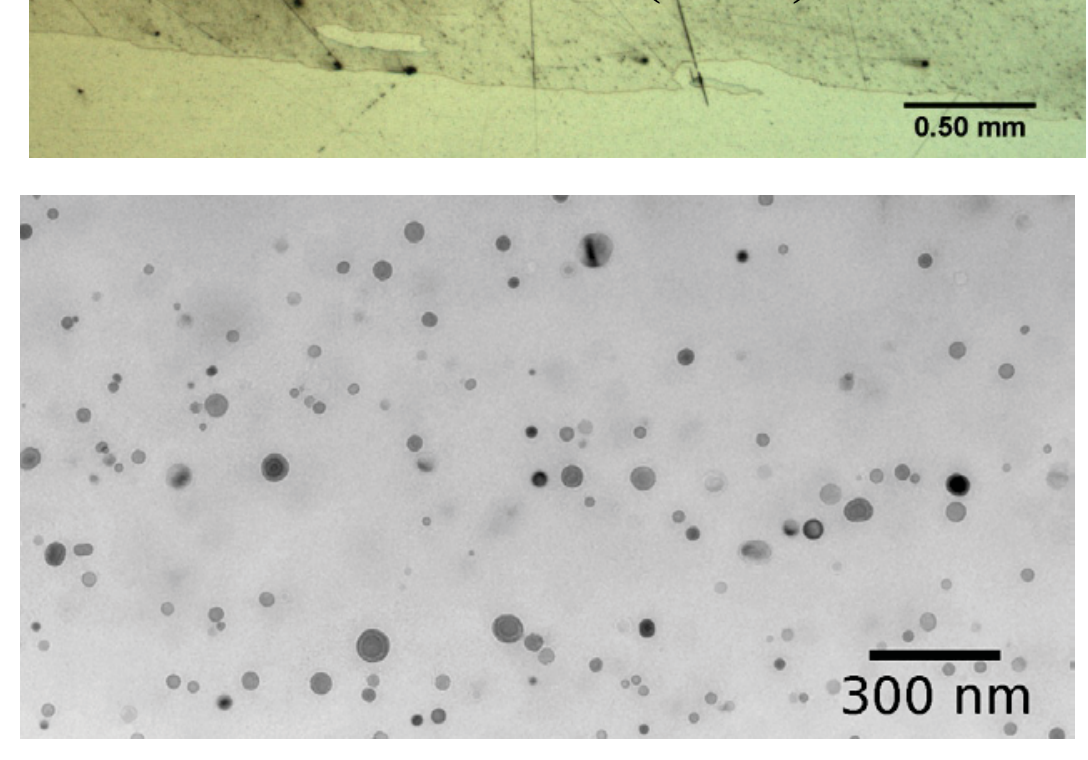
EXAFS of irradiated ODS - Cyclotron @ $570 \mathrm{~K}-\mathrm{Y}_{2} \mathrm{O}_{3}$ Results

\section{Comparison of the EXAFS signal for the irradiated and the non- irradiated sample}

\section{Difference!}

Irradiation:

- $1 \mathrm{dpa}$

- $\underline{570 \mathrm{~K}}$ irrad. temperature

$\rightarrow$ Structure of $\mathrm{Y}_{2} \mathrm{O}_{3}$ changes

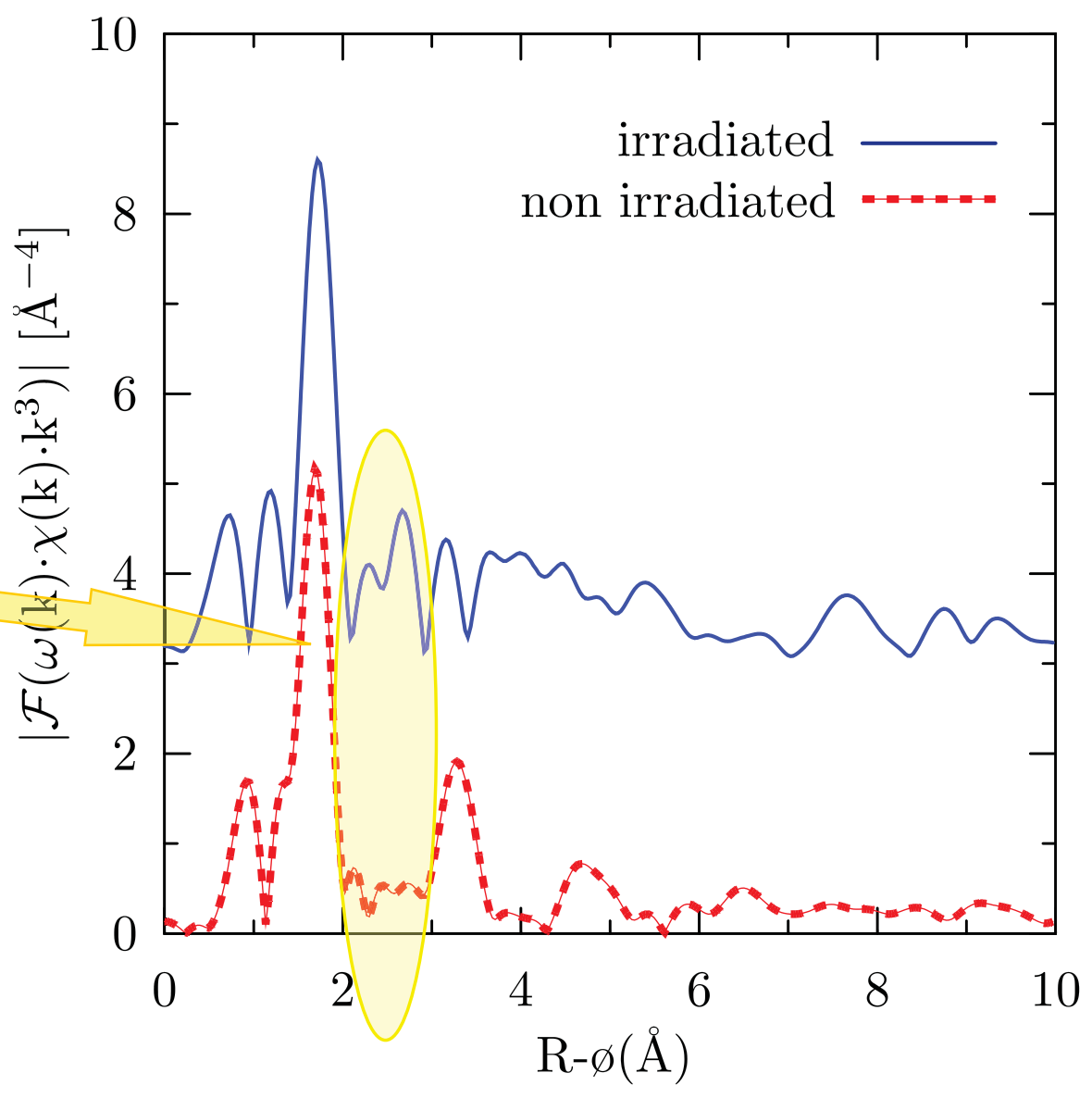




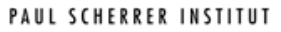 $\in[\in]=$ \\ Example for in situ $\mu$-XRD}
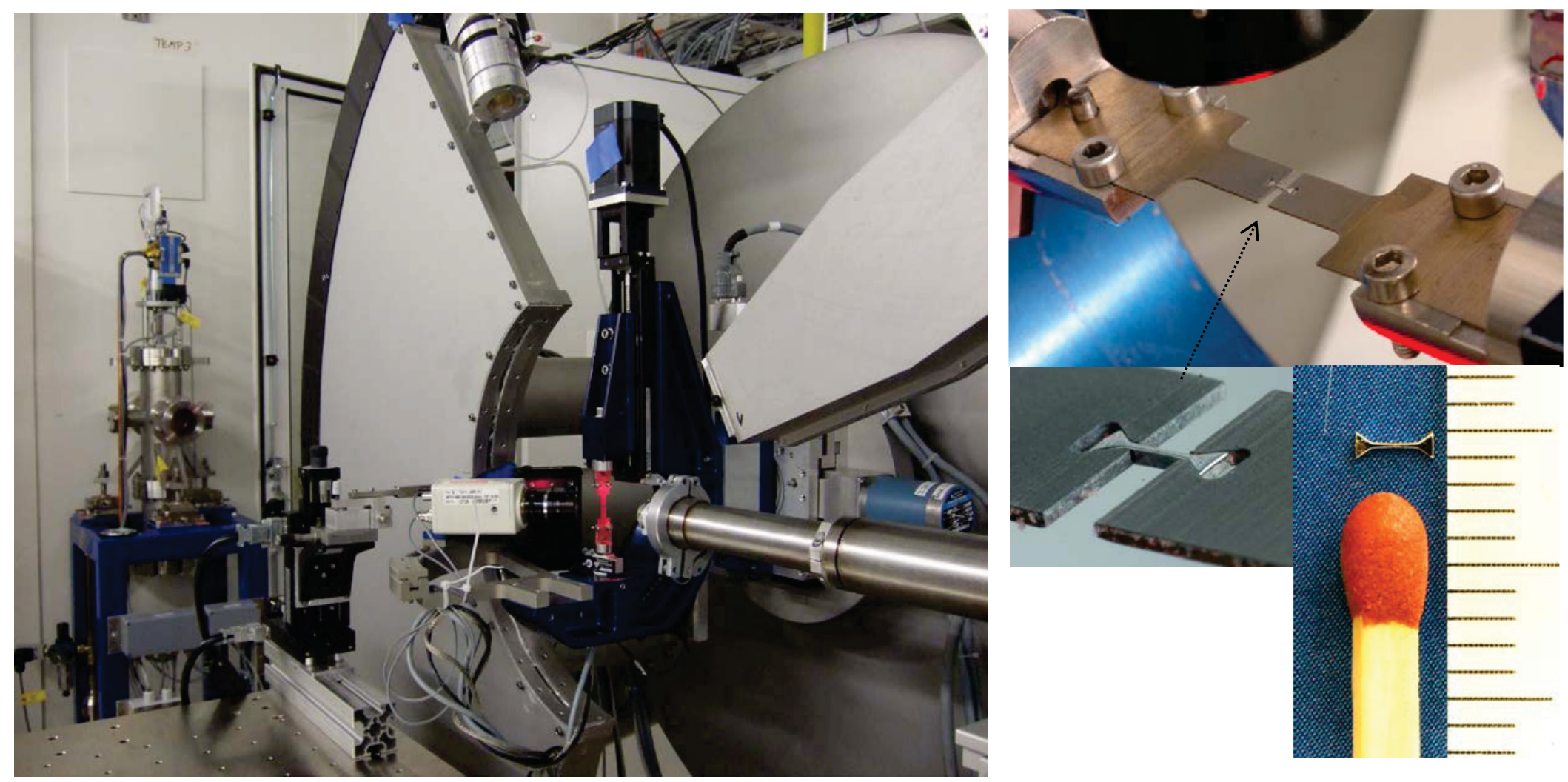


\section{paul scherrer institut}

\section{ODS Material - K1 from Kyoto university}
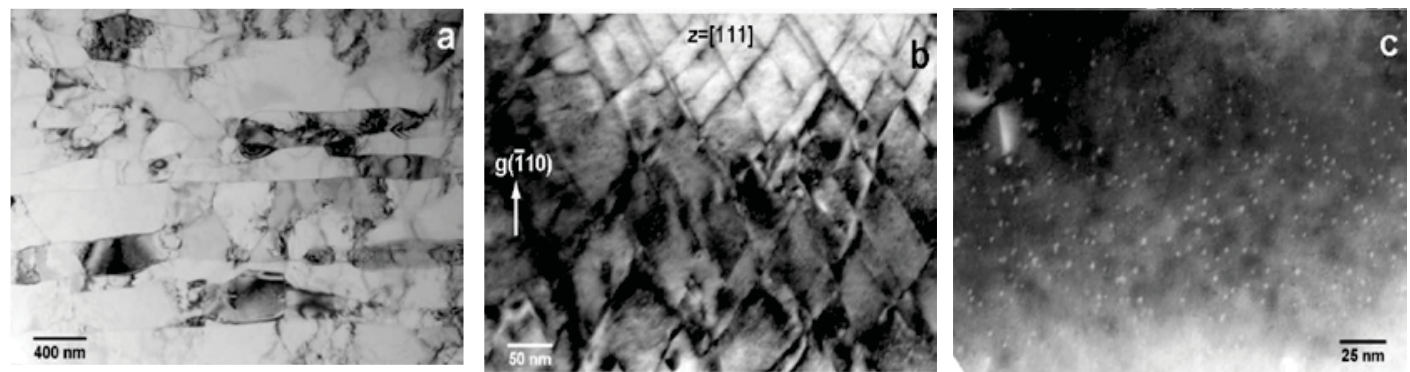

Peak shift / Load

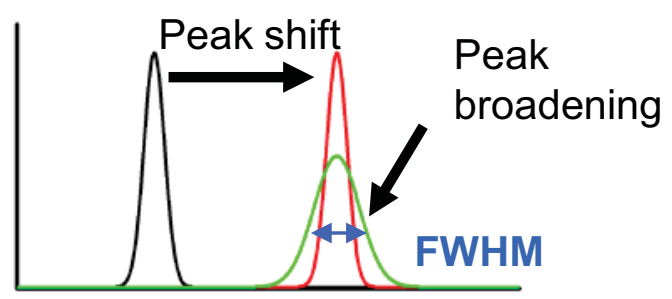

Scattering angle $(2 \theta)$

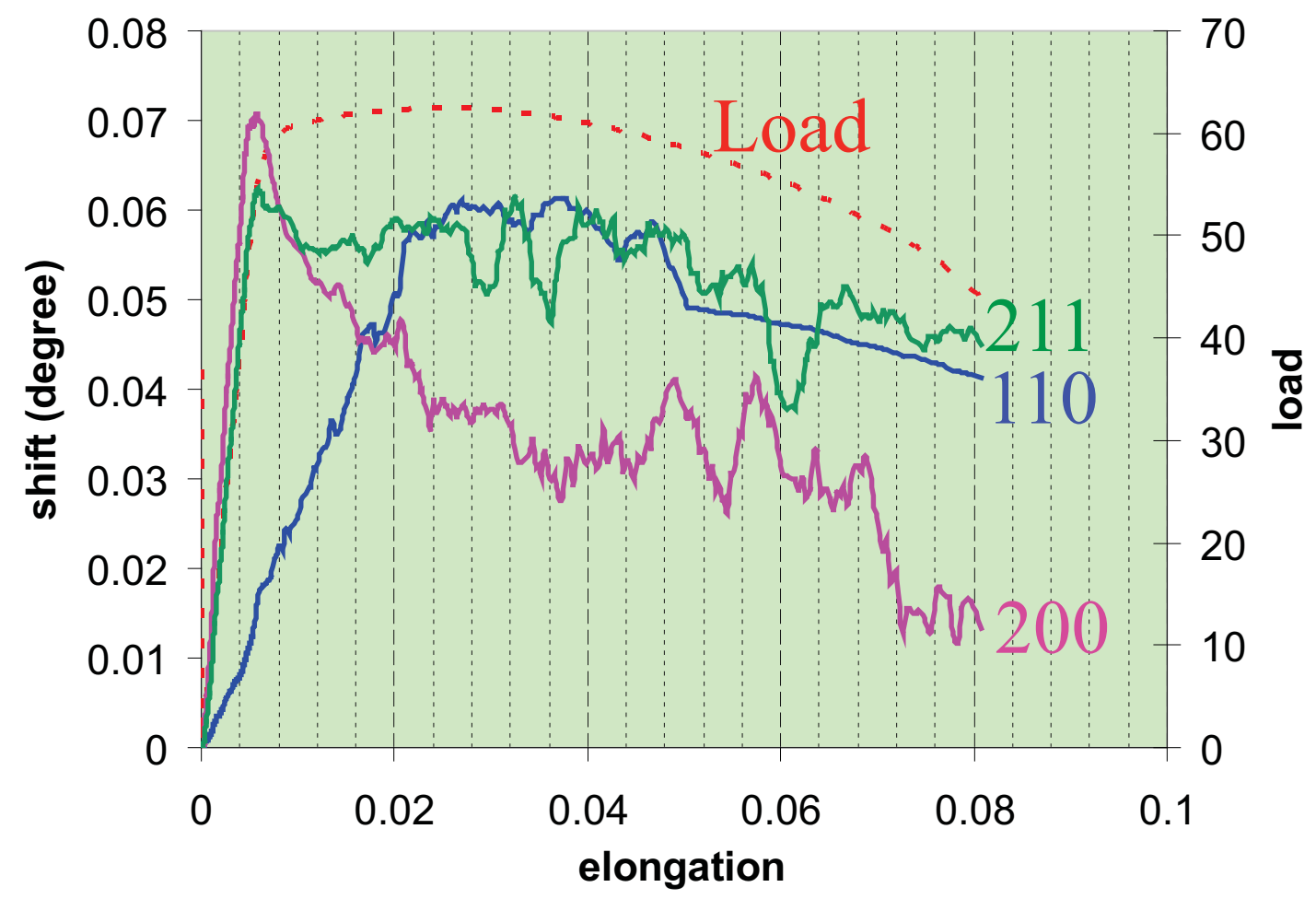




\section{Table of contents}

- Introduction

- Aspects of beamlines / Types of beamlines

- X-Ray beamlines

- Synchrotron light sources

- Basics / Beamlines in the world

- Selection of analysis techniques

- Examples

$$
\text { -PIE of MOX by } \mu \text { XRD, EXAFS }
$$

$-X R D$ of ODS after He irradiation

- Free electron laser (FEL)

- Special aspects/Possible application

- Neutrons

- Sources / Features

- One example 


\section{X-Ray FEL}

undulator (wiggler) $\rightarrow$ light emission

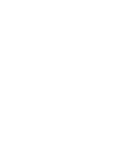

a
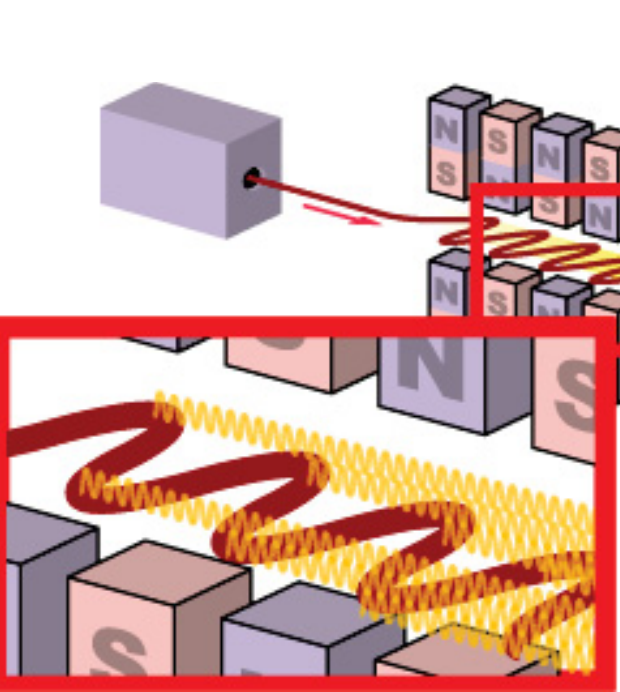

Laser:

- coherent electromagnetic radiation

- high intensity

- pulsed light ( 30 fs with $10^{11}$ photons $)$
* electron motion is in phase

with the field of the light already emitted $\rightarrow$ coherency

* instabilities of e- beam lead to bunching $\rightarrow$ light pulses

- FLASH in Hamburg

- LCLS at SLAC National Accelerator Laboratory

- XFEL in Hamburg

- SCSS at SPring-8

- SwissFEL at the PSI SACLA at the RIKEN Harima Inst.

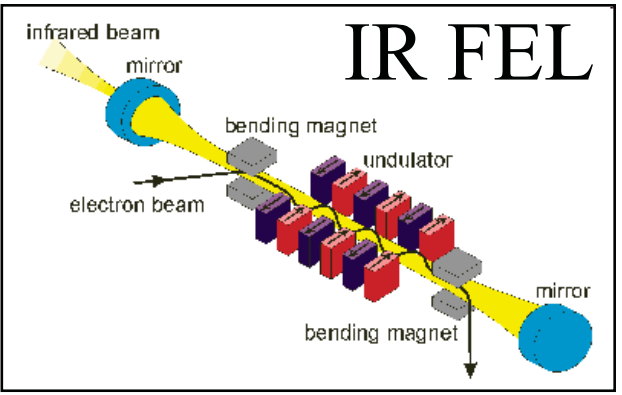




\section{Possible application of a FEL}

\section{Taking advantage of very short (fs range) pulses:}

- Dynamics of irradiation-induced defects in nuclear materials

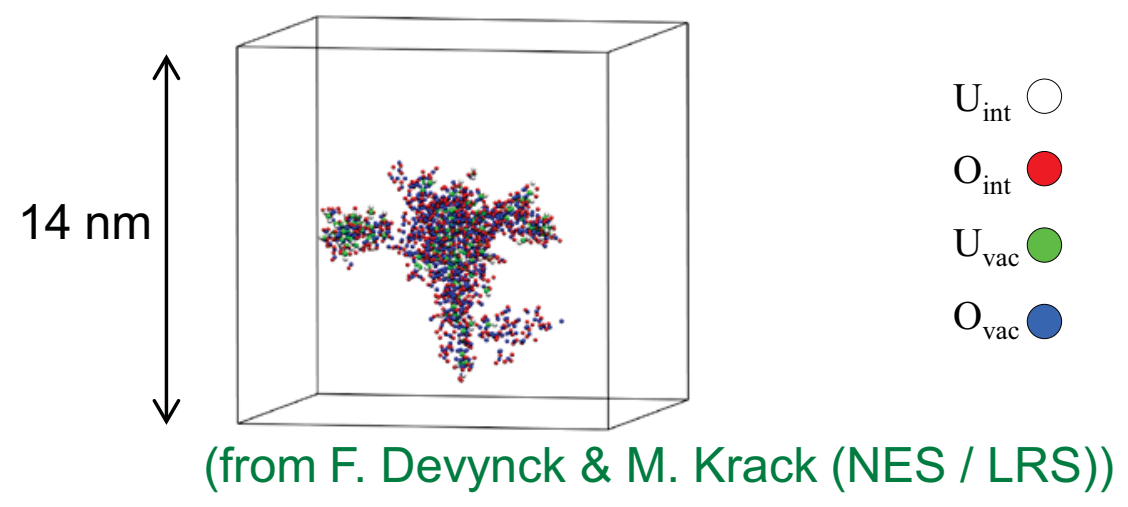

$$
\mathrm{t}: \sim 0.1-30 \mathrm{ps}, \mathrm{L}: 0.1-10 \mathrm{~nm}
$$

Method: pump - probe diffuse scattering

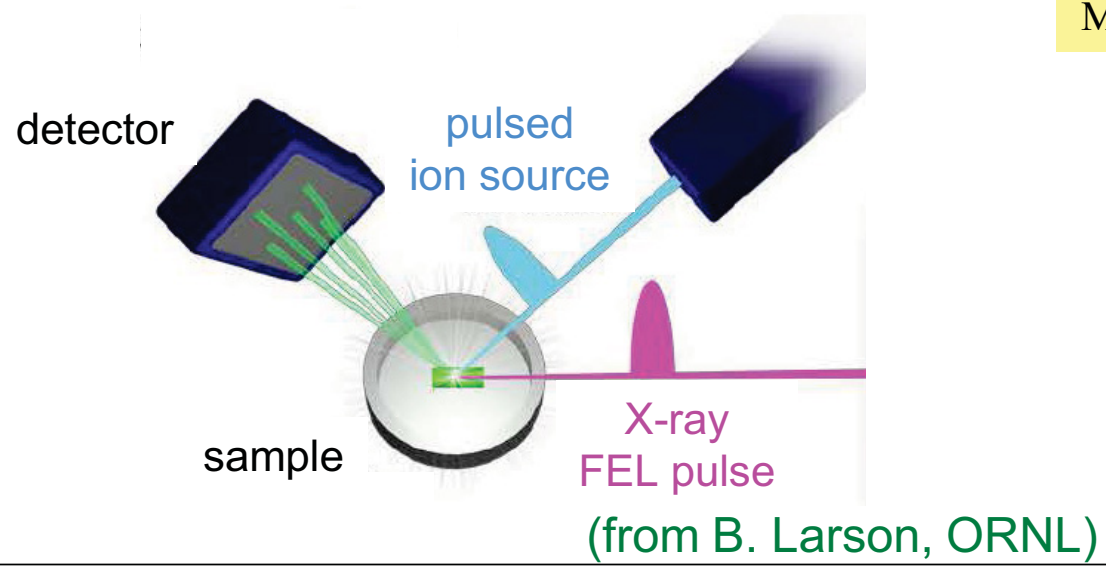

A. Froideval, A. Badillo, J. Bertsch, S. Churakov, R. Dähn, C. Degueldre, T. Lind, D. Paladino, B.D. Patterson, J. Nucl. Mater. (2011), article in press 
Taking advantage of coherency:

$\rightarrow$ Possibility to take advantage of holographic techniques

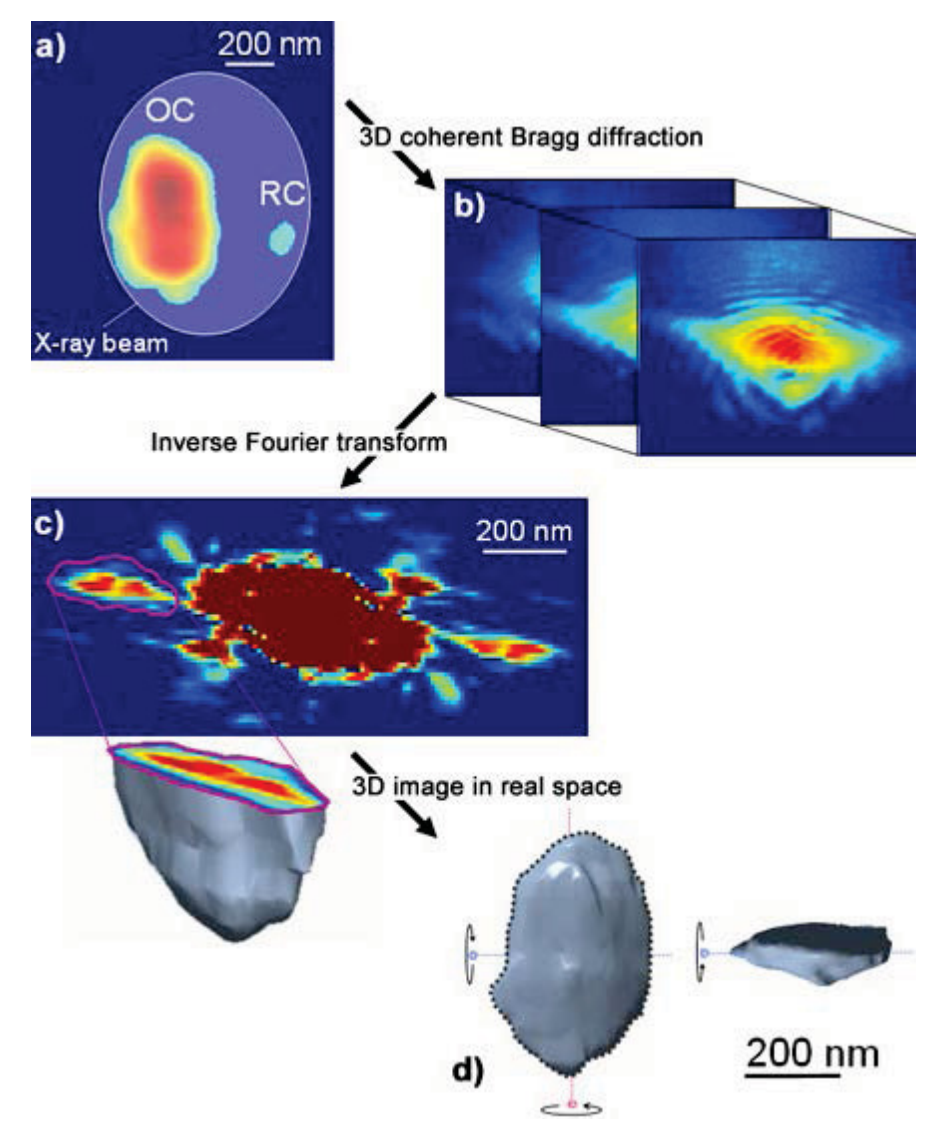

http://www.esrf.eu/news/ spotlight/spotlight 122 


\section{Table of contents}

- Introduction

- Aspects of beamlines / Types of beamlines

- X-Ray beamlines

- Synchrotron light sources

- Basics / Beamlines in the world

- Selection of analysis techniques

- Examples

$$
\text { -PIE of MOX by } \mu \text { XRD, EXAFS }
$$

$-X R D$ of ODS after He irradiation

- Free electron laser (FEL)

- Special aspects/Possible application

- Neutrons

- Sources / Features

- One example 


\section{:}

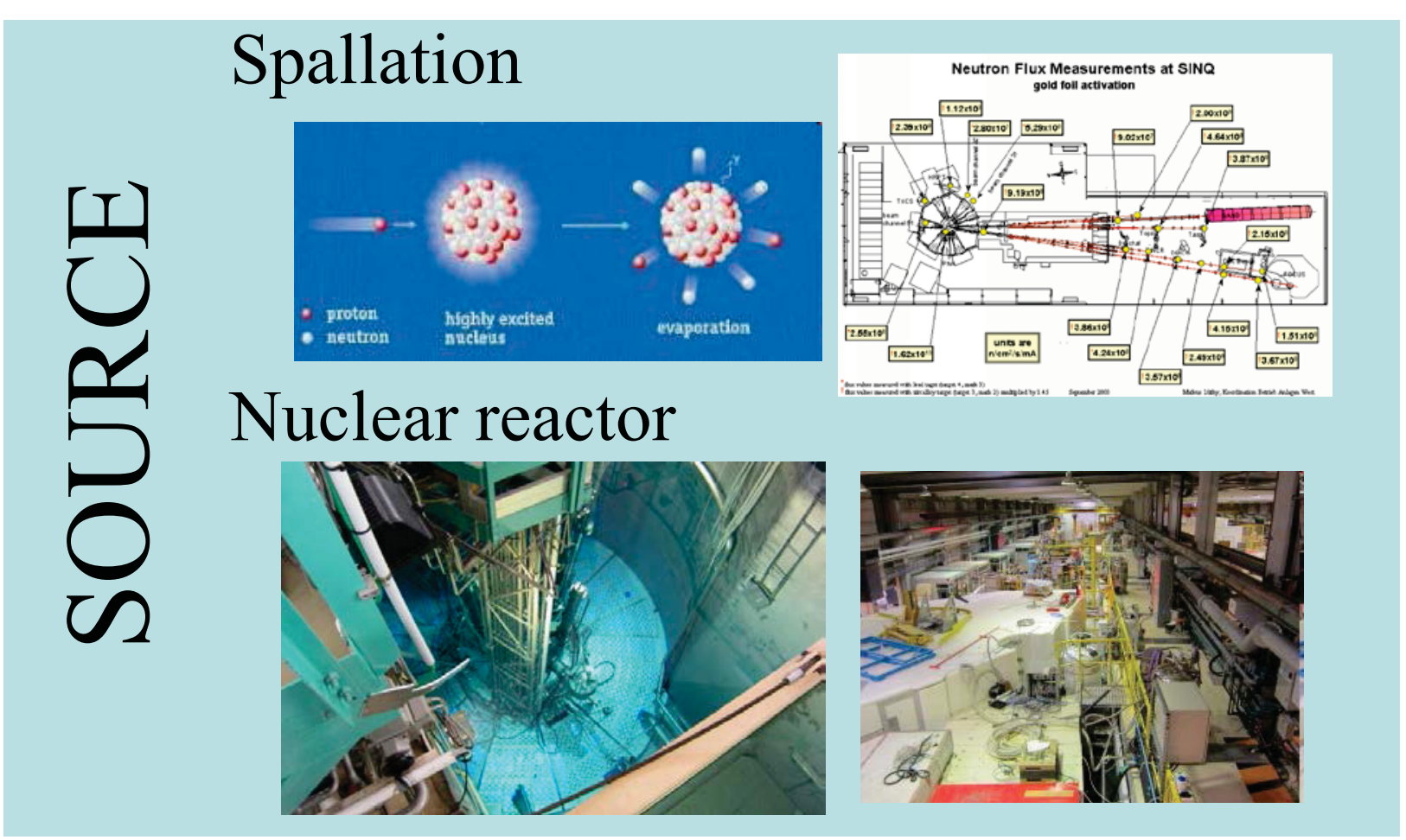

Sensitivity

密
Magnetic interaction

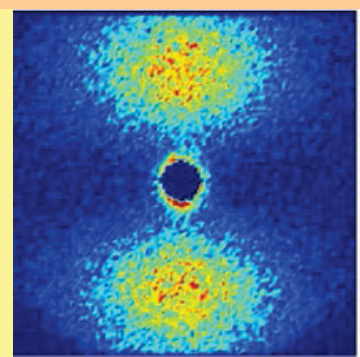

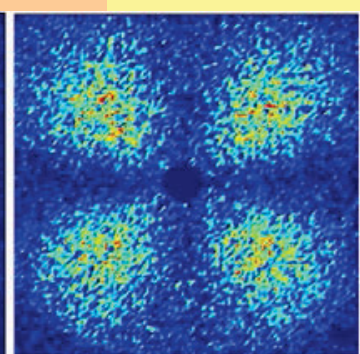




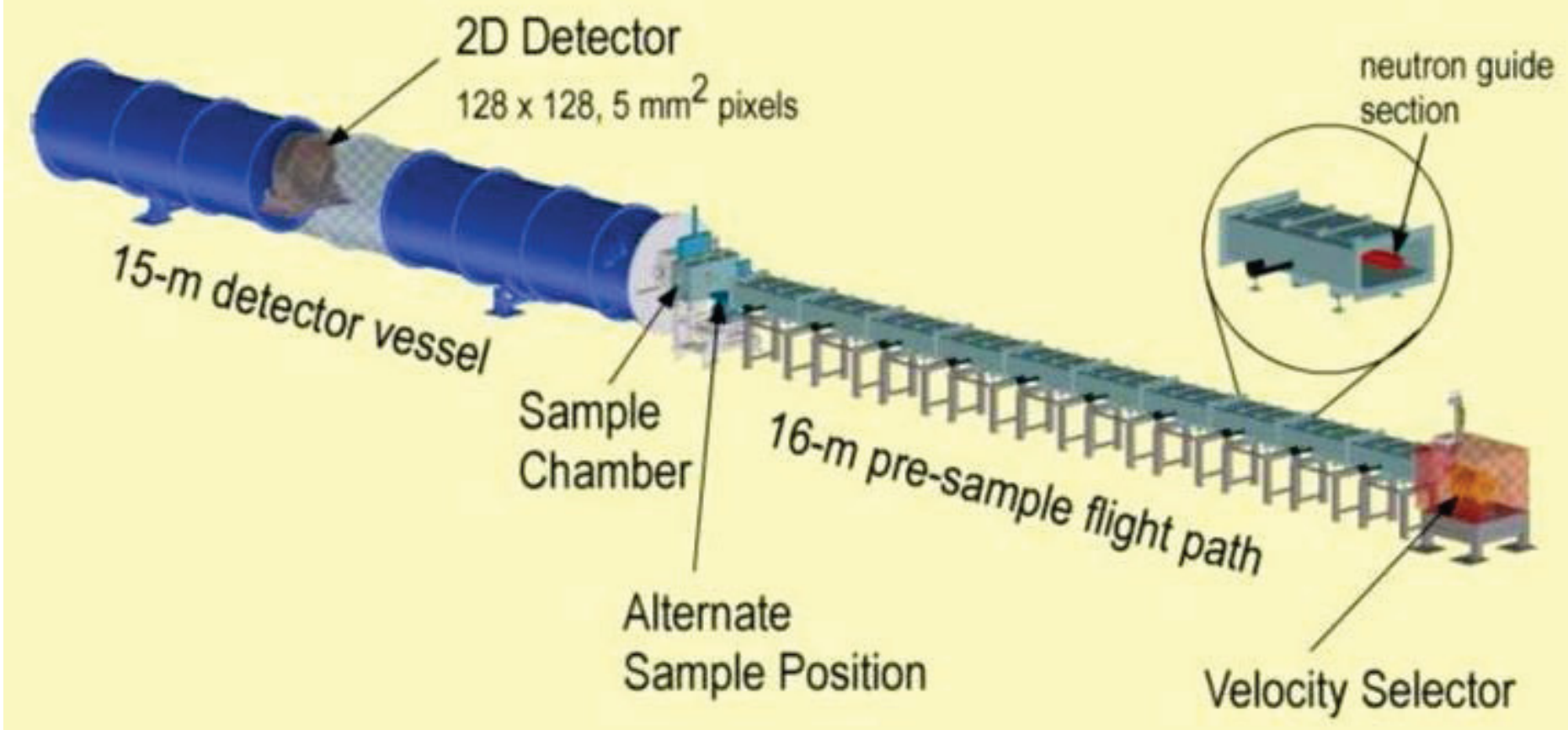

Detection of very small features 


\section{paul scherrer institut}

Porosity investigation of a ceramic (YSZ) as an inert matrix fuel
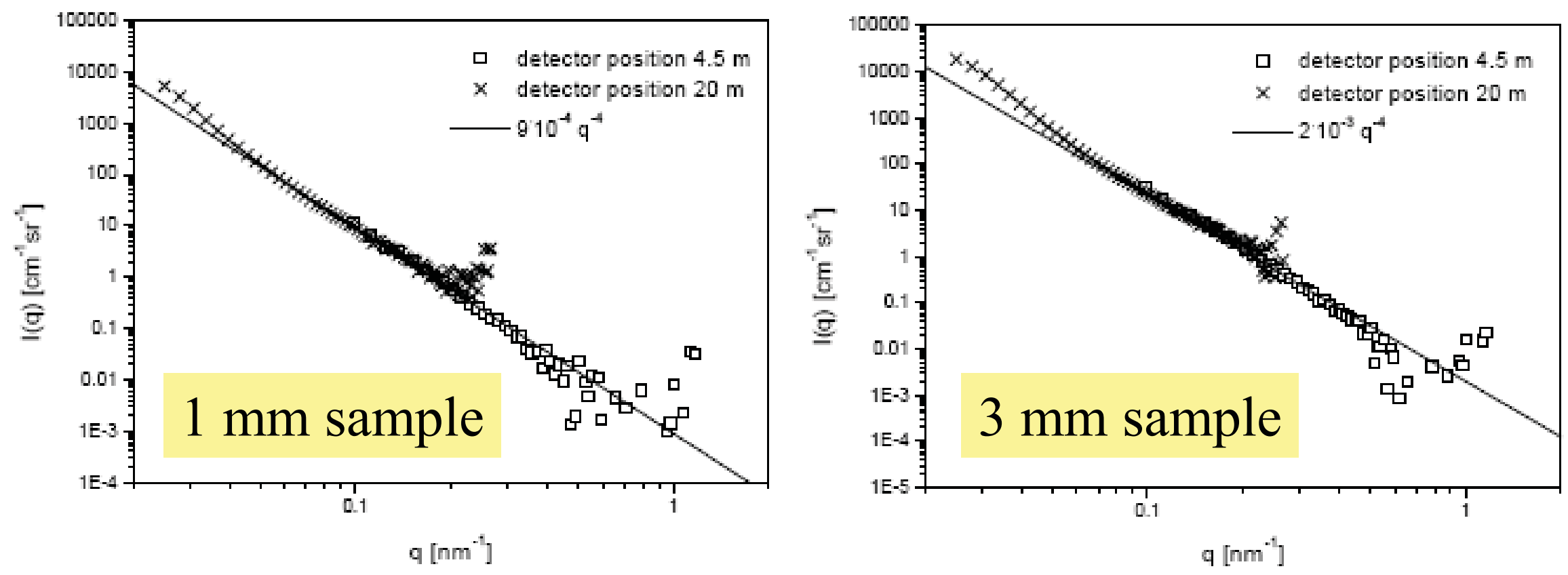

$\rightarrow$ Volumetric identification of porosity in the $<300 \mathrm{~nm}$ range 


\section{Conclusions}

-Beamline techniques offer many new possibilities, but require a good planning

-Radioactive samples will often require important downsizing / miniaturization and equipped beamlines

-Some techniques allow atomistic resolution, fast processes, ...

$\rightarrow$ useful for validation of modeling

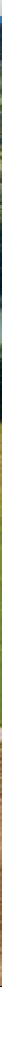


Laser-based Measurement Techniques for Nuclear Materials

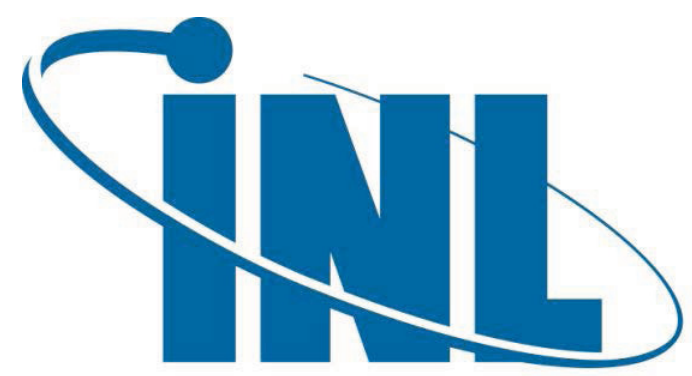

Idaho National Laboratory
J. Rory Kennedy, David Hurley, Robert Schley, Stephen Reese, Matthew Fig

Idaho National Laboratory

OECD/NEA PIE Workshop

Paris, France

June 16, 2011 
- Thermal Diffusivity

- Laser-based Resonant Ultrasound

- Average elastic constants

- Ultrasonic attenuation and microstructure

- Dispersion relation

- In-pile measurements 
Scanning thermal diffusivity microscope (STDM) allows determination of thermal diffusivity at $\mathbf{5 0} \mu \mathrm{m}$ spatial resolution (highest spatial resolution capability in world). Laser based and developed for hot cell application over past 4 years.

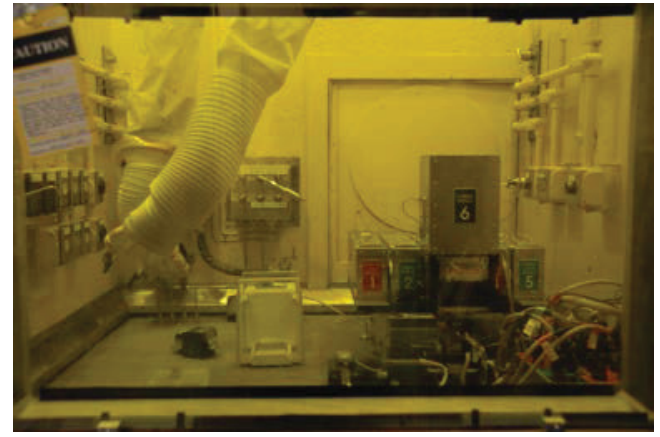

STDM in hot cell

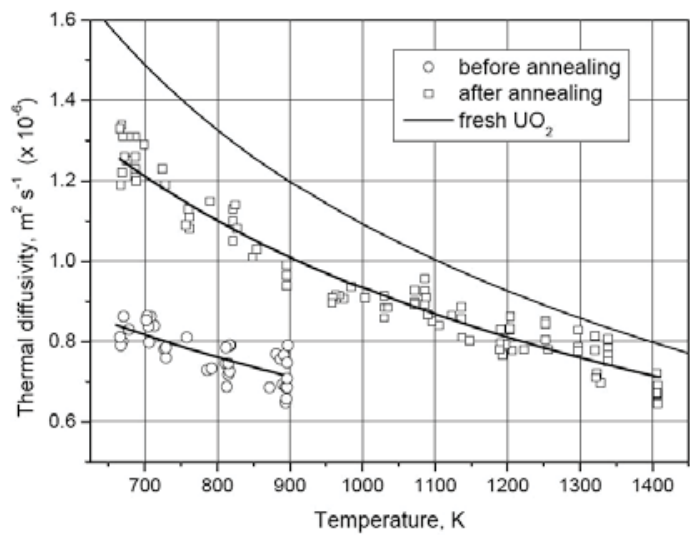

D. Staicu, M. Joergensen, G. Pagliosa, D. Papaioannou, M. Sheindlin, C.T. Walker

ANS 2005 Water Reactor Fuel Performance Meeting, Kyoto, Oct. 2-6, 2005

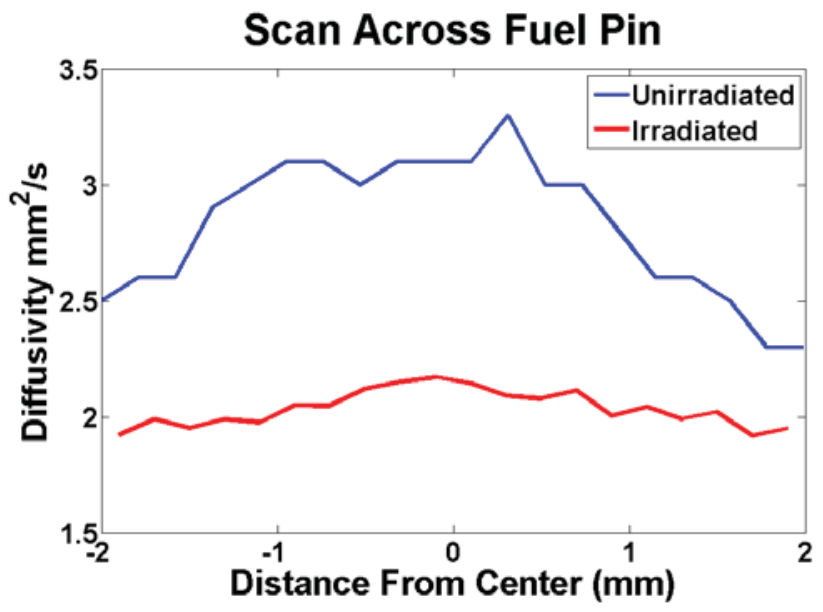

- Scan results at every $200 \mu \mathrm{m}$ across diameter of $4 \mathrm{~mm}$ metal fuel pin.

- Unirradiated: middle area of fuel yields thermal diffusivity of about 3.1 $\mathrm{mm}^{2} / \mathrm{sec}$ dropping off at periphery to $2.3-2.5 \mathrm{~mm}^{2} / \mathrm{sec}$.

- Irradiated ( $\sim 6 \%$ burnup): drop to $\sim 2$ $\mathrm{mm}^{2} / \mathrm{sec}$ and flatter radial profile. Smaller decrease than in oxides.

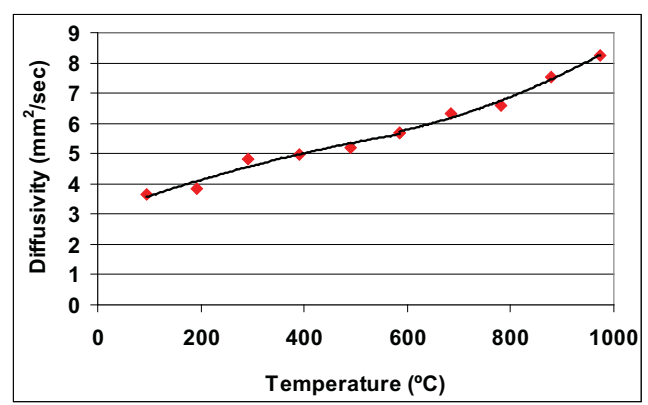

- Thermal diffusivity of bulk material from laser flash measurements.

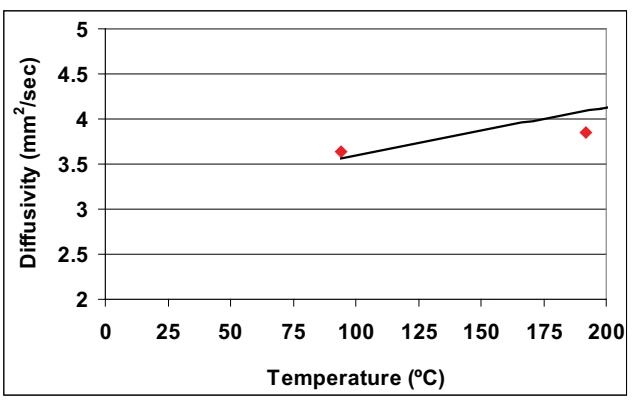

- Extrapolation of curve to room temperature yields value very close to $3.1 \mathrm{~mm}^{2} / \mathrm{sec}$. 
Nuclear Energy

\section{Laser Ultrasonics}

Thermoelastic generation

Laser interferometric detection

Ideal for remote sensing applications

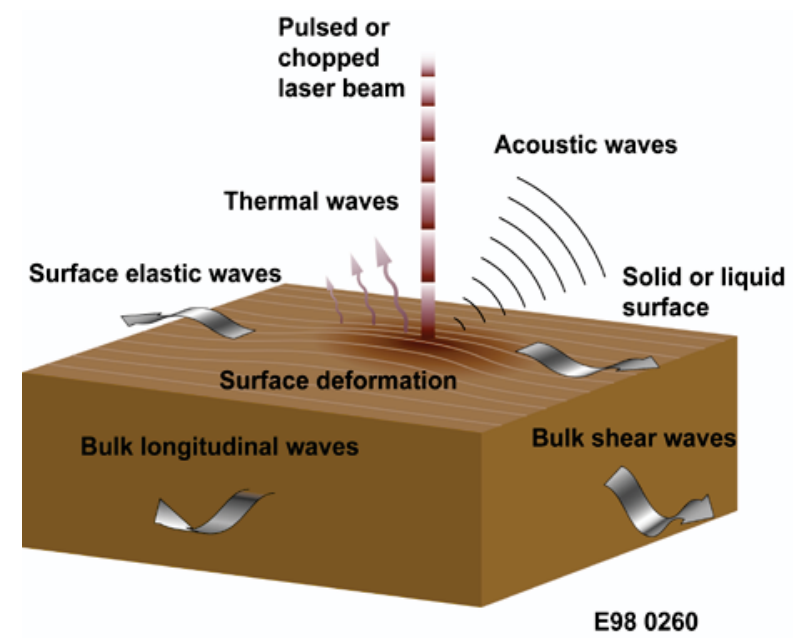

\section{Resonant Ultrasound Spectroscopy}

Effective tool to measure mechanical properties of materials, which are function of microstructure

Relate signal to elastic stiffness tensor

Relate attenuation to anelastic behavior

Typically use contact transducers

Typically use narrowband generation
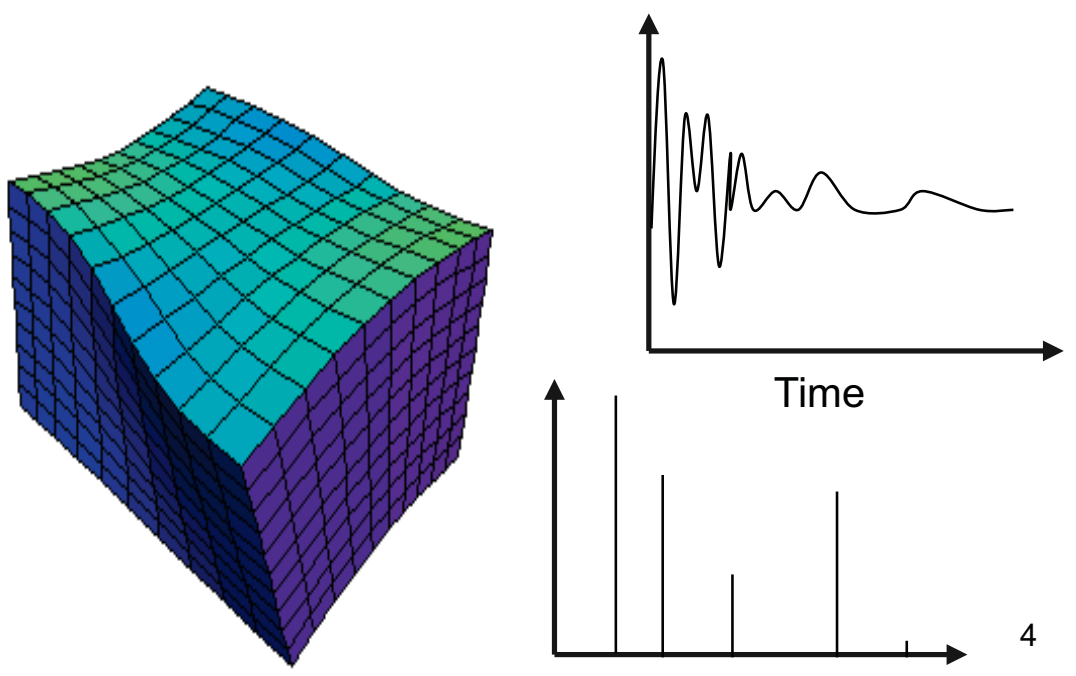

Frequency 


\section{Combining Laser Ultrasonics and Resonance Ultrasound Spectroscopy}

Nuclear Energy
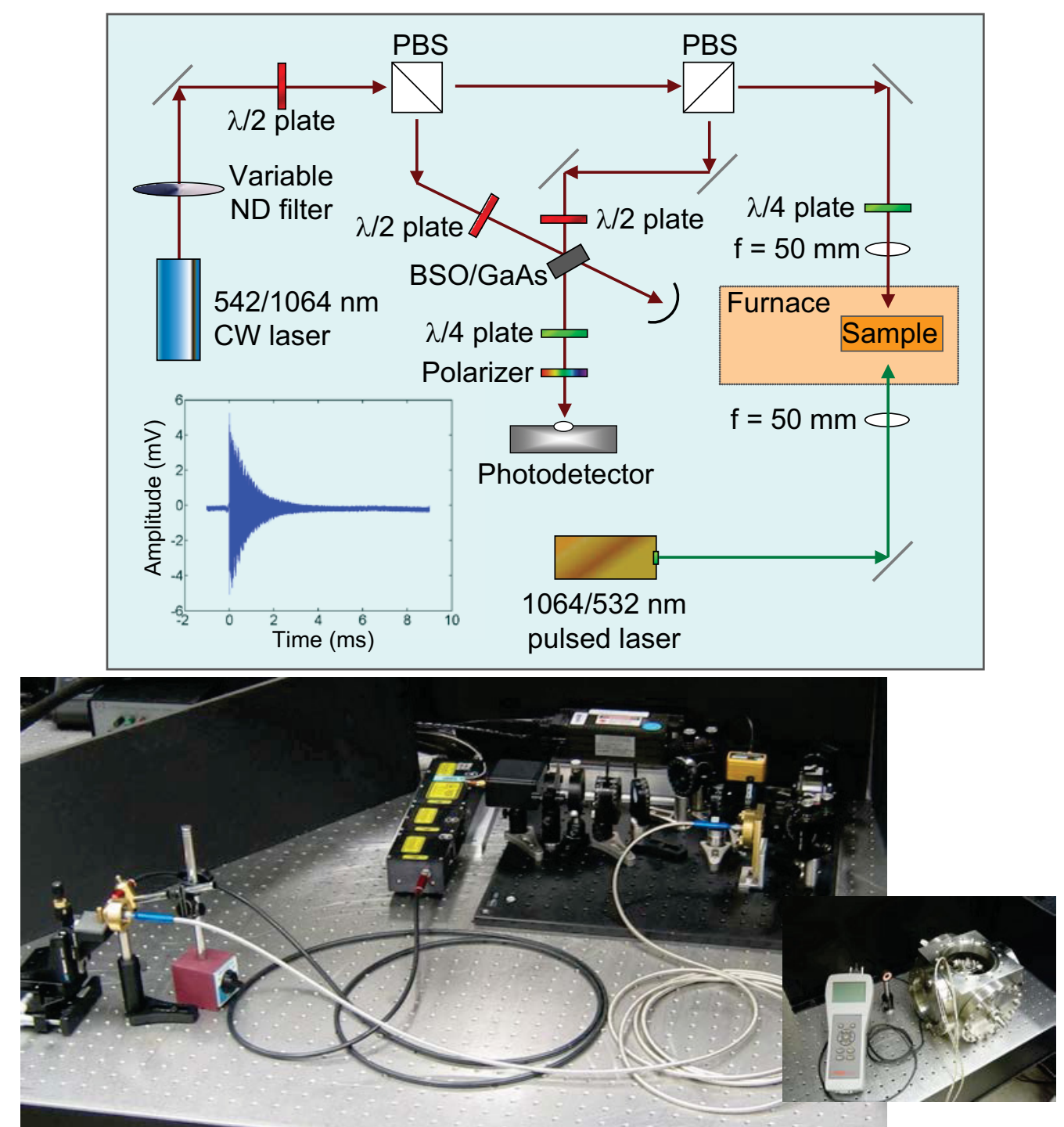

- Broadband resonant ultrasonic modes thermoelastically excited - generation and detection of all modes. Fast acquisition times $\rightarrow$ can see dynamic changes in microstructure mediated mechanical properties.

- Non-contact photorefractive interferometer detects out-of plane surface motion.

- Non-contact - more pure attenuation measurement.

- Raster scanning ability - allows mode identification.

- Remote operation - ideal for in-situ monitoring.

- Monitor microstructural evolution when combined with modern metallurgical imaging by tracking modes. 
High purity $\mathrm{Cu}$ can be cold rolled to produce a microstructure that changes dramatically upon heat treatment as observed using Electron Backscatter Diffraction (EBSD).

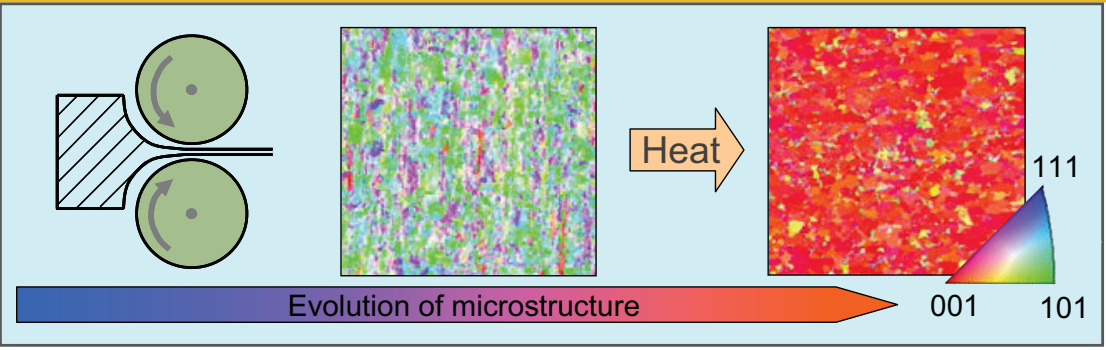

Electron

Backscatter Diffraction (EBD)

- Non-contact LRUS allows generation and detection of all resonance modes in one measurement. Since acquisition times are fast, dynamic changes in microstructure mediated mechanical properties can be detected.

- Raster scanning before and after annealing yields image of each resonant mode and allows tracking of individual modes during annealing. Theory connects mode shape to polycrystal average elastic stiffness tensor derived from EBSD data.

Current work - directly correlate this experiment with modeling and simulation that can predict the relationship between the polycrystalline elastic constants and the evolving microstructure. This is accomplished by coupling a polycrystal plasticity model with a phase field simulation to capture the defectdriven grain growth.

- Averaged elastic constants are both experimentally and computationally determined as a function of time. RUS can provide a crucial validation metric for this modeling approach

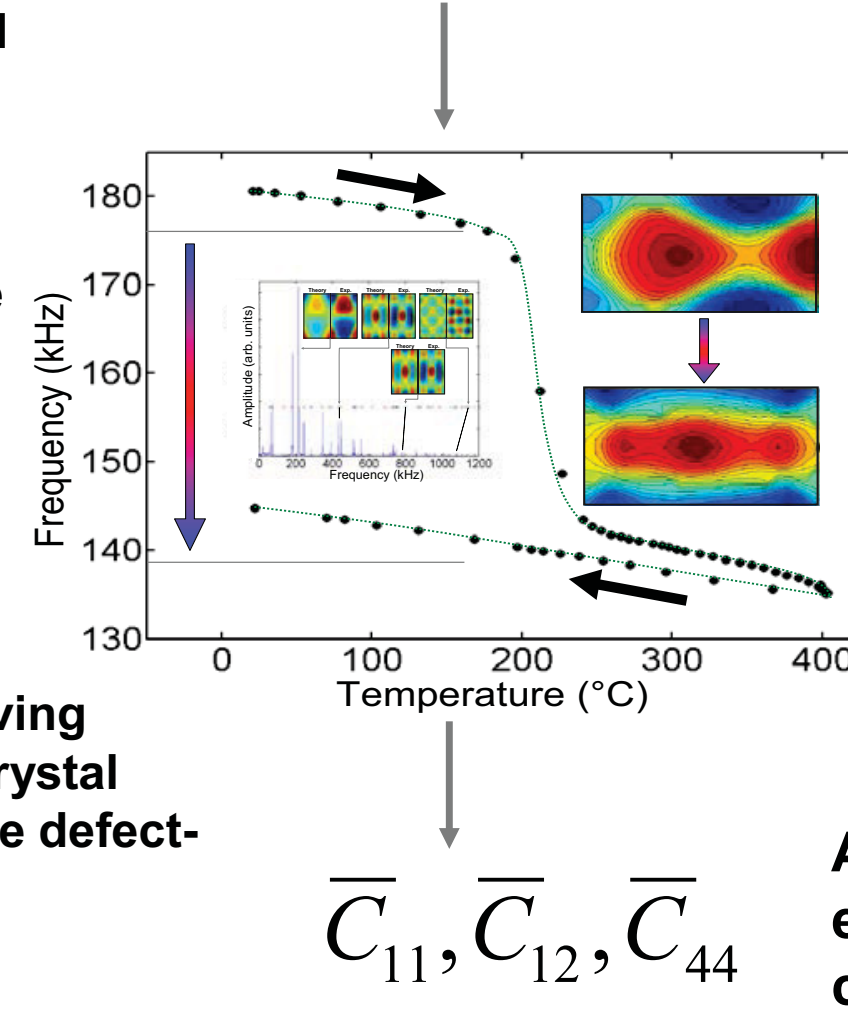

Averaged elastic constants

Hurley, Reese, Park, Utegulov, Kennedy, Telschow J. Appl. Phys. 107, 2010, (063510-) 1-5 


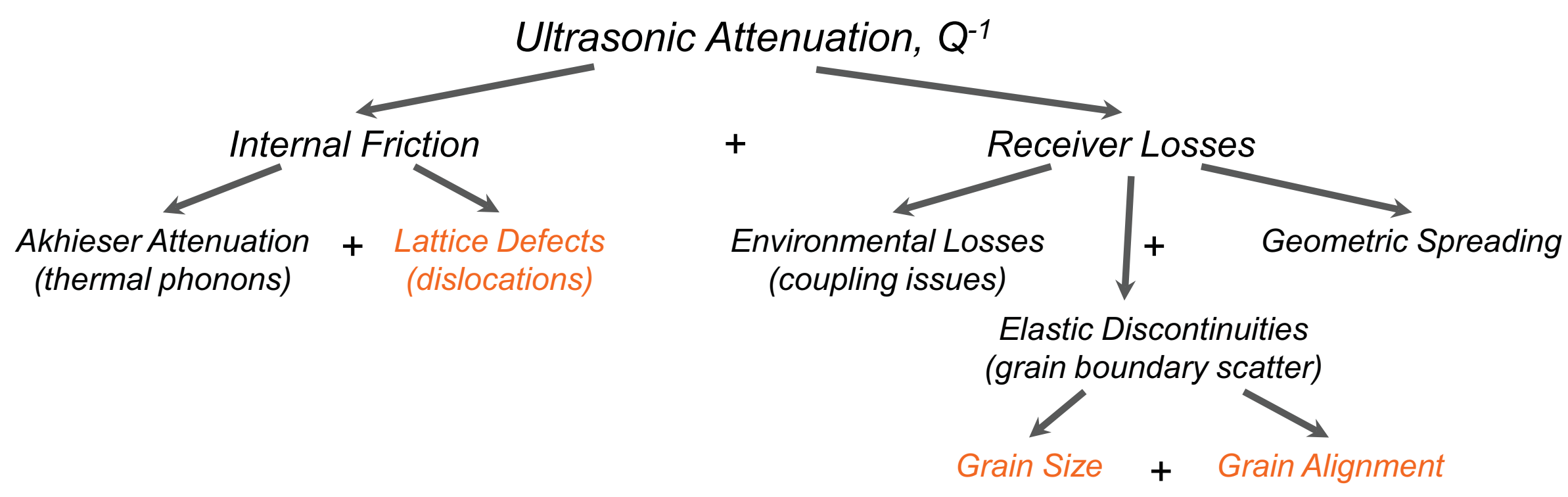

- Akhieser attenuation is a function of temperature and can be known.

- Environmental losses are minimized using a non-contacting laser-based measurement apparatus.

- Geometric spreading is irrelevant for measurements made in the frequency domain (i.e., only an issue with time-based measurements).

Dislocations, grain size, and grain alignment are material properties governed by the state of the microstructure. Parsing their contributions to the attenuation measurement is key to accurately revealing the state of, or changes in, the material microstructure. 
Equal channel angular extrusion (ECAE) sample lacks texture. During annealing, dislocations are annihilated and grains grow.

Rolled sample has strong texture. During annealing, dislocations are annihilated, grains grow and align.

- Decreasing dislocation density decreases attenutation $\left(Q^{-1}\right)$.

- Grain growth increases $Q^{-1}$.

- Grain alignment decreases $Q^{-1}$.
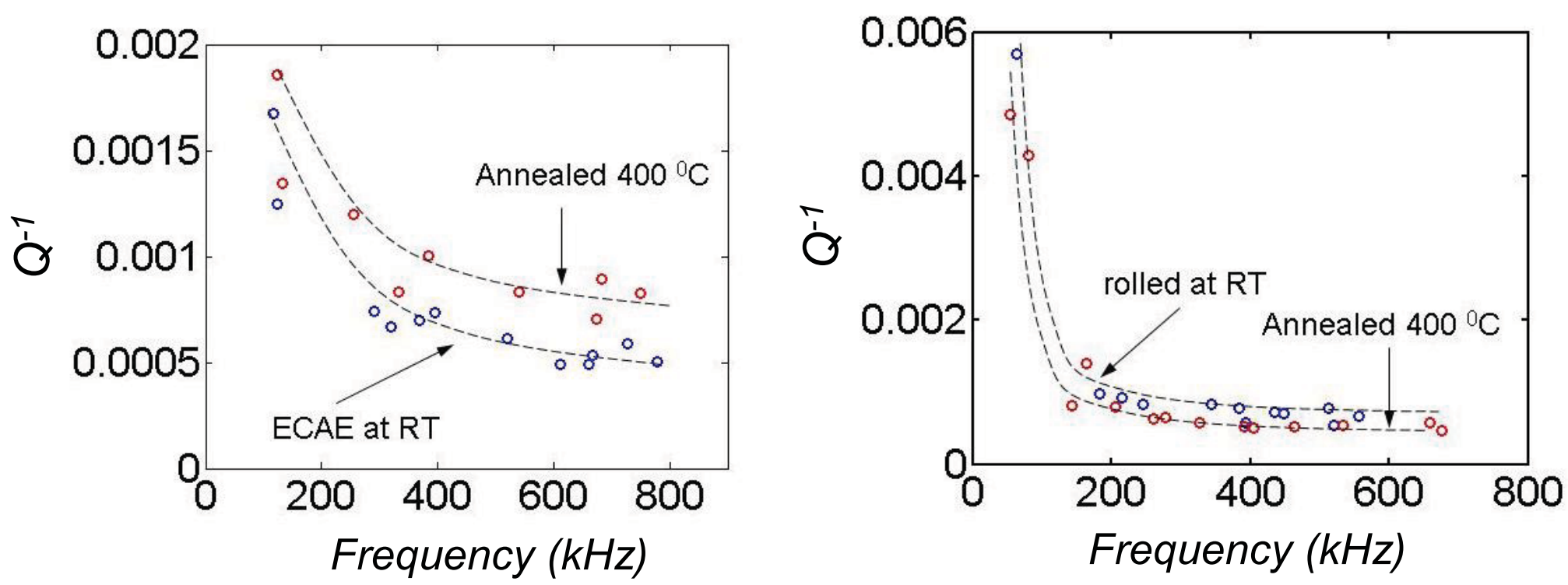

- In the ECAE sample, $Q^{-1}$ increases overall during annealing (left figure), showing that grain growth is a larger factor than dislocation density.

- In the rolled sample, $Q^{-1}$ decreases overall during annealing (right figure), showing that grain alignment (+ dislocation density) is a larger factor than grain growth.

- These two results combined show that grain boundary scatter (i.e., grain growth and alignment) is the dominant attenuation mechanism (vs. dislocation density). 
Experimental Setup (CW/pulsed)

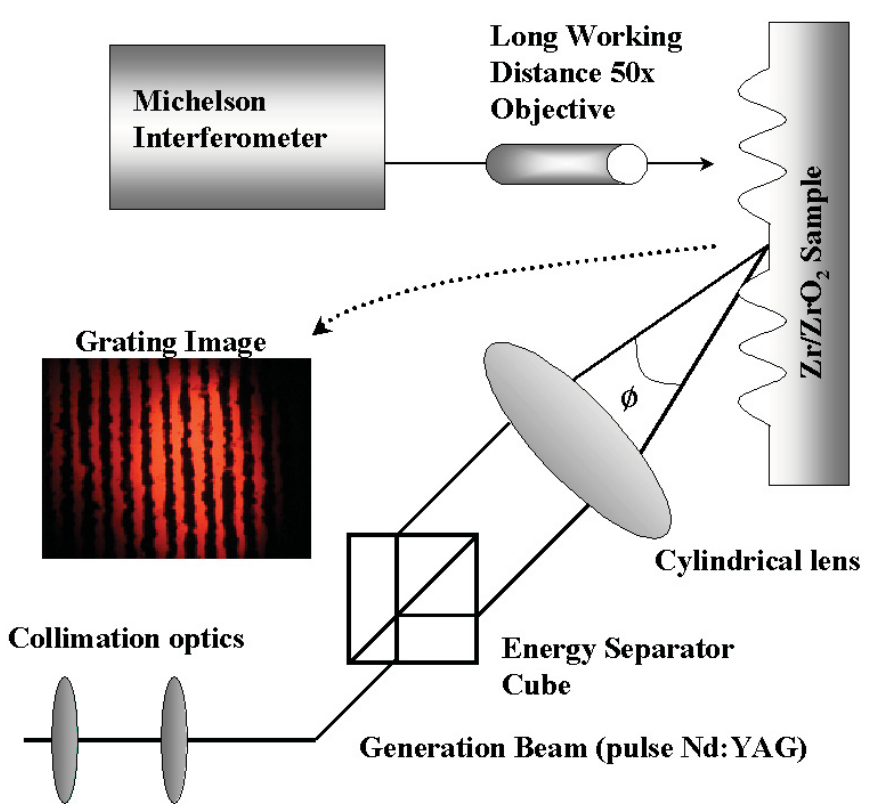

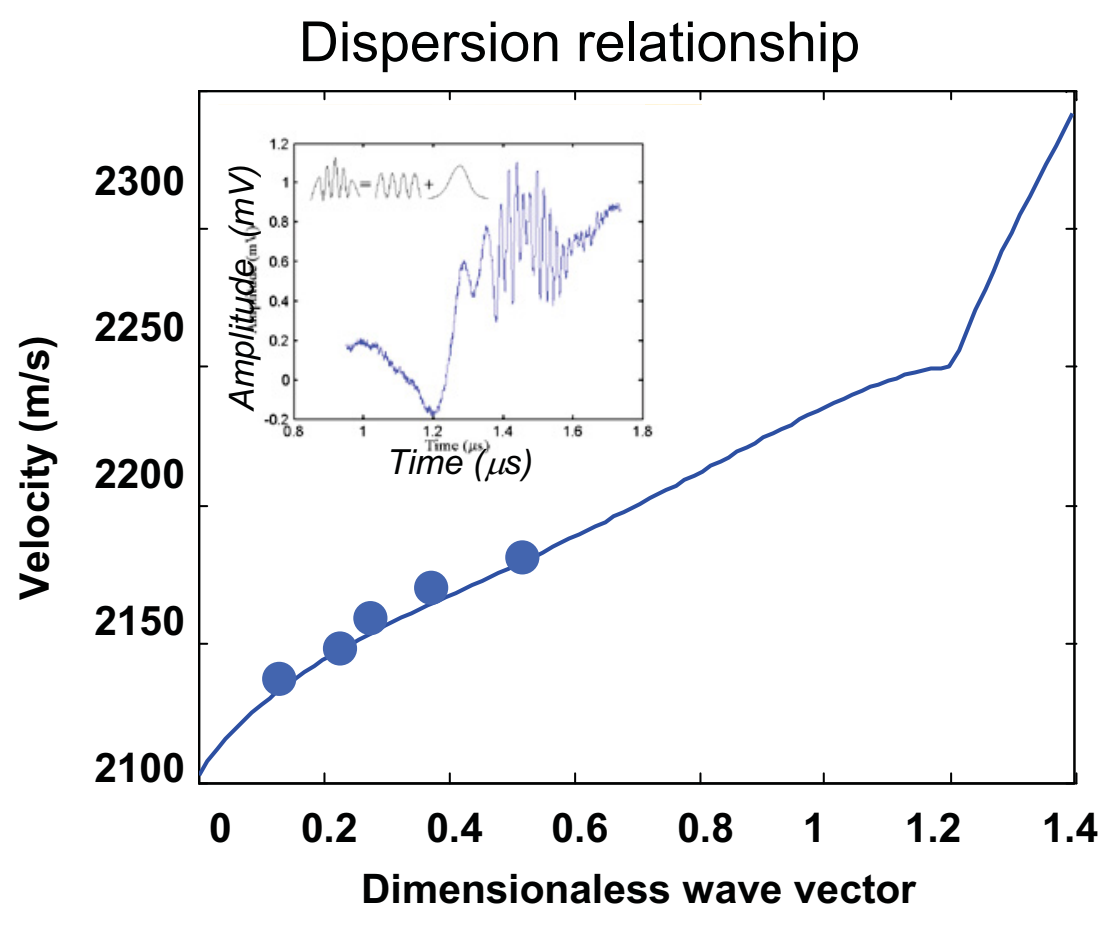

- Single frequency generation $(\mathrm{CW})$ involves setting up an absorption grating at the samples surface by interfering two laser beams.

- This approach involves building the dispersion relation one point at a time. Dispersion relation can be used to back out the layer thickness

- Applications include monitoring the growth of corrosion films and hydride layers 
Laser RUS in high radiation environment: Gamma tube facility at ATR
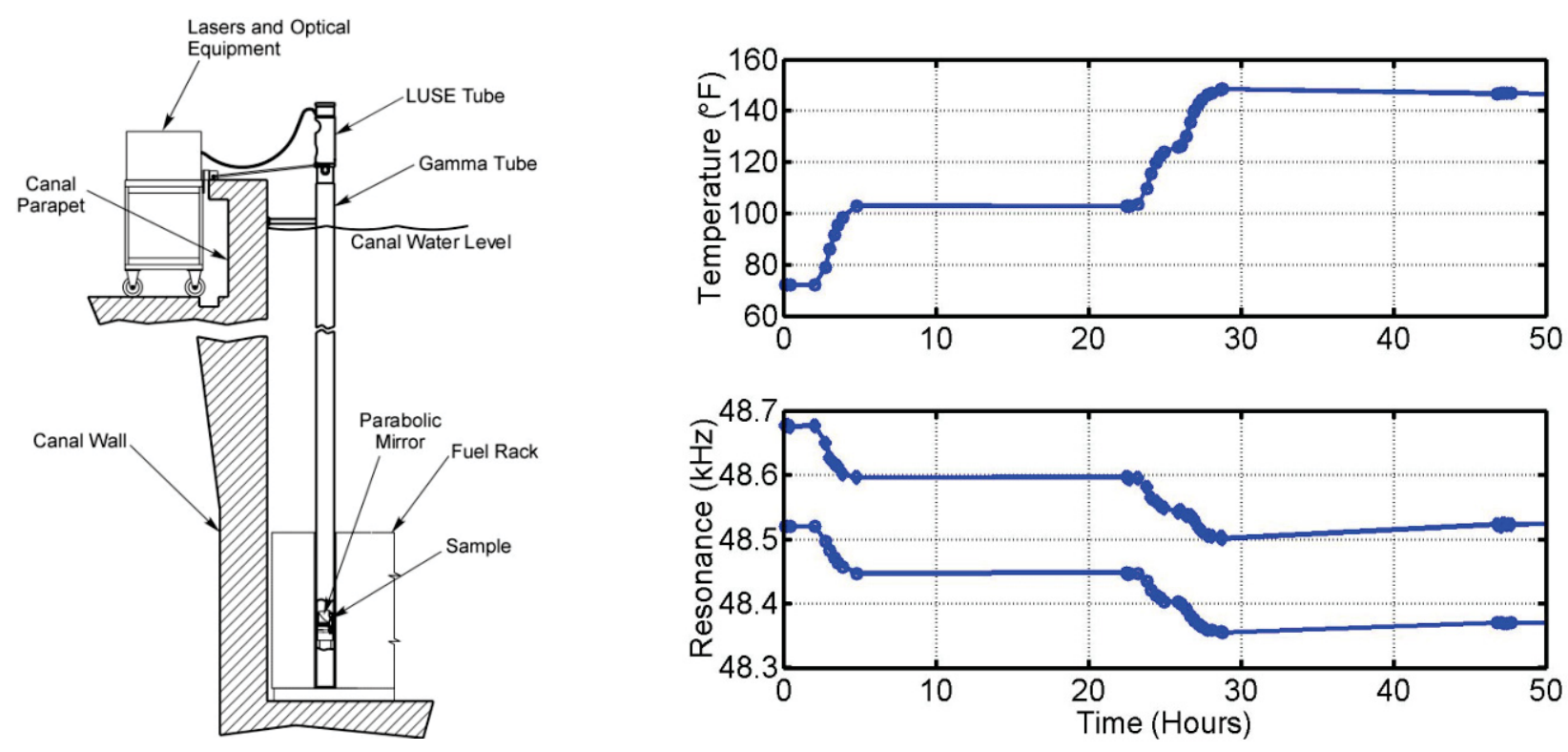

In situ laser ultrasonic measurements of Inconel in the high gamma radiation field at ATR showing the sample temperature and resonant frequencies of a split vibration mode as irradiation was increased by $(3$ times) placing fuel rods closer to the sample. 


\section{Central void formation in $\mathrm{UO}_{2}$}

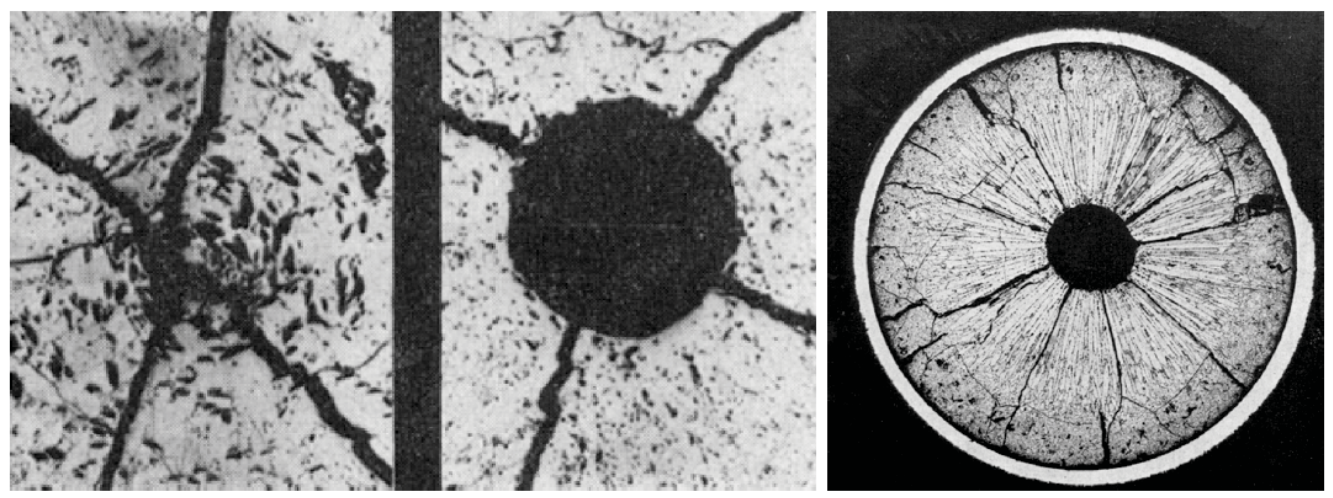

- The sintering process used to manufacture $\mathrm{UO}_{2}$ fuel pellets results in a material with a density greater than $90 \%$ theoretical, with the porosity distributed uniformly throughout the pellet

- During the first day of reactor operation, the initial porosity migrates towards the center of the fuel pellet, eventually forming a center void

- In addition, a unique columnar grain structure with low porosity forms around the center void, with the grains oriented radially outward from the center

- A steep temperature gradient was applied to a $\mathrm{UO}_{2}$ sintered fuel pellet out of pile and center void formation and columnar grain structure were observed (MacEwan and Lawson) 
Nuclear Energy

Initial Microstructure

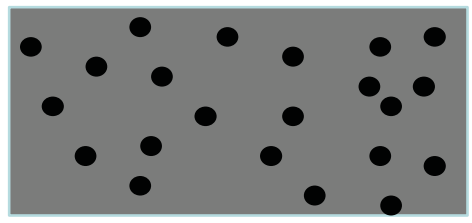

- Link void pinning and void migration models

- As a void migrates up the temperature gradient, it drags the grain boundary forming a columnar structure
Final Microstructure

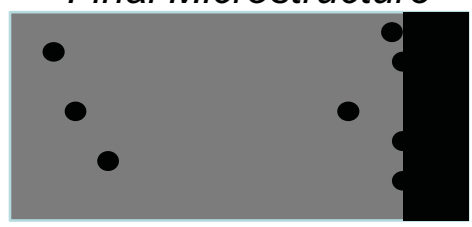

(b)

Void pinning of g.b.

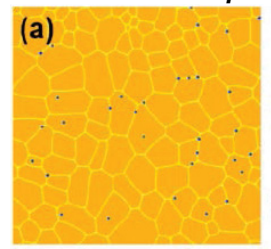

(c)

(d)

(d)

Measure spatial variation in porosity using laser ultrasound

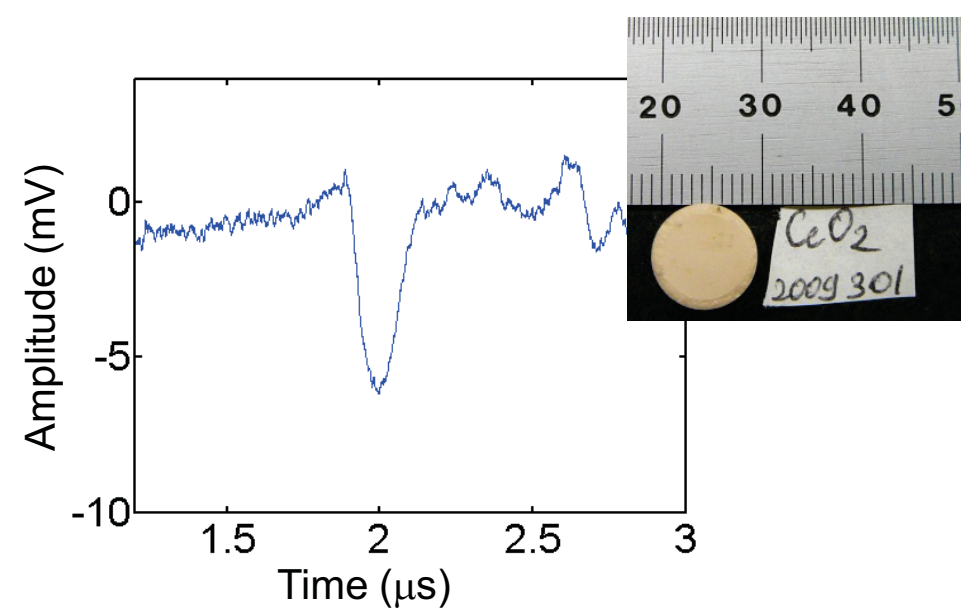

For long wavelengths we can relate phase velocity to porosity using semiempirical analytical formulas:

$E=E_{0} \exp (-b p)$

Duckworth, J. Amer. Ceram. Soc. 34 (1951) 1

Viscoelastic behavior for shorter wavelengths 


\section{X-Ray Microtomography}

OECD/NEA International PIE Workshop

Paris, France

June 16, 2011

Lance Snead

Oak Ridge National Laboratory 
X-ray Microtomography

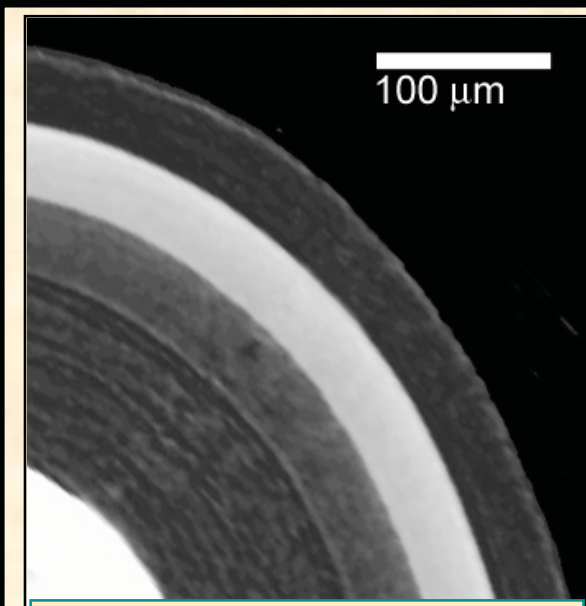

high resolution imaging

Nondestructive cross-sectioning

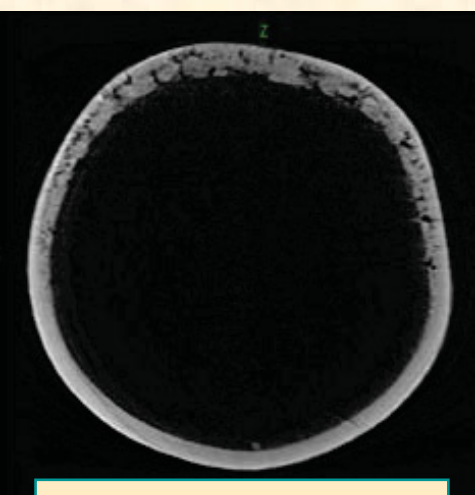

through thickness $\mathrm{SiC}$ defect<smiles>[CH]C</smiles>

OAK RIDGE NATIONAL LABORATORY

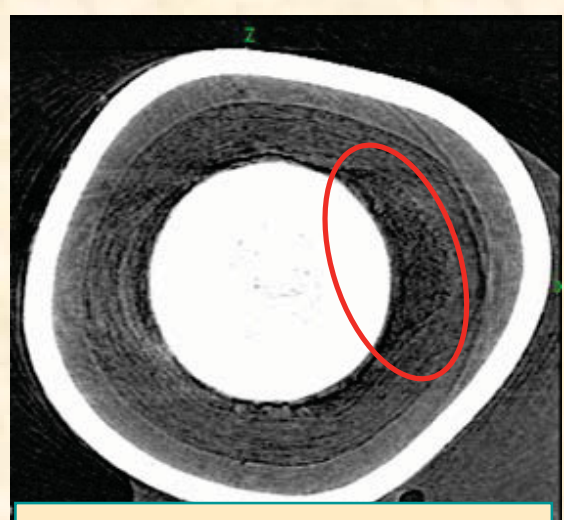

soot inclusion in buffer

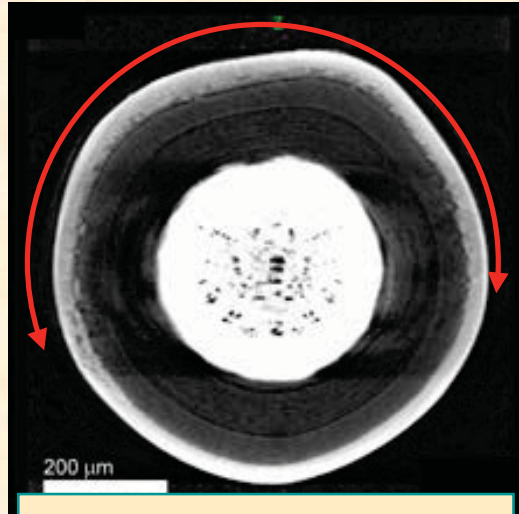

soot inclusion in $\mathrm{SiC}$

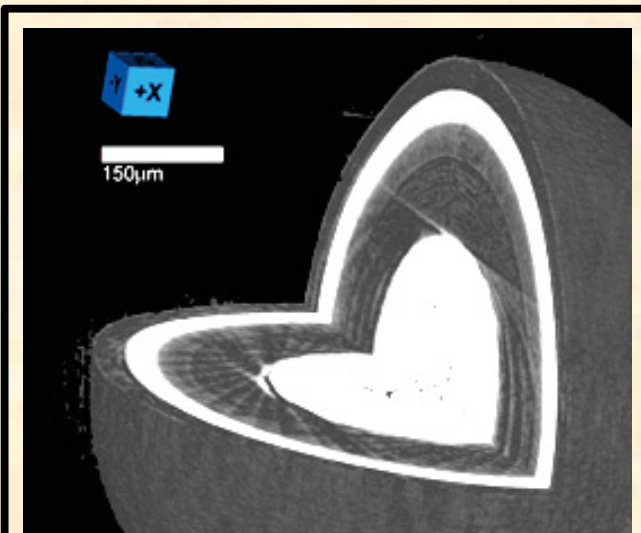

\section{3-D visualization}
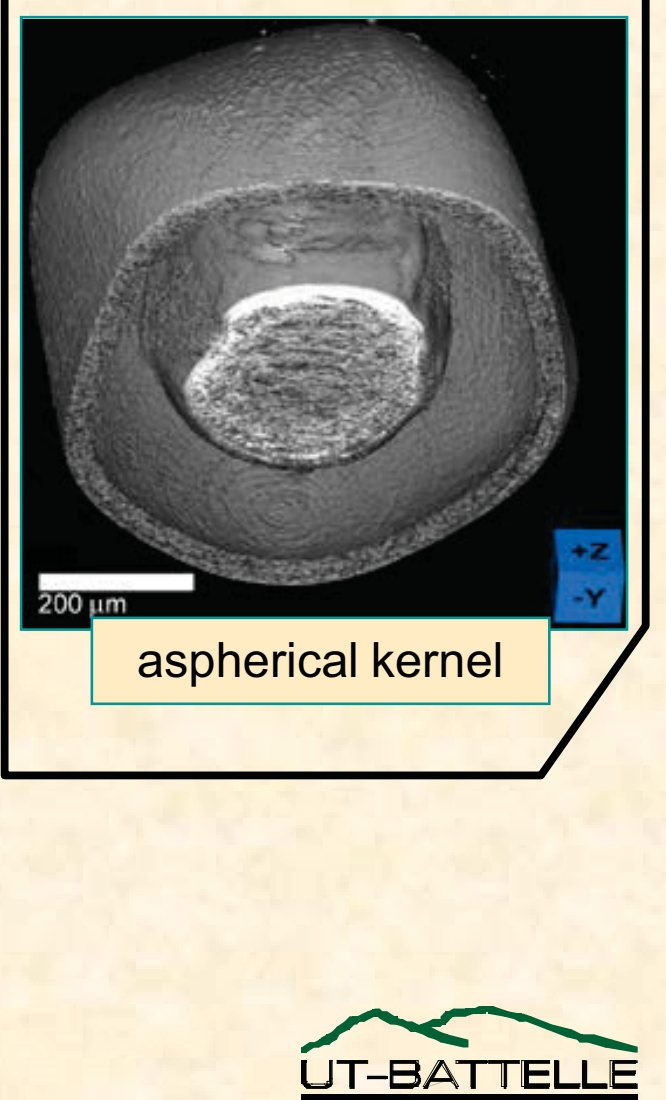


\section{X-ray Microtomography Application to Hot Samples}

- Unit located in LAMDA facility (Low Activation Materials Development Analysis)

- Applied to irradiated graphite, surrogate and fueled TRISO (up to $100 \mathrm{mR} / \mathrm{hr}$ at one foot.)

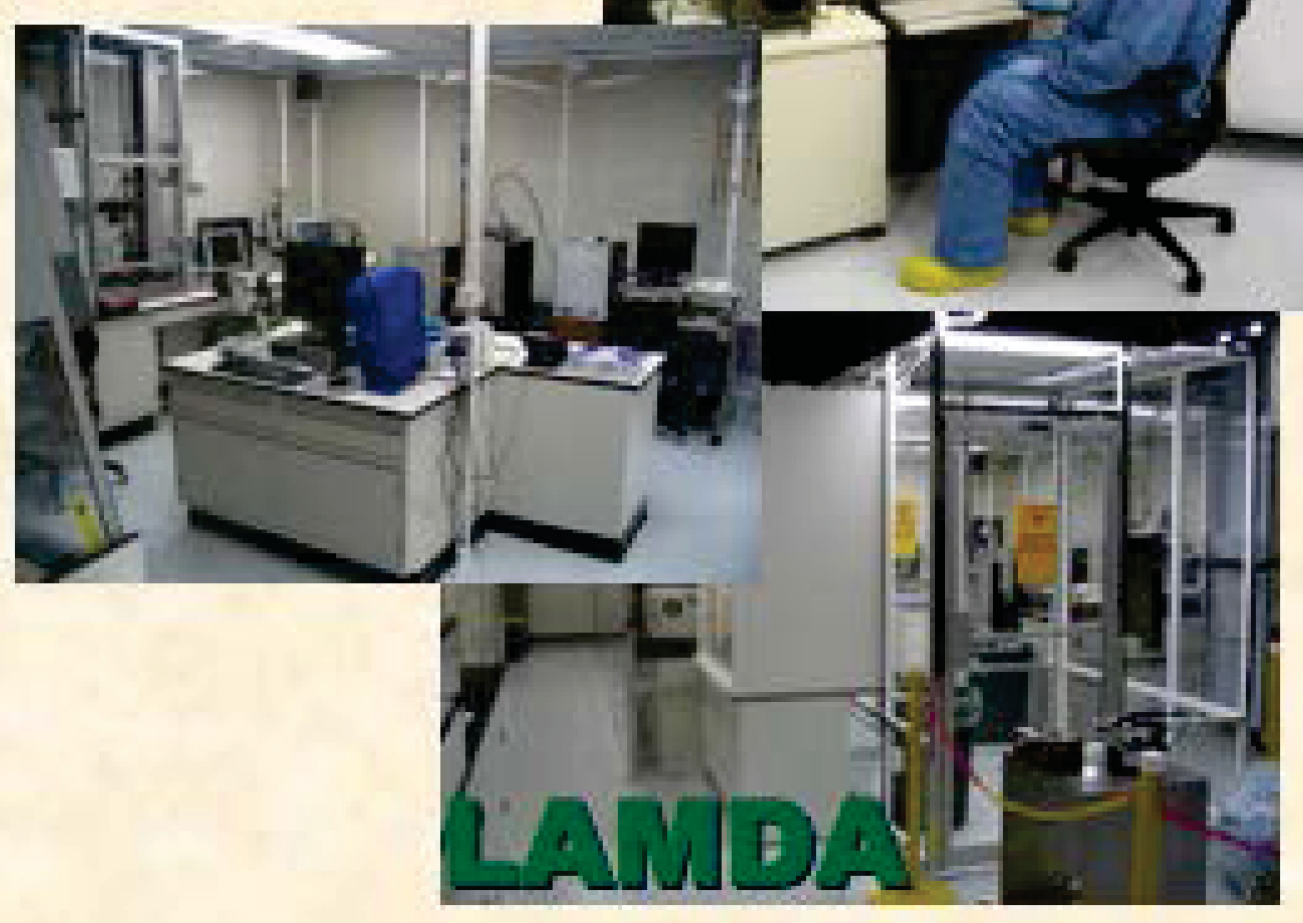

- Current Upgrades Underway

- Significant increase in resolution (sub-micron) and contrast and rad hard hardening optics.

- Shielded transfer/loading for TRISO and other highly activated samples 


\section{Actual Imaging Resolution of Current System Surrogate TRISO Particle}

$1.4 \mu \mathrm{m}$

Resolution

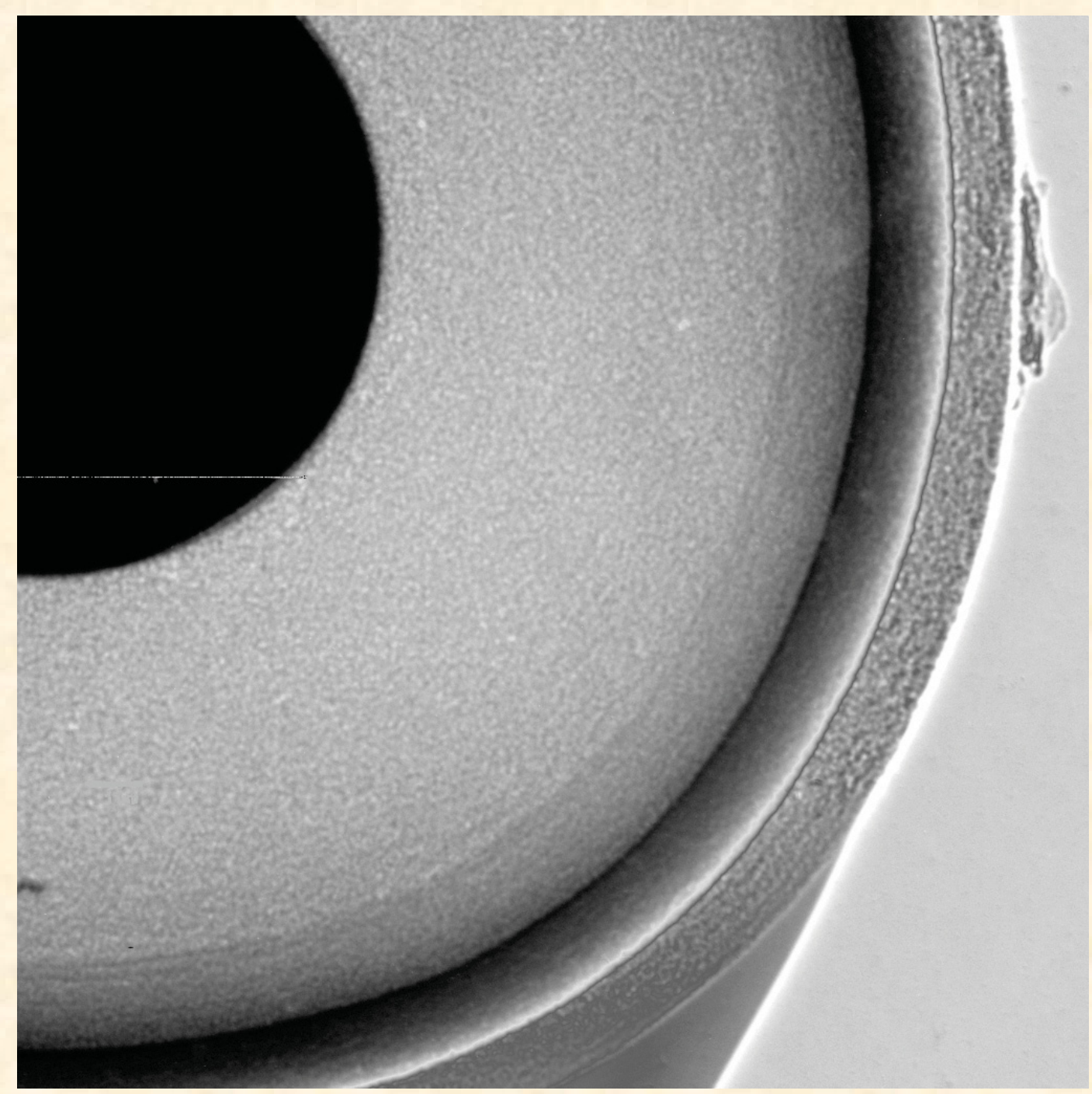




\section{In-depth analysis of defective TRISO particles}

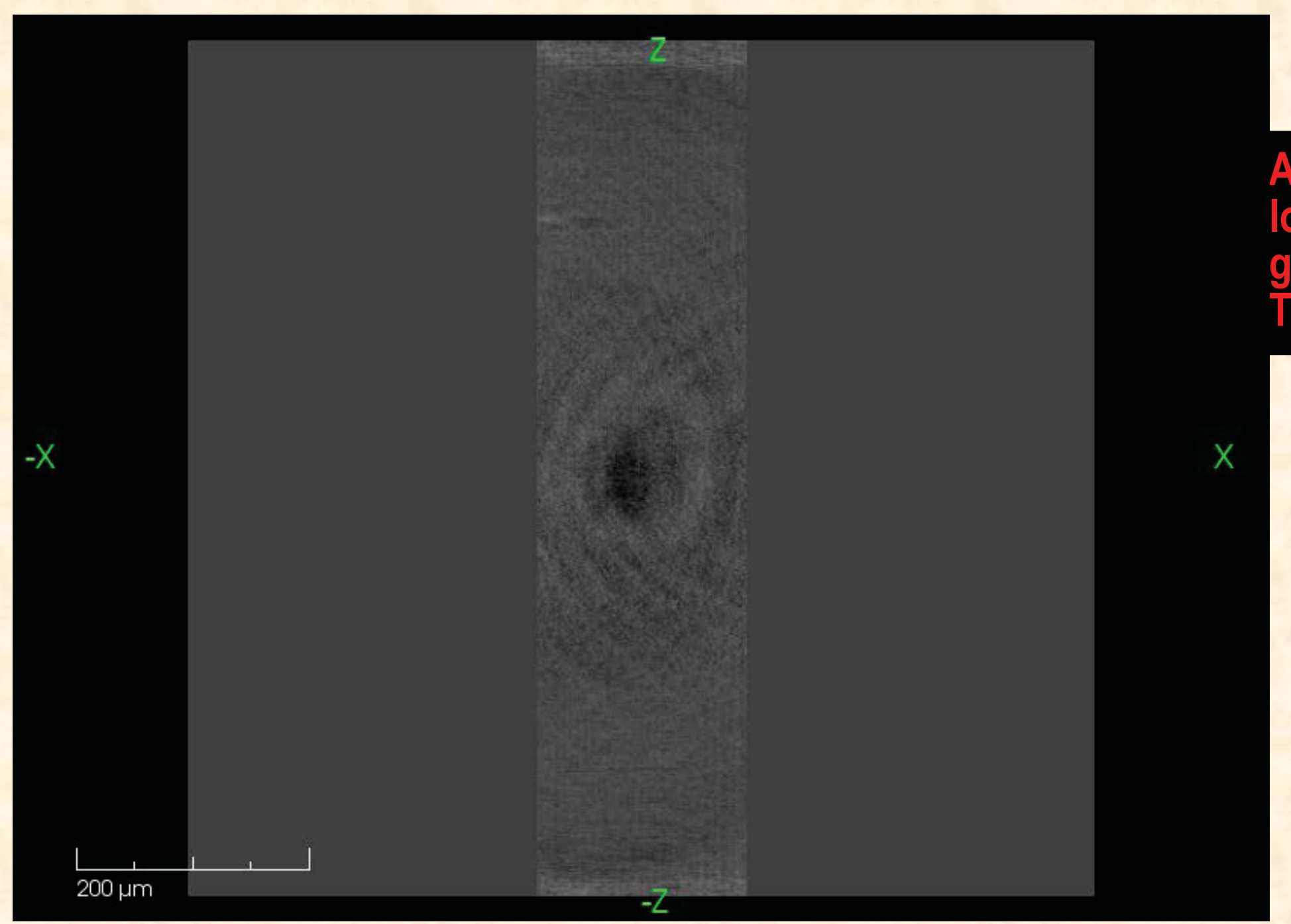

TRISO particle with goldspot which was identified during visual examination of particles with OPyC burned off

OAK RIDGE NATIONAL LABORATORY 


\section{Crack in SiC Layer}

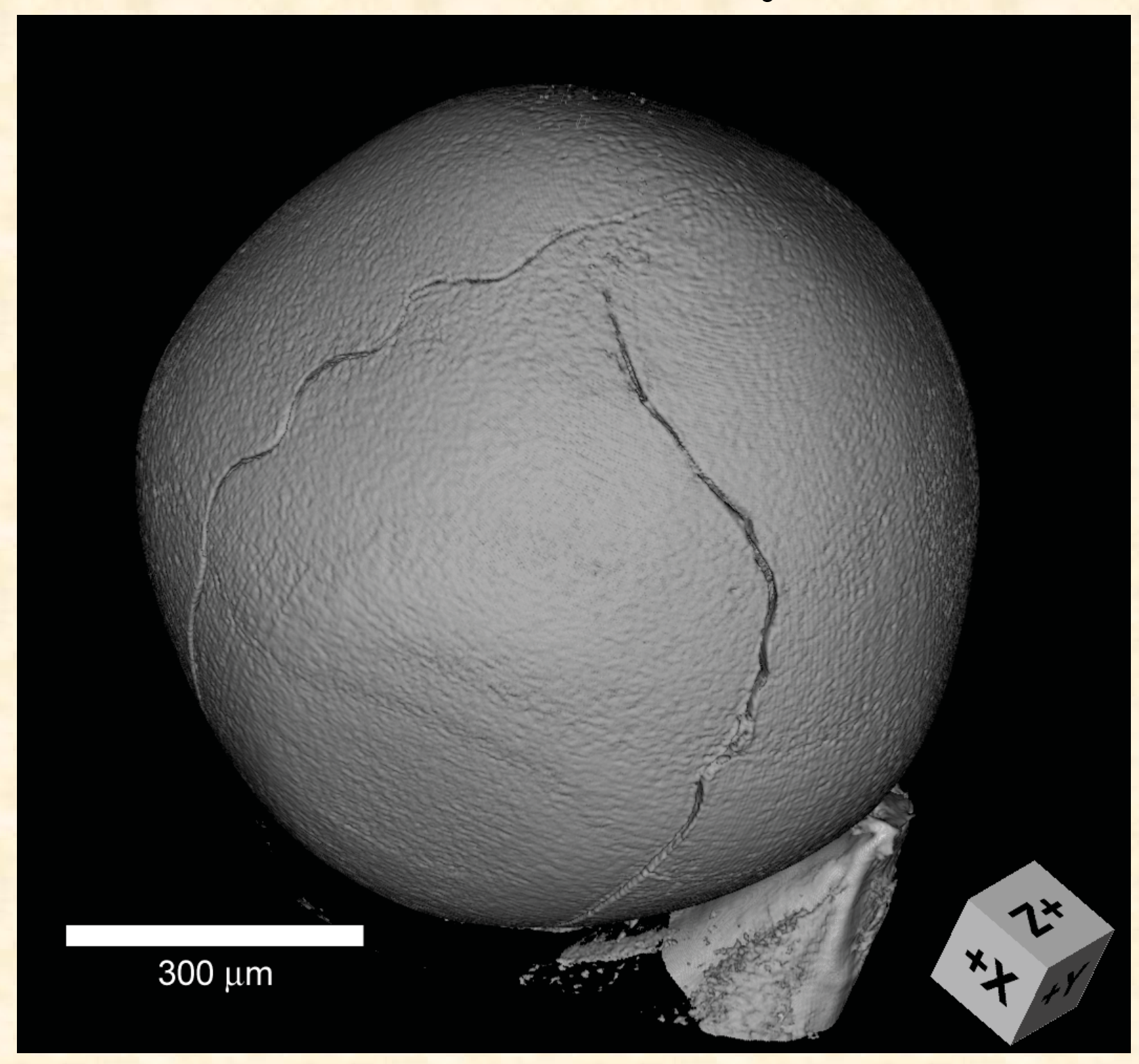



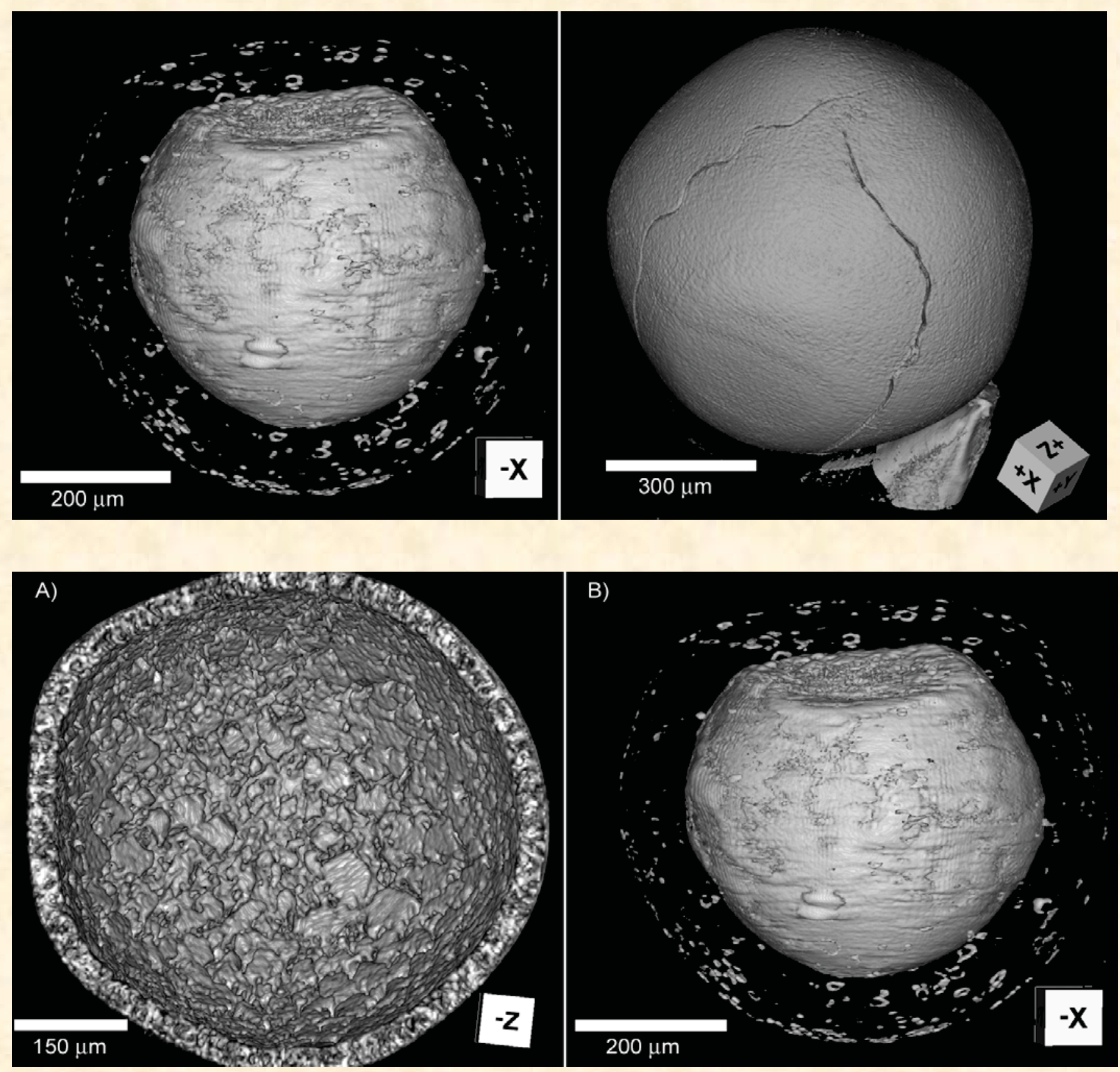


\section{Broken IPyC}
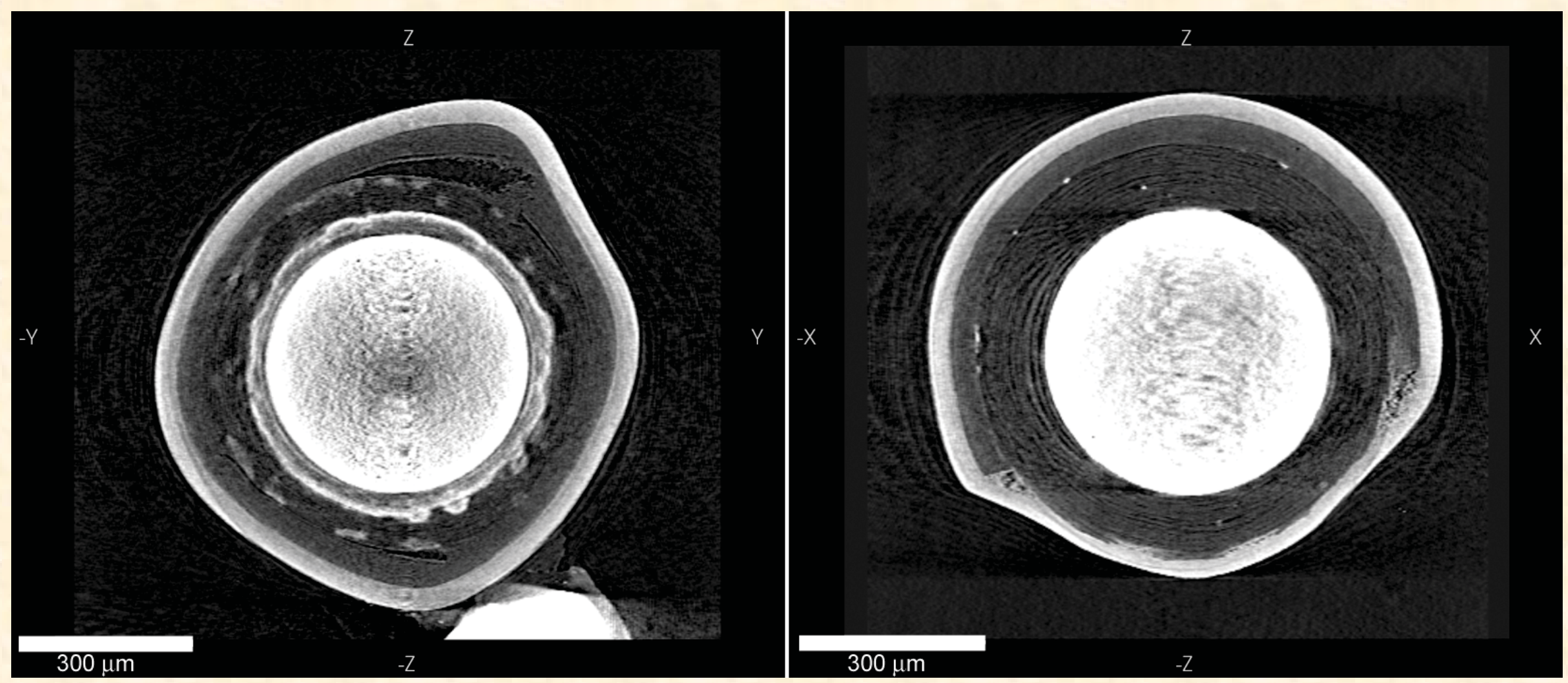

OAK RIDGE NATIONAL LABORATORY

U. S. DEPARTMENT OF ENERGY

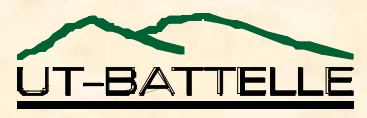




\section{Buffer Suit}

OAK RIDGE

U. S. DEPART MIENT OF ENERGYY

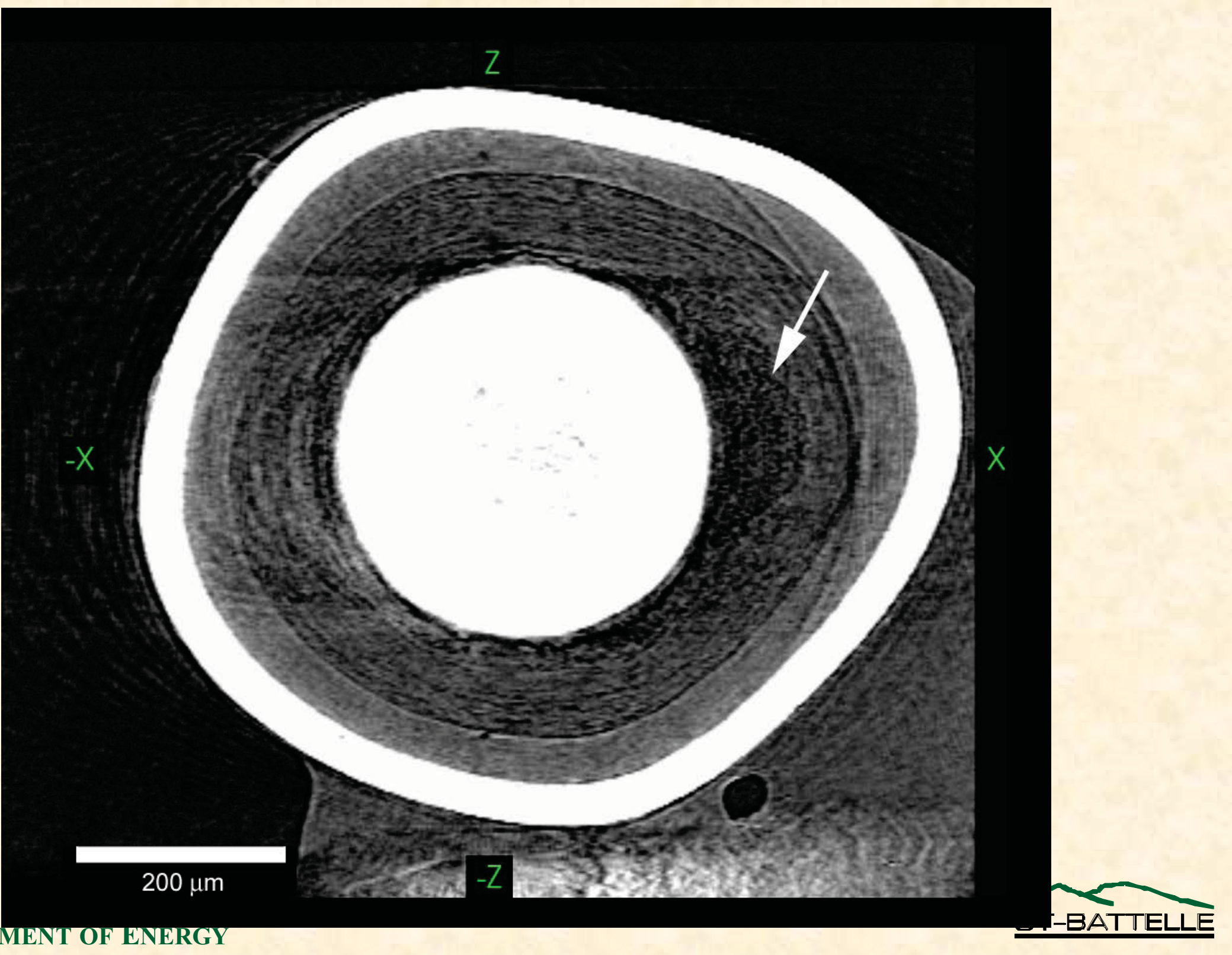




\section{Even better performance possible: Diffraction contrast dramatically improves contrast in low $\mathrm{Z}$ materials}

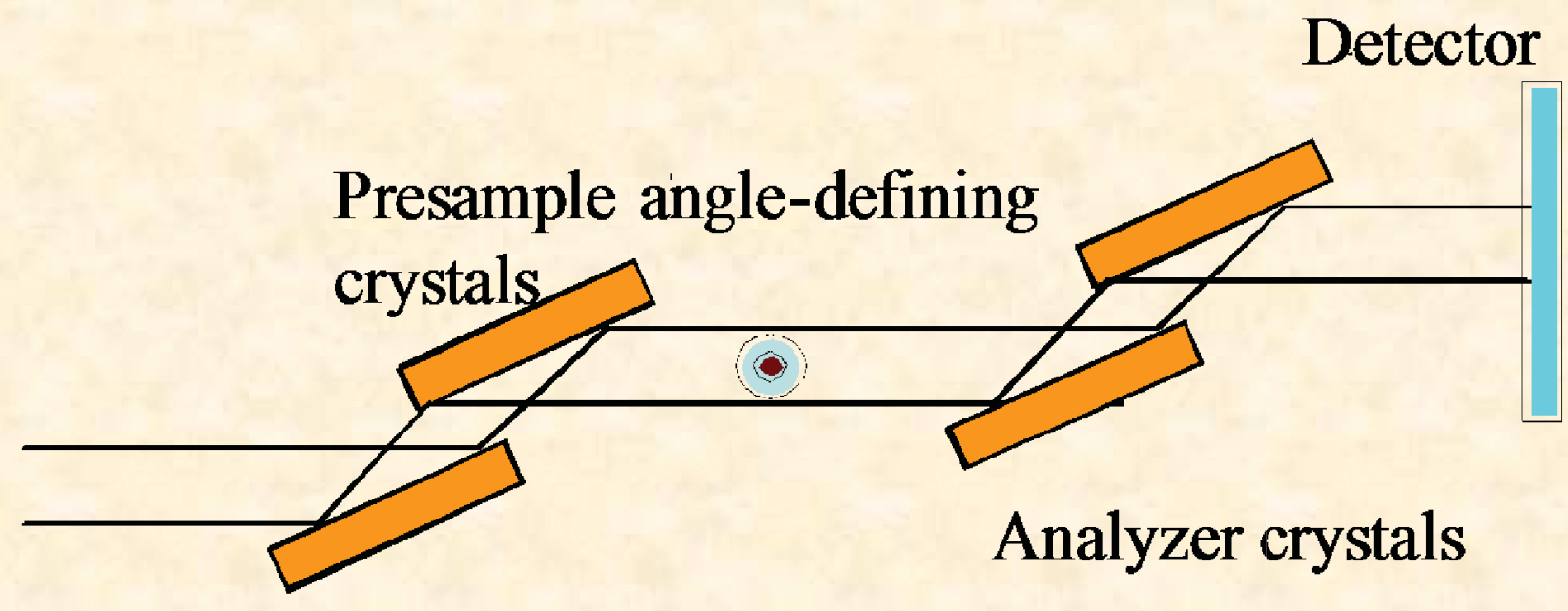

- Light elements like carbon have low $x$-ray absorption

- Diffraction contrast is sensitive to the refraction of $x$-rays, a stronger effect for these elements.

- Detector is also located further away from sample (less rad-sensitivity.)

- This technique is being developed at synchrotrons; we will use advanced $x$-ray optics to implement it using a laboratory $x$-ray source 


\section{Diffraction Contrast Imaging}

- ongoing upgrade -

- Orders of magnitude better contrast

- Particularly sensitive to surfaces, cracks, voids, and inclusions

- We will be able to detect features which are smaller than the instrumental resolution (e.g. fine cracks)

\section{Diffraction Contrast}




\section{Concluding Remarks}

- Current tomography unit is being applied in the research mode (research on the technique, equipment, and fuel) for TRISO fuels and graphite.

- Current resolution is $\sim 1.4$ micron. Effort is underway (within a year) for submicron resolution and improved contrast. Technique has been demonstrated with $70 \mathrm{~nm}$ resolution.

- Current limitation is $\sim 100 \mathrm{mR} / \mathrm{hr} @$ one foot. (LAMDA guideline.) Both the newly installed LAMDA FIBs and the Tomography unit are being rad-hardened and having transfer/loading fixtures which will allow higher dose samples.

- This instrument has been applied to metallic samples (steel, tungsten.) Due to higher $\mathrm{Z}$ the samples must be significantly smaller. However, this is consistent with fundamental studies for metallic fuels. 


\section{Current and Future Micro-analysis Devices in the LECA-STAR Facility}

\section{J. LAMONTAGNE}

Commissariat à l'Energie Atomique et aux Energies Alternatives Cadarache Center Fuel Studies Department 13108 St Paul Lez Durance cedex, France 


\section{A large number of questions, sometimes asked from many years}

\section{....including the transmutation targets}

- Formation mechanism of the nano-scale bubbles?

- Transition mechanism from nano-scale bubbles to microscale bubbles?

- Link between the grain size / release, grain boundaries behavior (irradiation, ramp, heat treatment)?

- Parameters involved in the HBS (High Burnup Structure) formation?

- Gas release during the HBS formation?

- HBS evolution at very high Burnup?

- Existence of Fission Products compounds in intergranular position in the HBS? other phase?

- Precipitation and release gas mechanism during an annealing test? Movement of the bubbles?

\section{... and many more}

\section{Strategy:}

- Mechanical approach

- Physical chemistry approach

\section{$\Leftrightarrow$ multi-scale analyses}

\section{Optical Macrography of a fuel radial} (BU $\sim 80 \mathrm{GWd} / \mathrm{t}$ )

HBS in periphery, precipitation en central area (0R to $0.26 R$ ) + ring precipitation around $0.55 R$

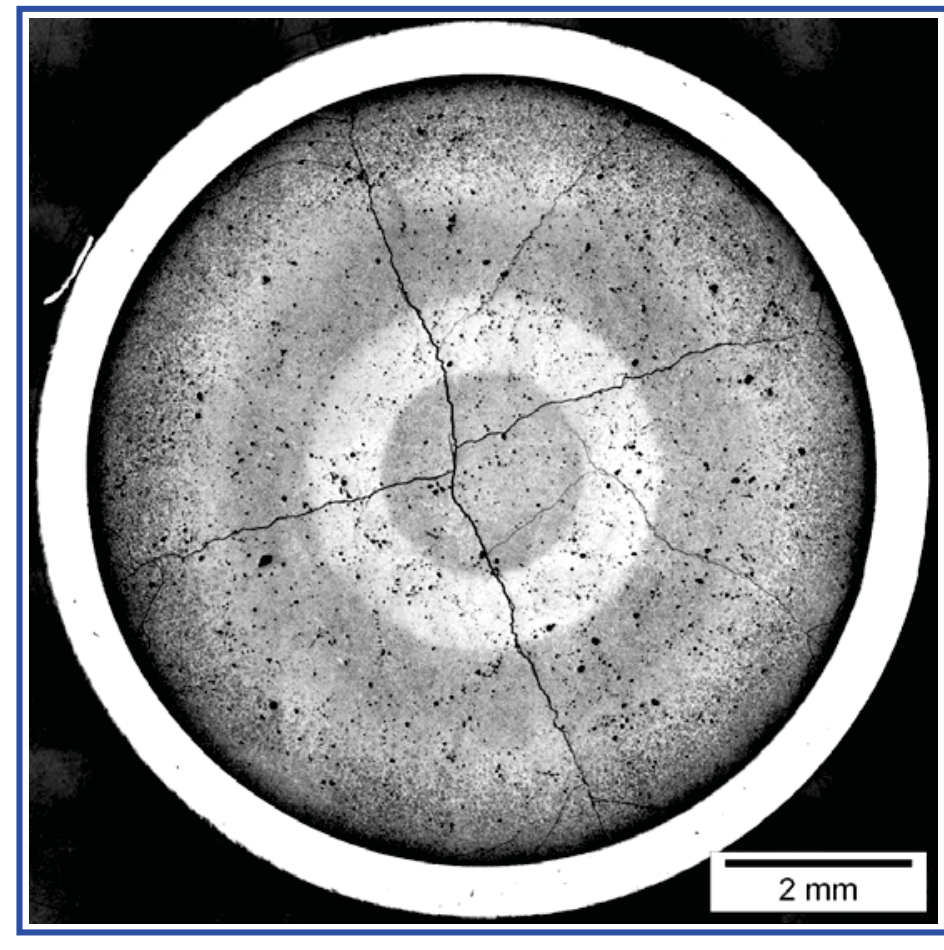




\section{Basic framework:}

Heterogeneous monorecycling of Minor Actinides (MA) under a locally moderated neutron flux in Na-cooled Fast Reactors (SFR)

Béjaoui et al, JNM (2011)

\section{Transmutation targets:}

$\mathrm{AmO}_{1.62}$ microdispersed in $\mathrm{MgO}$ with $0.66 \mathrm{~g}$ of $\mathrm{Am} / \mathrm{cm}^{3}$

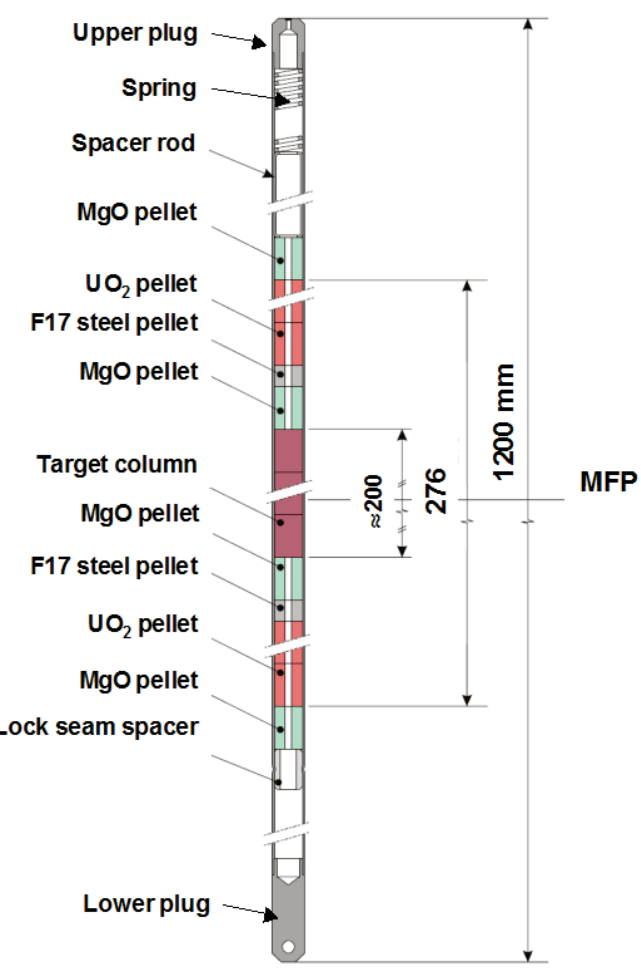

Irradiation in Phenix core during 318 EFPD

Expected transmutation and fission rates from pre-irradiation simulations: $\rightarrow 92.6$ and 33.9 at\% (at the maximum flux plane)

PIE Results:

Satisfactory behavior of the $\mathrm{MgO}-\mathrm{AmO}_{1.62}$ targets (moderate swelling) from a macroscopic point of view

Lamontagne et al, JNM (2011)

Microscopic point of view?

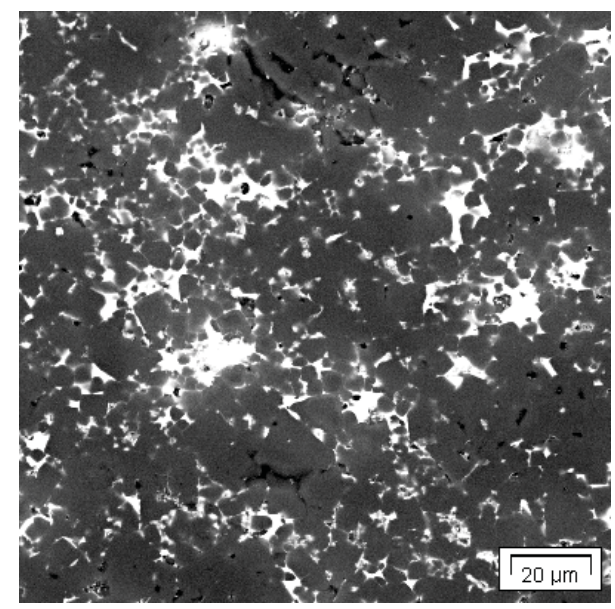


SEM XL 30 (FEI) In operation since 1994 Lateral Resolution: $0.1 \mu \mathrm{m}$ Magnification: x 10000

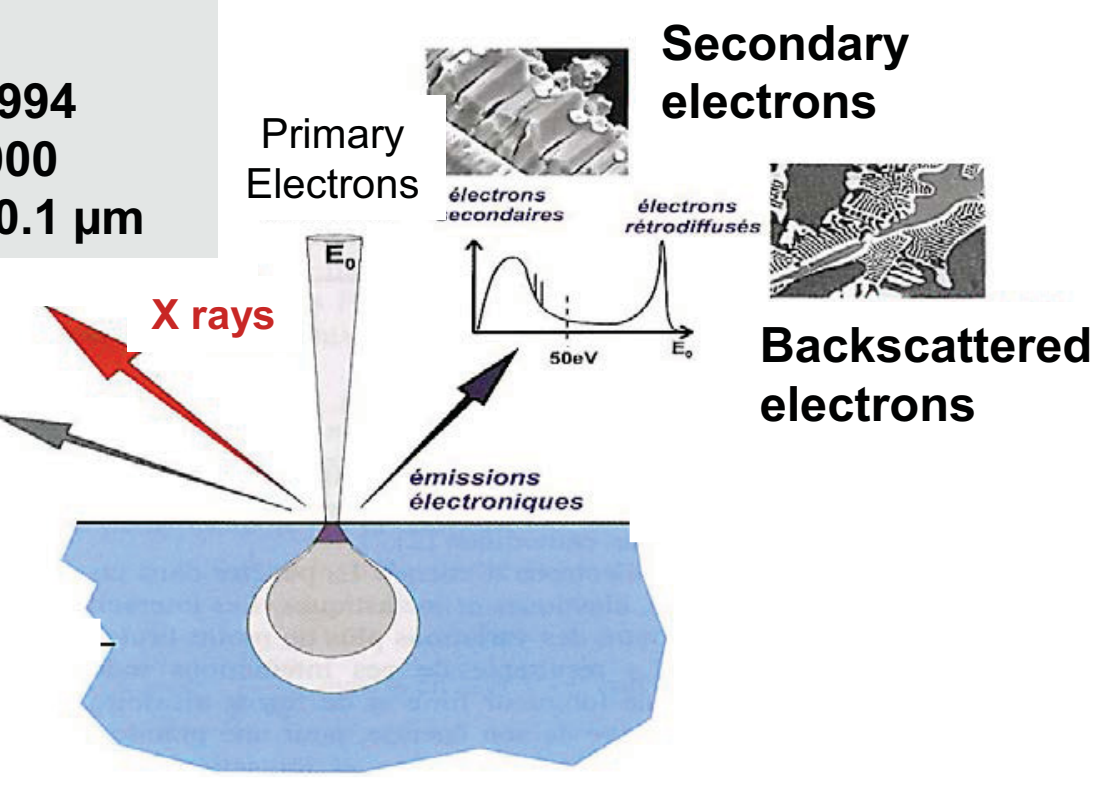

\section{Fractography}

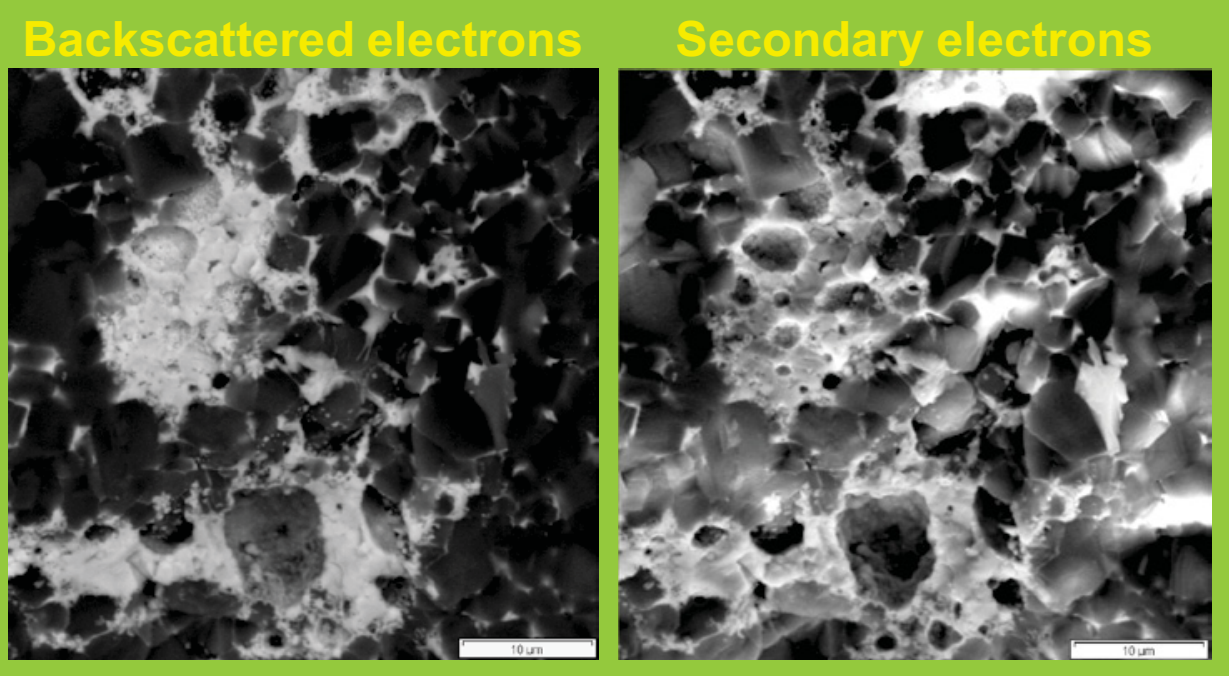

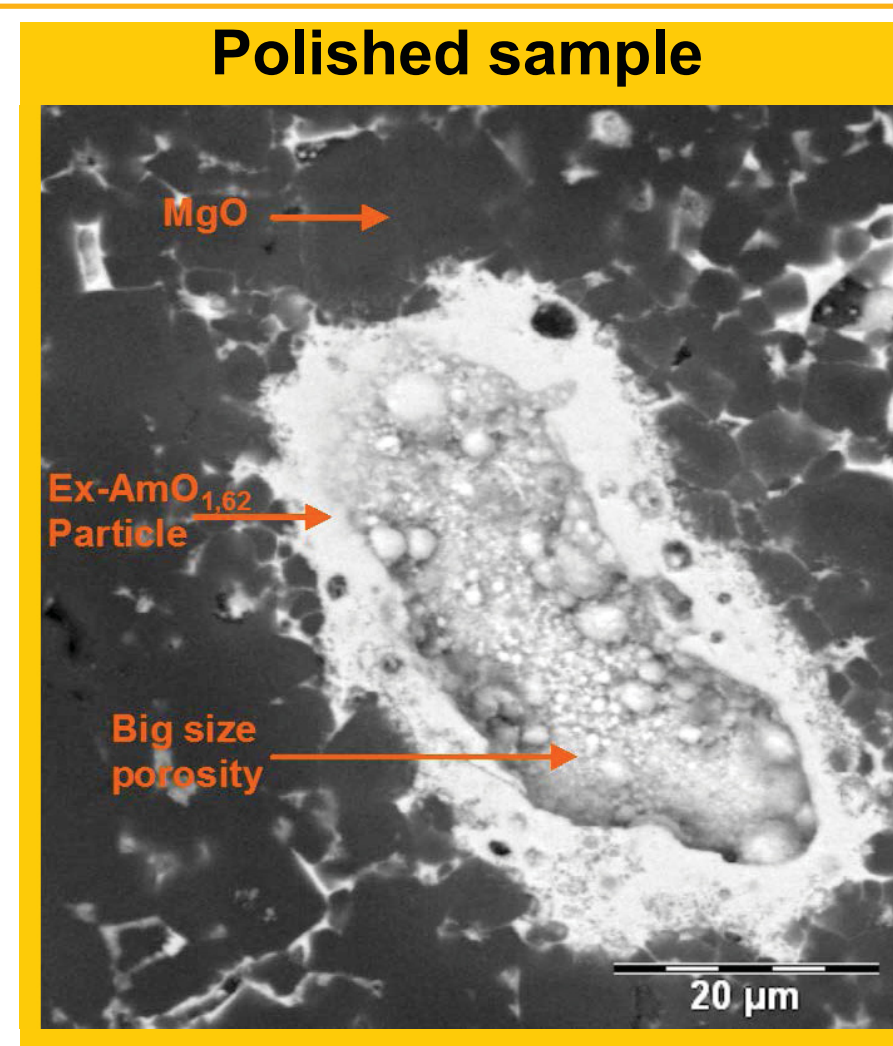

Characterization along a radius:

-Porosity (in, out the ex-AmO particle, interface) -HBS

- MgO grains fractures

$>$ Nanoscale bubbles and their formation mechanism? $>$ Transition mechanism from nano-scale bubbles to micro-scale bubbles? 


\section{cea EPMA (Electron Probe Micro-Analyser): chemical analyses}

\section{Shielded EPMA CAMECA SX100R}

In operation since December 2009 Detection: $<1 \%$ Lateral Resolution $<1 \mu \mathrm{m}$

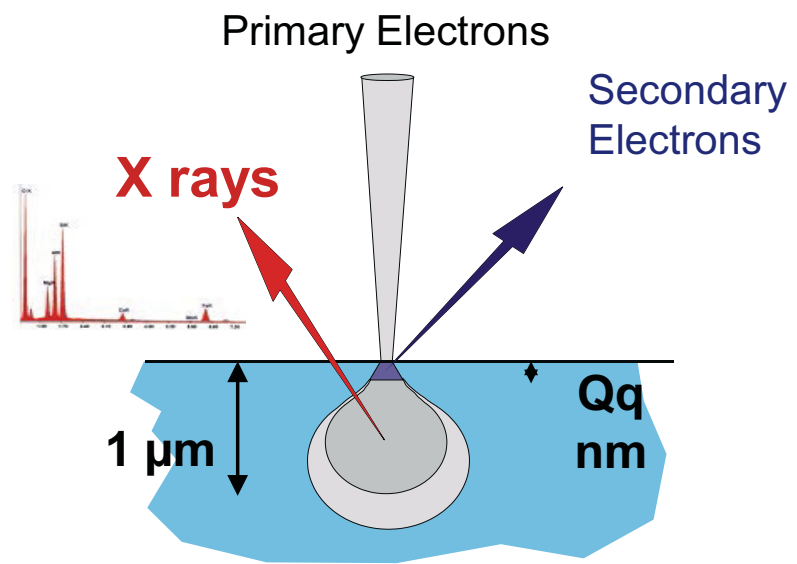

Distribution and content: Fission Products, actinides ...
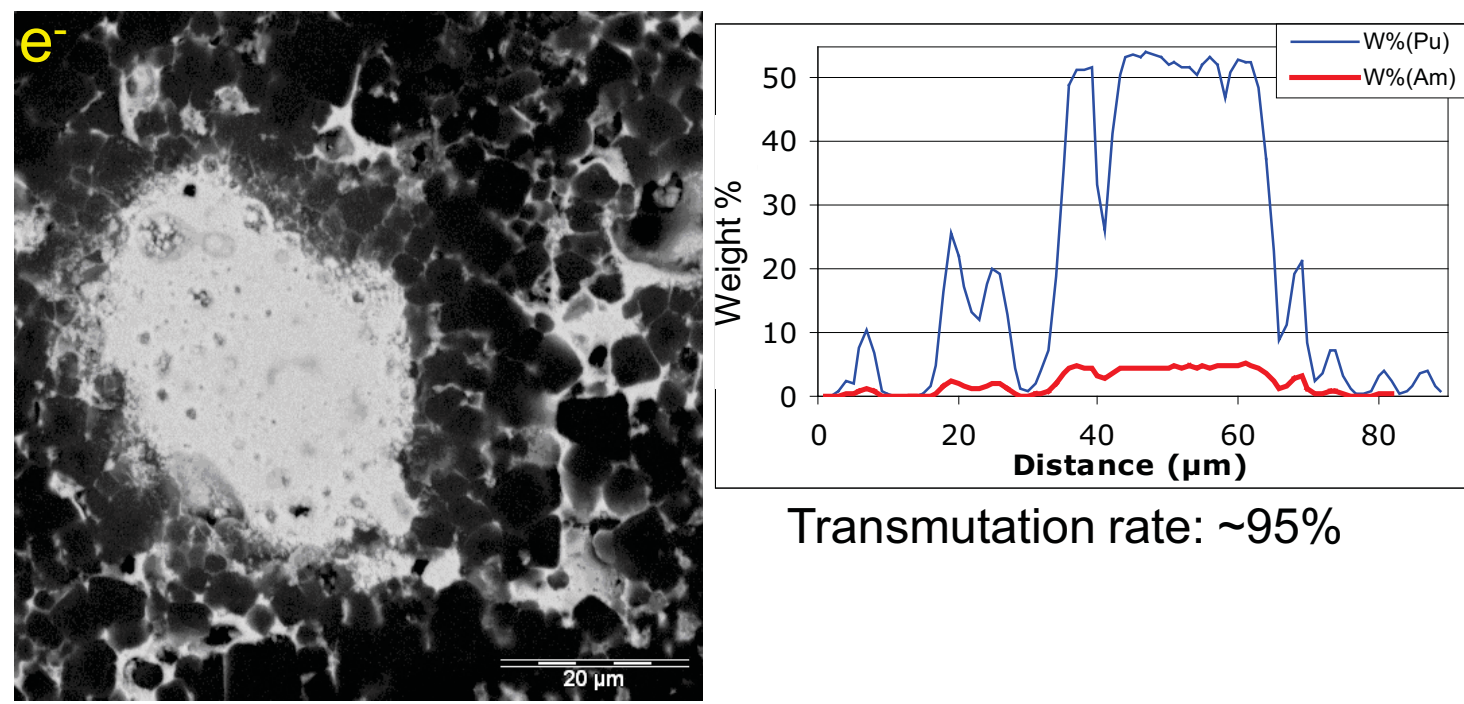

Transmutation rate: $\sim 95 \%$
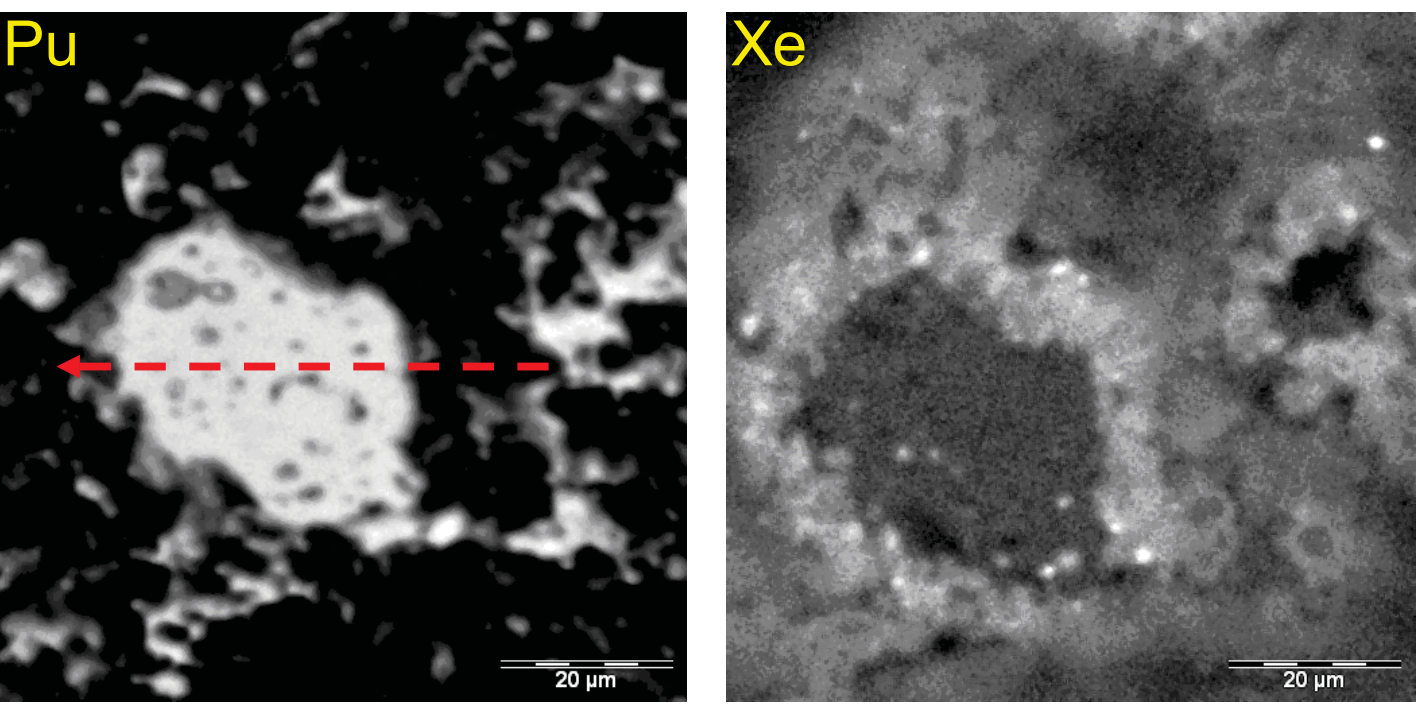

Pu formation in the ex-AmOx particle

Xe (+others FPs) departure from particle

$>$ Mechanism of the FPs Movement?

$>$ Nanoscale position of the Fission Products compounds? 


\section{cea SIMS (Secondary lon Mass Spectrometry): isotopic analyses}

Shielded SIMS CAMECA 6F In operation since 1998 (2002 for irradiated fuel)

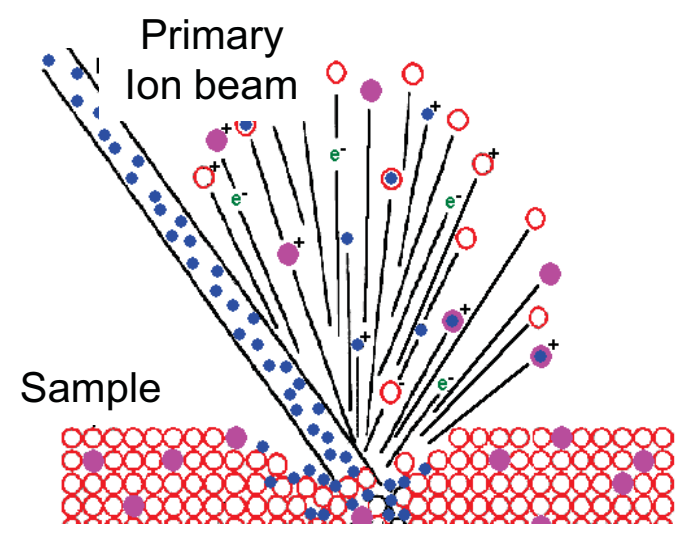

Isotopic analyses

- Trace elements (ppb)

- Gas inventory

\section{Optical macrography of a radial cut}

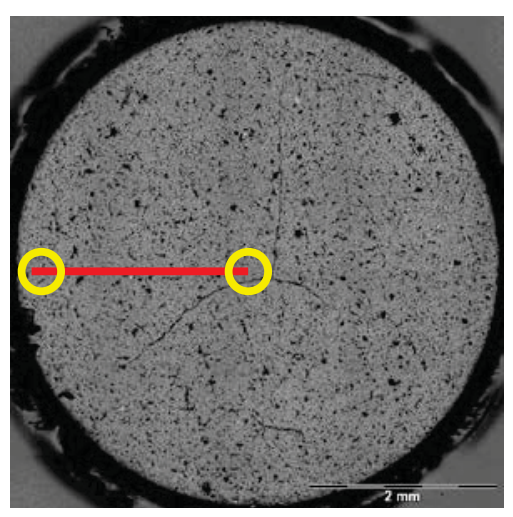

He depth Profile

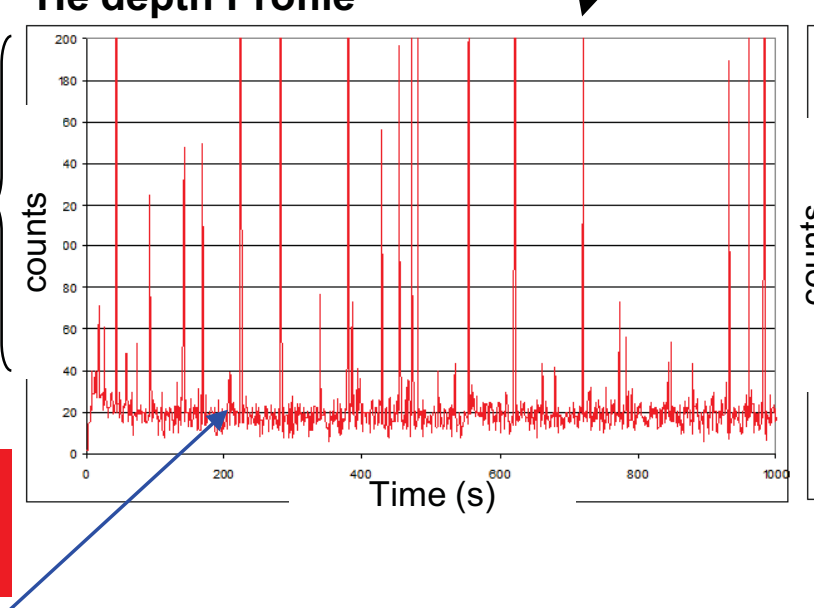

He radial Profile

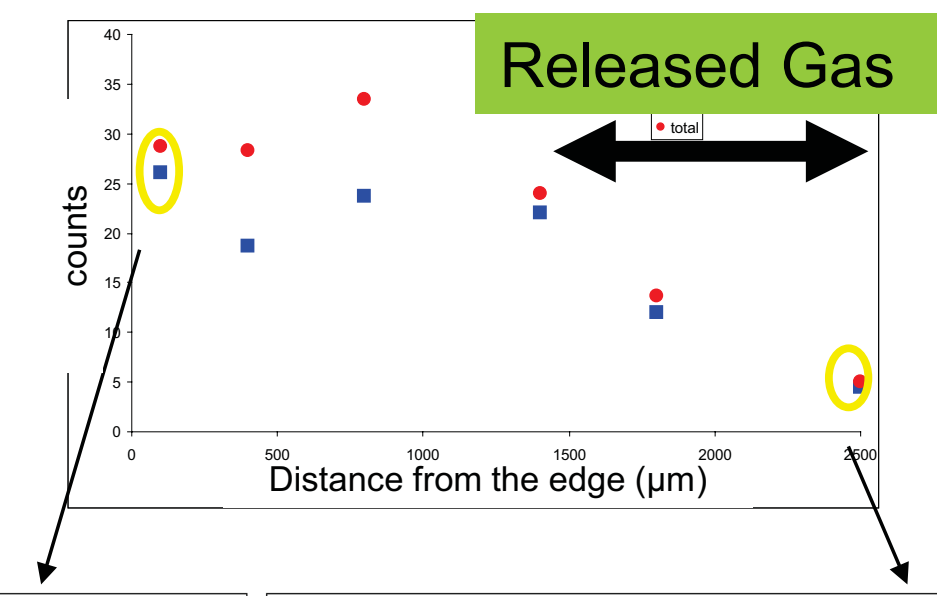

$>$ Mechanism of the gas release?

\section{Baseline}

( Gas dissolved in the matrix)

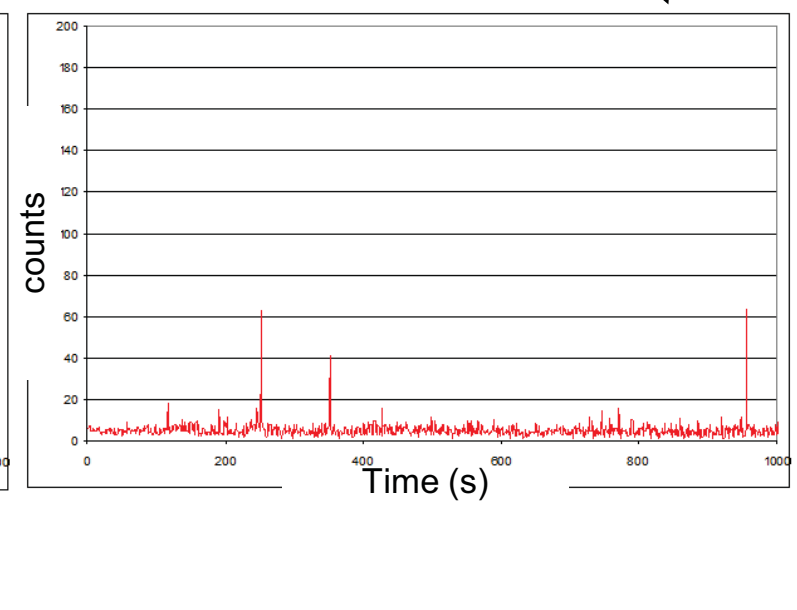

(bubbles full of gas) 


\section{General Electric}

Micro-beam Module (500 $\mu \mathrm{m})$

In operation since December 2008

-Phases (identification, phase \%, cristalline evolution...)

$\cdot \mu$-distortion and strain

\section{EPMA mappings}
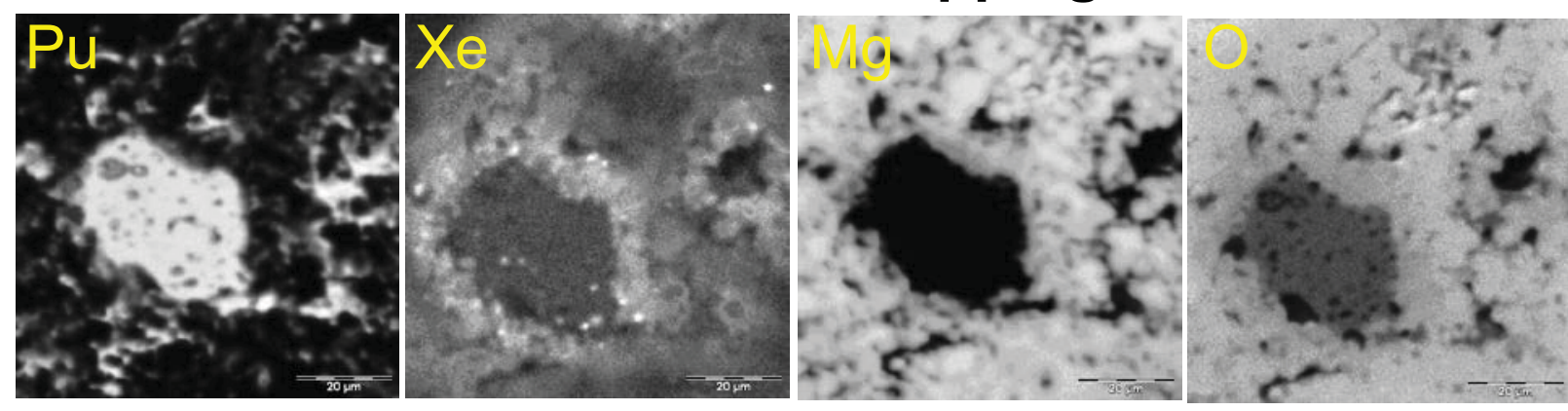

\section{Quantitative Phases Analyse}

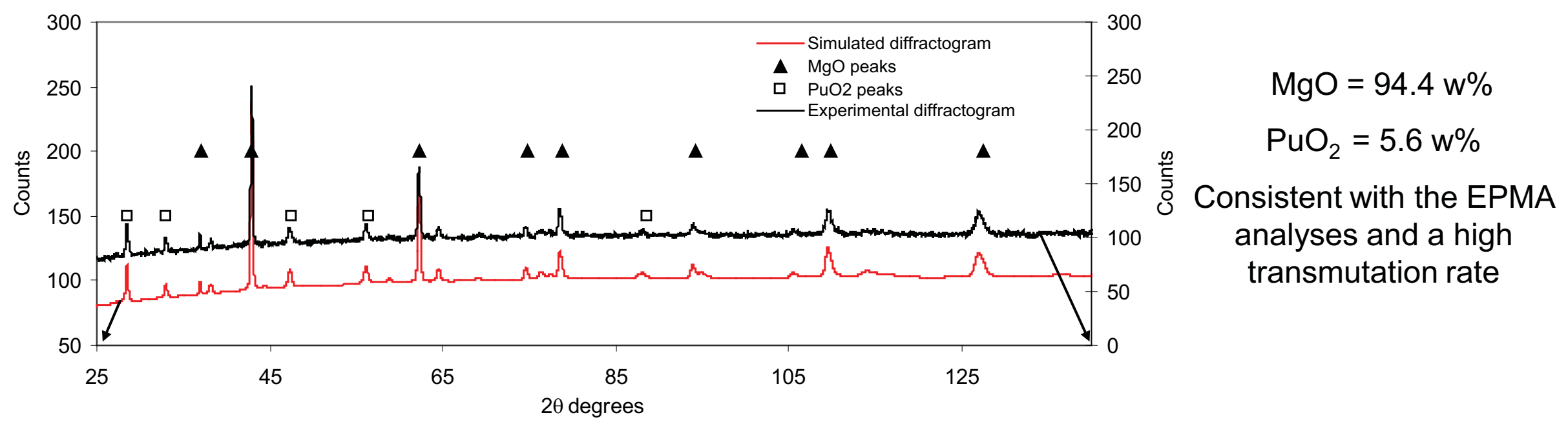

D Which structure for the few Am remaining (detected by EPMA but not by XRD)?

$>$ Which strain in the MgO grain at the periphery of the particle (FPs implantation effect)? 


\section{Elemental}

and isotopic analyse:

-Local concentrations and profiles

-Mappings

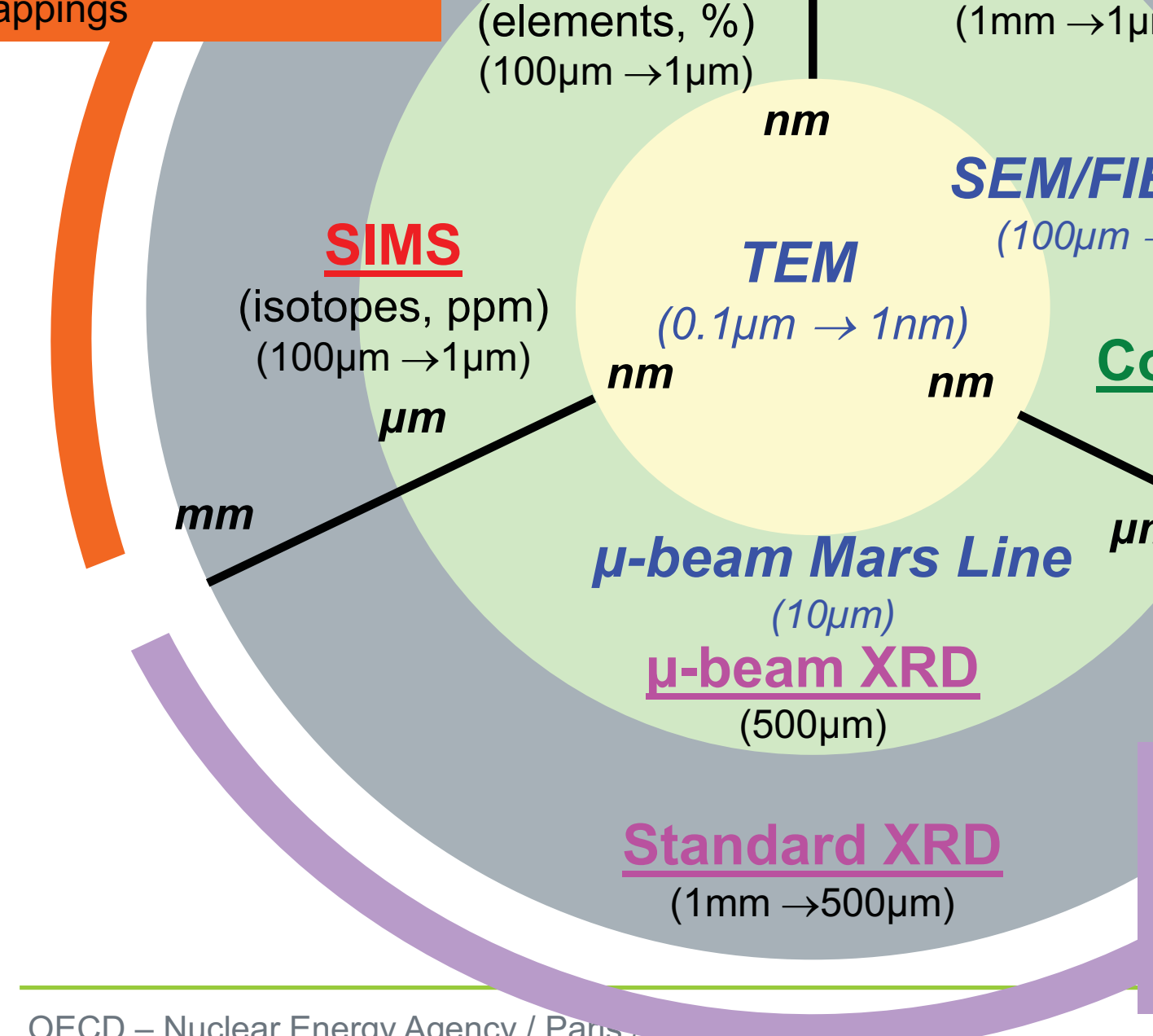

\section{EPMA}

(elements, \%)

$(100 \mu \mathrm{m} \rightarrow 1 \mu \mathrm{m})$ $\mu m$ Optical Microscopy

um)

\section{$m m$}

2D morphological characterization

-Size and number objects (grains, porosity, bubbles phases, ...) -Cracking

Cristalline and microstructural analysis: -Phases identification -Cristalline evolution (swelling, amorphisation) 


\section{SEM-FIB (Focused Ion Beam)}

\section{Principle}

- SEM with a ionic beam

- Electronic column + ionic column

- The 2 beams are focused on the same sample position

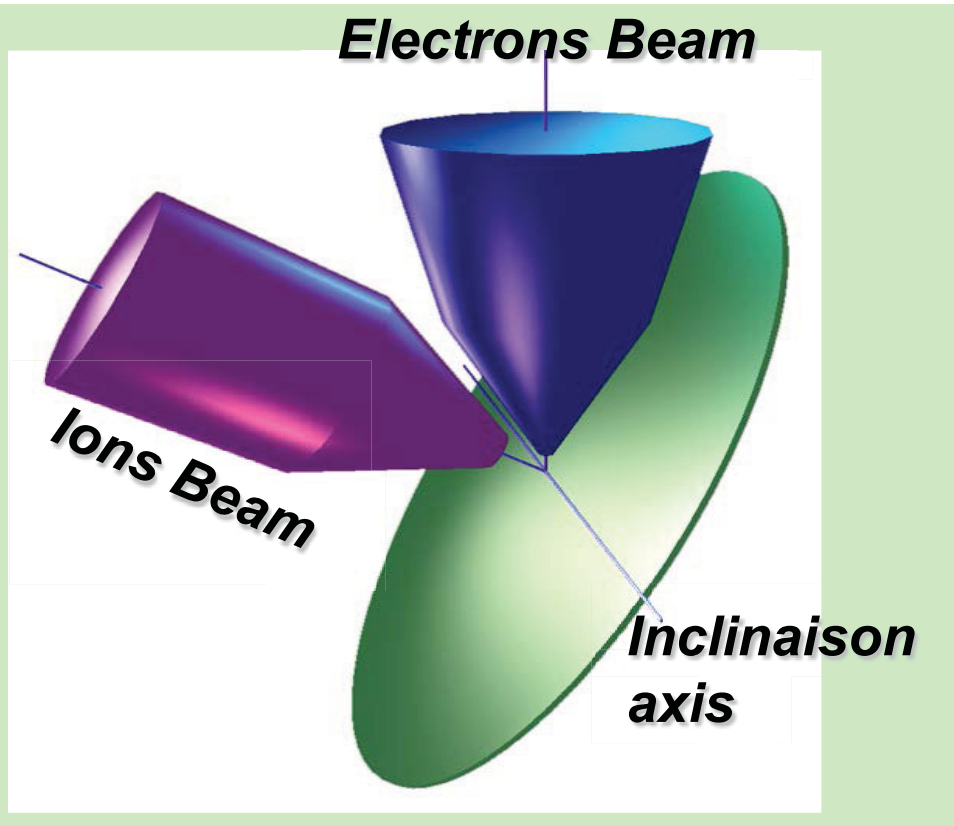

\section{Project status:}

$>$ Installation in the hotcell in place of the current SEM by 2014

$>$ Commercial process ongoing

\section{Progress for the irradiated fuel:}

-3D imaging of the microstructure: gas behavior (tunneling, bubbles location and interconnection), cracking

- Preparation of thin samples 


\section{Electronic imaging during ionic sputtering}
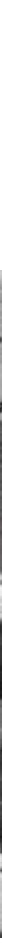

Progress for the irradiated fuel:

- Study of a delicate sample without mechanical polishing (ex: porous sample)

$\rightarrow$ no damage

$\rightarrow$ for EBSD analyse

- Cracks: study of the cracks initiation and the propagation

- Study of the thin porosity distinguishing inter and intragranular, interconnection 


\section{SEM-FIB: contribution \#2}

\section{Preparation of small and/or thin samples}

\section{Cutting of the sample}

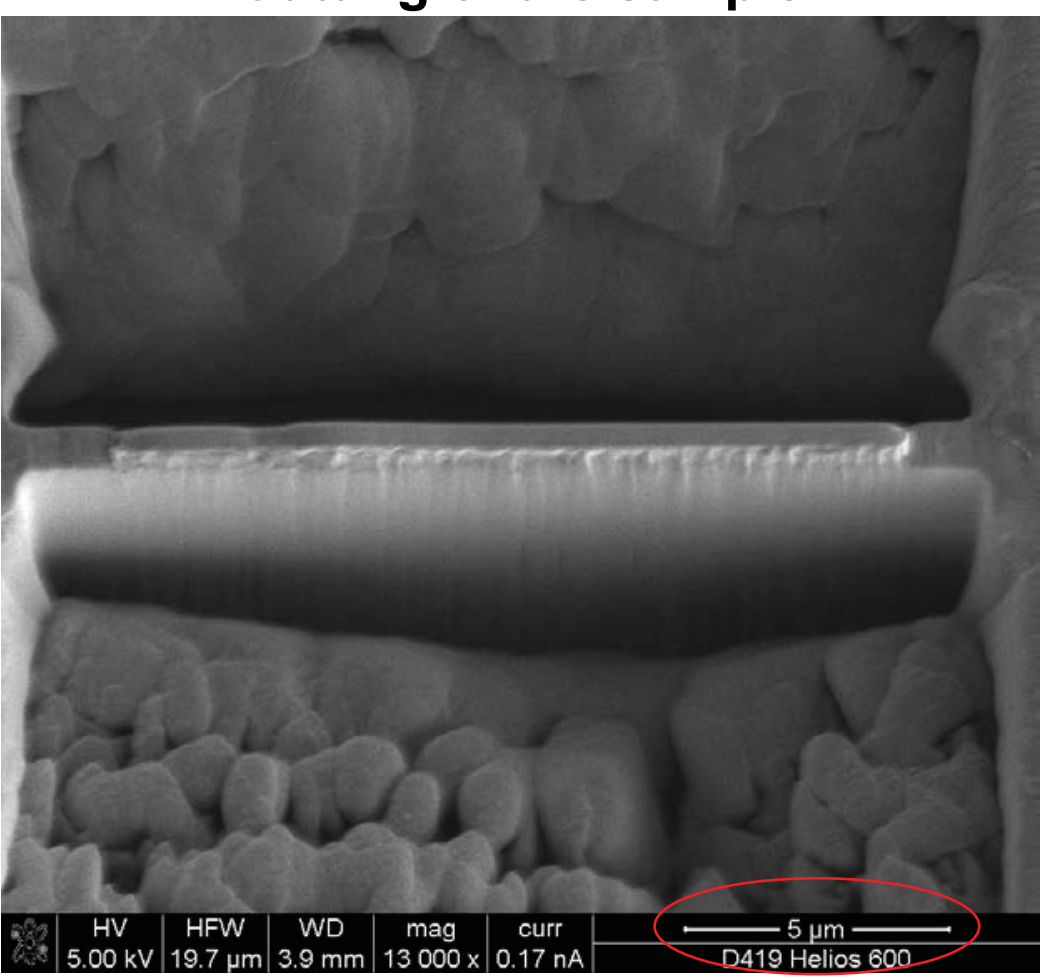

\section{Sample extraction}

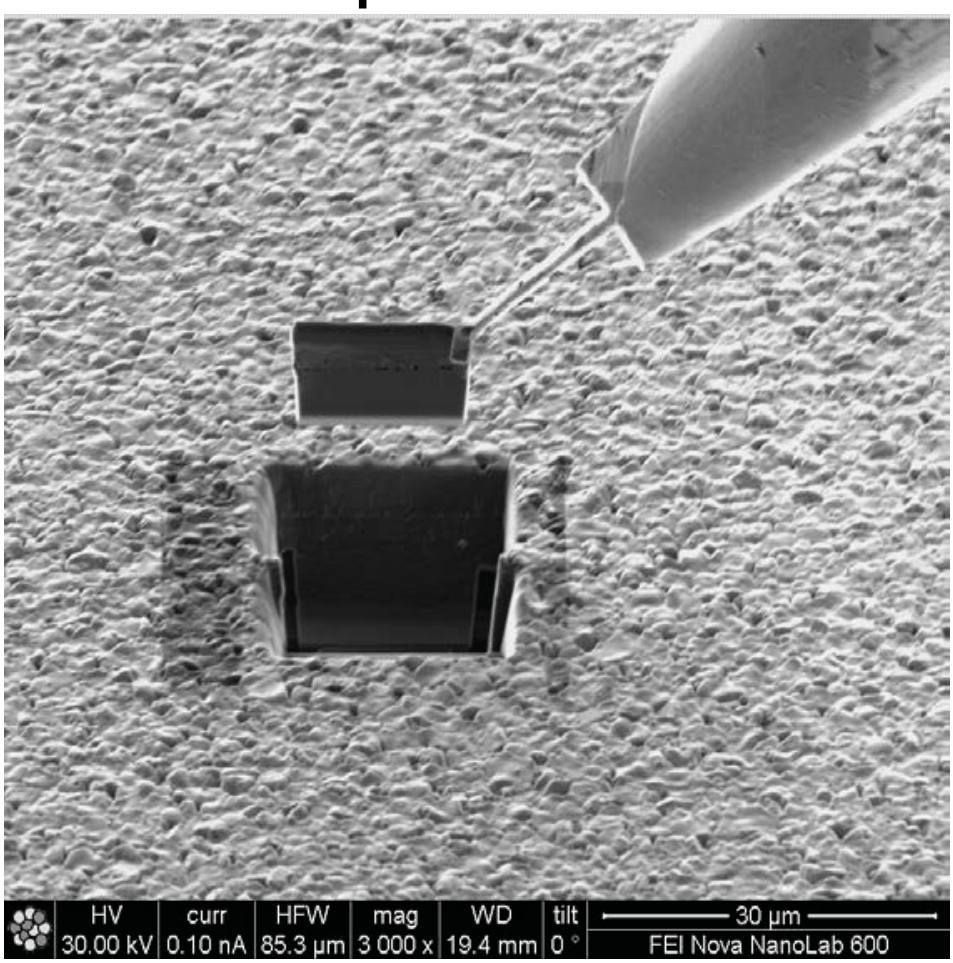

Progress for the irradiated fuel:

$\rightarrow$ Irradiated sample preparation for the TEM

$\rightarrow$ Irradiated sample preparation for the Mars Line

$\rightarrow$ Choice of the sample location (AmOx particle, MgO, Interface)

$\rightarrow$ Reduction of the radioactive background for the current microanalyse devices (XRD, SEM, EPMA) 
$\overline{c e a}$ EBSD (Electron BackScattered Diffraction)

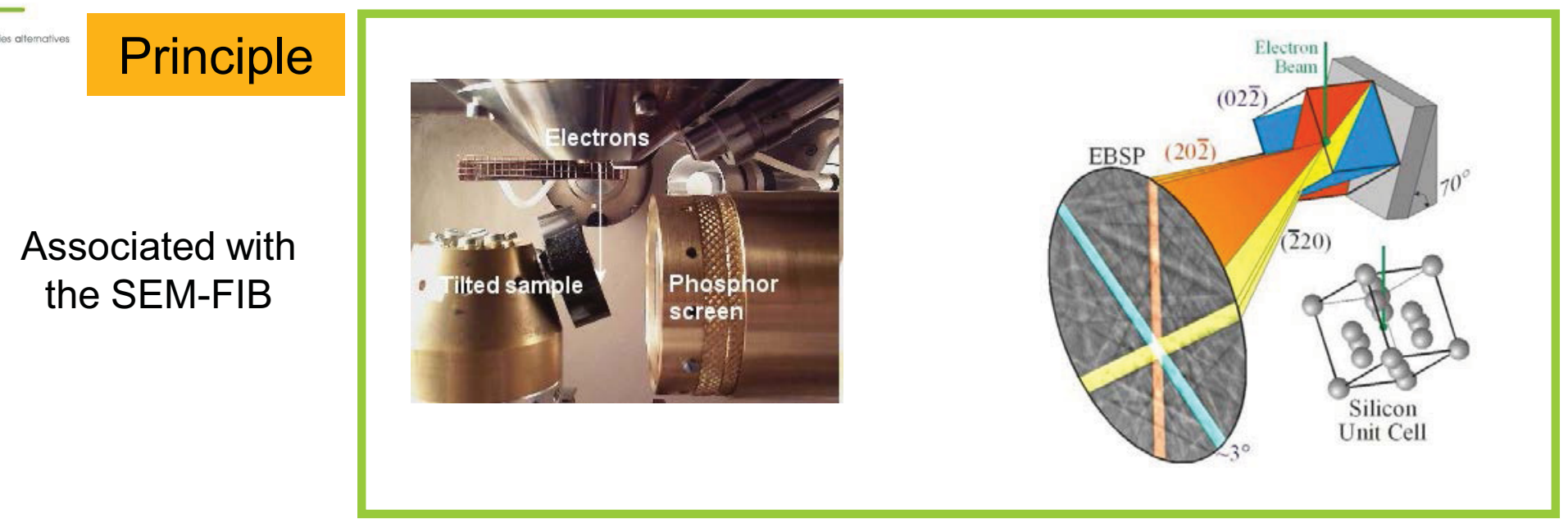

- Interaction between a crystal and the primary electrons

$>$ Diffraction of the primary electrons by the cristalline plans

$>$ Acquisition of a diffraction pattern

$>$ The cristalline structure is obtained on a grain scale

$>$ High quality of sample preparation is needed $\rightarrow$ SEM-FIB

\section{Project status:}

> Installation associated with the SEM-FIB

$>$ Installation in the hotcell in place of the current SEM by 2014

$>$ Commercial process ongoing 


\section{EBSD: example of contribution}

\section{Displaying of the grain boundary by SEM/FIB/EBSD}

\section{$\rightarrow$ Correlation between the grain restructuration and their cristalline orientation}

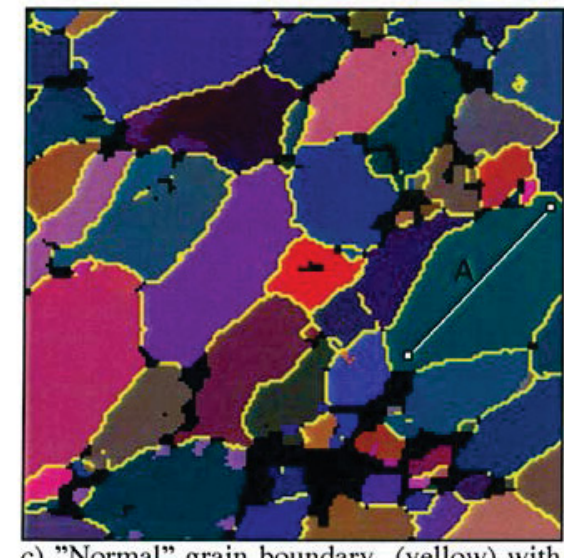

c) "Normal" grain boundary (yellow) with $>10^{\circ}$ mismatch between two adjacent measurement points. A $6^{\circ}$ orientation mismatch between two sides of the same grain is indicated at "A".

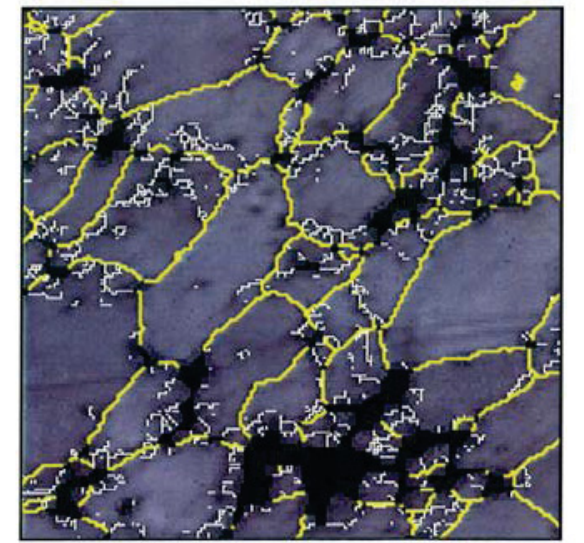

d) "Normal" grain boundaries (yellow) and "Sub-grain" boundaries (white) with a mismatch between adjacent measurements in the range 1 and $10^{\circ}$.

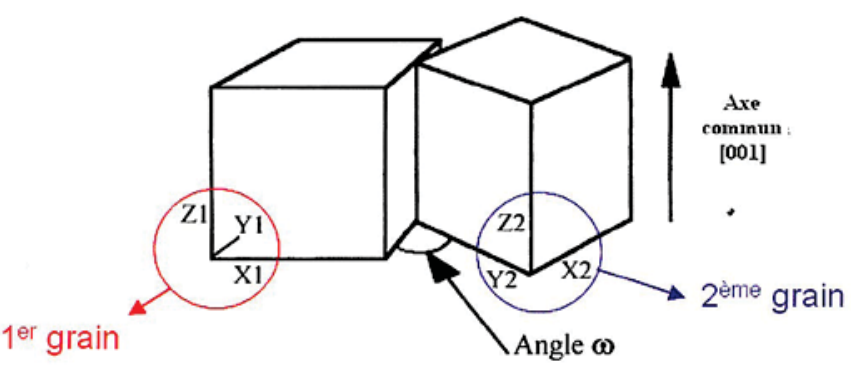

Addition of EBSP equipment to the Studsvik HCL SEM - S. Bengtsonn Meeting 5 and 6 June 1997 Studsvik

Progress for the irradiated fuel:

Phase cristalline study at the grain scale

- Extraction of the grain boundaries ( $\rightarrow$ Porosity location) and the sub-grain $(\rightarrow$ restructuration in HBS)

* To correlate the cracks propagation and/or the grain restructuration with the cristalline orientation

Studying the sub-grain strains during a mechanical test or during the irradiation of the material 


\section{At the nano-scale, the TEM allows to...}

- Study the microstructure

$\rightarrow$ imaging, until to the atomic columns

- Perform the cristalline study

- Determine the elemental composition,

$\rightarrow$ From heavy (EDS) to light elements

- Obtain some information on the atom environnement
C. Sabathier

Bright field image of $\mathrm{UO}_{2}$ thin

foil implanted with $\mathrm{Xe}$ ions

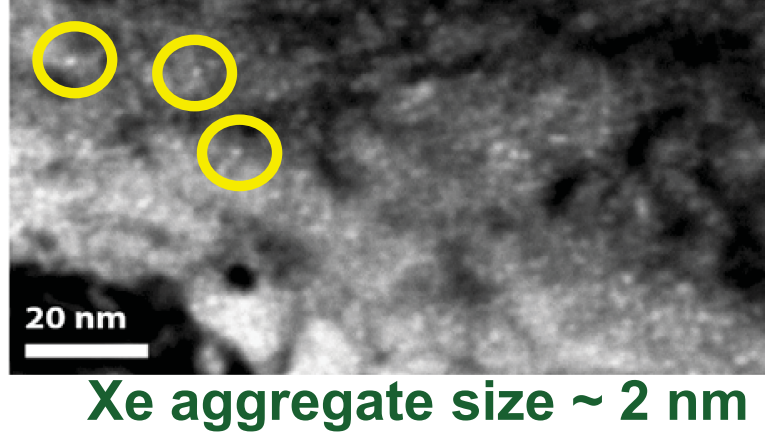

These investigations are performed at the CEA Fuel Studies Department on ion irradiated $\mathrm{UO}_{2}$ samples

$\rightarrow$ Objective: perform the same investigations on irradiated fuels in reactor (all fuels)

\section{Characterisation in support to the modelling / simulation}

\section{$\Rightarrow$ an essential device for the irradiated fuel studies}

How to perform these PIE:

$>$ Collaboration with ITU

$>$ LECA-STAR facility: Project under discussion in the framework of a French invitation to tender for the excellence equipments / installation by the end of 2015 


\section{Location: SOLEIL Synchrotron, Saclay, France}

\section{of radioactive materials}

* MAtière Radioactive à SOLEIL or Multi Analyses on Radioactive Samples

2 experimental stations : $3.5-36 \mathrm{keV}$

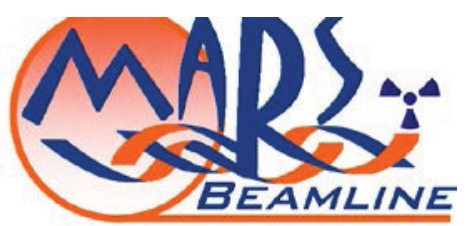

\section{Standard Absorption station \\ High-resolution XRD}

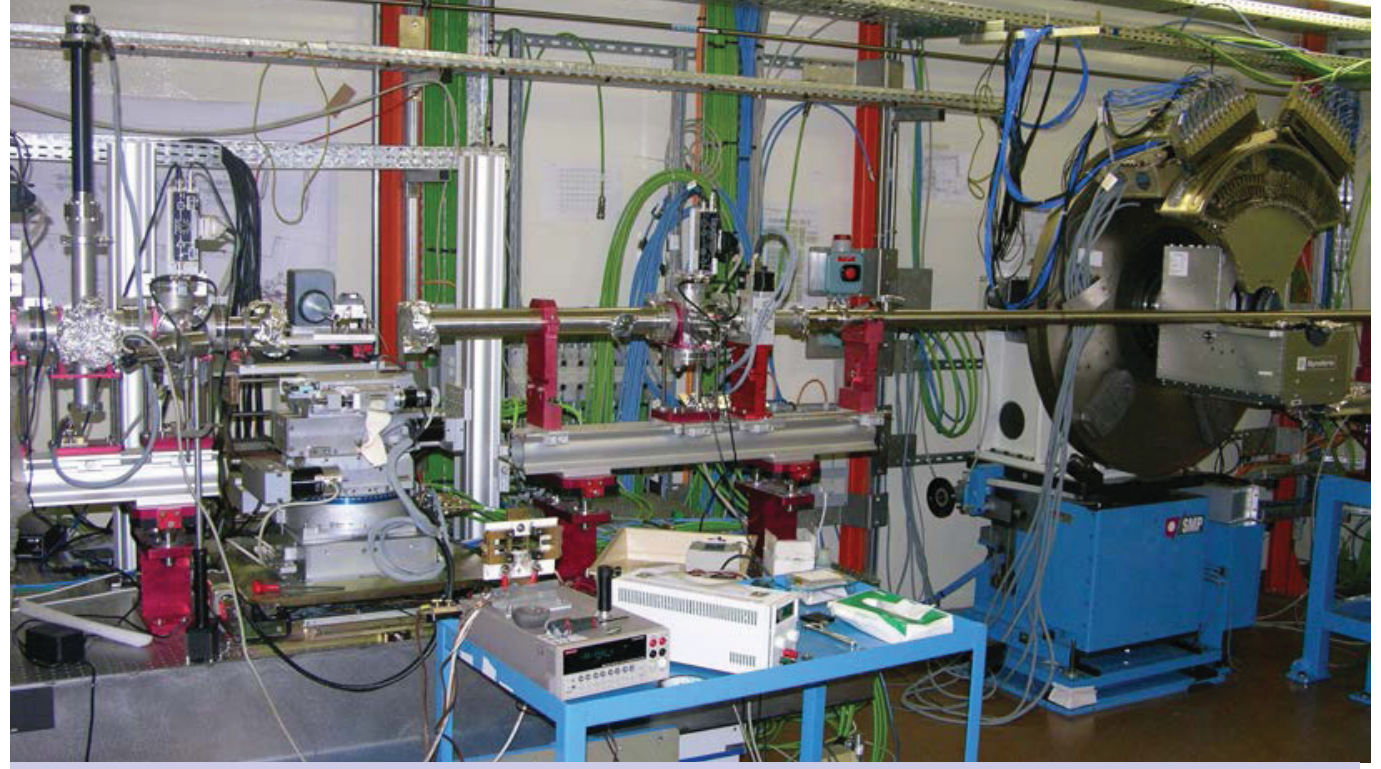

Commissioning on irradiated fuel by the end of 2012

\section{Synchrotron radiation $\Leftrightarrow \mathrm{XRD}$ station}

High resolution goniometer + synchrotron flux $\left(10^{8}\right.$ compare to hotlab XRD device $)$
Resolution on LaB6

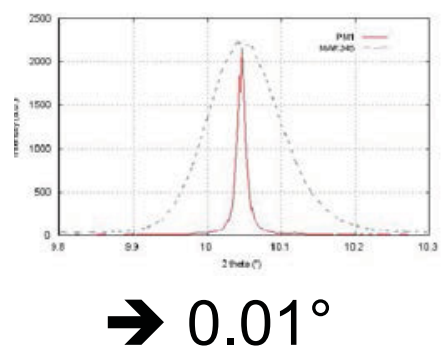

Further on ECRIX-H experiment

- minor phase detection

- Pu, Am local environment - $(\mathrm{Pu}, \mathrm{Am}) \mathrm{O}_{(2 \pm \mathrm{x})}$ structure determination

- $\mu$-strain in fissile clusters -.... 
For the nuclear fuel studies, including transmutation studies, new microanalysis devices are needed:

* To improve the comprehension of irradiated fuel behavior (including the transmutation),

* To improve the necessary data for the modeling and simulation

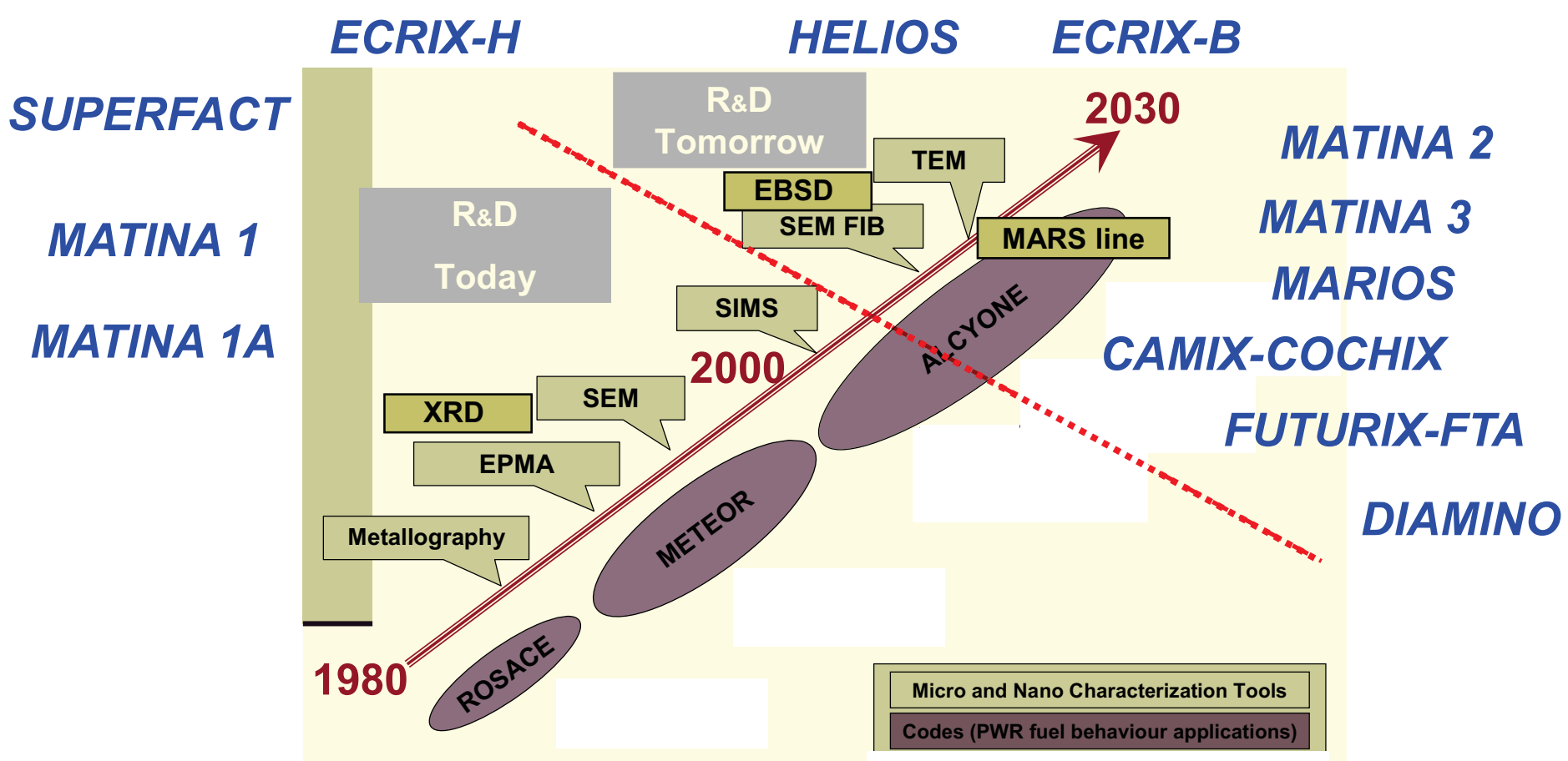




\section{Post Irradiation Examinations LECA-STAR Facility}

François SUDREAU

Fuel behaviour characterization and analysis service 
- Main characteristics

- Sample : from 100 mg to $10 \mathrm{~g}$

- Induction furnace

- Max. temperature : $2800^{\circ} \mathrm{C}$

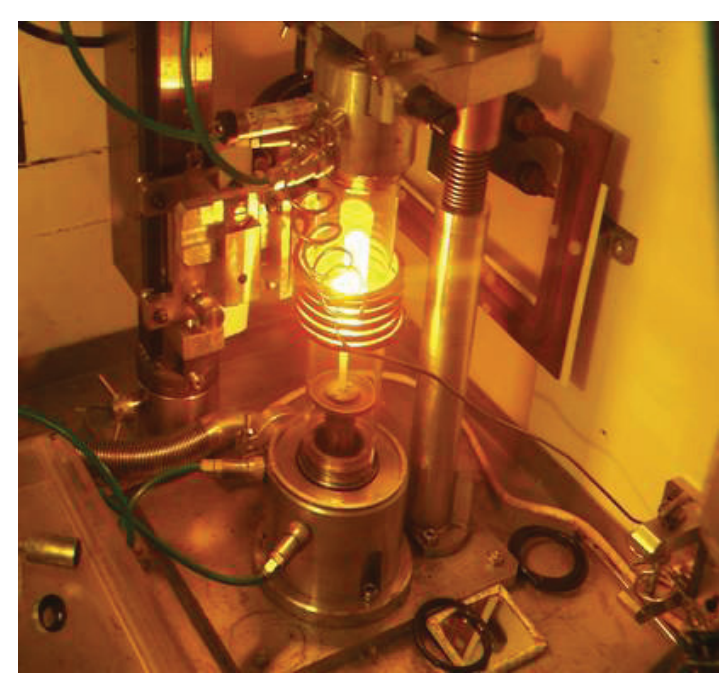

- Max. temperature ramps : higher than $200^{\circ} \mathrm{C} / \mathrm{sec}$

- Atmospheres : He, Ar, air

- Room pressure

- Sample temperature measured by 1 thermocouple and 1 pyrometer

- Fission gas release kinetics measurements

- On-line gamma spectrometry : ${ }^{85} \mathrm{Kr}$

- Post test analysis of released gas (stored in capacities) : gaseous chromatography or mass spectrometry 


\section{VERDON :}

Facility devoted to FP release from irradiated fuels studies
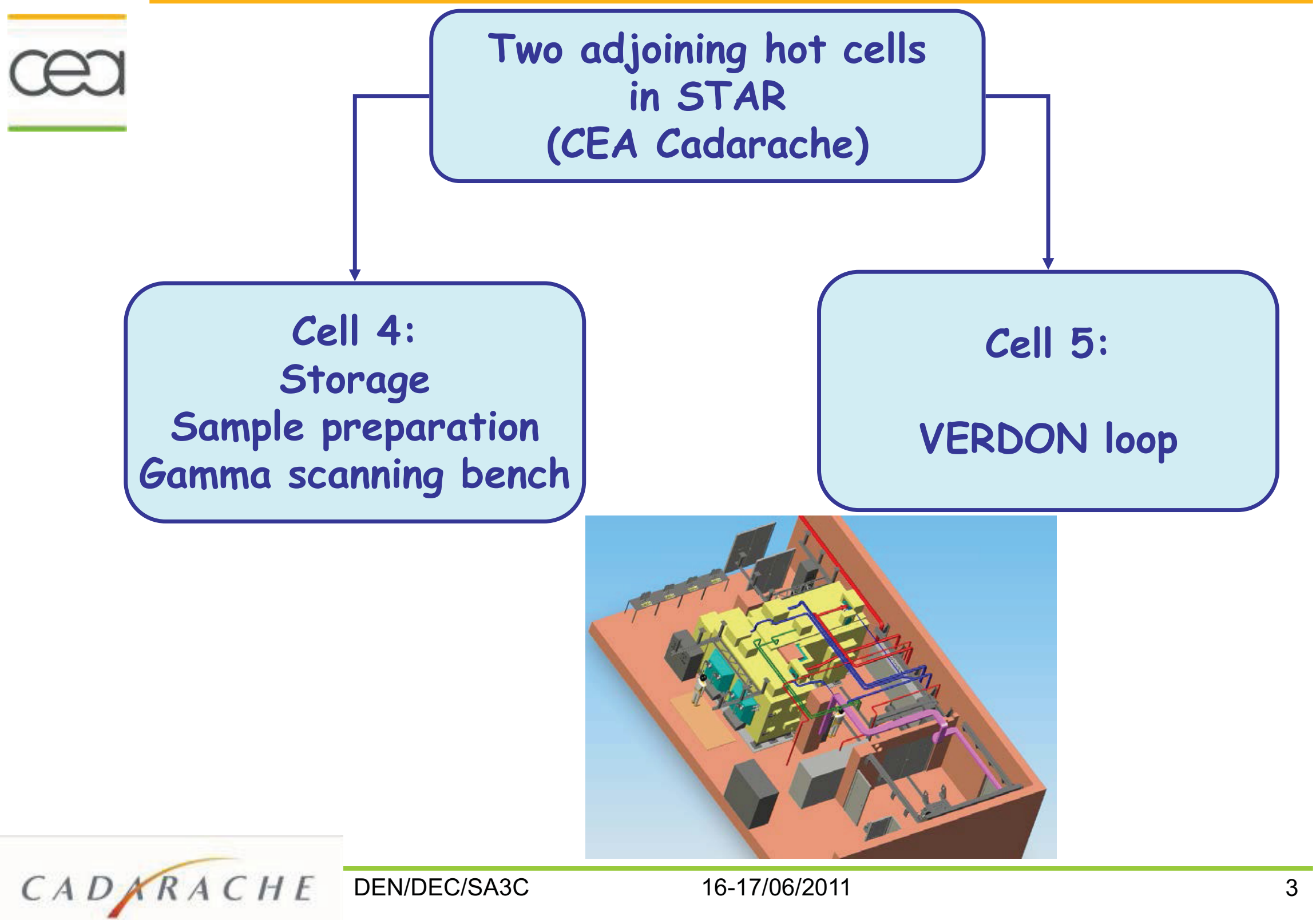


\section{VERDON :}

\section{2 loops configurations}

- VERDON loop, "Release" configuration (CER)

- VERDON loop, "Transport" configuration (CET)
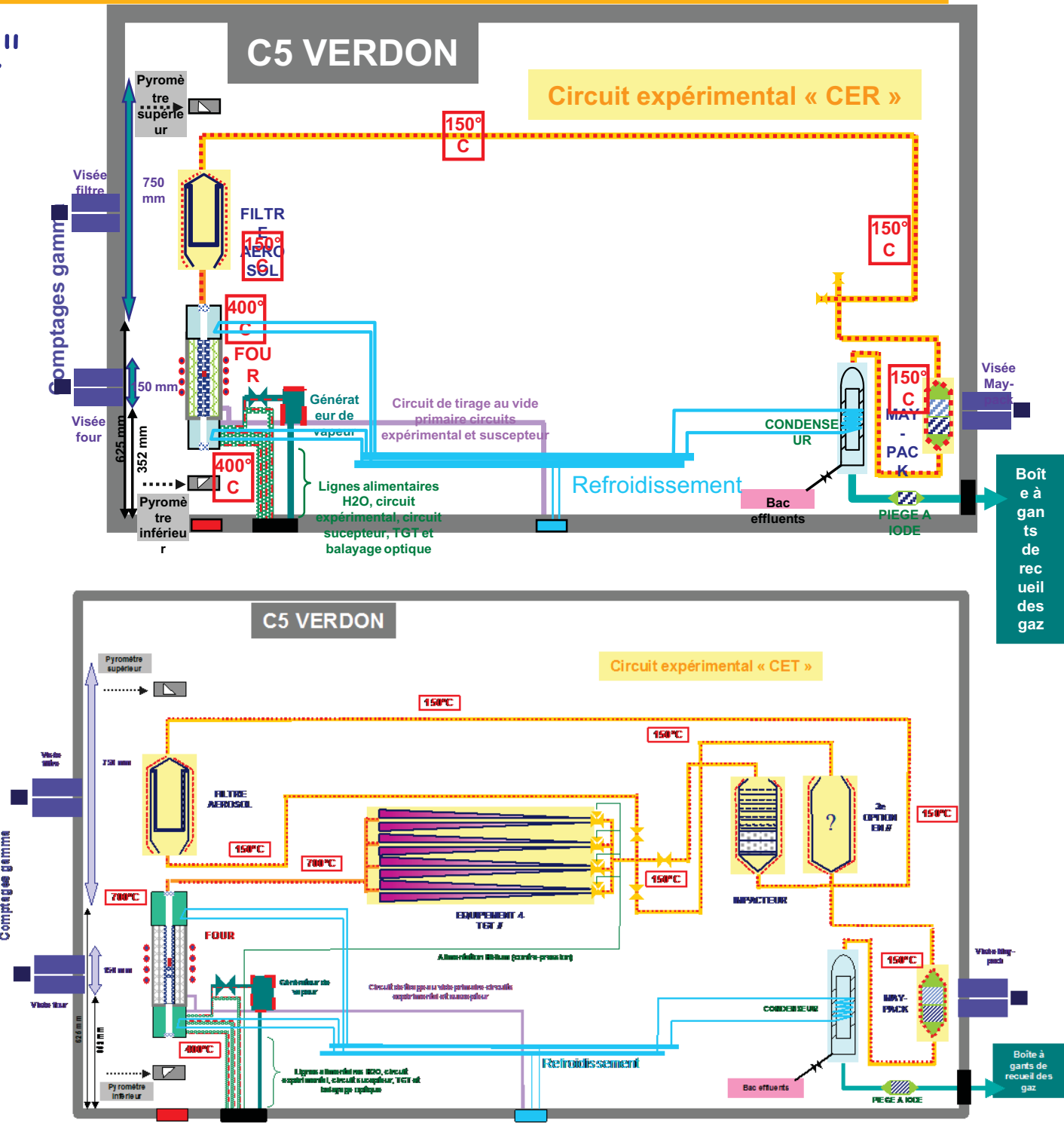


\section{VERDON : \\ Test conditions and on-line measurements}

- Fuel sample

- "pellet scale" for FP release; $10 \mathrm{~cm}$ fuel long for studying the coupling between fuel degradation and FP release

- Reirradiation in MTR reactor for short half life FP

- Tests conditions

- Temperature up to fuel delocation or slightly more: inductive heating

- Tests performed under variable atmosphere: helium, hydrogen, steam, air

- On line FP measurements

- 3 on line gamma spectrometers in sight of: fuel, filter, maypack

- FP measurements before and post tests

- 1 gamma spectrometer "multi-samples"

- FP balance before and after the test : FP deposit quantification along the loop downstream the furnace

- 1 glove box for fission gas total balance

- 1 chromatograph coupled with mass spectrometer: quantification of released stable gas 


\section{LECA-STAR}

cea

\section{A complete set of devices to study fuel behavior under various conditions}

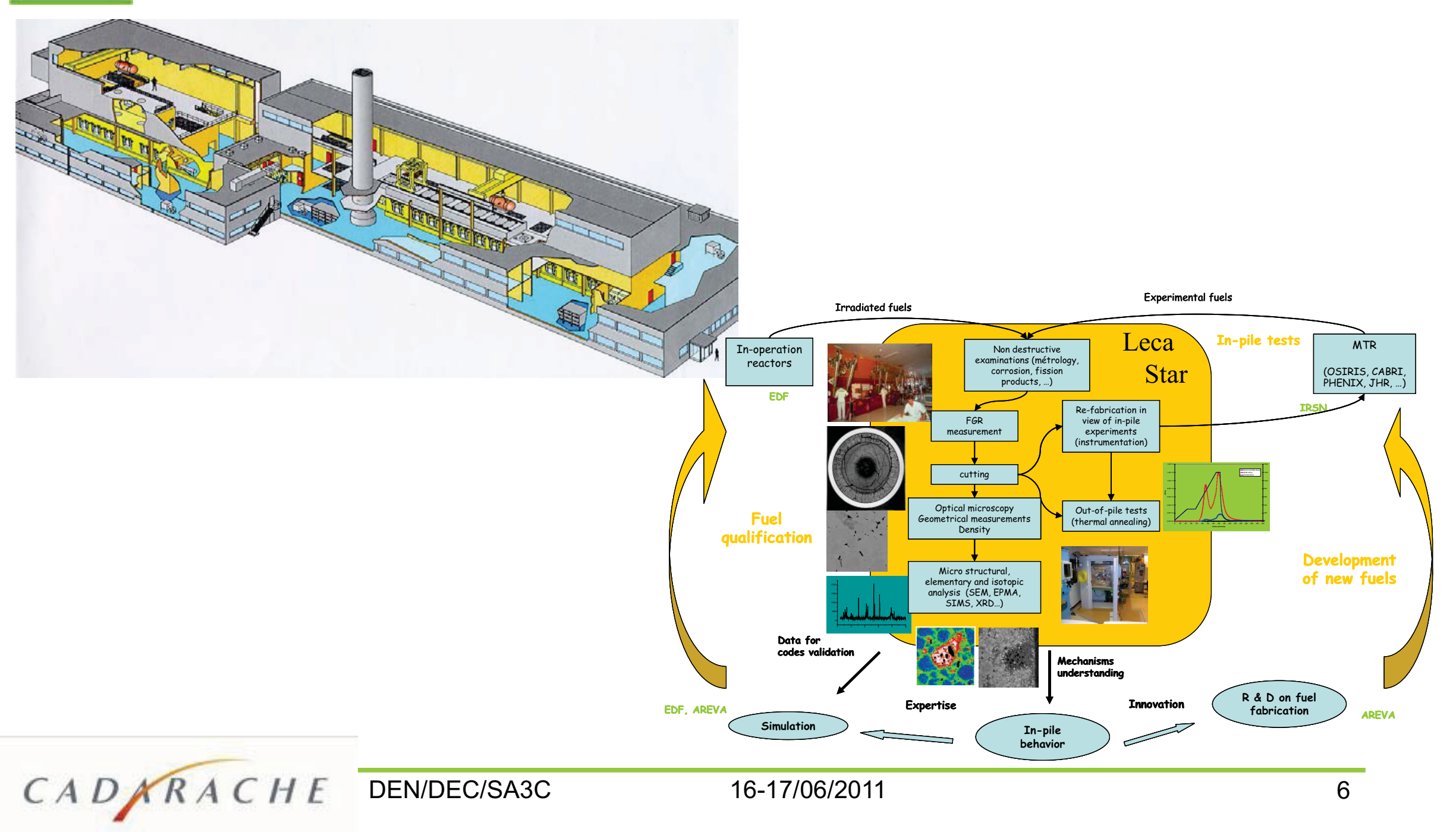




\section{Joint Research Centre (JRC)}

\section{Application of X-ray absorption to density measurements \\ D. Papaioannou (presented by J. Somers)}

ITU - Institute for Transuranium Elements

Karlsruhe - Germany

http://itu.jrc.ec.europa.eu/

http://www.jrc.ec.europa.eu/ 


\section{Attenuation law}

$I=I_{o} \exp \left(-\mu_{m} \rho x\right) \quad$ or $\quad \rho=\ln \left(I_{o} / l\right) /\left(\mu_{m} x\right)$

I transmitted intensity

$I_{o}$ incident intensity

$\mu_{m}$ mass absorption coefficient $\left(\mathrm{cm}^{2} / \mathrm{g}\right)$

$\rho$ density

$x$ sample thickness

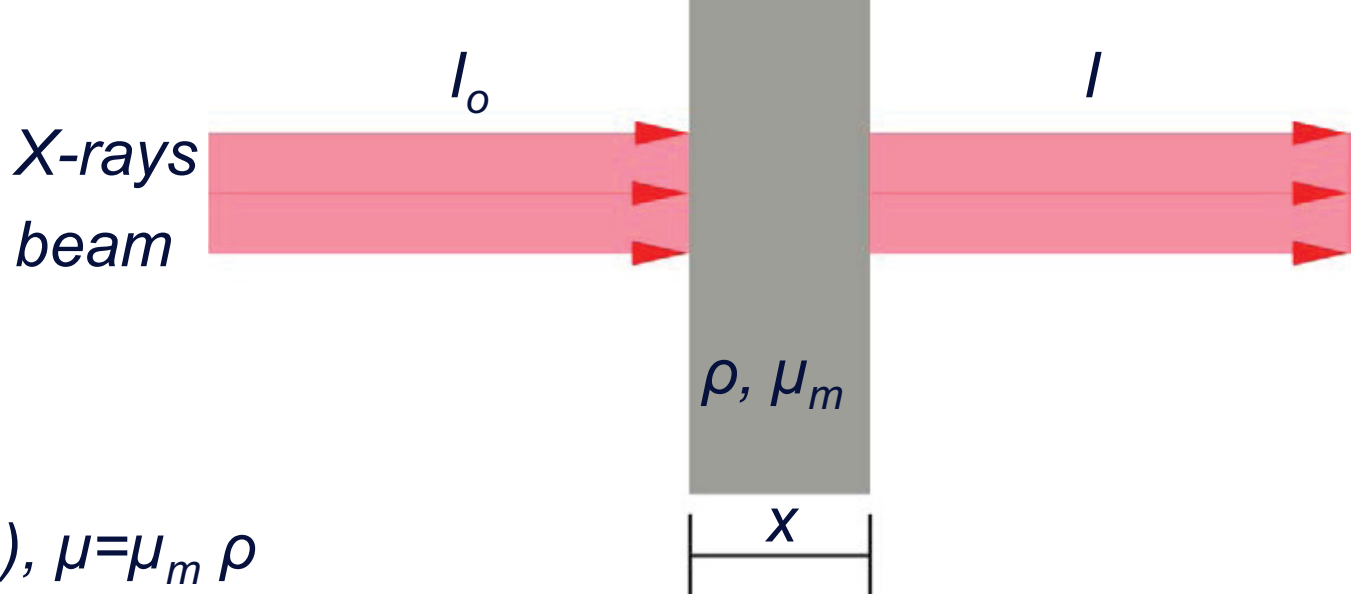

Note: $\quad \mu$ linear absorption coefficient $\left(\mathrm{cm}^{-1}\right), \mu=\mu_{m} \rho$

$\mu$ depends on the wavelength, $\lambda$

Mixtures and compounds: $\mu_{m}=\Sigma\left(w_{i} \mu_{m i}\right)$,

$w_{i}$ is the weight fraction of the $i^{\text {th }}$ atomic constituent

Assumption: $\mu, \mu_{m}$ is independent on $x$, hence homogeneity 


\section{Literature source}

\section{"Density measurements of liquid under high pressure and} high temperature",

Y. Katayama et. al., J. Synchrotron Rad. (1998), 5, 1023-1025

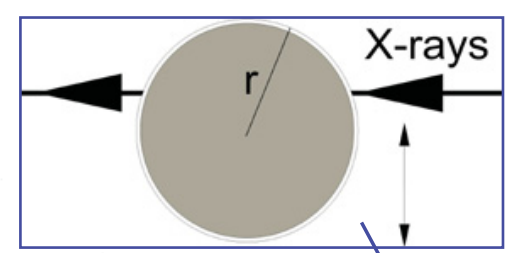

Photodiode

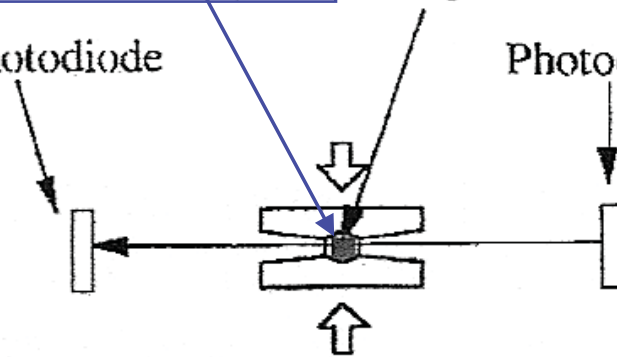

Paris-Edinburgh press

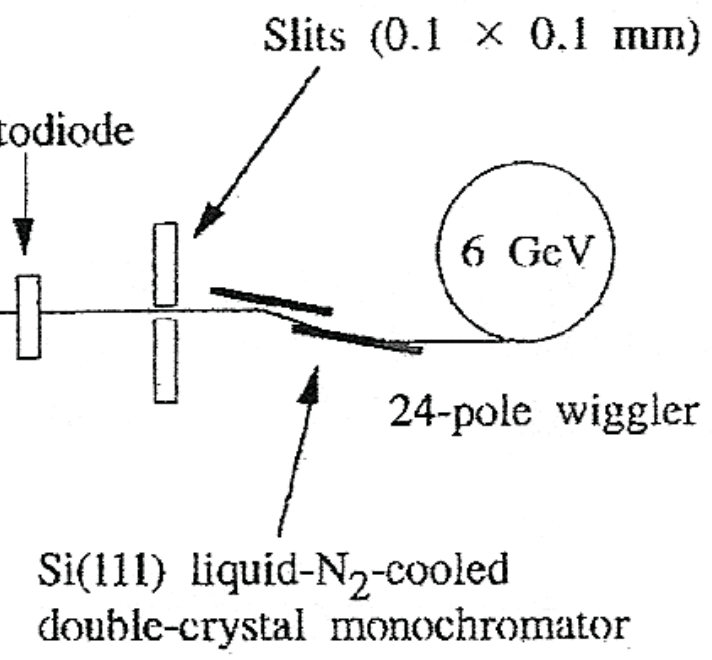

\section{Figure 1}

Schematic diagram of the experimental arrangements.

Y. Katayama et al.: ... the error was less than $1 \% \ldots$

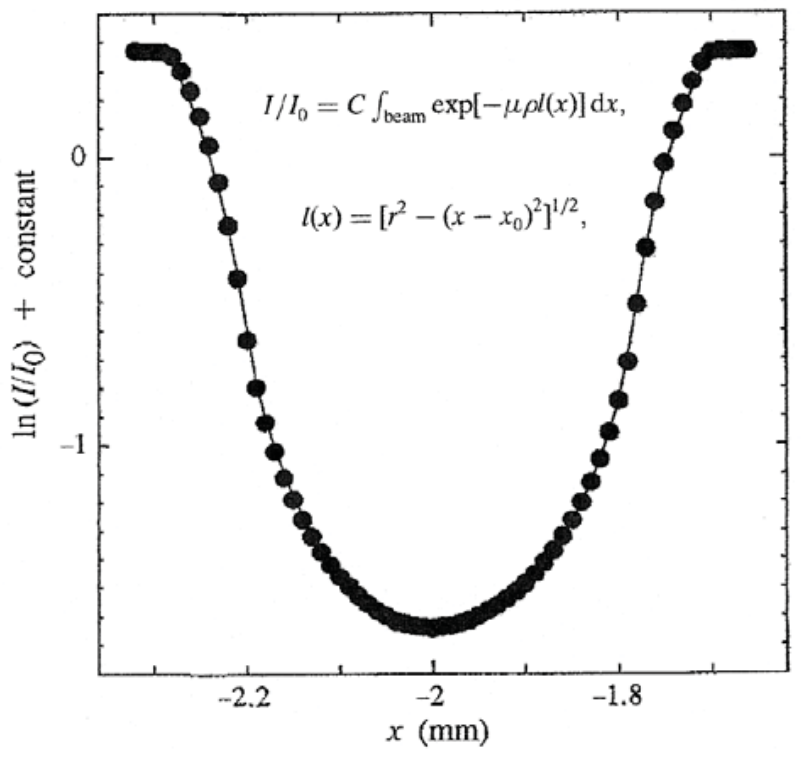

\section{Figure 3}

Logarithm of $I / I_{0}$ for liquid $\mathrm{Bi}$ at $1 \mathrm{GPa}$ and at $750 \mathrm{~K}$ as a function of sample position. Circles are experimental data. The line is the result of parameter fitting.

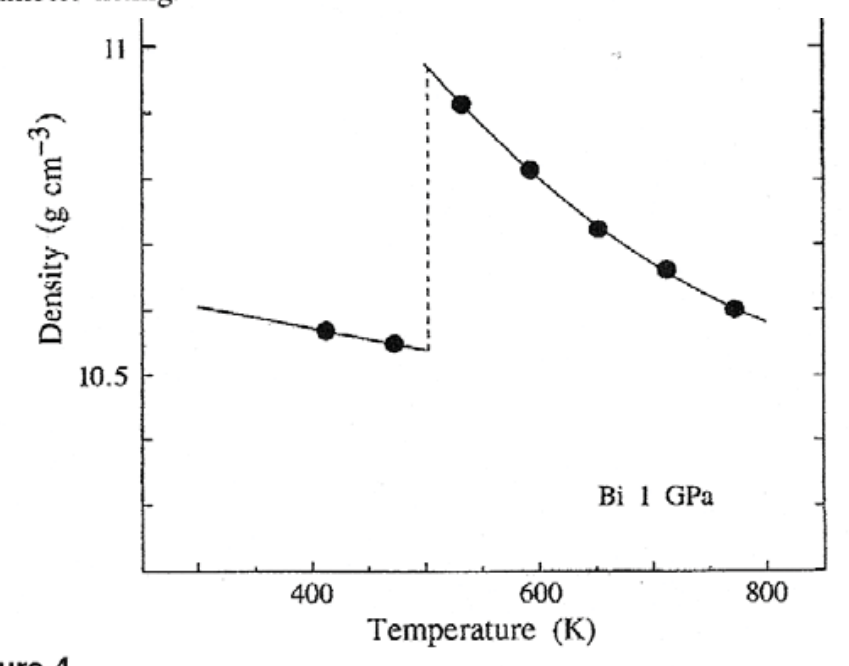

Figure 4

Density of crystalline and liquid $\mathrm{Bi}$ at $1 \mathrm{GPa}$ as a function of temperature. 


\section{Available equipment}

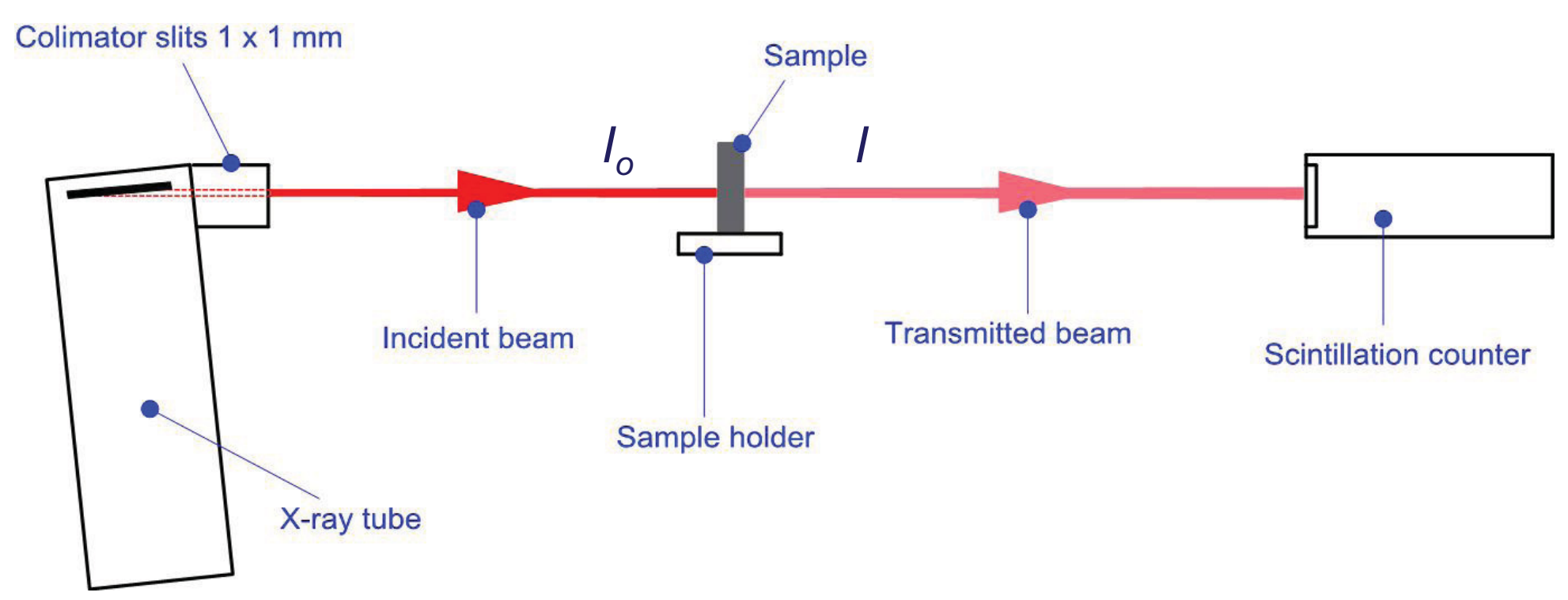

X-ray powder diffractometer (Seifert XRD 3000 PTS)

Tube: Cu fine focus, $1,5 \mathrm{KW}$

Wavelength: Ni filtered $K_{\alpha}(8.05 \mathrm{keV})$

Collimated incident beam: $1 \mathrm{~mm} \times 1 \mathrm{~mm}$

Detector: Nal scintillation counter 


\section{Initial measurements}
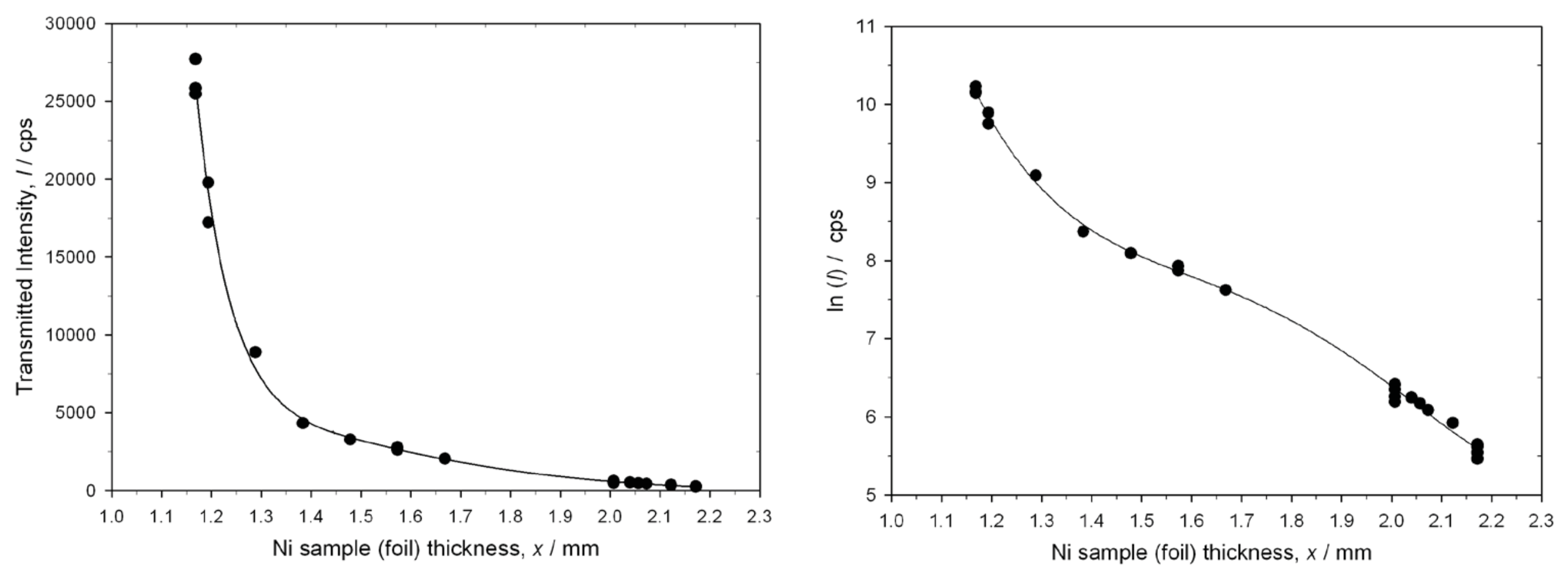

Intensity (I) of X-rays transmitted through Ni foils

Remark: Data deviate from attenuation law due to experiment conditions, mainly to detector's specification 


\section{Preliminary results-1}

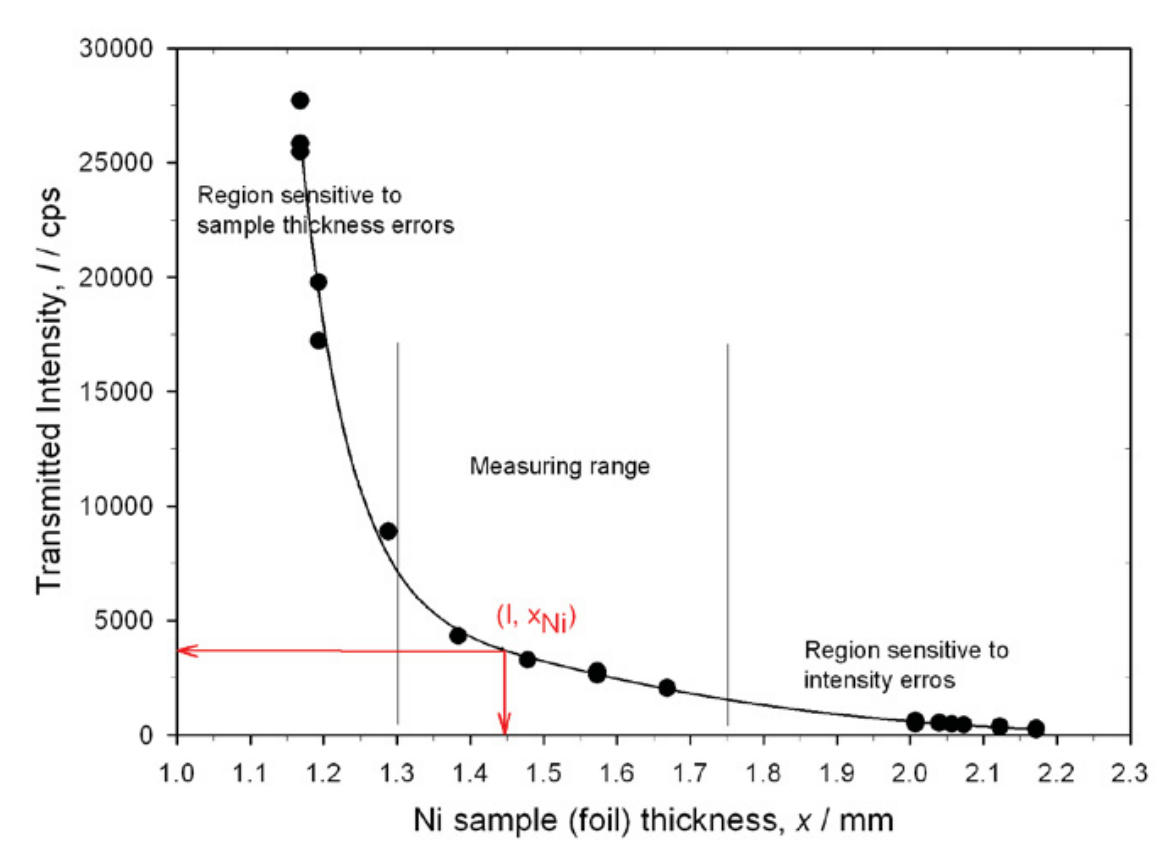

For an "unknown" sample: $\ln \left(I_{o} / l\right)=\rho_{s} \mu_{m, s} x_{s}$

In the graph, intensity I corresponds to Ni sample of thickness $x_{N i}$, that is: $\ln \left(I_{\delta} / I\right)=\rho_{N i} \mu_{m, N i} x_{N i}$

Therefore: $\rho_{s}=\left(\rho_{N i} \mu_{m, N i} x_{N i}\right) /\left(\mu_{m, s} x_{s}\right)$

If the transmitted intensity I is too high, Ni foils with thickness $\mathrm{x}_{N i \text {, extra }}$ can be placed in the front side of the sample, and Eq. (1) is modified:

$$
\rho s=\left[\rho_{N i} \mu_{m, N i}\left(x_{N i}-x_{N i, e x t r a}\right)\right] /\left(\mu_{m, s} x_{s}\right)
$$




\section{Preliminary results-2}

\begin{tabular}{|c|c|c|c|c|}
\hline Sample & Thickness, $x$ & $\mu_{m}$ for $\lambda=8.05 \mathrm{keV}$ & $\underline{\text { Known density, } \rho}$ & $\begin{array}{c}\text { Density, } \rho \\
\text { X-ray absorption }\end{array}$ \\
\hline $\mathrm{Cu}$ & $0.529 \mathrm{~mm}$ & $51.37\left(\mathrm{~cm}^{2} / \mathrm{g}\right)$ & $8.94 \mathrm{~g} / \mathrm{cm}^{3}$ & $8.90 \mathrm{~g} / \mathrm{cm}^{3}$ \\
\hline Natural $\mathrm{UO}_{2}$ & $0.355 \mathrm{~mm}$ & $269.49\left(\mathrm{~cm}^{2} / \mathrm{g}\right)$ & $10.64 \mathrm{~g} / \mathrm{cm}^{3}$ & $10.62 \mathrm{~g} / \mathrm{cm}^{3}$ \\
\hline
\end{tabular}

\section{Notes:}

The Cu measurement is based on the Ni calibration graphs of last slides $(99.9 \%$ pureness and $\rho=8.899 \mathrm{~g} / \mathrm{cm}^{3}$ )

The natural $\cup_{2}$ measurement is based on calibration with depleted $\cup_{2}$ disks and $\rho=10.011 \mathrm{~g} / \mathrm{cm}^{3}$ 


\section{Carry over to irradiated fuel demands}

\section{Optimum measuring conditions:}
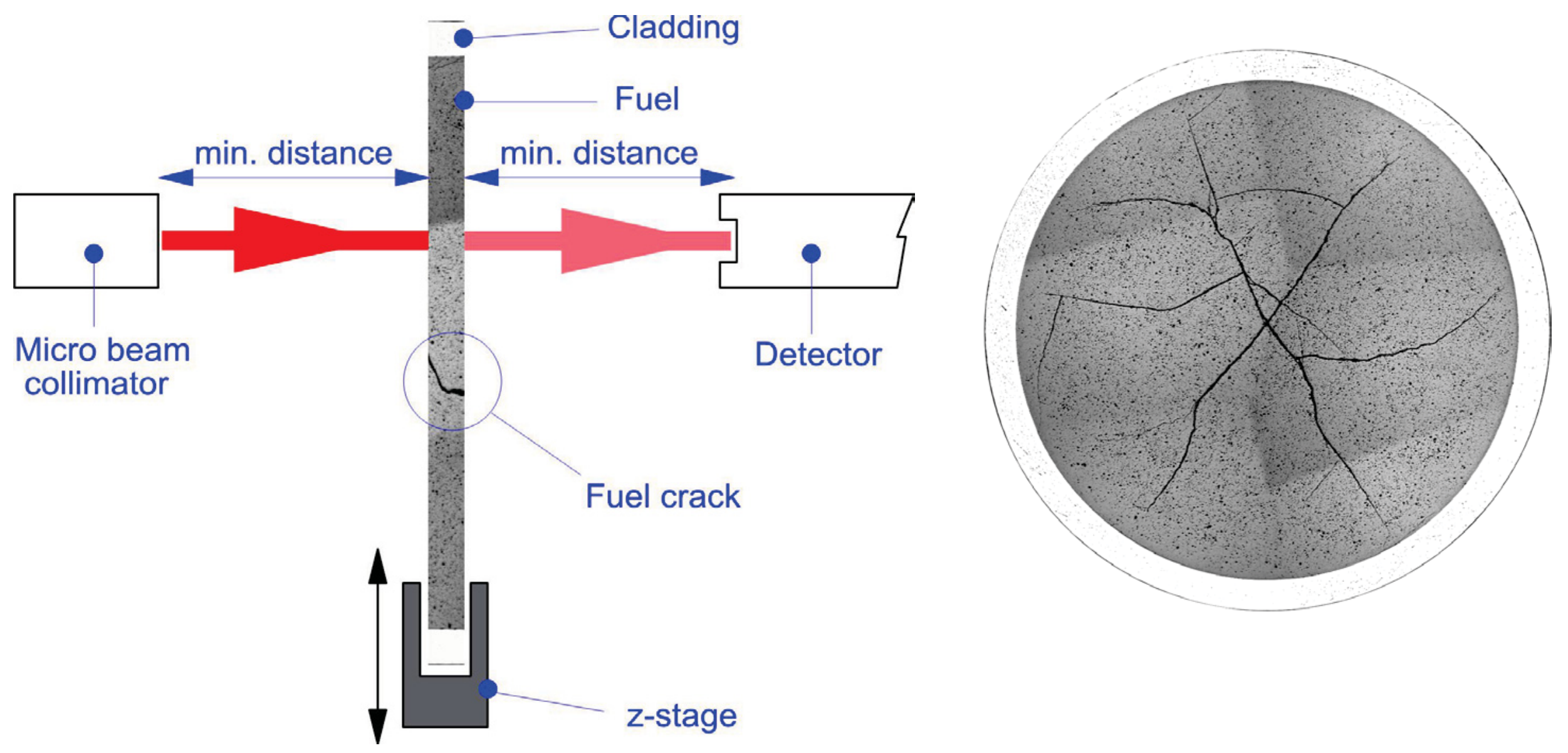


\section{The X-ray absorption as complementary/alternative to immersion technique}

Advantages

- non destructive method, a fuel disk with parallel sides is required - not affected by temperature and pressure fluctuations in the hot cell -radial total porosity/density profiles on fuel pellets can be measured - Easily repeatable and fast measurements

Disadvantages

- fuel cracks must be avoided (similar to diffusivity measurements with laser flash) -difficult calibration (solid fission products can be not considered, only empirical corrections) 
